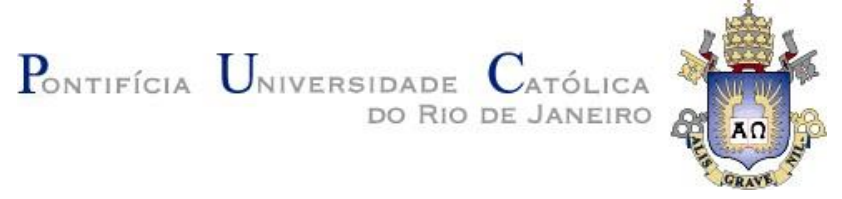

Danilo Lopes do Carmo

Decomposição Parcial para Geração de Cenários

de Carga Horária de Longo Prazo

Tese de Doutorado

Tese apresentada como requisito parcial para obtenção do grau de Doutor pelo Programa de Pósgraduação em Engenharia de Produção do Departamento de Engenharia Industrial da PUC-Rio.

Orientador: Prof. Reinaldo Castro Souza Coorientador: Prof. Carlos Roberto Hall Barbosa

Rio de Janeiro

Março de 2020 
Danilo Lopes do Carmo

\section{Decomposição Parcial para Geração de Cenários de Carga Horária de Longo Prazo}

Tese apresentada como requisito parcial para obtenção do grau de Doutor pelo Programa de Pós-graduação em Engenharia de Produção da PUC-Rio. Aprovada pela Comissão Examinadora abaixo.

Prof. Reinaldo Castro Souza

Orientador

Departamento de Engenharia Industrial - PUC-Rio

Prof. Carlos Roberto Hall Barbosa Co-orientador

Programa de Pós-graduação em Metrologia - PUC-Rio

Prof. Fernando Luiz Cyrino Oliveira Departamento de Engenharia Industrial - PUC-Rio

Prof. José Francisco Moreira Pessanha CEPEL

Prof. André Luís Marques Marcato UFJF

Prof. Felipe Leite Coelho da Silva

UFRRJ

Rio de Janeiro, 03 de março de 2020 
Todos os direitos reservados. É proibida a reprodução total ou parcial do trabalho sem autorização da universidade, do autor e do orientador.

\section{Danilo Lopes do Carmo}

Possui graduação em Engenharia de Produção pelas Faculdades Integradas de Cataguases (2011) e mestrado em Metrologia pela Pontifícia Universidade Católica do Rio de Janeiro (2014). É aluno de doutorado na mesma instituição, na área de Sistemas de Energia Elétrica. Participou de projetos P\&D para mercado de energia de 2012 a 2016 e atualmente é Engenheiro de Sistemas de Potência no operador Nacional do Sistema Elétrico (ONS). Seus interesses de pesquisa incluem planejamento energético, despacho hidro-termo-eólico e aplicação de técnicas de machine learning para previsão de séries temporais.

Ficha Catalográfica

Carmo, Danilo Lopes do
Decomposição parcial para geração de cenários de carga
horária de longo prazo / Danilo Lopes do Carmo; orientador: Reinaldo
Castro Souza; coorientador: Carlos Roberto Hall Barbosa. - 2020.
143 f.; $30 \mathrm{~cm}$
Tese (doutorado)-Pontifícia Universidade Católica do Rio de
Janeiro, Departamento de Engenharia Industrial, 2020.
Inclui bibliografia
1. Engenharia Industrial - Teses. 2. Previsão de curva de carga.
3. Demanda horária. 4. Dados horários. 5. Abordagem bottom-up. 6 .
Abordagem de decomposição parcial. I. Souza, Reinaldo Castro. II.
Barbosa, Carlos Roberto Hall. III. Pontifícia Universidade Católica do
Rio de Janeiro. Departamento de Engenharia Industrial. IV. Título.

CDD: 658.5 


\section{Agradecimentos}

Agradeço aos meus pais, Marli de Almeida Lopes e José Maria Montorsi do Carmo pelo apoio incondicional.

À minha irmã, Camilla Lopes do Carmo, por me ajudar com os problemas de saúde.

Ao meu professor, orientador e amigo, Reinaldo Castro Souza, por me guiar ao longo do caminho.

Ao meu professor, coorientador e amigo, Carlos Roberto Hall Barbosa, pelo apoio e disponibilidade para melhoria dos trabalhos.

Ao amigo Marco Antônio, por me ajudar com a programação ao longo do caminho.

Ao amigo, Bruno Bastos, pelas dicas e contribuições relevantes.

Aos amigos Hugo Baldiotti e Paula Maçaira pelas boas horas de conversas, trocas e contribuições.

Ao amigo Fernando Cyrino, pelos ensinamentos e por ter aceitado fazer parte da banca. 
Aos amigos, Plutarcho Maravilha e Felipe Leite, por todo apoio e sugestões ao longo do caminho.

Ao meu amigo e companheiro de trabalho, Evandro, com suas dicas essenciais para a publicação do artigo.

O presente trabalho foi realizado com apoio da Coordenação de Aperfeiçoamento de Pessoal de Nível Superior - Brasil (CAPES) - Código de Financiamento 001.

À PUC-Rio, pelos auxílios concedidos, sem os quais este trabalho não poderia ter sido realizado.

A todos os professores e funcionários do Departamento de Engenharia Industrial.

Aos amigos de infância, separados pela vida adulta.

E a todos os outros que contribuíram nessa jornada.

Muito obrigado! 


\section{Resumo}

Carmo, Danilo Lopes; Souza, Reinaldo Castro; Barbosa. Carlos Roberto Hall. Decomposição Parcial para Geração de Cenários de Carga Horária de Longo Prazo. Rio de Janeiro, 2020. 143. Tese de Doutorado Departamento de Engenharia Industrial, Pontifícia Universidade Católica do Rio de Janeiro.

O Brasil possui um Sistema Interligado Nacional (SIN) que se baseia na geração de energia elétrica por meio de usinas hidrelétricas, térmicas, solares fotovoltaicas e eólicas. O planejamento e operação deste sistema é efetuado com base em previsões efetuadas em curto, médio e longo prazo a fim de evitar imprevistos que possam afetar o suprimento da demanda de energia elétrica em território nacional. Uma das informações consideradas fundamentais em cada uma das etapas do planejamento da operação é a carga, ou seja, a demanda por energia elétrica. Quando trabalhada em curto prazo, esta é importante para a programação diária da operação, garantindo um cenário ótimo para uso dos recursos disponíveis e, em cenário mais atual, determinação do Preço de Liquidação das Diferenças a cada hora. Quando trabalhada em médio prazo, esta funciona como base para manutenções de redes e negociações de contrato. Já em longo prazo, a previsão é importante para fornecer informações usadas como base para estratégias de expansão do Sistema. Normalmente a previsão em longo prazo é trabalhada de maneira a escalonar a curva histórica anual, mas as constantes alterações no hábito de consumo da população e a inserção de novas fontes ocasionam relevantes alterações no perfil da curva de carga diária em longo prazo, tornando necessário o planejamento não somente da expansão do sistema, mas também a forma com que este poderá ser programado. Assim, com o objetivo de propor uma ferramenta de suporte ao mercado brasileiro de energia, este trabalho propõe uma Metodologia para Geração de Cenários de Carga de Longo Prazo. O método proposto propõe uma abordagem bottom-up para previsão anual da demanda utilizando premissas de trabalhos acadêmicos recentes, propõe um método de geração de perfis específicos para suprir a escassez de dados horários detalhados no Brasil e propõe a utilização da Abordagem de Decomposição Parcial a fim de transformar as previsões anuais de demanda em curvas de carga horária. Finalizando a aplicação da Metodologia para Geração de Cenários de Longo 
Prazo, diferentes resultados gerados são utilizados para aplicação de simulação por Monte Carlo, sendo os intervalos de confianças gerados com base na resposta, possíveis cenários de comportamento da carga no futuro, transformando um método de previsão previamente determinístico em um previsor de cenários. Com o objetivo de demonstrar resultados da método, a Metodologia é aplicada para geração de cenários de longo prazo para a região sudeste brasileira até $2020 \mathrm{com}$ base na curva histórica de 2016, apesar de ser capaz de gerar previsões para horizontes maiores, demonstrando verdadeiro potencial para se adaptar a possíveis alterações na curva de carga.

\section{Palavras-chave}

Previsão de Curva de Carga; Demanda Horária; Dados Horários; Abordagem bottom-up; Abordagem de Decomposição Parcial. 


\section{Abstract}

Carmo, Danilo Lopes; Souza, Reinaldo Castro; Barbosa. Carlos Roberto Hall (Advisor). Partial Decomposition to Long-term Generation of Load Scenarios. Rio de Janeiro, 2020. 143. Tese de Doutorado - Departamento de Engenharia Industrial, Pontifícia Universidade Católica do Rio de Janeiro.

Brazil has a National Interconnected System which produces and transmits electrical energy through a hydro-thermo-wind system. The planning and operation of this system is based on short, medium and long term on forecasts in order to avoid unforeseen that may affect the electricity supply in national territory. The short-term forecast is important for daily schedule of operation, certifying the resource use optimal scenario and, in a current scenario, the determination of Settlement Price for Differences at each hour. The medium-term forecast is used as a basis for network maintenance and contract negotiations. The long-term forecast is important to provide information used as basis for system expansion strategies. Usually, the long-term forecast is made staggering the annual load curve, however, the constant changes on people electrical consumption habits and insertion of new electrical generation sources cause relevant changes in daily load curve profile over the long term, making necessary not only the expansion planning, but also the way it can be programmed on longterm horizon. Thus, in order to propose a support tool to the Brazilian energy market, this work presents a Scenarios Generation Methodology. Such procedure proposes bottom-up approach as an annual demand projection provider, using assumptions of recent academic works, proposes a specific profile generation method as a way to overcome the lack of specific hourly data in Brazil. Not only that, the method also proposes Partial Decomposition Approach to adapt annual electricity demand into hourly load curves. Concluding the Scenarios Generation Methodology, future scenarios are developed by Monte Carlo simulation applied over different obtained results and confidence intervals calculated based on response are possible values of load behavior in the future, thus turning a deterministic forecasting method into a scenarios generation methodology. In order to demonstrate the Methodology application, it is used to generate long-term scenarios for the southeast Brazilian region by 2020 based on historical load curve 
from 2016, although it is capable of generating forecasts for larger horizons, proving true potential to adapt to possible changes on load curve.

\section{Keywords}

Load curve forecasting; Load Demand; Hourly data; bottom-up approach; Partial Decomposition Approach. 


\section{Sumário}

1 Introdução 17

$\begin{array}{ll}\text { 1.1. Motivação } & 17\end{array}$

1.2. Objetivos 24

1.3. Metodologia 25

1.4. Contribuições Acadêmicas 26

1.5. Organização do Documento 27

2 Referencial Teórico 28

2.1. Modelagem Bottom-up e o FORECAST 28

2.1.1. FORECAST Residencial 29

2.1.2. FORECAST Terciário 30

2.1.3. FORECAST Industrial 31

2.1.4. Método de Decomposição Parcial e o eLOAD 33

2.2. Método de Decomposição Parcial 34

$\begin{array}{ll}\text { 2.2.1. eLOAD } & 39\end{array}$

3 Base de dados e Metodologia Proposta 40

3.1. Dados de Previsão Anual 40

3.2. Curvas de Carga Horária 42

3.3. Perfis Diários de Processos 43

3.4. Metodologia de Geração de Perfis Específicos dos Processos 45

3.4.1. Perfis Específicos de Processos 49

3.5. Estrutura de Geração de Cenários 50

3.5.1. Adaptação para Geração de Cenários 51

4 Resultados $\quad 56$

4.1. Relevância dos processos 56

4.2. Avaliação da Curva de Carga Projetada 58

4.3. Avaliação dos Perfis Projetados 62

4.3.1. Análise dos Perfis Projetados para os Processos 63 
4.3.2. Previsão de Longo Prazo Utilizando a Estrutura de Geração de Cenários

5 Conclusões $\quad 70$

5.1. Vantagens e Desvantagens do Método Proposto 72

5.2. Trabalhos Futuros 73

6 Referências Bibliográficas $\quad 74$

7 Apêndice A 81

8 Apêndice B 108

9 Apêndice C $\quad 117$ 


\section{Lista de tabelas}

Tabela 1 - Informações-base para uso do FORECAST Residencial .................... 30

Tabela 2 - Informações-base para uso do FORECAST Terciário....................... 31

Tabela 3 - Informações-base para uso do FORECAST Industrial. ...................... 33

Tabela 4 - Relevância de cada Processo............................................................... 57

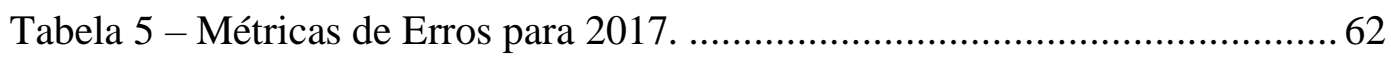

Tabela 6 - Resultados das Métricas para Perfis Específicos de 2017.................. 62

Tabela 7 - Patamares de Carga Adaptados para Validação................................ 63

Tabela 8 - Percentual de Carga por Patamar................................................. 63

Tabela 9 - Participação média dos Setores por Patamar do Ano Base de 2016.... 64

Tabela 10 - Participação média dos Setores por Patamar de 2017....................... 64

Tabela 11 - Participação Média dos Processos por Patamar de Carga ................. 68

Tabela 12 - Participação Média de Setores por Patamar ................................... 69

Tabela 14 - Estatística dos Processos: Alimentos, bebidas e Tabaco. ............... 108

Tabela 15 - Estatística dos Processos: Ar Condicionado. ................................ 108

Tabela 16 - Estatística dos Processos: Atacado e Varejo................................ 108

Tabela 17 - Estatística dos Processos: Cerâmica ................................................ 109

Tabela 18 - Estatística dos Processos: Chuveiro Elétrico. ................................ 109

Tabela 19 - Estatística dos Processos: Cimento................................................. 109

Tabela 20 - Estatística dos Processos: Educação........................................... 110

Tabela 21 - Estatística dos Processos: Escritório Público............................... 110

Tabela 22 - Estatística dos Processos: Ferro e Aço. ........................................ 110

Tabela 23 - Estatística dos Processos: Finanças. ........................................... 111

Tabela 24 - Estatística dos Processos: Freezer. .............................................. 111

Tabela 25 - Estatística dos Processos: Hotel, Café e Restaurante. .................... 111

Tabela 26 - Estatística dos Processos: Iluminação........................................ 112

Tabela 27 - Estatística dos Processos: Lava Roupas....................................... 112

Tabela 28 - Estatística dos Processos: Liga de Ferro.................................... 112

Tabela 29 - Estatística dos Processos: Metais Não-Ferrosos. .......................... 113

Tabela 30 - Estatística dos Processos: Mineração e Peletização. ...................... 113

Tabela 31 - Estatística dos Processos: Outros Industrial.................................. 113 
Tabela 32 - Estatística dos Processos: Outros Residencial. ............................ 114

Tabela 33 - Estatística dos Processos: Outros Terciário. ................................. 114

Tabela 34 - Estatística dos Processos: Papel e Celulose. ............................... 114

Tabela 35 - Estatística dos Processos: Química............................................ 115

Tabela 36 - Estatística dos Processos: Refrigerador. .................................... 115

Tabela 37 - Estatística dos Processos: Saúde. …............................................. 115

Tabela 38 - Estatística dos Processos: Televisores. ...................................... 116

Tabela 39 - Estatística dos Processos: Têxtil............................................... 116

Tabela 40 - Estatística dos Processos: Tráfego e Transmissão de Dados. ......... 116 


\section{Lista de figuras}

Figura 1 - Curva de Carga Horária do subsistema sudeste/centro-oeste brasileiro -2001 a 2019.

Figura 2 - Mapa de calor da curva de carga horária normalizada do subsistema sudeste/centro-oeste - 2001 a 2019.

Figura 3 - Mapa de calor da curva de carga horária normalizada do subsistema sudeste/centro-oeste para os anos de 2005 e 2016.

Figura 4 - Perfis médios de dias típicos para inverno e verão do subsistema sudeste/centro-oeste para os anos de 2005 e 2016. 21

Figura 5 - Simplificação do esquema de cálculo da PDA................................. 35

Figura 6 - Ilustração de aplicação dos passos 1 e 2 ......................................... 36

Figura 7 - Ilustração de aplicação do passo 3 …............................................. 37

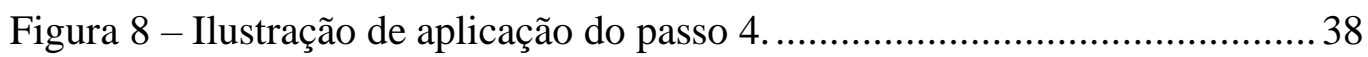

Figura 9 - Ilustração de aplicação do passo 5............................................... 39

Figura 10 - Módulo de Projeção para o Brasil. ................................................. 39

Figura 11 - Previsão Anual de Demanda por Setor até 2020 ........................... 41

Figura 12 - Série Horária de Carga do Subsistema Sudeste/Centro-Oeste. ........ 42

Figura 13 - Perfis Médios de Estações Estimados para a Região Sudeste Brasileira.

Figura 14 - Perfis Médios de Tipos de Dia Estimados para a Região Sudeste Brasileira.

Figura 15 - Perfis Agregados de Processos e Equipamentos por Setor.

Figura 16 - Carga média obtida por número de valores gerados por simulação para

a hora 1 do ar condicionado. 47

Figura 17 - Agregado de Perfis médios específicos por estação de ano. 49

Figura 18 - Agregado de Perfis médios específicos por tipo de dia..................50

Figura 19 - Estrutura de Geração de Cenários.

Figura 20 - Perfis específicos históricos médios para a região Sudeste no ano de 2016 ......... 60

Figura 21 - Validação da Projeção para 2017. 61

Figura 22 - Resultados de Projeção de Cenários para 2020. 66 
Figura 23 - Bloxplot dos valores projetados para 2017 e 2020. 67

Figura 24 - Perfis Médios Gerais do Ar Condicionado 68 Figura 25 - Perfis Médios Gerais do Chuveiro ElétricoPara oferecer uma visão geral dos resultados, a Tabela 12 mostra uma análise das projeções horárias médias de cada setor feitas para 2020 em comparação com a participação esperada em 2016. 69

Figura 26 - Perfis Médios Sintéticos Históricos: Alimentos, bebidas e Tabaco. 81

Figura 27 - Perfis Médios Sintéticos Históricos: Ar Condicionado................... 82

Figura 28 - Perfis Médios Sintéticos Históricos: Atacado e Varejo. ................. 83

Figura 29 - Perfis Médios Sintéticos Históricos: Cerâmica.............................. 84

Figura 30 - Perfis Médios Sintéticos Históricos: Chuveiro Elétrico.................. 85

Figura 31 - Perfis Médios Sintéticos Históricos: Cimento................................. 86

Figura 32 - Perfis Médios Sintéticos Históricos: Educação.............................. 87

Figura 33 - Perfis Médios Sintéticos Históricos: Escritório Público. .................88

Figura 34 - Perfis Médios Sintéticos Históricos: Ferro e Aço........................... 89

Figura 35 - Perfis Médios Sintéticos Históricos: Finanças. ............................... 90

Figura 36 - Perfis Médios Sintéticos Históricos: Freezer................................. 91

Figura 37 - Perfis Médios Sintéticos Históricos: Hotel, Café e Restaurante...... 92

Figura 38 - Perfis Médios Sintéticos Históricos: Iluminação. ........................... 93

Figura 39 - Perfis Médios Sintéticos Históricos: Lava Roupas........................ 94

Figura 40 - Perfis Médios Sintéticos Históricos: Liga de Ferro. ...................... 95

Figura 41 - Perfis Médios Sintéticos Históricos: Metais Não-Ferrosos............. 96

Figura 42 - Perfis Médios Sintéticos Históricos: Mineração e Peletização. ...... 97

Figura 43 - Perfis Médios Sintéticos Históricos: Outros Industrial................... 98

Figura 44 - Perfis Médios Sintéticos Históricos: Outros Residencial................ 99

Figura 45 - Perfis Médios Sintéticos Históricos: Outros Terciário................... 100

Figura 46 - Perfis Médios Sintéticos Históricos: Papel e Celulose. ................. 101

Figura 47 - Perfis Médios Sintéticos Históricos: Química............................. 102

Figura 48 - Perfis Médios Sintéticos Históricos: Refrigerador. ..................... 103

Figura 49 - Perfis Médios Sintéticos Históricos: Saúde................................. 104

Figura 50 - Perfis Médios Sintéticos Históricos: Televisores. ......................... 105

Figura 51 - Perfis Médios Sintéticos Históricos: Têxtil................................. 106 
Figura 52 - Perfis Médios Sintéticos Históricos: Tráfego e Transmissão de Dados. 107

Figura 53 - Perfis Médios Previstos 2020: Alimentos, Bebidas e Tabaco........ 117

Figura 54 - Perfis Médios Previstos 2020: Ar condicionado.......................... 118

Figura 55 - Perfis Médios Previstos 2020: Atacado e Varejo.......................... 119

Figura 56 - Perfis Médios Previstos 2020: Cerâmica. ..................................... 120

Figura 57 - Perfis Médios Previstos 2020: Cimento...................................... 121

Figura 58 - Perfis Médios Previstos 2020: Chuveiro Elétrico. ....................... 122

Figura 59 - Perfis Médios Previstos 2020: Educação. .................................... 123

Figura 60 - Perfis Médios Previstos 2020: Escritório Público......................... 124

Figura 61 - Perfis Médios Previstos 2020: Ferro e Aço Gusa.......................... 125

Figura 62 - Perfis Médios Previstos 2020: Finanças. ..................................... 126

Figura 63 - Perfis Médios Previstos 2020: Freezer. ........................................ 127

Figura 64 - Perfis Médios Previstos 2020: Hotel, Café e Restaurante. ............ 128

Figura 65 - Perfis Médios Previstos 2020: Iluminação................................... 129

Figura 66 - Perfis Médios Previstos 2020: Lava Roupas................................. 130

Figura 67 - Perfis Médios Previstos 2020: Liga de Ferro............................... 131

Figura 68 - Perfis Médios Previstos 2020: Metais Não-Ferrosos..................... 132

Figura 69 - Perfis Médios Previstos 2020: Mineração e Peletização. ............... 133

Figura 70 - Perfis Médios Previstos 2020: Outros Industrial.......................... 134

Figura 71 - Perfis Médios Previstos 2020: Outros Residencial....................... 135

Figura 72 - Perfis Médios Previstos 2020: Outros Terciário. .......................... 136

Figura 73 - Perfis Médios Previstos 2020: Papel e Celulose. ......................... 137

Figura 74 - Perfis Médios Previstos 2020: Química....................................... 138

Figura 75 - Perfis Médios Previstos 2020: Refrigerador. ............................... 139

Figura 76 - Perfis Médios Previstos 2020: Saúde.......................................... 140

Figura 77 - Perfis Médios Previstos 2020: Televisor. .................................... 141

Figura 78 - Perfis Médios Previstos 2020: Têxtil.......................................... 142

Figura 79 - Perfis Médios Previstos 2020: Tráfego e Transmissão de Dados. . 143 


\section{Introdução}

\section{1. Motivação}

O Brasil dispõe de uma matriz elétrica de origem predominantemente renovável, com destaque para a geração hídrica, que responde por aproximadamente 66,6\% da oferta interna (Empresa de Pesquisa Energética - EPE, 2019a). Apesar de ser uma fonte não poluente e de baixo custo, essa estratégia é vulnerável aos períodos de estiagem, sendo as usinas térmicas essenciais para suprir a demanda do país nesse caso. Assim, é fundamental que se conheça a demanda horária de energia elétrica para que se possa estabelecer um despacho adequado das usinas térmicas, na integrabilidade de fontes de energia renovável e em investimentos na capacidade de geração de eletricidade (Boßmann, Pfluger e Wietschel, 2013).

Em 2000, a Agência Nacional de Energia Elétrica (ANEEL) publicou a resolução Nº 290 (Agência Nacional de Energia Elétrica - ANEEL, 2000) sobre o projeto de reestruturação do setor elétrico. Este foi um dos marcos iniciais para a definição do modelo DESSEM (Modelo de Despacho Hidrotérmico de Curtíssimo Prazo) e validação da metodologia para cálculo do preço horário (Subgrupo de Trabalho de Operação e Preço, 2019). Tendo este como assunto em destaque no setor elétrico brasileiro, em janeiro de 2020 o Operador Nacional do Sistema Elétrico (ONS) passou a adotar o DESSEM na programação da operação a fim de reduzir inconsistências e permitir reprodutibilidade por parte dos agentes. Assim, para janeiro de 2021 está definido o uso do DESSEM pela Câmara de Comercialização de Energia Elétrica CCEE para cálculo do Preço de Liquidação das Diferenças (PLD) (Ministério de Minas e Energia, 2019).

Dentre os principais insumos do modelo DESSEM pode-se destacar a previsão de carga (Subgrupo de Trabalho de Operação e Preço, 2019). Esta é requerida em intervalos de meia hora e ganhou evidência no mercado com a modernização do setor elétrico. 
Apesar do fato de que o PLD horário será determinado com previsões de carga a curto prazo, informações de carga horária de longo prazo têm seu destaque no mercado energético brasileiro. Balanços de demanda são anualmente efetuados pelo ONS e apresentados no Plano da Operação (Operador Nacional do Sistema Elétrico, 2019a) a fim de servir como base de informações para empresas, como a EPE estimar necessidade de ampliação de limite de potência (Empresa de Pesquisa Energética - EPE, 2020), por exemplo.

Contudo, este balanço de demanda é efetuado com base no histórico dos últimos cinco anos (Operador Nacional do Sistema Elétrico, 2019b), ou seja, a ponta estimada não é alterada até o horizonte final. Porém, em um horizonte de longo prazo, há possibilidade de alterações significativas no comportamento da curva de carga, ocasionando alterações expressivas no perfil horário, como apresentado a seguir.

$\mathrm{Na}$ Figura 1 apresenta-se a curva de carga horária do subsistema Sudeste/Centro-Oeste brasileiro de 2001 a 2019. Na série temporal apresentada é possível notar que, além da sazonalidade típica, ocasionada pelos ciclos de verão com cargas mais altas e inverno com cargas mais baixas, esta também é impactada pelas crises locais e globais. Apesar de tais peculiaridades já serem significativas para alterar o comportamento da carga, estes são eventos que ocorrem de maneira extraordinária e que afetam geralmente o nível da carga. No entanto, ainda que não seja possível notar por meio da série temporal, a inserção de novas tecnologias e alterações do hábito de consumo acarretam alterações no comportamento da carga, impossibilitando a estimação de perfis futuros utilizando-se somente dos perfis históricos. 


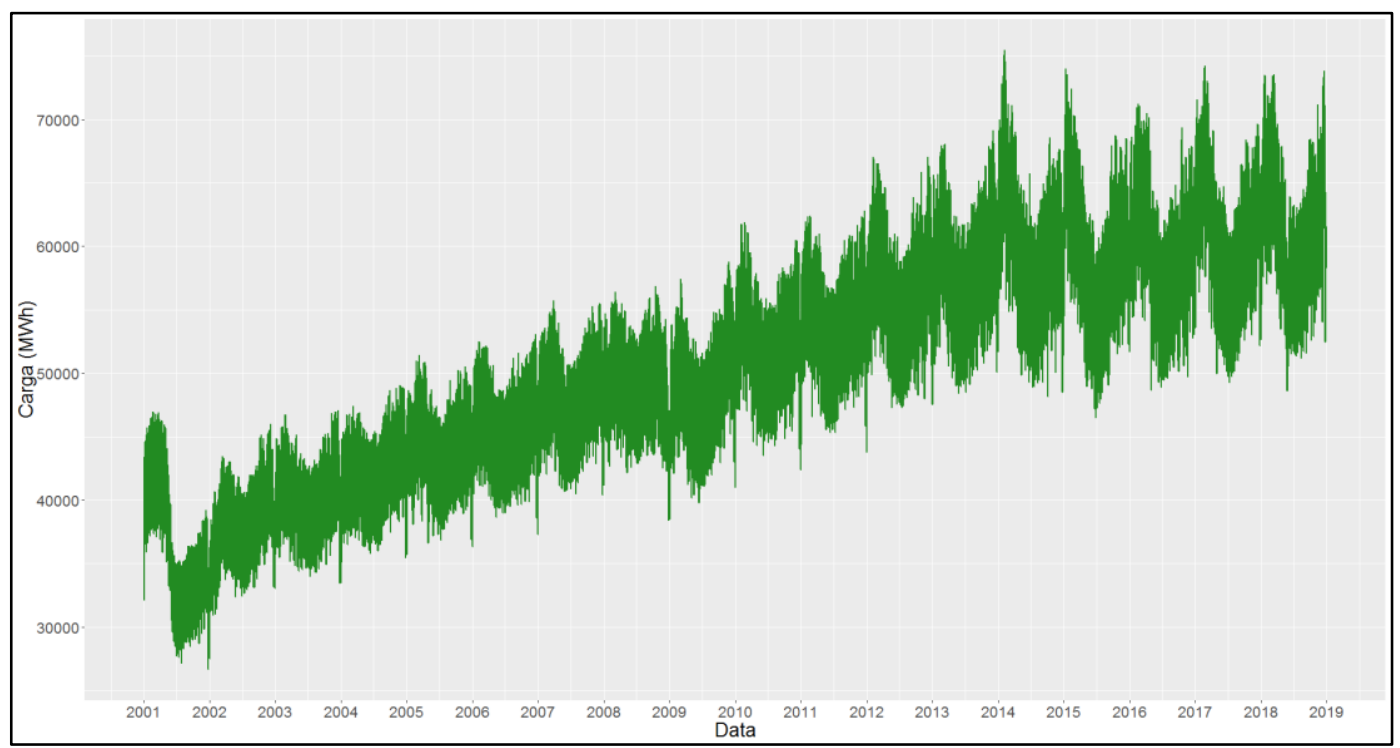

Figura 1 - Curva de Carga Horária do subsistema sudeste/centro-oeste brasileiro - 2001 a 2019 (elaborado pelo autor, 2019).

A Erro! Fonte de referência não encontrada. apresenta um mapa de calor d a curva de carga horária normalizada do subsistema sudeste/centro-oeste de 2001 a 2019. Ao longo dos anos é possível observar uma intensificação do tom de vermelho durante a tarde, indicando maiores níveis de carga no horário, assim como o aumento de demanda ocorrido durante a madrugada, apontado pelo tom de azul mais leve no horário.

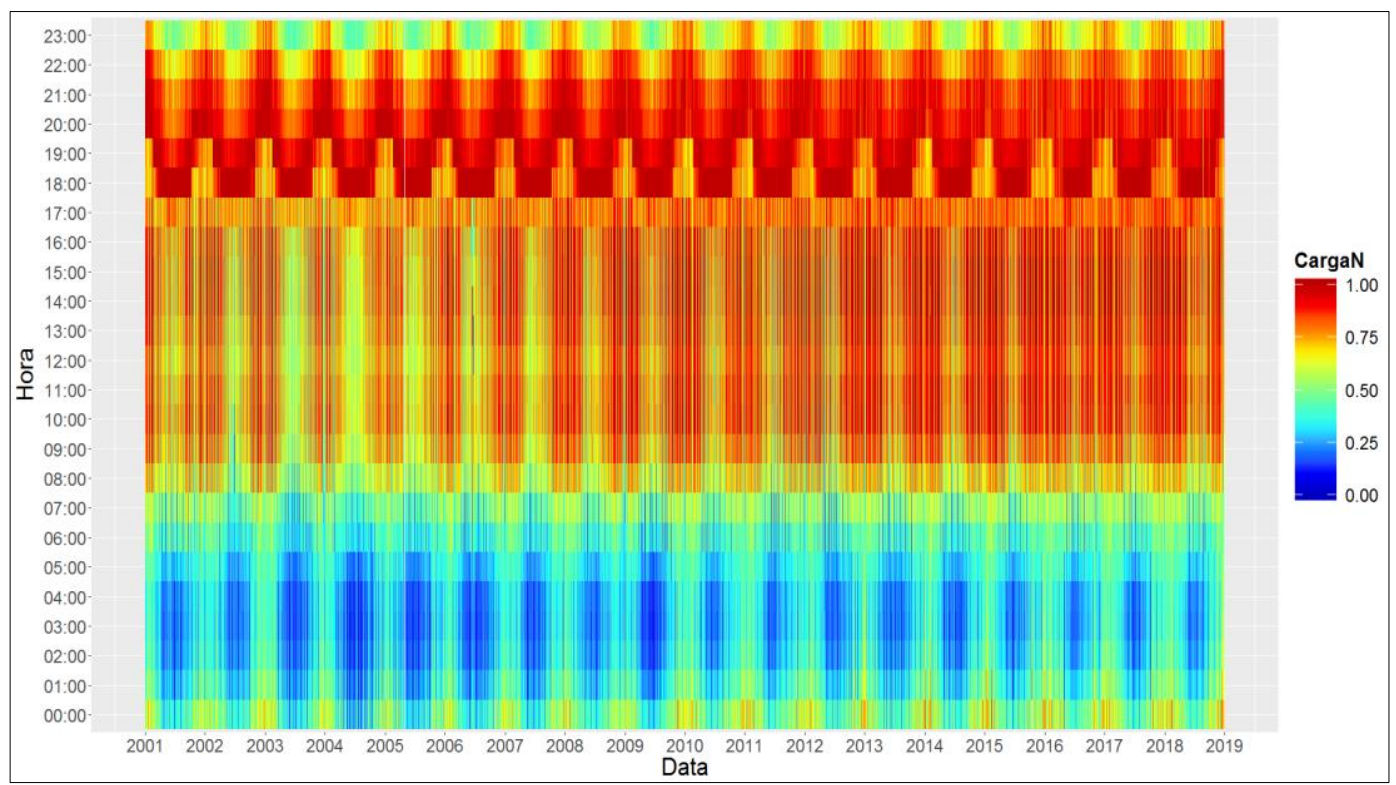

Figura 2 - Mapa de calor da curva de carga horária normalizada do subsistema sudeste/centro-oeste - 2001 a 2019 (elaborado pelo autor).

Para uma visão mais detalhada da alteração dos perfis ao longo dos anos, tomam-se os anos de 2005 e 2016 para comparação (Figura 3). Nota-se que, em 
2016, a carga demandada entre os meses de maio e outubro cresceu substancialmente durante a tarde e madrugada, dificultando a clara visualização da sazonalidade verão/inverno, proporcionada pelo mapa de calor de 2005.

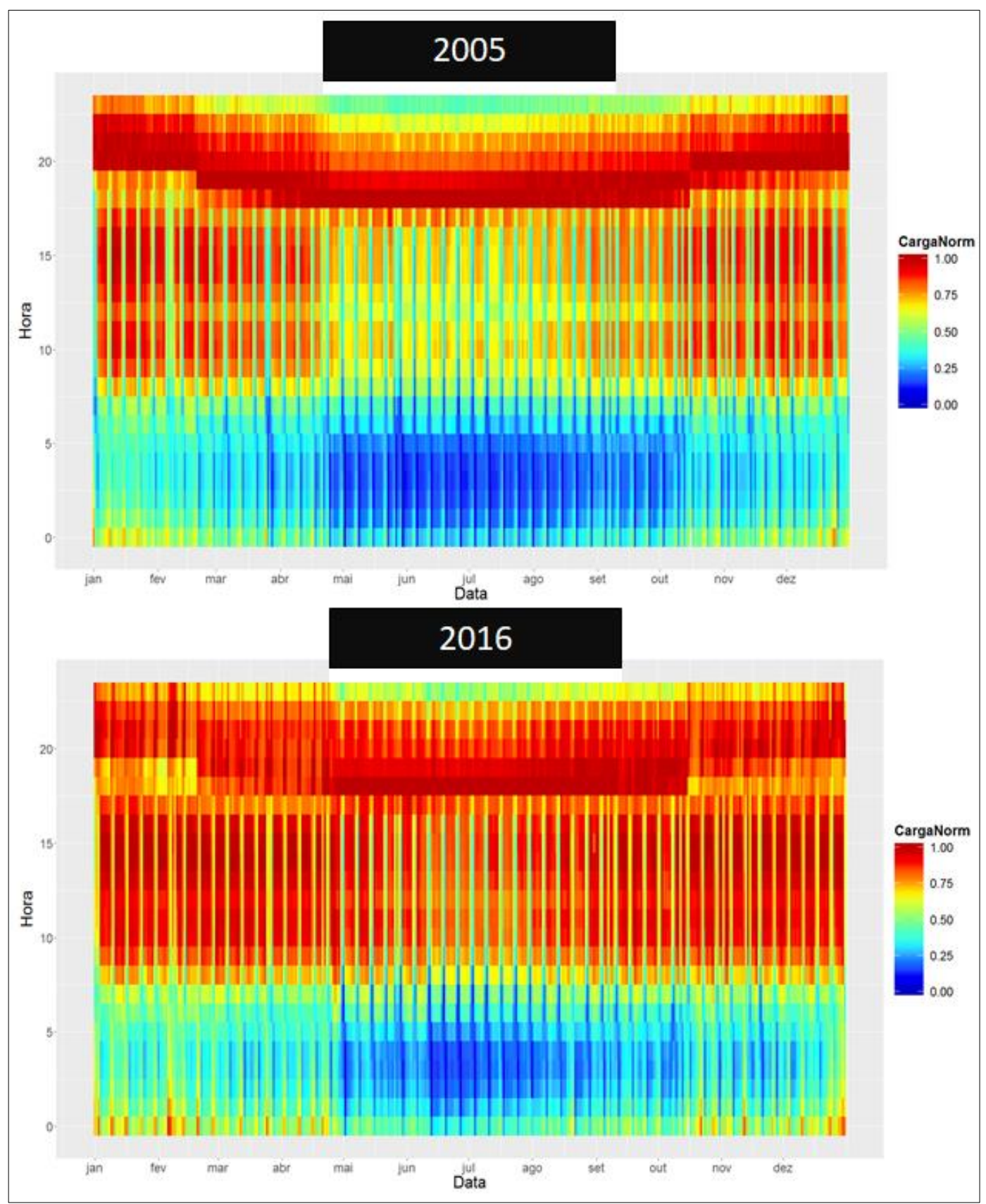

Figura 3 - Mapa de calor da curva de carga horária normalizada do subsistema sudeste/centro-oeste para os anos de 2005 e 2016 (elaborado pelo autor, 2019).

Na Figura 4 apresentam-se os gráficos dos perfis médios de dias típicos de 2005 e 2016, em épocas de verão e inverno, de modo a evidenciar ainda mais as alterações ocorridas no hábito do consumidor ao longo dos anos. No perfil de inverno de 2005 é possível notar horários de ponta mais evidentes por volta das 19 h, com valores bem acima dos vespertinos. Em 2016 a diferença de carga entre 
os horários reduziu consideravelmente, como já havia sido mostrado no mapa de calor, incluindo uma carga noturna mais acentuada. No perfil de verão as mudanças foram ainda mais drásticas, com alteração do horário de ponta, que antes ocorria por volta das $19 \mathrm{~h}$, para o horário da tarde, ocorrendo atualmente por volta das $15 \mathrm{~h}$.

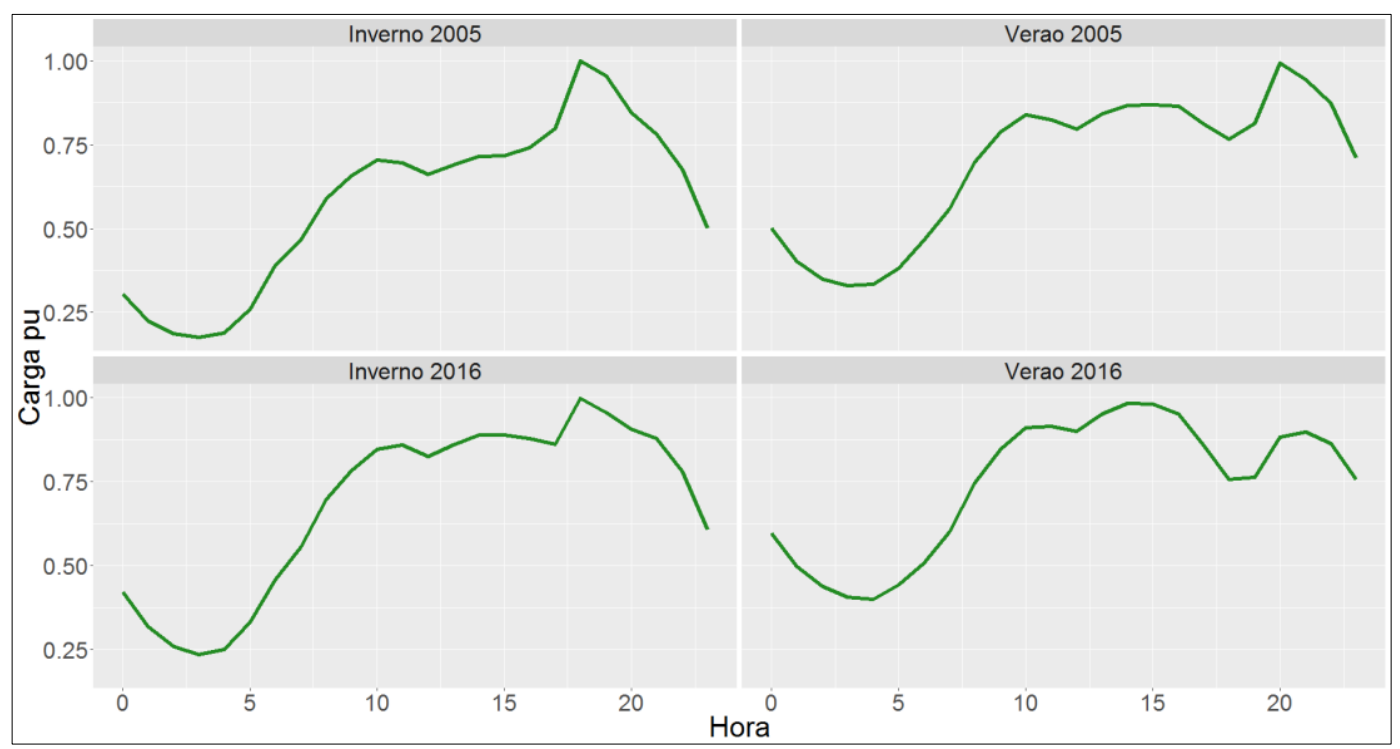

Figura 4 - Perfis médios de dias típicos para inverno e verão do subsistema sudeste/centro-oeste para os anos de 2005 e 2016 (elaborado pelo autor, 2019).

Sempre em alta e relevante para os diferentes tipos de mercado, pesquisadores nos mais variados campos sempre buscaram efetuar a previsão de carga das maneiras mais diversas possíveis a fim de obter os melhores resultados. Por muitos anos, modelos matemáticos foram o foco para realização das previsões (Bunn, 1980; Christiaanse, 1971; Haida e Muto, 1994; Uri e Maybee, 1978; Vähäkyla, Hakonen e Léman, 1980), mas com o crescente interesse em técnicas como Redes Neurais Artificiais (Haykin, 1994), Lógica Nebulosa (Zadeh, 1965) e Algoritmos Genéticos (Whitley, 1994), os modelos matemáticos passaram a dividir a atenção no campo da previsão com os modelos computacionais (Chenthur Pandian et al., 2006; Kandil et al., 2006; Torrini et al., 2016), sendo desenvolvidas, com o passar dos anos, modelagens híbridas (Akdemir e Çetinkaya, 2012; Chen, 2012; Lou e Dong, 2015; Niño, 2016) capazes de alcançar bons resultados.

Apesar de difundida a aplicação de modelos e técnicas para previsão de carga, seja a longo, médio ou curto prazo, a previsão de carga horária é um assunto bem mais recente na literatura. Apesar de Uri e Maybee (1978) já buscarem mapear curvas de carga futuras, este trabalho foca apenas em uma característica da curva, ou seja, ele visa apenas à aproximação da duração da curva de carga por meio de 
Box \& Jenkins, assim como Poulin et al. (2008) buscaram fazê-lo mais recentemente por meio de relações paramétricas específicas.

Friedrich e Afshari (2015) explicam que a previsão de carga pode ser dividida em quatro classes. A primeira corresponde às previsões de longo prazo, feitas de um a vinte anos à frente e consideradas fundamentais para o planejamento estratégico. A segunda classe, muito usada para programação de manutenção, inclui previsões de médio prazo, de um mês a um ano. Na terceira classe são consideradas as previsões de curto prazo, com horizonte que varia de uma hora a semanas à frente, enquanto a quarta classe são as previsões de curtíssimo prazo, variando de alguns minutos a uma hora à frente.

Apesar da maioria das previsões serem classificadas na terceira classe (Hernández et al., 2013; López et al., 2018; Wang, Y. et al., 2018), na primeira classe podem ser incluídos alguns métodos que se destacam. Richardson et al. (2010) têm seu foco na estimação do uso doméstico de eletricidade por meio da combinação de padrão de ocupação e atividade diária, enquanto Dickert e Schegner (2011) usam uma abordagem bottom-up visando ao uso dos eletrodomésticos mais relevantes para estimar a curva residencial. Nota-se que ambos se concentram em determinado setor, assim como muitos dos trabalhos da área (Chuan e Ukil, 2015; Elsland et al., 2013; Grandjean, Adnot e Binet, 2012; Muratori et al., 2013; Paatero e Lund, 2006; Wang, H. et al., 2018).

De maneira mais geral e com um foco mais amplo, Andersen et al. (2013) sugerem um modelo que visa diferir o consumo em categorias e alocar pesos para determinados locais, com o objetivo de estimar eletricidade horária a longo prazo na Dinamarca. Ainda que seja uma abordagem que visa a diferentes setores e uma área ampla de aplicação, trata-se de uma abordagem que não pode ser expandida de forma contínua para um ano todo.

Em um estudo dos tipos de abordagens que visam à previsão horária, contínua e que englobe curvas de sistemas nacionais durante todo um ano, identificaram-se algumas das mais relevantes.

A primeira, mais simples e mais utilizada abordagem caracteriza-se pelo simples escalonamento da curva de carga de acordo com a projeção de demanda anual, assumindo que a forma da curva se mantém a mesma durante todo o horizonte de previsão (Green, Staffell e Vasilakos, 2014; Schill, 2014). 
Outra abordagem visa à extrapolação da periodicidade diária, semanal e sazonal (Filik, Gerek e Kurban, 2011). Em um primeiro momento é efetuada uma estimativa grosseira da carga média horária utilizando-se uma função polinomial aplicada sobre históricos de tendência anuais para, em seguida, esses valores serem refinados por meio de uma modelagem das variações de resíduos semanais durante um ano. Em um terceiro momento faz-se um aperfeiçoamento dos valores obtidos até aqui por meio de uma modelagem das variações horárias dentro de uma semana por meio de uma representação matemática 2-D. Apesar da simplicidade dos modelos matemáticos aplicados em cada passo, resultados plausíveis foram obtidos, indicando uma interessante ferramenta para estimativa horária de carga.

A abordagem de Koreneff et al. (2009) foca a previsão horária em processos específicos. Um estudo é efetuado em países nórdicos com o intuito de mostrar a possível penetração em larga escala de aquecedores e carros elétricos. Os hábitos de uso de tais equipamentos são estudados e projetados para, por fim, efetuar-se a agregação da curva final e obter-se a demanda de eletricidade para os países nórdicos em 2020 e 2030 em situações específicas.

Em 2009, uma abordagem efetuada por Hainoun (2009) usa a demanda horária de eletricidade de usuários específicos do setor residencial, serviços, transporte e indústria em um determinado ano base para projetar a demanda até 2030. Essa projeção é realizada por meio do escalonamento da previsão de demanda anual de eletricidade efetuada por meio de abordagem bottom-up e comparada com uma curva de carga sintética. A mesma abordagem para previsão horária também foi utilizada e validada por Pina et al. (2011), em um trabalho de aplicação para a ilha de São Miguel, nos Açores, e também foi utilizada por Andersen et al. (2013), na Dinamarca, com um foco maior em aquecedores e veículos elétricos. Apesar de eficiente, Boßmann (2015) deixa claro que esta metodologia negligencia características irregulares, ou seja, ela mantém sempre a similaridade entre curvas do mesmo tipo (dia da semana, estação do ano, etc.).

Além desses trabalhos, é importante enfatizar que técnicas de aprendizado de máquina também foram testadas para projeções de longo prazo (Agrawal e Muchahary, 2018; Carpinteiro et al., 2006; Yue et al., 2007). Apesar dos bons resultados obtidos, essas técnicas são automatizadas e focam em exatidão, negligenciando a interpretação do modelo e dificultando para o usuário comum a compreensão sobre o modelo aplicado. 
Com as lacunas existentes nas metodologias para previsão horária, Boßmann (2015) sugere a Partial Decomposition Approach (PDA), baseada na abordagem de Hainoun (2009), no sentido de que usa perfis específicos para gerar a previsão. Esta usa processos que possuem impactos relevantes na transformação da forma da curva de carga e possuem características específicas de comportamento de consumo. No fim, a curva agregada de todos os processos é escalonada de acordo com a projeção de demanda anual, como efetuado na primeira abordagem citada.

O Energy Load Curve Adjustment Tool (eLOAD) é uma ferramenta desenvolvida pelo Fraunhofer Institute que utiliza a PDA com o intuito de adaptar para demandas horárias as previsões de demanda anual efetuadas pela ferramenta bottom-up Forecasting Energy Consumption Analysis and Simulation Tool (FORECAST), que foi desenvolvida e adaptada para os setores residencial, terciário e industrial brasileiros. Além das previsões advindas do FORECAST, para pleno funcionamento do eLOAD são necessários perfis de uso dos processos mais relevantes, curva de carga horária histórica base e dados horários meteorológicos (Fraunhofer ISI, IREES, 2017).

Apesar de obter resultados coerentes com a realidade da região onde é aplicado, os valores determinísticos resultantes da previsão de carga horária efetuada pelo eLOAD dependem muito dos valores históricos adicionados, principalmente dos perfis de uso dos processos mais relevantes. Isso faz com que a má qualidade/escassez de informações horárias no Brasil possa ocasionar irregularidades na previsão, exigindo adaptações capazes de amenizar determinadas inconsistências.

\section{2.}

\section{Objetivos}

Esta Tese de Doutorado teve por objetivo geral desenvolver uma metodologia que visa à adaptação de diferentes perfis de consumo de equipamentos do setor residencial e subsetores do setor terciário e industrial ao uso do PDA para geração de cenários de carga até 2020. Tais cenários, por serem desenvolvidos com base em perfis sintéticos, passam a apresentar inconsistências que devem ser amenizadas por meio da aplicação de simulação. 
O objetivo geral acima descrito pode ser desdobrado nos seguintes objetivos específicos:

- Gerar três cenários de perfis diários específicos para 27 processos da região sudeste que representem o consumo destes em três tipos de estações de ano (verão, inverno e intermediária) e dois tipos de dia da semana (dia útil e dia não útil), totalizando 162 perfis específicos gerados, baseados em perfis únicos de consumo oriundos de pesquisas científicas (Carmo, 2018; Programa Nacional de Conservação de Energia Elétrica - PROCEL, 2005);

- Adaptar o Partial Decomposition Approach (Boßmann, 2015), que gera resultados determinísticos, de modo a obter um previsor de cenários de longo prazo.

- Desenvolver cenários de previsão horários para a região Sudeste brasileira para o ano de 2020 com base em dados horários de carga de 2016, fornecidos pelo Operador Nacional do Sistema Elétrico (ONS); e

- Validar as previsões efetuadas por meio de métricas de erros que visam avaliar tanto os cenários simulados, quanto os valores médios dos cenários obtidos.

\section{3. Metodologia da Pesquisa}

Com os interessantes resultados obtidos em termos de previsão horária a longo prazo na Europa (Boßmann, 2015), o atual trabalho visa à adaptação e aperfeiçoamento da metodologia para que possa servir como ferramenta de apoio à decisão no mercado de energia brasileiro.

Neste contexto, em um primeiro momento este trabalho propõe uma estratégia para superar a escassez de dados horários no Brasil. Uma metodologia baseada na diferença percentual entre curvas diárias médias de carga e curvas diárias específicas calculadas a partir de históricos fornecidos pelo Operador Nacional do Sistema Elétrico (ONS) visa adaptar os perfis únicos de uso de equipamentos do setor residencial, serviços do terciário e subsetores do industrial para diferentes estações de ano (no caso, considera-se verão, inverno e intermediária) e diferentes dias da semana (no caso, trabalha-se com dias úteis e não-úteis). Tais perfis específicos, por serem calculados, passam a apresentar inconsistências que precisam ser amenizadas por meio da aplicação de simulação, utilizando o Método de Monte Carlo (Kim, Robert e Casella, 2000). O trabalho é 
efetuado utilizando-se perfis regionais de oito equipamentos residenciais, obtidos por meio da Pesquisa de Posses e Hábitos (PPH) do Programa Nacional de Conservação de Energia Elétrica (PROCEL) (Programa Nacional de Conservação de Energia Elétrica - PROCEL, 2005), além de oito perfis de serviços do terciário e onze perfis de subsetores industriais obtidos por meio de uma base de dados de uma concessionária da região sudeste (Carmo, 2018) e, após as simulações geradas, definem-se cenários máximo, médio e mínimo para cada perfil de uso específico.

Em um segundo momento do trabalho, utilizam-se estes cenários desenvolvidos e valores de demanda anuais estimados por meio da metodologia bottom-up do FORECAST para o setor residencial (Maçaira, 2015), setor terciário (Bastos et al., 2017) e setor industrial (Silva et al., 2018) a fim de projetar os processos mais relevantes, utilizando o modelo PDA do eLOAD, e obter previsões a longo prazo para a carga da região Sudeste brasileira para o ano de 2020. A fim de validar os resultados da previsão efetuada, utilizando o ano de 2016 como base e o ano de 2017 como validação, métricas de erro são empregadas de forma a comparar os valores verificados de carga para 2017 e os valores previstos para o mesmo ano.

\section{4. \\ Contribuições Acadêmicas}

Ao longo do desenvolvimento desta tese alguns trabalhos foram aceitos ou publicados em congressos nacionais e internacionais, além de periódicos nacionais e internacionais, que estão relacionados com o tema da pesquisa e da modelagem proposta neste trabalho.

ESTEVES, G. R. et al. Long-term Scenarios Development for the Electricity Tariffs in Brazil. 13 International Conference on the European Energy Market. Anais. Portugal: 2016.

OLIVEIRA, F. L. C. et al. A Bottom-up and Partial Decomposition Model for Long-Term Forecasting. European Conference on Operational Research, 2016, Poznan - Poland. Conference Handbook, 2016. p. 269-269.

CARMO, D. L. DO et al. Simulação Dos Perfis De Consumo Específicos De Energia Elétrica Para Equipamentos E Subsetores. Simpósio Brasileiro de Pesquisa Operacional. Anais. Rio de Janeiro: 2018. 
CARMO, D.L. et al. Partial decomposition approach to generate load curve forecasting scenarios. INTERNATIONAL JOURNAL OF ELECTRICAL POWER \& ENERGY SYSTEMS, v. 115, p. 105436, 2020.

\section{5 .}

Organização do Documento

Esta tese apresenta no Capítulo 2 detalhes sobre os modelos que servem como base para a metodologia proposta, como a modelagem bottom-up e o FORECAST, além de detalhes sobre a metodologia PDA e o eLOAD. No Capítulo 3 são expostos detalhes sobre a base de dados utilizada e sobre as metodologias propostas, seja aquela utilizada para geração dos perfis diários específicos, seja a utilizada para criação dos cenários de previsão horária de carga. O Capítulo 4 oferece detalhes sobre os resultados obtidos para a região sudeste brasileira e analisa os resultados por meio de métricas de erros e análise de perfis. Por fim, no Capítulo 5 são apresentadas as conclusões e considerações finais do trabalho.

Para o desenvolvimento computacional das metodologias propostas, utilizouse a linguagem de programação e o software RStudio. Para exemplos básicos e elaboração de alguns gráficos utilizou-se o Microsoft Excel. 


\section{2 \\ Referencial Teórico}

Neste capítulo são apresentados os modelos e métodos utilizados nesta Tese de Doutorado. Inicialmente, descreve-se como se dá a geração da previsão anual a longo prazo por bottom-up, logo após é apresentado com detalhes o PDA e a ferramenta de aplicação do método, eLOAD, utilizado para previsão a longo prazo nesta Tese. Em seguida, é exposto o método de geração de perfis específicos para processos dos setores residencial, terciário e industrial, além da metodologia proposta para geração de cenários com base nos resultados determinísticos do eLOAD.

\section{1. Modelagem Bottom-up e o FORECAST}

Os modelos de previsão top-down (Guan et al., 2013; Pang et al., 2018) caracterizam-se por sua simplicidade e sua confiança em séries totais históricas e variáveis explicativas. Contudo, verifica-se sua fragilidade ao se ter conhecimento que compondo o total a ser modelado possam existir diferentes processos com características distintas e que impactam de maneiras distintas no total.

De modo a solucionar tal fragilidade, os modelos de previsão bottom-up buscam prever de maneira independente cada um destes processos, aglomerandoos ao final para que se possa obter uma previsão da série histórica total. Desta maneira, características específicas da série de cada processo, como tendência e sazonalidade, são tratados separadamente e com maior relevância (Hendry e Hubrich, 2011; Widiarta, Viswanathan e Piplani, 2009).

De modo a complementar as vantagens da modelagem bottom-up, Worrel et al. (2004) e Worrel e Price (2001) indicam como trabalhar variáveis específicas pode ser vantajoso na estimativa das políticas de eficiência energética, difundindo o uso de tal modelagem em trabalhos recentes e incentivando a criação de ferramentas como o FORECAST, capaz de gerar cenários a longo prazo e já 
consolidado por meio da estimativa em diferentes setores na Europa (Elsland, Eichhammer e Schlomann, 2013; Fleiter et al., 2011; Jakob et al., 2012).

Composto de quatro diferentes módulos (Residencial, Terciário, Industrial e Outros) e com características específicas em cada um deles, o FORECAST foi adaptado para a realidade brasileira e utilizado para os setores residencial (Maçaira, 2015), terciário (Bastos et al., 2017) e industrial (Silva et al., 2018), de modo a obter a demanda de energia para as diferentes regiões brasileiras, incluindo o Sudeste.

\subsection{1.}

FORECAST Residencial

O FORECAST Residencial trabalha com o Módulo dos Bens finais (Módulo 1) e o Módulo para Sistemas de Aquecimento (Módulo 2), sendo este segundo não significativo para qualquer região geográfica brasileira. Para o Módulo 1 optou-se por trabalhar com geladeiras, freezers, televisores, chuveiros elétricos, ar condicionado e iluminação, pelo fato destes representarem mais de $90 \%$ do consumo total de energia em uma residência brasileira. Estes itens mais relevantes são divididos por classe de eficiência, enquanto o restante dos bens domésticos é modelado por uma categoria chamada Novos e Outros (Maçaira, 2015).

Maçaira (2015) explica que no FORECAST Residencial a demanda de eletricidade, apresentada conforme equação (2-1), depende de toda a demanda dos bens finais, ou tecnologias, que é calculada como o produto do consumo específico pelo estoque de cada bem final distinguido por difusão tecnológica e classe de eficiência, sendo estas difundidas de acordo com o cenário abordado.

$$
\mathbf{E}_{\mathrm{t}}=\mathbf{d}_{\mathrm{t}} \cdot \sum_{\mathrm{i}=1}^{l}\left(\boldsymbol{p}_{i, t} \cdot \mathbf{w}_{\mathrm{i}} \cdot \mathbf{o}_{\mathrm{i}} \cdot \mathbf{m s}_{\mathrm{i}, \mathrm{t}}\right)+e_{\text {outros }, t}
$$

Onde,

$\mathrm{E}_{\mathrm{t}}$ : Demanda total do setor residencial $(\mathrm{kWh})$;

$d_{t}$ : Número de domicílios no tempo t;

$p_{i, t}$ : Taxa de posse da tecnologia $i$ em operação ou em standby;

$w_{i}$ : Potência específica da tecnologia i em operação ou em standby (W);

$o_{i}$ : Tempo de operação ou standby da tecnologia $i(\mathrm{~h})$;

$m s_{i, t}$ : Estoque da tecnologia $i$ no tempo $t$;

$e_{\text {outros }, t}$ : Eletricidade demandada da categoria Novos e Outros; e

$i$ : Tecnologias, $i=1,2, \ldots, l$ 
A Erro! Fonte de referência não encontrada. apresenta algumas das $p$ rincipais informações utilizadas no FORECAST Residencial por região.

Tabela 1 - Informações-base para uso do FORECAST Residencial (adaptado de (Maçaira, 2015)).

\begin{tabular}{|c|c|}
\hline BENS FINAIS & \\
\hline Refrigerador & \\
\hline Freezer & \\
\hline Lava-Roupas & \\
\hline Televisão & \\
\hline Chuveiro Elétrico & \\
\hline Iluminação & \\
\hline Ar Condicionado C, D, E e F & \\
\hline
\end{tabular}

\subsection{2.}

\section{FORECAST Terciário}

Segundo Bastos et al. (2017), o FORECAST Terciário consiste em uma metodologia de "soma-produto" entre variáveis globais (e.g., número de empregados por área), energia específica dos serviços (e.g., número de computadores por empregados) e consumo específico de eletricidade dos indicadores (e.g., potência instalada, número de horas em utilização). Para o modelo, consideram-se como as principais variáveis deste setor os serviços de energia, as medidas de eficiência energética (ME) e os dados tecno-econômicos. As MEs podem reduzir a potência instalada dos serviços de energia e o número de horas de utilização, ou ambos. A penetração de MEs nos subsetores é modelada com as curvas de difusão. No caso brasileiro, consideram-se 8 subsetores e 14 serviços de energia, sendo estes selecionados de acordo com o European Classification of Economic Activities.

A seguir, na equação (2-2) é mostrada uma descrição formal do modelo, enquanto que na Erro! Fonte de referência não encontrada. seguem algumas das i nformações principais para a Tese no FORECAST Terciário. 


$$
\begin{aligned}
\mathbf{T}_{\mathrm{t}}=\sum_{\mathrm{R}=1}^{\mathrm{n}} \sum_{\mathrm{S}=\mathbf{1}}^{\mathrm{l}} \sum_{\mathrm{E}=\mathbf{1}}^{\mathrm{k}} \mathbf{G}_{\mathrm{C}, \mathrm{S}, \mathrm{t}} \cdot \mathbf{D}_{\mathrm{C}, \mathrm{S}, \mathrm{E}, \mathrm{t}} \cdot \mathbf{P}_{\mathrm{C}, \mathrm{S}, \mathrm{E}} \\
\cdot \mathbf{U}_{\mathrm{C}, \mathrm{S}, \mathrm{E}} \prod_{\mathbf{M E}=\mathbf{1}}^{\mathrm{x}}\left(1-\Delta \mathbf{D R}_{\mathrm{C}, \mathrm{S}, \mathrm{E}, \mathrm{ME}, \mathrm{t}} \cdot \Delta \mathbf{P}_{\mathrm{C}, \mathrm{S}, \mathrm{E}, \mathrm{ME}}\right) \\
\cdot \prod_{\mathbf{E E M}=1}^{\mathrm{x}}\left(1-\Delta \mathbf{D R}_{\mathrm{C}, \mathrm{S}, \mathrm{E}, \mathrm{ME}, \mathrm{t}} \cdot \Delta \mathbf{U}_{\mathrm{C}, \mathrm{S}, \mathrm{E}, \mathrm{ME}}\right)
\end{aligned}
$$

Onde,

$\mathrm{T}_{\mathrm{t}}$ : Demanda total do setor terciário $(\mathrm{kWh})$;

$\mathrm{G}_{\mathrm{C}, \mathrm{s}, \mathrm{t}}$ : Variáveis Globais;

$\mathrm{D}_{\mathrm{C}, \mathrm{S}, \mathrm{E}, \mathrm{t}}$ : Variáveis de serviços de energia;

$\mathrm{P}_{\mathrm{C}, \mathrm{S}, \mathrm{E}}$ : Potência instalada por variável $(\mathrm{W})$;

$\mathrm{U}_{\mathrm{C}, \mathrm{S}, \mathrm{E}}$ : taxa de utilização anual (h/a);

$\Delta \mathrm{DR}_{\mathrm{C}, \mathrm{S}, \mathrm{E}, \mathrm{ME}, \mathrm{t}}$ : taxa de difusão de medidas de eficiência energética $(\%)$;

$\Delta \mathrm{P}_{\mathrm{C}, \mathrm{S}, \mathrm{E}, \mathrm{ME}}$ : redução relativa da potência instalada por opção de eficiência energética (\%);

$\Delta \mathrm{U}_{\mathrm{C}, \mathrm{S}, \mathrm{E}, \mathrm{ME}}$ : redução relativa da taxa de utilização por opção de eficiência energética (\%);

$\mathrm{R}$ : regiões brasileiras, $R=1,2, \ldots, n$;

S: subsetores, $S=1,2, \ldots, l$;

E: serviços de energia, $E=1,2, \ldots, k$; e

$M E$ : medidas de eficiência energética, $M E=1,2, \ldots, x$.

Tabela 2 - Informações-base para uso do FORECAST Terciário (adaptado de (Bastos et al., 2017)).

\begin{tabular}{|c|c|}
\hline SUBSETORES & SERVIÇOS DE ENERGIA \\
\hline Atacado e Varejo & Iluminação \\
\hline Hotéis, cafés e restaurantes & Iluminação pública \\
Tráfego e transmissão de dados & Ventilação e ar condicionado \\
\hline Finanças & Elevadores \\
Saúde & Lavandeira \\
Educação & Refrigeração \\
\hline Escritórios Públicos & Tecnologias de construção \\
\hline Outros Serviços & $\ldots$ \\
\hline
\end{tabular}

\subsection{3.}

\section{FORECAST Industrial}

Silva et al. (2018) explicam que no FORECAST Industrial o cálculo da demanda de energia dos processos inicia-se com base na previsão da produção anual e no consumo de energia específico (SEC) de cada processo. Em seguida, as EEMs específicas dos processos são modeladas para se difundir entre os mesmos e reduzir 
a demanda de energia para, por fim, a demanda remanescente ser calculada por subsetor. A demanda de eletricidade estará, então, sujeita às economias de energia via tecnologias transversais (CCT), seguindo uma abordagem similar à de tecnologias do processo.

Para o caso brasileiro foram selecionados 79 processos industriais e 11 subsetores da indústria, considerados por meio de mapeamento daqueles de maior consumo da indústria brasileira (Silva, 2017). De maneira geral, o consumo calculado por subsetor no setor industrial se dá pela equação (2-3) e na Erro! Fonte d e referência não encontrada. são expostas algumas das principais informações utilizadas para o setor.

$$
\begin{gathered}
S_{i, t}=\sum_{j=1}^{n_{i}} P_{i, j, t}+R_{i, t}-E_{i, t} \\
P_{i, j, t}=g\left(\operatorname{Prod}_{i, j, t}\right)-E_{i, j, t}
\end{gathered}
$$

Onde,

$S_{i, t}$ : Consumo de eletricidade no subsetor $(\mathrm{kWh})$;

$P_{j, t}$ : Consumo de eletricidade de um processo pertencente ao subsetor $(\mathrm{kWh})$;

$R_{i, t}$ : Estimativa obtida por meio do valor adicionado de cada subsetor $(\mathrm{kWh})$;

$E_{i, t}$ : Economia de energia obtida pelas MEEs aplicadas ao subsetor $(\mathrm{kWh})$;

$\operatorname{Prod}_{i, j, t}$ : Produção em toneladas do processo (t);

$E_{i, j, t}$ : Economia de energia obtida pelas MEEs aplicadas ao processo do subsetor (kWh);

$j$ : Processos, $j=1,2, \ldots, n_{i}$;

$i$ : Subsetores, $i=11$; e

$t$ : Tempo, $t=1,2, \ldots, T$. 
Tabela 3 - Informações-base para uso do FORECAST Industrial (adaptado de (Silva, 2017)).

\begin{tabular}{|c|c|}
\hline SUBSETORES & PROCESSOS \\
\hline Ferro gusa e aço & $\begin{array}{c}\text { Sinterização } \\
\text { Aço Oxigenado }\end{array}$ \\
\hline Metais não ferrosos & $\begin{array}{l}\text { Alumínio Primário } \\
\text { Cobre Primário }\end{array}$ \\
\hline Papel e celulose & $\begin{array}{c}\text { Papel } \\
\text { Mecânica de celulose }\end{array}$ \\
\hline Química & $\begin{array}{l}\text { Amônia } \\
\text { Oxigênio }\end{array}$ \\
\hline Alimentos e bebidas & $\begin{array}{c}\text { Açúcares } \\
\text { Bebidas }\end{array}$ \\
\hline Cimento & $\begin{array}{c}\text { Clinquerização do cimento } \\
\text { Preparação de matérias-primas }\end{array}$ \\
\hline Ferro ligas & $\begin{array}{l}\text { Preparação de matéria prima } \\
\text { Fusão redução da carga }\end{array}$ \\
\hline Mineração e Pelotização & $\begin{array}{c}\text { Mineração } \\
\text { Pelotizacão }\end{array}$ \\
\hline Têxtil & $\begin{array}{c}\text { Fiação } \\
\text { Tecelagem }\end{array}$ \\
\hline Cerâmica & $\begin{array}{l}\text { Revestimentos cerâmicos } \\
\text { Cerâmicas vermelhas }\end{array}$ \\
\hline Outras Indústrias & Outros \\
\hline
\end{tabular}

\subsection{4.}

\section{Método de Decomposição Parcial e o eLOAD}

A previsão de carga é essencial para o planejamento do sistema elétrico, porém a previsão a longo prazo, efetuada de maneira geral para a demanda anual, possui altos graus de incerteza, intensificando ainda mais o problema quando o intuito é detalhar a demanda mensal, semanal, diária ou horária.

O Método de Decomposição Parcial, metodologia utilizada para construção do software eLOAD, foi desenvolvida e validada por Boßmann (2015) a fim de complementar abordagens existentes e suprir lacunas existentes nas mesmas. Este é inicialmente baseado na possibilidade de desagregar a projeção anual de demanda de eletricidade do sistema $\left(D_{A P}^{S i s}\right)$ para um ano de projeção $A P$, efetuada por meio 
do FORECAST, nas demandas de processos individuais do mesmo ano futuro específico, $D_{A P, p}^{p r o c}$, como mostra a equação (2-4).

$$
D_{A P}^{s i s}=\sum_{p=1}^{n} D_{A P, p}^{p r o c}
$$

Onde,

$D_{A P}^{s i s}$ : Demanda do sistema no ano de projeção;

$D_{A P, p}^{p r o c}$ : Demanda do processo no ano de projeção; e $p$ : Processo, $p=1,2, \ldots, n$.

\section{2.}

\section{Método de Decomposição Parcial}

Consistindo em cinco passos, conforme mostra a Figura 5 de forma simplificada, em um primeiro passo os processos mais relevantes são mapeados, enquanto no passo dois uma curva horária é gerada para cada um desses processos por meio de um escalonamento do ano base. Tais processos são extraídos da curva base, a fim de obter a curva residual, composta pelos processos menos relevantes. No passo três há o escalonamento das curvas geradas para os processos e no passo quatro o escalonamento da curva residual, ambos baseados nas projeções anuais efetuadas. Por fim, no passo cinco as curvas dos processos são adicionadas à curva residual, previamente escalonadas, a fim de obter a curva total resultante para o ano de projeção especificado. 


\section{Entrada: projeção de demanda anual por região, setor e processo}

\section{Distinguir processos relevantes e menos relevantes}

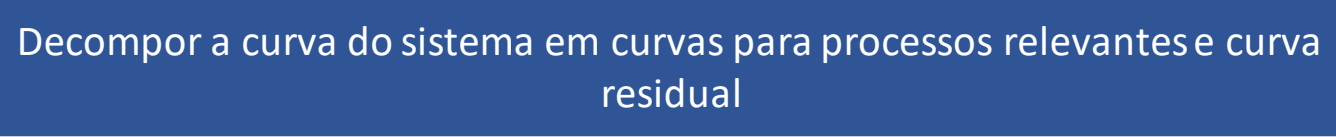

Escalar o perfil dos processos relevantes de acordo com a projeção anual de demanda

Escalar o perfil residual de acordo com a demanda agregada dos processos menos relevantes

Compor a curva do sistema por meio da união entre processos relevantese curva residual escalada

\section{Saída: projeção de carga horária por região, setor e processo}

Figura 5 - Simplificação do esquema de cálculo da PDA (adaptado de (Boßmann, 2015)).

Com relação ao passo um, os processos mais relevantes são aqueles que tiveram alterações mais significativas quando se compara o ano base ou histórico, $A H$, com o ano de projeção, $A P$, ou seja, um processo $p$ é considerado relevante, $P_{\text {relev }}$, caso a relação de mudança entre a demanda anual do mesmo e a demanda total no ano base, $D_{A H}^{s i s}$, exceda um valor crítico, conforme cálculo apresentado pela equação (2-5). Caso contrário, o processo é considerado como menos relevante, $P_{\text {Irrelev }}$, como mostra a equação (2-6).

$$
\begin{gathered}
p \in P_{\text {relev }} \text { se } \lim \leq \frac{D_{A P, p}^{\text {proc }}-D_{A H, p}^{\text {proc }}}{D_{A H}^{\text {sis }}} \\
p \in P_{\text {Irrelev }} \text { se lim }>\frac{D_{A P, p}^{\text {proc }}-D_{A H, p}^{\text {proc }}}{D_{A H}^{\text {sis }}}
\end{gathered}
$$

Onde,

$p$ : Processo, $p=1,2, \ldots, n$;

$P_{\text {relev }}$ : Processo relevante;

$P_{\text {Irrelev: }}$ : Processo relevante;

lim: Valor limiar de relevância a ser determinado pelo analista;

$D_{A P, p}^{p r o c}$ : Demanda do processo no ano de projeção;

$D_{A H, p}^{p r o c}$ : Demanda do processo no ano histórico;

$D_{A H}^{\text {sis }}$ : Demanda do sistema no ano histórico. 
Com relação ao passo dois, constrói-se a curva de carga horária de cada processo relevante no ano base, $C_{A H, p, h}^{p r o c}$, ao longo de todo o ano. Esta é construída com a alocação do perfil diário do processo ao longo do ano, de acordo com informações específicas (tipo de dia, estação do ano, ...), para depois sua participação na carga ser determinada por meio do escalonamento efetuado de acordo com a demanda anual de eletricidade no ano base, $D_{A H, p}^{\text {proc }}$.

Somando todos os processos relevantes e os subtraindo da curva de carga do sistema do ano base, $C_{A H, h}^{s i s}$, obtém-se a curva residual, $C_{A H, h}^{r e s}$, como mostra a equação (2-7).

$$
C_{A H, h}^{r e s}=C_{A H, h}^{s i s}-\sum_{p=1}^{n} C_{A H, p, h}^{p r o c} \forall p \in P_{r e l e v}, \forall h \in\left[1, h_{\text {max }, \text { ano }}\right]
$$

Onde,

$C_{A H, h}^{r e s}$ : Carga horária residual no ano histórico;

$C_{A H, h}^{s i s}$ : Carga horária do sistema no ano histórico;

$C_{A H, p, h}^{p r o c}$ : Carga horária do processo no ano histórico;

$p$ : Processo, $p=1,2, \ldots, n$;

$P_{\text {relev }}$ : Processo relevante; e

$h$ : Hora do ano, $h=1,2, \ldots, h_{\max , \text { ano }}$.

A Figura 6 apresenta uma ilustração da aplicação dos passos 1 e 2, a exemplo de um dia. Da curva histórica identificam-se os processos relevantes, como feito em A, extraem-se os perfis mais relevantes, como feito em B, a fim de obter a curva residual, $\mathrm{C}$.

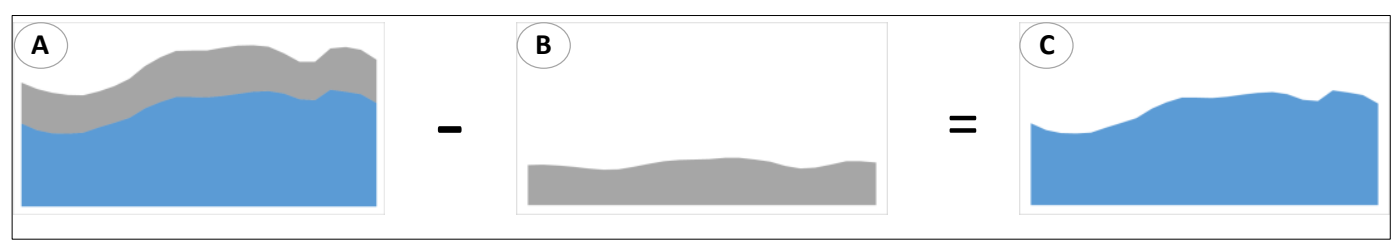

Figura 6 - Ilustração de aplicação dos passos 1 e 2 (adaptado de (Boßmann, 2015)).

No passo três são geradas as curvas de carga de todos os processos relevantes para o ano de projeção considerando a demanda anual, $C_{A P, p, h}^{p r o c}$, como mostra a equação (2-8). A Figura 7 ilustra a aplicação deste passo.

$$
C_{A P, p, h}^{\text {proc }}=\frac{D_{A P, p}^{\text {proc }}}{D_{A H, p}^{\text {proc }}} \cdot C_{A H, p, h}^{\text {proc }} \forall p \in P_{\text {relev }}, \forall h \in\left[1, h_{\text {max }, \text { ano }}\right]
$$

Onde,

$C_{A P, p, h}^{p r o c}:$ Carga horária do processo no ano de projeção; 
$D_{A P, p}^{p r o c}$ : Demanda do processo no ano de projeção;

$D_{A H, p}^{p r o c}$ : Demanda do processo no ano histórico;

$C_{A H, p, h}^{p r o c}$ : Carga horária do processo no ano histórico;

$p$ : Processo, $p=1,2, \ldots, n$;

$P_{\text {relev }}$ : Processo relevante; e

$h$ : Hora do ano, $h=1,2, \ldots, h_{\max , \text { ano }}$.

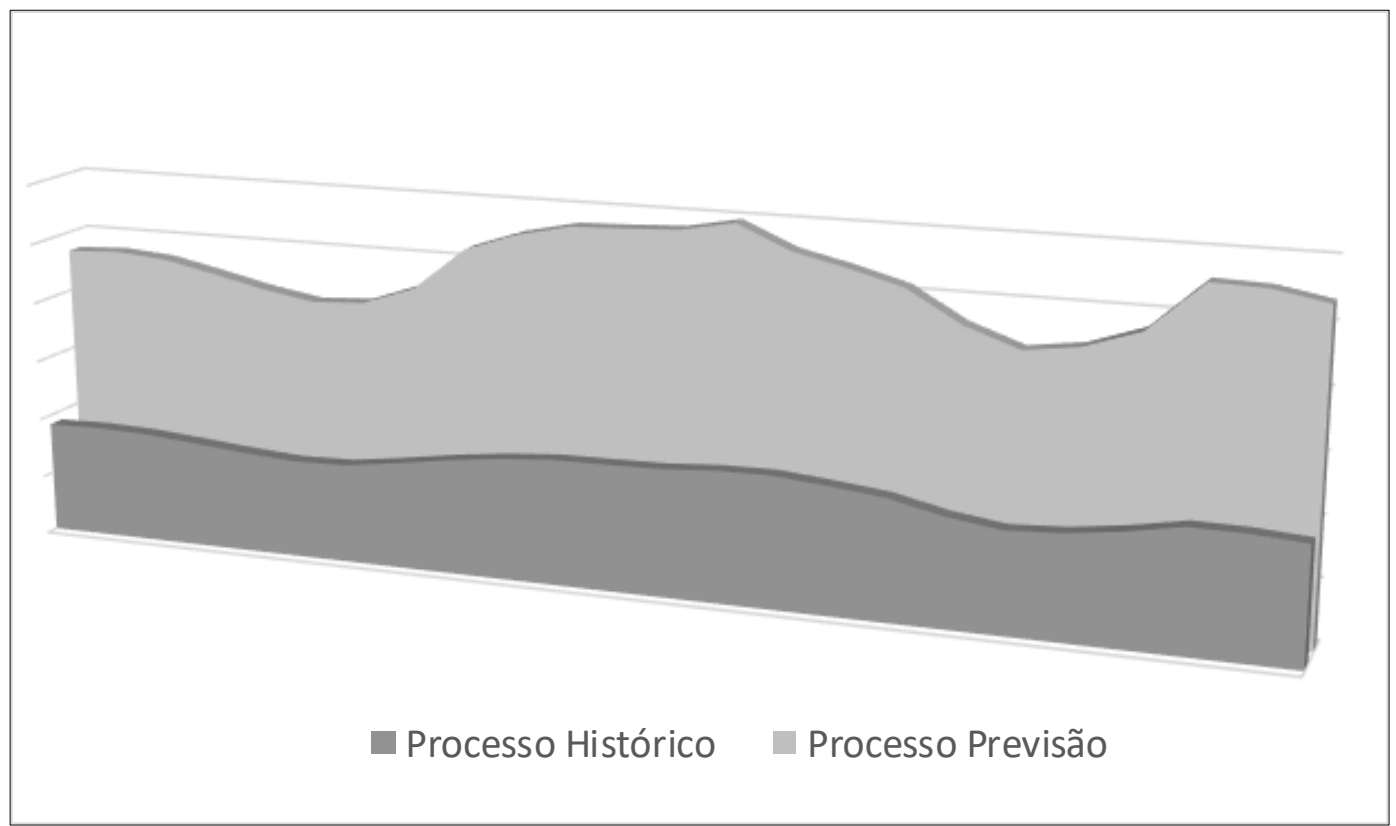

Figura 7 - Ilustração de aplicação do passo 3 (adaptado de (Boßmann, 2015)).

No passo quatro, os processos menos relevantes são escalonados de acordo com a alteração acumulativa na demanda anual de eletricidade, como apresenta a equação (2-9). A Figura 8 ilustra a aplicação deste passo.

$$
C_{A P, h}^{r e s}=\frac{D_{A P}^{s i s}-\sum_{p=1}^{n} D_{A P, p}^{p r o c}}{D_{A H}^{s i s}-\sum_{p=1}^{n} D_{A H, p}^{p r o c}} \cdot C_{A H, h}^{r e s} \forall p \in P_{\text {relev }}, \forall h \in\left[1, h_{\text {max }, \text { ano }}\right]
$$

Onde,

$C_{A P, h}^{r e s}$ : Carga horária residual no ano de projeção;

$D_{A P}^{s i s}$ : Demanda do sistema no ano de projeção;

$D_{A H}^{\text {sis }}$ : Demanda do sistema no ano histórico;

$D_{A P, p}^{p r o c}$ : Demanda do processo no ano de projeção;

$D_{A H, p}^{p r o c}$ : Demanda do processo no ano histórico;

$C_{A H, h}^{r e s}$ : Carga horária residual no ano histórico;

$p$ : Processo, $p=1,2, \ldots, n$;

$P_{\text {relev }}$ : Processo relevante; e

$h$ : Hora do ano, $h=1,2, \ldots, h_{\max , \text { ano }}$. 


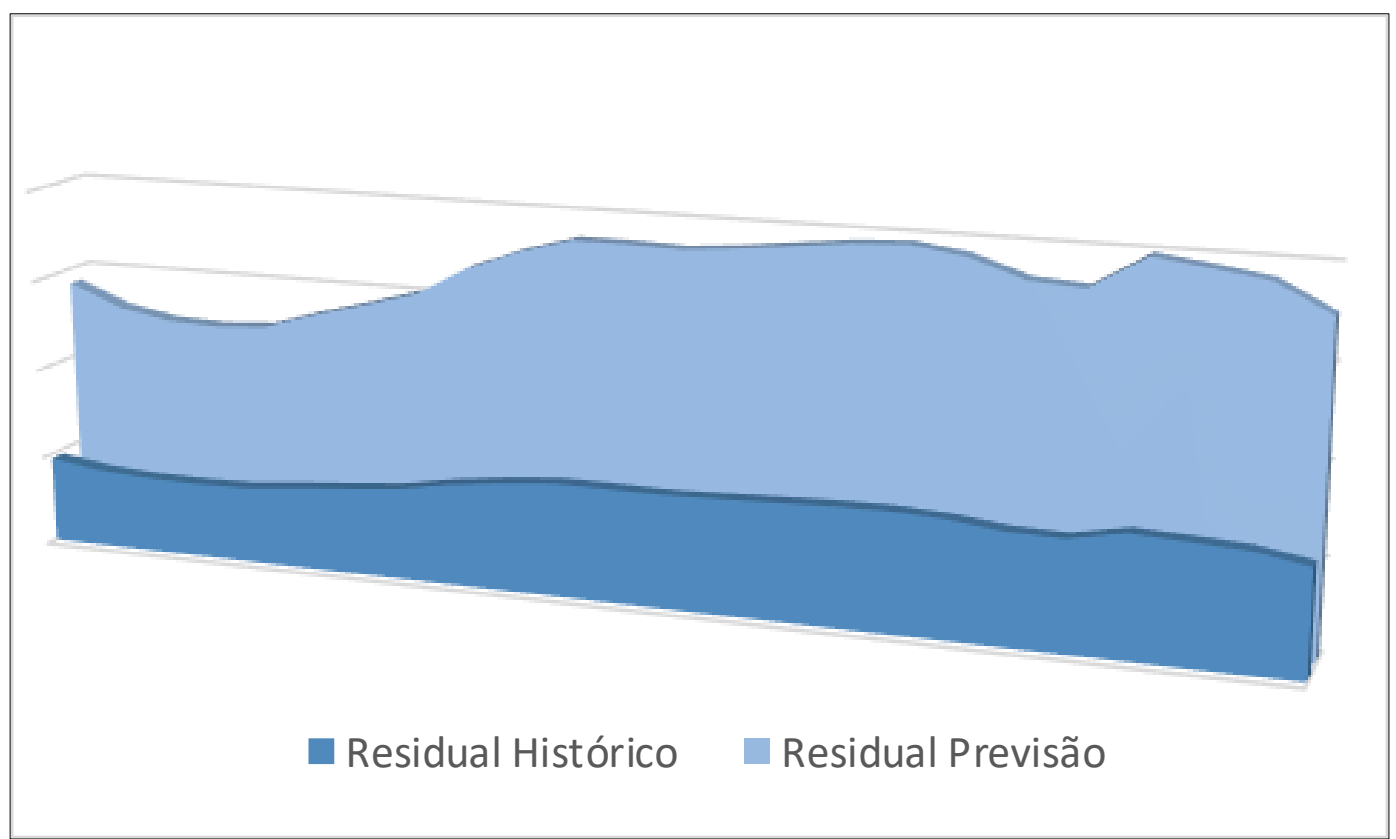

Figura 8 - llustração de aplicação do passo 4 (adaptado de (Boßmann, 2015)).

Com relação ao quinto e último passo, a curva de carga agregada dos processos relevantes é adicionada à curva escalonada dos processos menos relevantes, produzindo a curva de carga horária total de um ano de projeção futuro específico $C_{A P, h}^{s i s}$, como mostra a equação (2-10).

$$
C_{A P, h}^{s i s}=C_{A P, h}^{r e s}+\sum_{p=1}^{n} C_{A P, p, h}^{p r o c} \forall p \in P_{\text {relev }}, \forall h \in\left[1, h_{\text {max }, \text { ano }}\right]
$$

Onde,

$C_{A P, h}^{\text {sis }}$ : Carga horária do sistema no ano de projeção;

$C_{A P, h}^{r e s}$ : Carga horária residual no ano de projeção;

$C_{A P, p, h}^{p r o c}:$ Carga horária do processo no ano de projeção;

$p$ : Processo, $p=1,2, \ldots, n$;

$P_{\text {relev }}$ : Processo relevante; e

$h$ : Hora do ano, $h=1,2, \ldots, h_{\max , a n o}$.

A Figura 9 ilustra um exemplo de aplicação do passo 5, onde a curva residual escalonada para o ano de previsão, A, é agregada com o perfil dos processos mais relevantes escalonados para o mesmo ano de previsão, B, a fim de obter a curva final estimada, $\mathrm{C}$. 


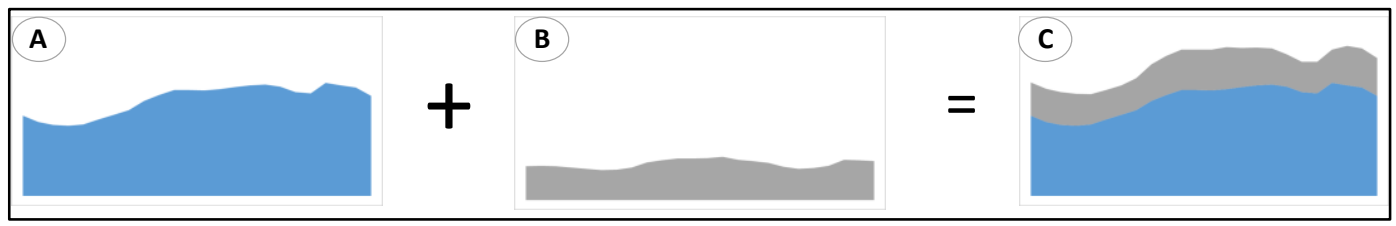

Figura 9 - llustração de aplicação do passo 5 (adaptado de (Boßmann, 2015)).

\subsection{1.}

eLOAD

O PDA foi implementado em linguagem JAVA dando origem ao eLOAD. A plataforma usa diferentes informações referentes à curva de carga e compõe um módulo de projeção em conjunto com o FORECAST, como mostra a Figura 6.

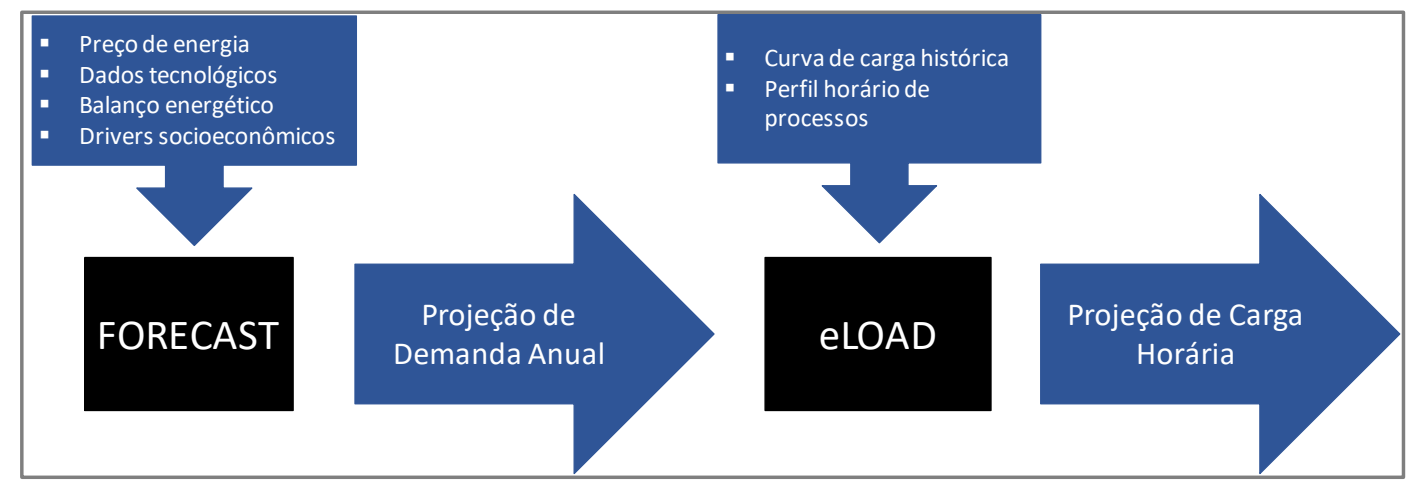

Figura 10 - Módulo de Projeção para o Brasil (adaptado de (Boßmann, 2015)).

Para o caso brasileiro são usados os perfis dos processos específicos para cada região, a curva de carga histórica base para cada região e previsões de demanda advindas do FORECAST, dados básicos para aplicação do PDA.

Os resultados do FORECAST são baseados em premissas tomadas e projeções efetuadas por Maçaira (2015), Bastos et al. (2017) e Silva (2017), enquanto os dados horários de carga de sistema são originários do histórico de operação do Operador Nacional do Sistema Elétrico (ONS) (2017).

Por limitação de dados disponíveis, os chamados processos utilizados para a projeção de carga são referentes aos equipamentos do setor residencial, subsetores do setor terciário e subsetores do setor industrial. 


\section{3 \\ Base de dados e Metodologia Proposta}

Neste capítulo são apresentadas as informações utilizadas para previsão horária de carga até 2020, juntamente com as metodologias propostas por esta tese de doutorado. Informações sobre resultados da previsão anual do FORECAST, sobre a curva de carga horária e, por fim, sobre os perfis diários dos processos e o resultado da aplicação da Metodologia de Geração de Perfis Específicos dos Processos, serão apresentados juntamente à metodologia de simulação aplicada à previsão efetuada pelo PDA.

\section{1. \\ Dados de Previsão Anual}

Os dados de previsões anuais foram obtidos com base nas previsões efetuadas para cada um dos três setores por meio da abordagem bottom-up (Bastos et al., 2017; Maçaira, 2015; Silva, 2017), utilizando-se de um cenário em que, além de considerado o potencial de mercado associado a um eventual cenário de difusão autônoma, também é considerada a adoção de medidas de eficiência energética que possuam viabilidade econômica.

O total de demanda de eletricidade para o Sudeste previsto por meio da abordagem bottom-up é comparado aos resultados apresentados pela CCEE. Com o resultado da CCEE sendo apresentado por subsistema, baseia-se no Anuário Estatístico de Energia Elétrica 2018 (Empresa de Pesquisa Energética - EPE, 2018) (o mais recente disponível nesta data) para concluir que a região Sudeste tem 86,93 $\%$ do total da soma de demanda de energia entre a região Sudeste e a região CentroOeste, sendo esta aplicada sobre a demanda do subsistema a fim a de se obter a demanda da região.

Quando aplicada a divisão da demanda previamente apresentada, tem-se que o total de demanda esperado para a região Sudeste previsto pela abordagem bottomup, com um total de $275.59 \mathrm{GW}$, é bem superior ao total obtido após aplicar a 
mesma divisão para as projeções mostradas em relatórios mais recentes (Câmara de Comercialização de Energia Elétrica - CCEE, 2019), com um total de 255.2 GW.

Juntamente ao total por região, os resultados das projeções anuais são apresentados para todos os processos pertencentes a cada um dos setores. A seguir, a Figura 11 apresenta a previsão de demanda anual por setor até 2020.

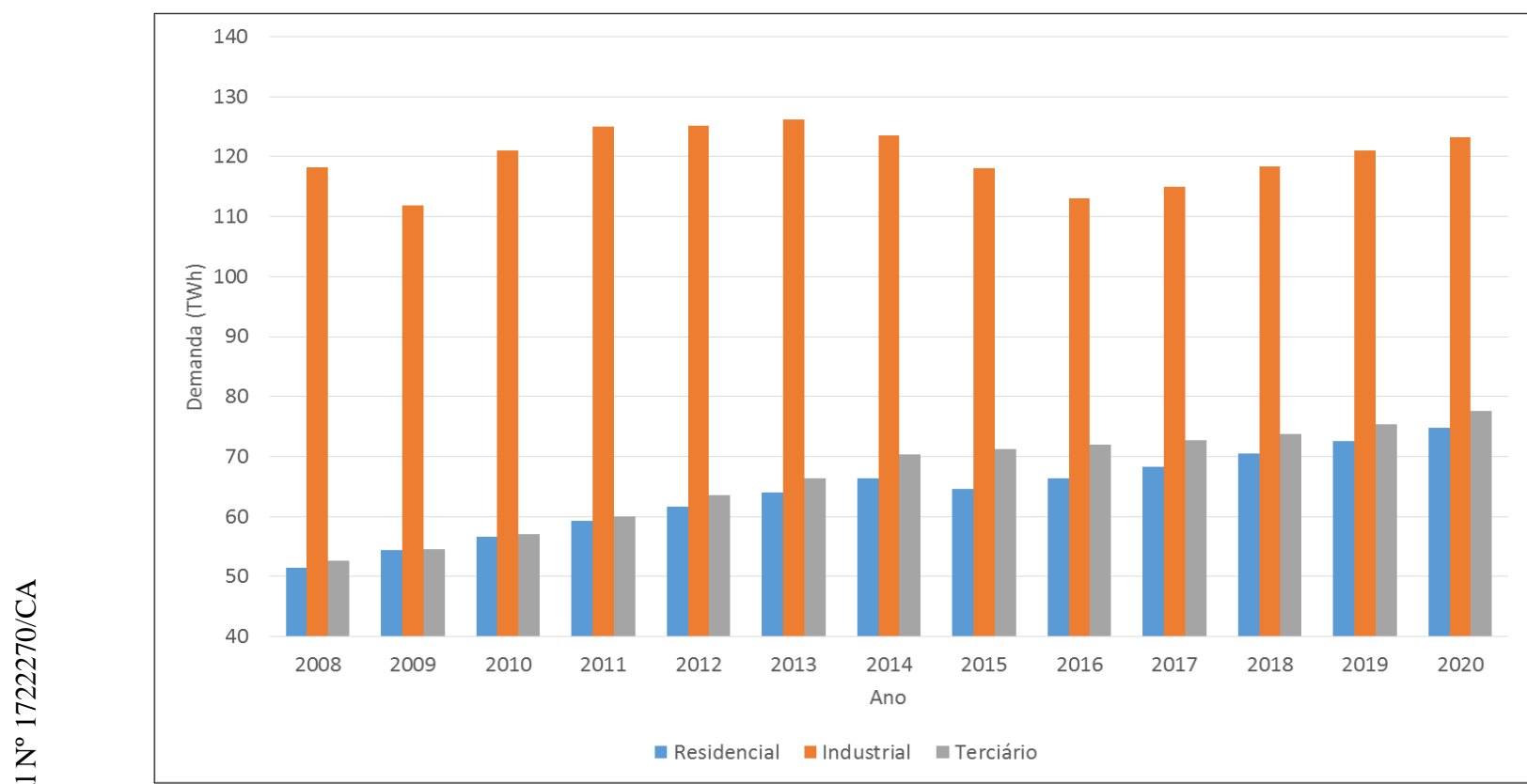

Figura 11 - Previsão Anual de Demanda por Setor até 2020 (adaptado de (Bastos et al., 2017; Maçaira, 2015; Silva, 2017)). 


\section{2.}

\section{Curvas de Carga Horária}

Nesta Tese, utilizaram-se dados de curva de carga horária (MWh) do dia 1 de janeiro de 2016 até o dia 31 de dezembro de 2016, para o subsistema Sudeste/Centro-Oeste brasileiro, extraídos do histórico de operações do Operador Nacional do Sistema Elétrico (ONS) (Figura 12).

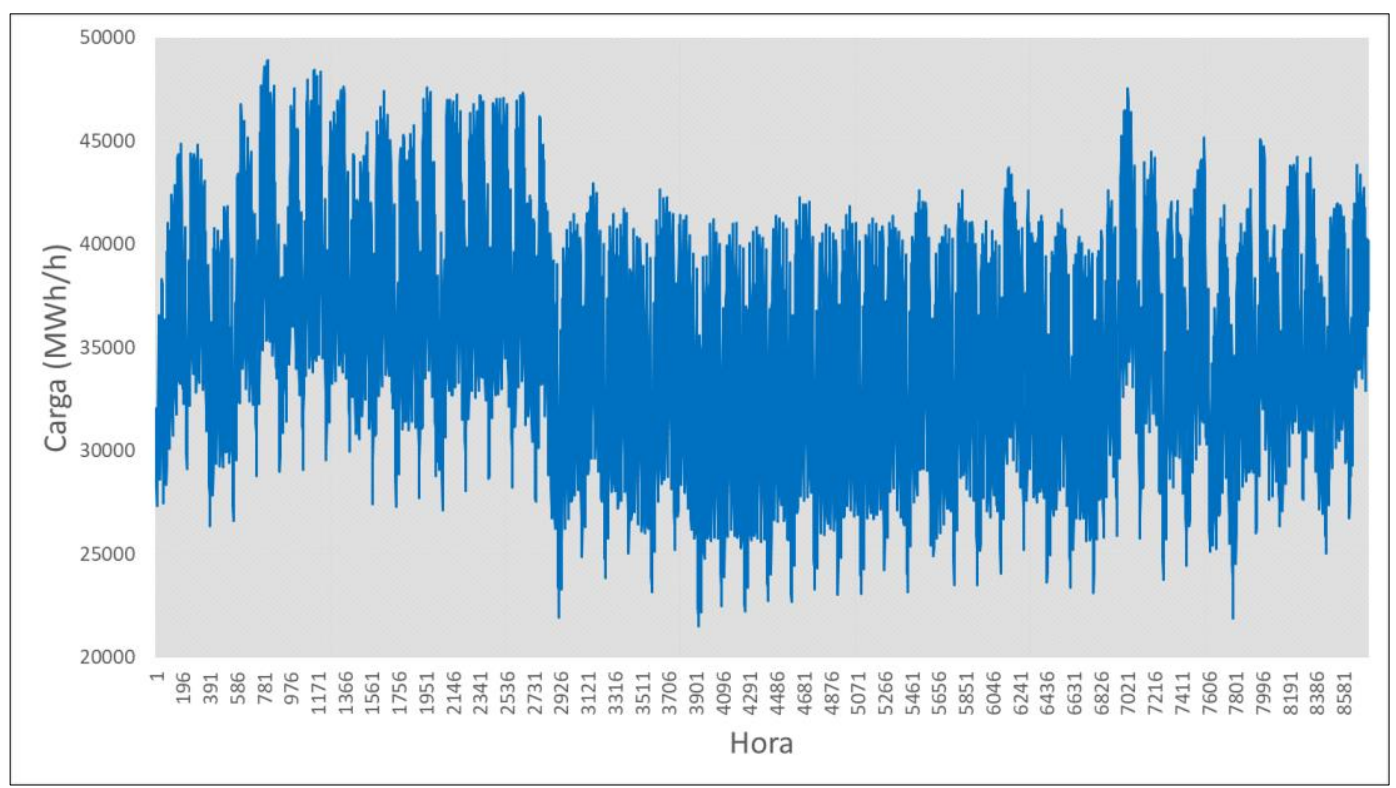

Figura 12 - Série Horária de Carga do Subsistema Sudeste/Centro-Oeste (Operador Nacional do Sistema Elétrico, 2017).

Apesar das alterações dos perfis nos últimos anos, na série ainda é possível notar a sazonalidade, principalmente a ocasionada pelos ciclos de dias quentes e frios, por meio dos níveis de carga altos e baixos, consecutivamente.

Segundo o Anuário Estatístico de Energia Elétrica 2017 (Empresa de Pesquisa Energética - EPE, 2018), o consumo na rede da região sudeste em 2016 foi de $229970 \mathrm{GWh}$, enquanto o da região Centro-Oeste foi de $34579 \mathrm{GWh}$. Assim, de um total de $264549 \mathrm{GWh}$ consumidos na rede pelas duas regiões, 86,93\% é proveniente da região sudeste, enquanto 13,07 \% é proveniente da região centrooeste, sendo estes valores aplicados em cada hora da curva de carga do subsistema a fim de gerar uma curva estimada para a região sudeste.

Na nova curva têm-se os níveis de carga definidos, assim como os perfis médios para cada estação, conforme Figura 13, e tipos de dia, conforme Figura 14. Nota-se que, após a aplicação do percentual estimado para o sudeste no ano de 2016, todos os perfis continuam coerentes com o que se espera do cenário brasileiro. 


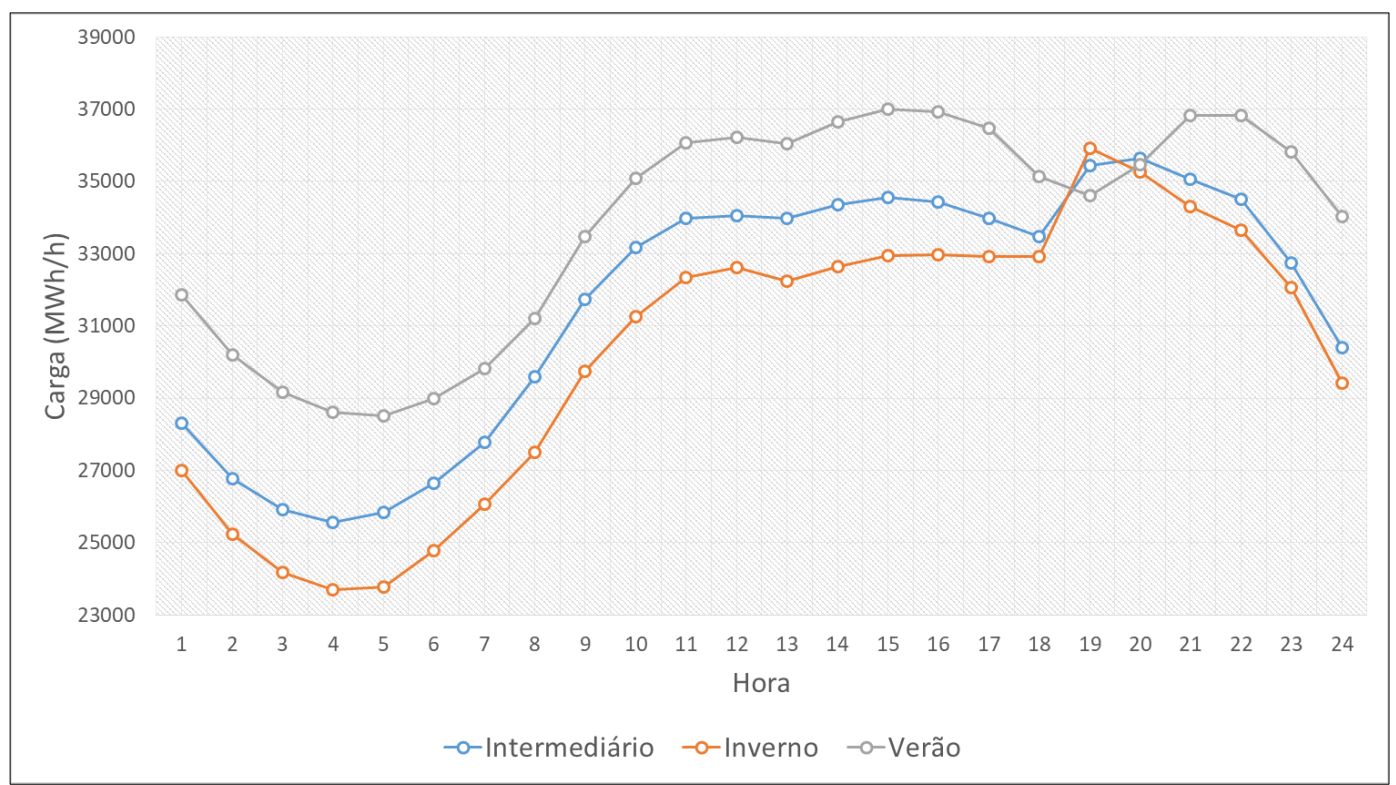

Figura 13 - Perfis Médios de Estações Estimados para a Região Sudeste Brasileira (elaborado pelo autor, 2019).

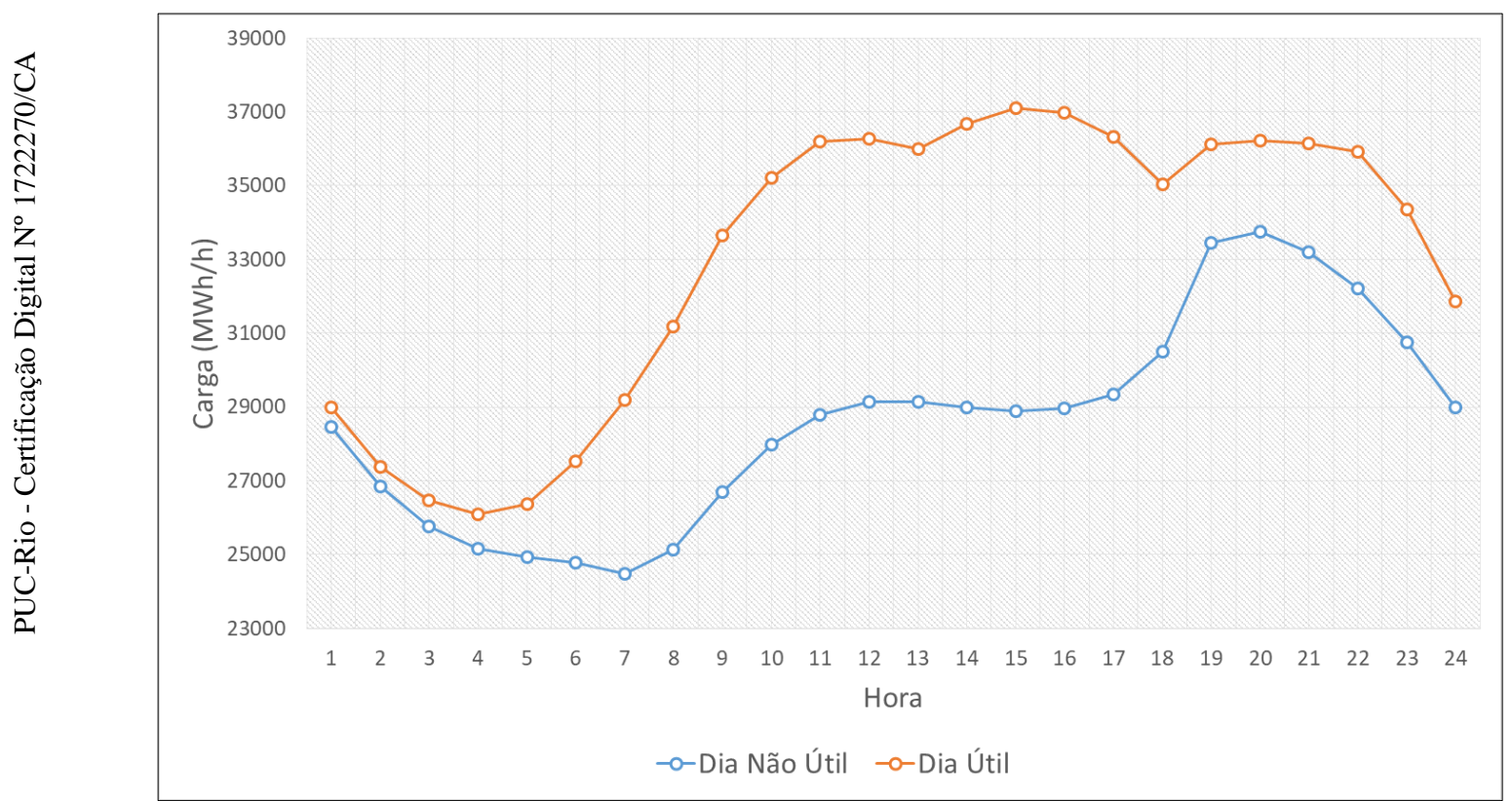

Figura 14 - Perfis Médios de Tipos de Dia Estimados para a Região Sudeste Brasileira (elaborado pelo autor, 2019).

\section{3.}

\section{Perfis Diários de Processos}

Perfis diários de todos os processos são necessários para a utilização do eLOAD. Originalmente, perfis únicos de equipamentos e subsetores foram extraídos de bases de dados com medições reais. Os perfis-base residenciais do 
sudeste ( $\mathrm{kWh}$ ou Wh) foram obtidos por meio da Pesquisa de Posses e Hábitos efetuadas em 2005 pelo PROCEL (2005), enquanto os perfis-base do setor terciário e industrial $(\mathrm{kWh})$ são originários de uma base de dados de perfis médios diários referentes a 2011, fornecida por uma concessionária de energia elétrica da região sudeste para fins científicos (Carmo, 2018).

Os perfis foram agregados e normalizados de forma a compor seus respectivos setores. Por meio da Figura 15 é possível notar que o perfil residencial tem seus picos de consumo na parte da manhã e na parte da noite, horários nos quais as pessoas estão ativas em suas residências; o perfil terciário mantém um consumo elevado durante o horário comercial; e, por fim, o perfil industrial tem seu maior consumo durante o dia com uma queda contínua no adentrar da noite.

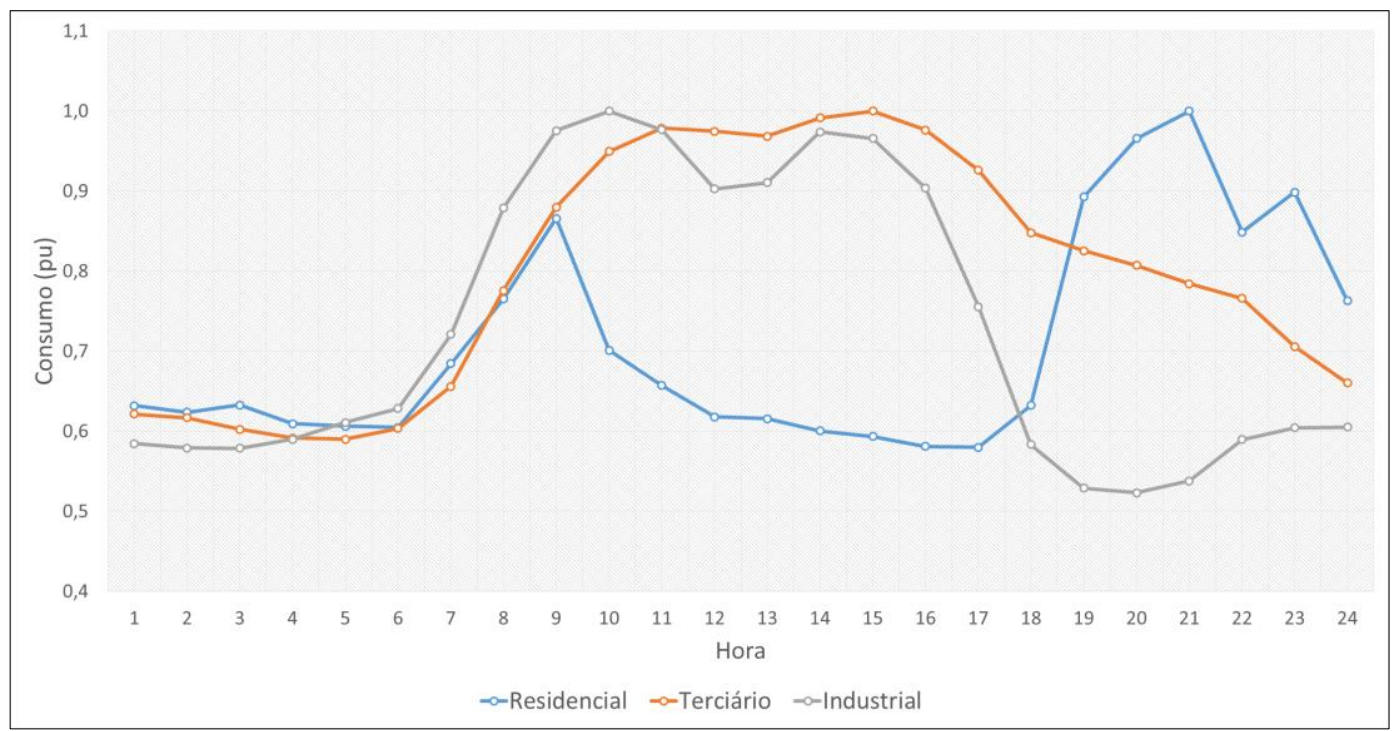

Figura 15 - Perfis Agregados de Processos e Equipamentos por Setor (Carmo, 2018).

Por mais que os perfis agregados pareçam condizentes com o que se espera de cada setor no Brasil, estes não possuem discriminação por tipo de dia e estação. São perfis gerais de processos e equipamentos que não representam a realidade do consumo brasileiro ao longo das diferentes épocas do ano.

Perfis específicos de equipamentos que representem o consumo dos mesmos durante situações peculiares não estão disponíveis em bases de dados brasileiras. Com isso, a escassez de informações específicas gera a necessidade do desenvolvimento de metodologias capazes de estimar dados apropriados para a situação, como a apresentada a seguir. 


\section{4. Metodologia de Geração de Perfis Específicos dos Processos}

Carmo et al (2018) propuseram um método para adaptar poucos dados de perfis horários para perfis específicos para diferentes estações do ano (verão, inverno e intermediária) e diferentes tipos de dia (dia útil e dia não-útil), ou seja, seis tipos de perfis específicos.

Para o setor residencial (Eq. 3.1), setor terciário (Eq. 3.2) e setor industrial (Eq. 3.3) são aplicadas diferenças percentuais entre a variação de um perfil típico geral de carga e perfis típicos específicos de carga nos perfis diários de processos previamente obtidos, ou seja,

$$
\begin{gathered}
P R E_{\text {eq,pe }}(h)=\left(P R_{e q}(h) \times D P_{p e}(h)\right)+e_{\text {eq,pe }}(h) \\
P T E_{\text {subt }, p e}(h)=\left(P T_{\text {subt }}(h) \times D P_{p e}(h)\right)+e_{\text {subt }, p e}(h) \\
P T I_{\text {subi,pe }}(h)=\left(P I_{\text {subi }}(h) \times D P_{p e}(h)\right)+e_{\text {subi,pe }}(h)
\end{gathered}
$$

Onde,

$P R E_{\text {eq,pe }}(h)$ : demanda normalizada específica calculada para um equipamento residencial $e q$, tipo de dia específico pe e hora $h$;

$P R_{e q}(h)$ : demanda normalizada para um equipamento residencial eq e hora $h$;

$e_{\text {eq,pe }}(h)$ : erro da demanda normalizada calculada para um equipamento residencial eq que segue uma distribuição Gaussiana com média $\mu$ e variância $\sigma^{2}$; PTE $E_{\text {subt,pe }}(h)$ : demanda normalizada específica calculada para um subsetor terciário subt, tipo de dia específico pe e hora $h$;

$P T_{\text {subt }}(h)$ : demanda normalizada para um subsetor terciário subt e hora $h$;

$e_{\text {subt,pe }}(h)$ : erro da demanda normalizada calculada para um subsetor terciário subt que segue uma distribuição Gaussiana com média $\mu$ e variância $\sigma^{2}$;

$P_{T I}$ subi,pe $(h)$ : demanda normalizada específica calculada para um subsetor industrial subi, tipo de dia específico pe e hora $h$;

$P I_{\text {subi }}(h)$ : demanda normalizada para um subsetor industrial subi e hora $h$;

$e_{\text {subi,pe }}(h)$ : erro da demanda normalizada calculada para um subsetor industrial subi que segue uma distribuição Gaussiana com média $\mu$ e variância $\sigma^{2}$;

$D P_{p e}(h)$ : Diferença percentual entre a demanda normalizada de um dia médio do ano e um tipo de dia específico pe do mesmo ano em uma hora $h$;

$e q$ : Tipo de equipamento residencial, $e q=1,2, \ldots, 8$;

subt: Tipo de subsetor terciário, subt $=1,2, \ldots, 8$;

subi: Tipo de subsetor industrial, $s u b i=1,2, \ldots, 11$;

$p e$ : Tipos de perfil específicos, $p e=1,2, \ldots, 6$; e

$h$ : Hora do dia, $h=1,2, \ldots, 24$. 
Os erros nas equações (3.1), (3.2) e (3.3) representam inconsistências esperadas que ocorrem após geração de dados sintéticos. Como os dados reais para perfis específicos não estão disponíveis, não existem meios de conhecer a média e real $\mu$ e a variância real $\sigma^{2}$ que caracterizam esses erros. Assim, como explicado por Carmo et al. (2018), com o objetivo de estimar e considerar esses erros nos perfis gerados, incertezas são adicionadas por meio de simulação de Monte Carlo (Cervantes, 1972). Pelo fato de não haver qualquer conhecimento prévio sobre o comportamento dessas incertezas, faz-se o uso de uma distribuição Gaussiana na simulação, dado que segundo o Teorema Central do Limite, a média de uma amostra de uma população tende a uma distribuição normal (Fischer, 2011). Assim, valores simulados para o setor residencial $\left(\operatorname{VSR}_{\text {eq,pe }}(h)\right)$, setor terciário $\left(V S T_{\text {subt,pe }}(h)\right)$ e setor industrial $\left(V S I_{\text {subi,pe }}(h)\right)$ são calculados de acordo com as equações (3.4), (3.5) e (3.6) com o objetivo de gerar três perfis diferentes (máximo, médio e mínimo).

Os três perfis são estimados de acordo com o intervalo de confiança de $95 \%$ aplicado sobre o valor de cada hora, considerando estações do ano e tipos de dia. Para cada hora são gerados 100 valores para simular a incerteza associada e, como consequência, ajustar resultados irregulares. Essa escolha foi efetuada após um teste de convergência em alguns processos, que mostrou que os cenários simulados gerados para cada hora tendem à mesma média após cerca de 50 cenários gerados, em geral. Como o custo computacional não era diferente e para garantir uma média robusta para todos os processos, optou-se pela geração desses 100 valores. Na Figura 16 é apresentado um exemplo, por meio da hora 1 do ar condicionado, de como a média tende a convergir antes dos 100 valores gerados. 


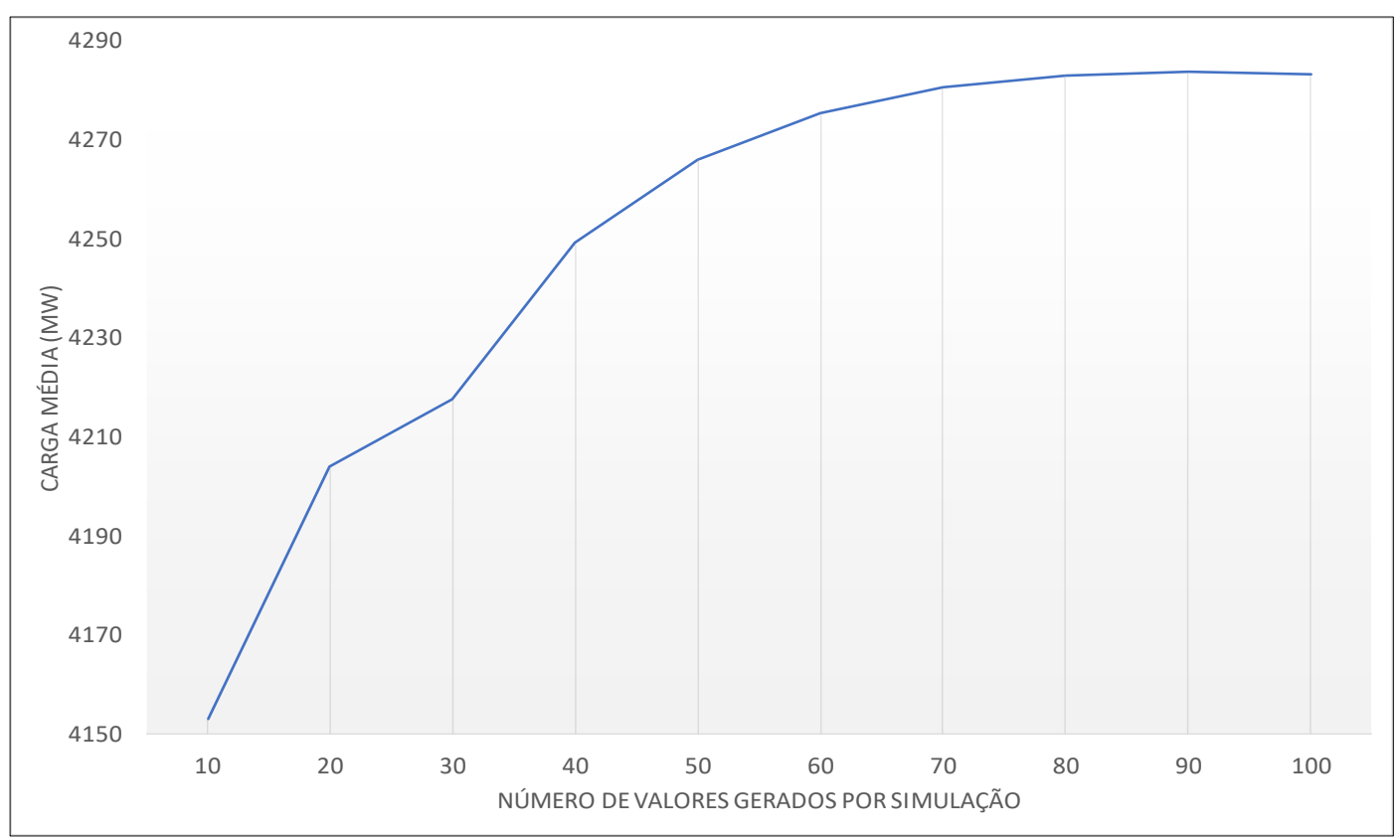

Figura 16 - Carga média obtida por número de valores gerados por simulação para a hora 1 do ar condicionado (elaborado pelo autor, 2020).

Com o objetivo de obter um possível cenário médio, um possível cenário otimista e um possível cenário pessimista, a média dos cenários, assim como os limites superior e inferior do intervalo de confiança, são usados como parâmetros para determinar os três perfis.

$$
\begin{gathered}
V S R_{\text {eq,pe }}(h) \sim N\left(M P R E_{\text {eq,pe }}(h), \sigma_{\text {eq,pe }}^{2}(h)\right) \\
V S T_{\text {subt,pe }}(h) \sim N\left(M P T E_{\text {subt,pe }}(h), \sigma_{\text {subt,pe }}^{2}(h)\right) \\
V S I_{\text {subi,pe }}(h) \sim N\left(M P I E_{\text {subi,pe }}(h), \sigma_{\text {subi,pe }}^{2}(h)\right)
\end{gathered}
$$

Onde,

$V S R_{e q, e s, t d}(h):$ Valores simulados para cada equipamento do setor residencial $e q$, perfil específico pe e hora $h$;

$M P R E_{\text {eq,es,td }}(h)$ : Média dos perfis calculados para cada equipamento do setor residencial $e q$, perfil específico pe e hora $h$;

$\sigma_{e q, p e}^{2}(h)$ : Variância dos perfis calculados para cada equipamento do setor residencial $e q$, perfil específico pe e hora $h$;

$V S T_{\text {subt,es,td }}(h)$ : Valores simulados para cada subsetor terciário subt, perfil específico pe e hora $h$;

$\operatorname{MPTE}_{\text {subt,pe }}(h)$ : Média dos perfis calculados para cada subsetor terciário subt, perfil específico pe e hora $h$;

$\sigma_{\text {subt,pe }}^{2}(h)$ : Variância dos perfis calculados para cada subsetor terciário subt, perfil específico pe e hora $h$; 
$V S I_{\text {subi,pe }}(h)$ : Valores simulados para cada subsetor industrial subi, perfil específico pe e hora $h$;

$M P I E_{\text {subi,pe }}(h)$ : Média dos perfis calculados para cada subsetor industrial subi, perfil específico pe e hora $h$;

$\sigma_{\text {subi,pe }}^{2}(h)$ : Variância dos perfis calculados para cada subsetor industrial subi, perfil específico pe e hora $h$;

$e q$ : Tipo de equipamento residencial, $e q=1,2, \ldots, 8$;

subt: Tipo de subsetor terciário, subt $=1,2, \ldots, 8$;

subi: Tipo de subsetor industrial, subi $=1,2, \ldots, 11$;

$p e$ : Tipos de perfil específicos, $p e=1,2, \ldots, 6$; e

$h$ : Hora do dia, $h=1,2, \ldots, 24$.

Com seis diferentes perfis gerados para cada processo (três estações de ano e dois tipos de dia), a média em cada caso é a demanda específica calculada para cada estação do ano, tipo de dia e hora, enquanto as variâncias são calculadas para cada hora com base nos seis perfis resultantes dos equipamentos residenciais e subsetores, terciário e industrial, como mostram as equações (3.7), (3.8) e (3.9).

$$
\begin{gathered}
\sigma_{e q, p e}^{2}(h)=\sum_{p e=1}^{6} \frac{S P R_{e q, p e}(h)}{(6-1)} \\
\sigma_{\text {subt }, p e}^{2}(h)=\sum_{p e=1}^{6} \frac{S P R_{t s u b, p e}(h)}{(6-1)} \\
\sigma_{\text {subi,pe }}^{2}(h)=\sum_{p e=1}^{6} \frac{S P R_{\text {isub }, p e}(h)}{(6-1)}
\end{gathered}
$$

Onde,

$\sigma_{e q, p e}^{2}(h)$ : Variância dos perfis calculados para cada equipamento do setor residencial eq, perfil específico pe e hora $h$;

$S P R_{e q, p e}(h)$ : Valor calculado cada equipamento do setor residencial $e q$, perfil específico pe e hora $h$;

$\sigma_{\text {subt,pe }}^{2}(h)$ : Variância dos perfis calculados para cada equipamento do setor residencial eq, perfil específico pe e hora $h$;

$S P R_{t s u b, p e}(h)$ : Valor calculado cada subsetor terciário subt, perfil específico pe e hora $h$;

$\sigma_{\text {subi,pe }}^{2}(h)$ : Média dos perfis calculados para cada subsetor terciário subt, perfil específico pe e hora $h$;

$S P R_{\text {isub,pe }}(h)$ : Valor calculado cada subsetor industrial subi, perfil específico pe e hora $h$;

$e q$ : Tipo de equipamento residencial, $e q=1,2, \ldots, 8$;

subt: Tipo de subsetor terciário, subt $=1,2, \ldots, 8$;

subi: Tipo de subsetor industrial, $s u b i=1,2, \ldots, 11$; 
pe: Tipos de perfil específicos, $p e=1,2, \ldots, 6$; e

$h$ : Hora do dia, $h=1,2, \ldots, 24$.

\subsection{1.}

\section{Perfis Específicos de Processos}

Após a aplicação da metodologia obtêm-se perfis específicos de todos os processos em três diferentes níveis, com um total de 162 perfis específicos de processos utilizados na estrutura de modo a gerar diferentes cenários de previsão.

No Apêndice A são apresentados os gráficos dos três perfis históricos de todos os processos usados na geração dos cenários. A fim de exemplificar o resultado do cálculo dos perfis específicos no texto, na Figura 17 são apresentados os agregados dos perfis médios gerados por meio da metodologia. Nota-se que, como se esperava, no verão o consumo durante o meio do dia e durante a madrugada se intensifica, como foi apresentado por meio da Figura 4, enquanto o inverno tem níveis mais baixos no mesmo período, apresentando um pico por volta das 19 h. Já as estações intermediárias, como contêm dias frios e quentes, espera-se que mantenham um meio termo entre verão e inverno.

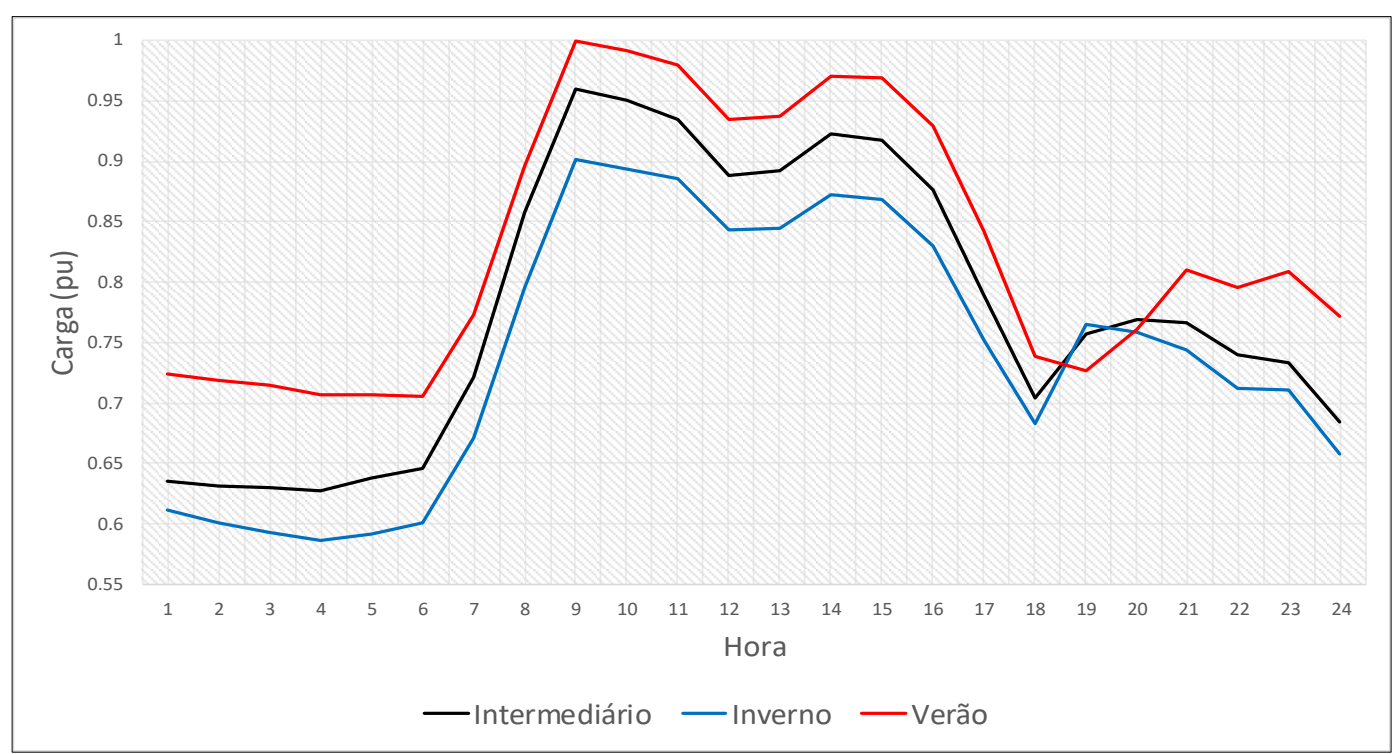

Figura 17 - Agregado de Perfis médios específicos por estação de ano (elaborado pelo autor, 2019).

A Figura 18 apresenta os perfis médios de processos agregados por tipo de dia gerados pela metodologia. Nota-se que para este caso a adaptação foi menos eficaz pois, apesar do nível durante a tarde ter sido reduzido e à noite elevado para os dias não úteis, o perfil em geral se manteve similar ao do dia útil. 


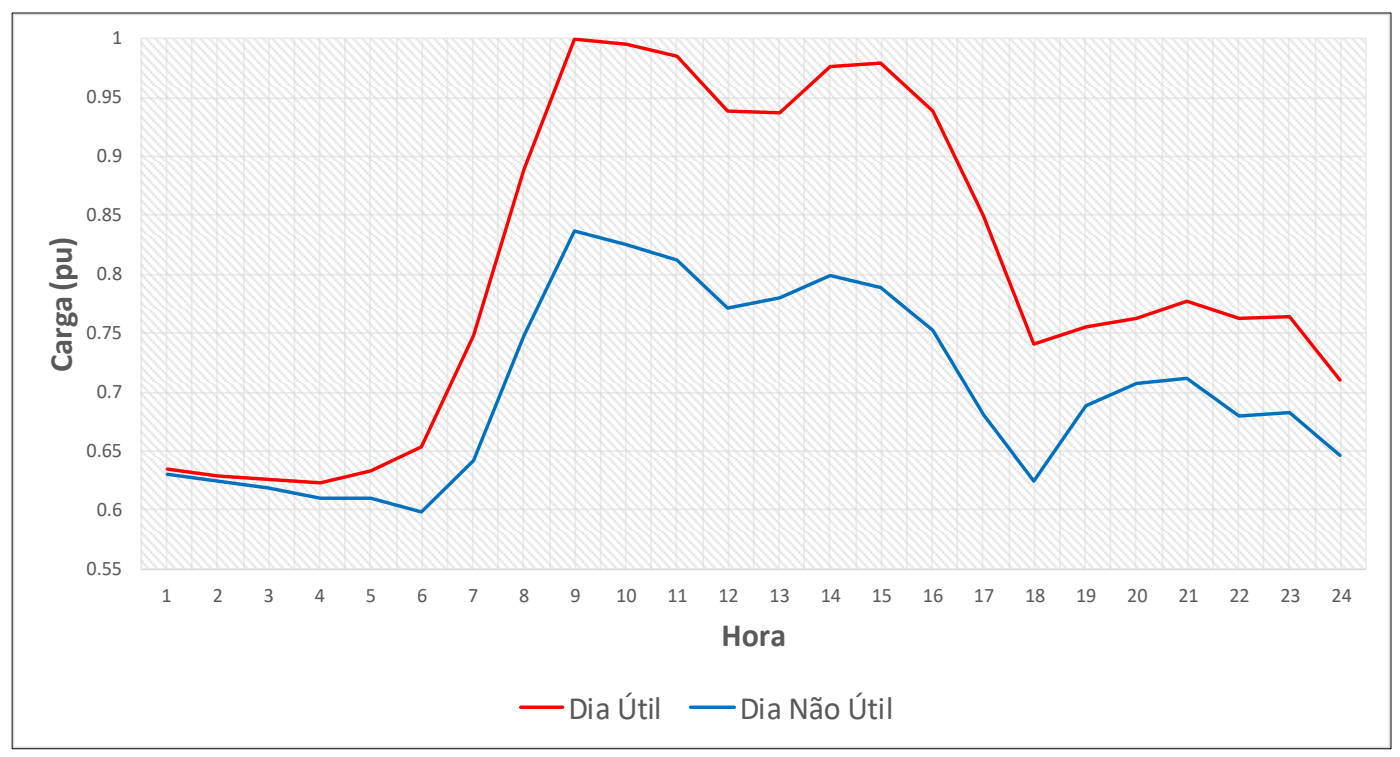

Figura 18 - Agregado de Perfis médios específicos por tipo de dia (elaborado pelo autor, 2019).

\section{5.}

\section{Estrutura de Geração de Cenários}

A estrutura de geração de cenários funciona de acordo com a Figura 19. Primeiramente, o método de geração de perfis específicos de processos (Carmo et al., 2018), descrito em 3.3.1, é usado nos dados históricos a fim de gerar três diferentes perfis para cada processo. Os perfis máximo ( $p M a x)$, médio ( $p M e d)$ e mínimo (pMin) são usados no Método de Decomposição Parcial, junto aos resultados anuais da abordagem bottom-up com três valores limiares. Essa estratégia visa usar valores limares de $0 \%, 5 \%$ e $10 \%$ com o objetivo de considerar um primeiro caso onde são usados todos os processos ( $\lim =0 \%$ ), sem a curva residual, um segundo caso que considera alguns processos relevantes e que têm grande influência da curva residual ( $\lim =5 \%$ ) e, por fim, um terceiro caso que usa somente os processos com maior relevância, juntamente a um grande impacto da curva residual $(\lim =10 \%)$.

Esse fator dos limiares oferece maior destaque para a curva residual pelo fato de oferecer situações em que tenham pouco ou nenhum processo relevante. Dessa forma, as inconsistências dos perfis sintéticos são diluídas e menos impactantes para o resultado, ainda que tenham sua relevância para os cenários previstos. 


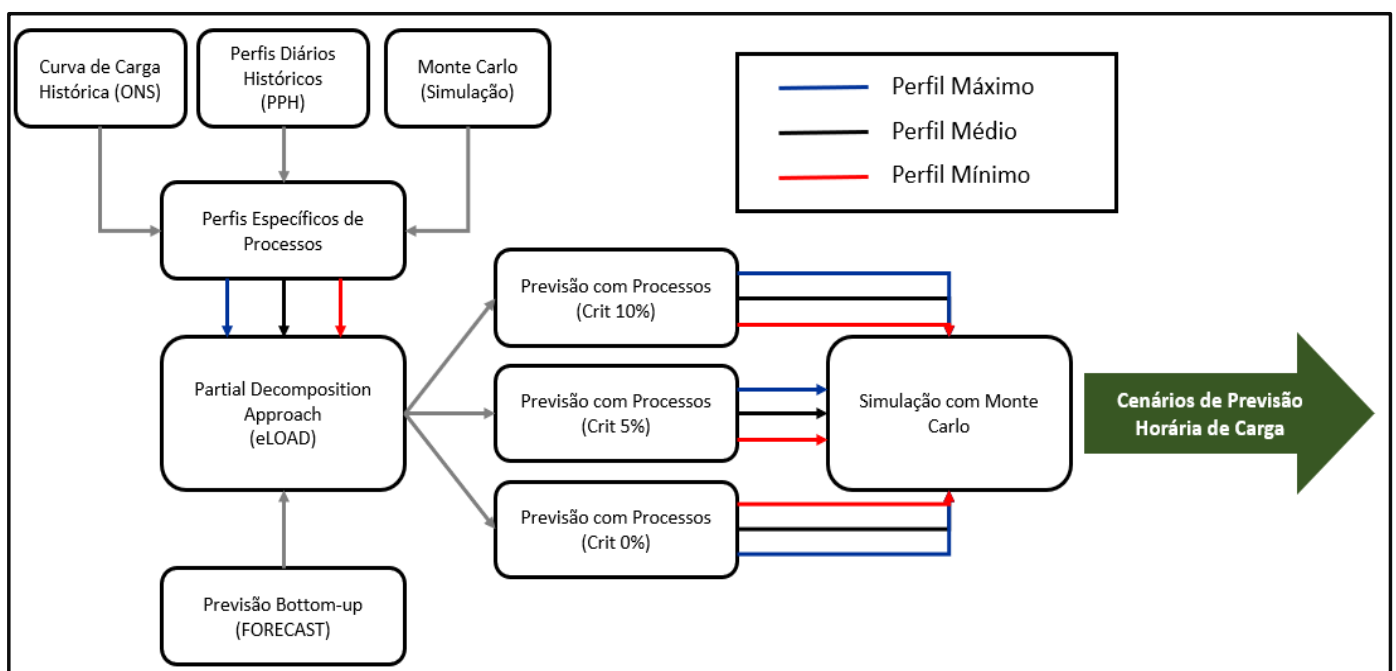

Figura 19 - Estrutura de Geração de Cenários (elaborado pelo autor, 2019).

É importante enfatizar que, em alguns casos, quando o horizonte de projeção não é grande o suficiente e a relevância dos processos não alcança valores consideráveis, utilizar os valores de $5 \%$ e $10 \%$ ocasionará no uso somente da curva residual para a previsão. Isso acontece devido ao fato de que, em horizontes curtos, grandes mudanças não são esperadas no comportamento da curva de carga, fazendo assim com que a curva excedente, que carrega o comportamento histórico, tenha grande influência na projeção.

\subsection{1.}

\section{Adaptação para Geração de Cenários}

Os cinco passos do Método de Decomposição Parcial, previamente explicados, são agora aplicados para os 27 processos dos setores residencial, terciário e industrial, considerando-se os diferentes perfis específicos desenvolvidos para esses processos e os três diferentes valores limiares previamente definidos, somando-se nove diferentes cenários usados na previsão.

No primeiro passo, os processos relevantes são obtidos por tipo de perfil e valor limiar, como mostram as equações (3.10) e (3.11).

$$
\begin{gathered}
p \in P_{\text {relev }} \text { se lim } \leq \frac{D_{A P, p}^{\text {proc }}-D_{A H, p}^{\text {proc }}}{D_{A H}^{\text {sis }}} \\
p \in P_{\text {Irrelev }} \text { se lim }>\frac{D_{A P, p}^{\text {proc }}-D_{A H, p}^{\text {proc }}}{D_{A H}^{\text {sis }}}
\end{gathered}
$$

Onde,

$p$ : Processo, $p=1,2, \ldots, 27$ 
$P_{\text {relev }}:$ Processo relevante;

$P_{\text {Irrelev }}$ : Processo relevante;

lim: Valor crítico, $\lim =0 \%, 5 \%$ e $10 \%$;

$D_{A P, p}^{p r o c}$ : Demanda do processo no ano de projeção;

$D_{A H, p}^{\text {proc }}$ : Demanda do processo no ano histórico; e

$D_{A H}^{s i s}$ : Demanda do sistema no ano histórico.

No passo dois, as curvas sintéticas dos processos relevantes são construídas e o agregado destas é usado para cálculo da curva excedente (3.12).

$$
C_{A H, P R O, \lim }^{r e s}(h)=C_{A H, P R O, \lim }^{\text {sis }}(h)-\sum_{P_{\text {relev }}=1}^{n} C_{A H, P R O, \text { lim }, P_{\text {relev }}}^{\text {proc }}(h)
$$

Onde,

$C_{A H, P R O, l i m}^{r e s}(h)$ : Carga horária residual no ano histórico por tipo de perfil $P R O$ e por valor limiar lim;

$C_{A H, P R O, l i m}^{\text {sis }}(h)$ : Carga horária do sistema no ano histórico por tipo de perfil $P R O$ e por valor limiar lim;

$C_{A H, P R O, \text { lim, } P_{\text {relev }}}^{\text {proc }}(h)$ : Carga horária do processo relevante no ano histórico por tipo de perfil $P R O$ e por valor limiar lim;

$P_{\text {relev }}$ : Processo relevante, $P_{\text {relev }}=1,2, \ldots, n$;

$h$ : Hora do ano, $h=1,2, \ldots, h_{\max , \text { ano }}$.

lim: Valor limiar, crit $=0 \%, 5 \%$ e $10 \%$; e

PRO: Tipo de Perfil, PRO = pMax, $p$ Med,pMin.

No passo três é feito um escalonamento da curva sintética dos processos relevantes para cada caso, considerando a projeção anual efetuada por meio da abordagem bottom-up (3.13).

$$
C_{A P, P R O, \text { lim }, P_{\text {relev }}}^{\text {proc }}(h)=\frac{D_{A P, P_{\text {relev }}}^{\text {proc }}}{D_{A H, P_{\text {relev }}}^{\text {proc }}} . C_{A H, P R O, \text { lim }, P_{\text {relev }}}^{\text {proc }}(\boldsymbol{h})
$$

Onde,

$C_{A P, P R O, \text { lim, }}^{\text {proclev }}(h)$ : Carga horária do processo relevante no ano de projeção por tipo de perfil $P R O$ e por valor limiar lim;

$D_{A P, P_{\text {relev }}}^{\text {proc }}$ : Demanda do processo relevante no ano de projeção;

$D_{A H, P_{\text {relev }}}^{\text {proc }}$ : Demanda do processo relevante no ano histórico;

$C_{A H, P R O, l i m, P_{\text {relev }}}^{\text {proc }}(h)$ : Carga horária do processo relevante no ano histórico por tipo de perfil $P R O$ e por valor limiar lim;

$P_{\text {relev }}$ : Processo relevante, $P_{\text {relev }}=1,2, \ldots, n$;

$h$ : Hora do ano, $h=1,2, \ldots, h_{\max , \text { ano }}$.

lim: Valor limiar, $\lim =0 \%, 5 \%$ e 10\%; e

PRO: Tipo de Perfil, PRO = pMax, $p$ Med,pMin. 
No passo quatro, também baseado na projeção anual efetuada por meio do abordagem bottom-up, a curva residual é escalonada. Como feito até agora, isso é efetuado para cada tipo de perfil e valor limiar, como mostra a equação (3.14).

$$
C_{A P, P R O, \text { lim }}^{r e s}(h)=\frac{D_{A P}^{s i s}-\sum_{P_{\text {relev }}=1}^{n} D_{A P, P_{\text {relev }}}^{\text {proc }}}{D_{A H}^{\text {sis }}-\sum_{P_{\text {relev }}=1}^{n} D_{A H, P_{\text {relev }}}^{\text {proc }}} . C_{A H, P R O, \text { lim }}^{\text {res }}(h)
$$

Onde,

$C_{A P, P R O, \lim }^{r e s}(h)$ : Carga horária residual no ano de projeção por tipo de perfil $P R O \mathrm{e}$ por valor limiar lim;

$D_{A P}^{\text {sis }}$ : Demanda do sistema no ano de projeção;

$D_{A H}^{\text {sis }}$ : Demanda do sistema no ano histórico;

$D_{A P, P_{\text {relev }}}^{\text {proc }}$ : Demanda do processo relevante no ano de projeção;

$D_{A H, P_{\text {relev }}}^{\text {proc }}$ : Demanda do processo relevante no ano histórico;

$C_{A H, P R O, l i m}^{r e s}(h)$ : Carga horária residual no ano histórico por tipo de perfil $P R O$ e por valor limiar lim;

$P_{\text {relev }}$ : Processo relevante, $P_{\text {relev }}=1,2, \ldots, n$;

$h$ : Hora do ano, $h=1,2, \ldots, h_{\max , a n o}$.

lim: Valor limiar, $\lim =0 \%, 5 \%$ e 10\%; e

PRO: Tipo de Perfil, $P R O=p M a x, p M e d, p M i n$.

No quinto passo, ambas as curvas sintéticas escalonadas são agregadas, com o objetivo de obter a curva de carga total de um ano de projeção específico (3.15).

$$
C_{A P, P R O, \text { lim }}^{\text {sis }}(\boldsymbol{h})=\boldsymbol{C}_{A P, P R O, \text { lim }}^{\text {res }}(\boldsymbol{h})+\sum_{P_{\text {relev }}=1}^{n} \boldsymbol{C}_{A P, P R O, \text { lim }, P_{\text {relev }}}^{\text {proc }}(\mathrm{h})
$$

Onde,

$C_{A P, P R O, \lim }^{\text {sis }}(h)$ : Carga horária do sistema no ano de projeção por tipo de perfil $P R O$ e por valor limiar lim;

$C_{A P, P R O, l i m}^{r e s}(h)$ : Carga horária residual no ano de projeção por tipo de perfil $P R O$ e por valor limiar lim;

$C_{A P, P R O, l i m, P_{\text {relev }}}^{\text {proc }}(h)$ : Carga horária do processo no ano de projeção por tipo de perfil $P R O$ e por valor limiar lim;

$P_{\text {relev }}$ : Processo relevante, $P_{\text {relev }}=1,2, \ldots, n$;

$h$ : Hora do ano, $h=1,2, \ldots, h_{\max , a n o}$.

lim: Valor limiar, $\lim =0 \%, 5 \%$ e 10\%; e

PRO: Tipo de Perfil, PRO = pMax, $p$ Med,pMin.

Deste ponto em diante, com a curva de projeção para três níveis de perfis específicos e três valores limiares, a estrutura computacional foca em, primeiramente, projetar nove diferentes cenários (cen) para cada ano por meio do 
Método de Decomposição Parcial. A equação (3.16) mostra a equação geral para a estrutura computacional como um todo.

$$
C_{A P, P R O, \text { lim }}^{\text {SisSIM }}(\boldsymbol{h})=z\left(\boldsymbol{C}_{A P}^{\text {sis }}(\boldsymbol{h})\right)+\varepsilon_{A P, P R O, \text { lim }}(\boldsymbol{h})
$$

Onde,

$C_{A P, P R O, l i m}^{\operatorname{SiSIM}}(h)$ : Carga horária simulada do sistema no ano de projeção por tipo de perfil $P R O$ e por valor limiar lim;

$C_{A P}^{\text {sis }}(h)$ : Carga horária do sistema no ano de projeção;

$\varepsilon_{A P, P R O, \text { lim }}(h)$ : Erro horário esperado no ano de projeção por tipo de perfil $P R O$ e por valor limiar lim;

$h$ : Hora do ano, $h=1,2, \ldots, h_{\max , a n o}$.

lim: Valor limiar, $\lim =0 \%, 5 \%$ e $10 \%$; e

PRO: Tipo de Perfil, $P R O=p M a x, p M e d, p M i n$.

$\mathrm{Na}$ equação, a função $z$ representa a estratégia aplicada para projetar os nove diferentes cenários usando o Método de Decomposição Parcial, que originalmente tem uma resposta única $\left(C_{A P}^{\text {Sis }}(h)\right)$, para projetar a carga simulada $C_{A P, P R O, l i m}^{\text {SiSSIM }}(h)$.

O erro $\left(\varepsilon_{A P, P R O, l i m}(h)\right)$ representa o erro esperado de cada projeção, assumindo que esse tem uma distribuição Gaussiana de média e variância desconhecida.

Com o erro de cada projeção, o próximo passo da estrutura visa simular cenários utilizando Monte Carlo com distribuição Gaussiana, baseando-se no Teorema Central do Limite (Fischer, 2011), com o objetivo de amenizar o impacto do erro de cada projeção. Assim, os cenários simulados são elaborados de acordo com a equação (3.17).

$$
C_{A P}^{\text {sisSIM }}(h) \sim N\left(\bar{M}_{A P}^{\text {sis }}(h), \operatorname{Var}_{A P}^{\text {sis }}(h)\right)
$$

Onde,

$C_{A P}^{\operatorname{sis} S I M}(h)$ : Carga horária simulada no sistema no ano de projeção;

$\bar{M}_{A P}^{s i s}(h)$ : Média horária do sistema no ano de projeção;

$\operatorname{Var}_{A P}^{\text {sis }}(h)$ : Variância horária do sistema no ano de projeção; e

$h$ : Hora do ano, $h=1,2, \ldots, h_{\max , \text { ano }}$.

Na equação (3.17), a média $\left(\bar{M}_{A P, c e n, h}^{s i s}\right)$ e a variância $\left(\operatorname{Var}_{A P, c e n, h}^{s i s}\right)$ são calculadas de acordo com as equações (3.18) e (3.19).

$$
\bar{M}_{A P}^{s i s}(h)=\sum_{c e n=1}^{9} \frac{C_{A P, c e n}^{s i s}(h)}{9}
$$




$$
\operatorname{Var}_{A P}^{\text {sis }}(h)=\frac{\sum_{c e n=1}^{9} C_{A P, c e n}^{s i s}(h)}{(9-1)}
$$

Onde,

$\bar{M}_{A P}^{s i s}(h)$ : Média horária do sistema no ano de projeção;

$\operatorname{Var}_{A P}^{s i s}(h)$ : Variância horária do sistema no ano de projeção;

$C_{A P, c e n}^{\text {sis }}(h)$ : Carga horária para o ano de projeção por cenário cen;

cen: Cenário projetado; cen $=1,2, \ldots, 9$

$h$ : Hora do ano, $h=1,2, \ldots, h_{\text {max }, \text { ano }}$. 


\section{4 \\ Resultados}

Este Capítulo apresenta os resultados para a região sudeste do Brasil, previamente selecionada por representar quase metade do consumo brasileiro (Empresa de Pesquisa Energética - EPE, 2018). As projeções são efetuadas para 2020 com base no ano de 2016 e, de modo a avaliar a qualidade dos valores previstos, utiliza-se 2017 como pilar de comparação, efetuando-se cálculos de métricas de erros entre os valores previstos um ano à frente e os valores verificados.

\section{1.}

\section{Relevância dos processos}

Como anteriormente explicado, três valores limiares foram utilizados para determinar três perspectivas com diferentes níveis de relevância dos processos. A Tabela 4 mostra a relevância calculada de cada processo para a previsão até 2020 da carga da região sudeste brasileira. 
Tabela 4 - Relevância de cada Processo (elaborado pelo autor, 2019).

\begin{tabular}{|c|c|}
\hline Processos & \multirow{2}{*}{$\begin{array}{c}\text { Relevância } \\
1,84 \%\end{array}$} \\
\hline Ar Condicionado & \\
\hline Iluminação & $1,13 \%$ \\
\hline Outras Indústrias & $0,99 \%$ \\
\hline Chuveiro Elétrico & $0,74 \%$ \\
\hline Refrigerador & $0,68 \%$ \\
\hline Metais Não-Ferrosos & $0,65 \%$ \\
\hline Atacado e Varejo & $0,56 \%$ \\
\hline Hotéis, Cafés e Restaurantes & $0,45 \%$ \\
\hline Química & $0,41 \%$ \\
\hline Alimentos e Bebidas & $0,38 \%$ \\
\hline Outros Serviços & $0,35 \%$ \\
\hline Aço e Ferro Gusa & $0,31 \%$ \\
\hline Cimento & $0,29 \%$ \\
\hline Tráfego e Transmissão de Dados & $0,25 \%$ \\
\hline Escritórios Públicos & $0,21 \%$ \\
\hline Papel e Celulose & $0,20 \%$ \\
\hline Mineração e Peletização & $0,19 \%$ \\
\hline Ferro Liga & $0,12 \%$ \\
\hline Têxtil & $0,10 \%$ \\
\hline Saúde & $0,10 \%$ \\
\hline Lava-Roupas & $0,10 \%$ \\
\hline Televisão & $0,10 \%$ \\
\hline Educação & $0,08 \%$ \\
\hline Freezer & $0,08 \%$ \\
\hline Cerâmica & $0,04 \%$ \\
\hline Finanças & $0,04 \%$ \\
\hline Outros Residencial & $0,01 \%$ \\
\hline
\end{tabular}

Nota-se que todos os processos possuem baixa relevância, indicando que, quando o valor limiar for de $0 \%$, a curva sintética gerada para os processos influenciará na previsão, sem qualquer impacto da curva de carga histórica, enquanto que, em projeções efetuadas com valores limiares de $5 \%$ e $10 \%$, a curva histórica será escalonada sem qualquer participação dos processos, sendo somente ela a responsável pelo aspecto final destes cenários. 
Este tipo de resultado já era esperado pelo fato de, como já apresentado na Figura 2, em um horizonte de poucos anos não se esperar grandes alterações nos hábitos de consumo de energia e, consequentemente, no formato da curva de carga.

\section{2.}

\section{Avaliação da Curva de Carga Projetada}

A validação do modelo foi efetuado comparando os cenários de curvas de carga projetadas para 2017 com os valores de carga verificados no mesmo ano fornecidos pelo ONS (o ONS fornece dados por subsistema, então a repartição SE/CO explicada em 3.2 foi aplicada aqui também). É importante enfatizar que o ano base é 2016 não somente por este ser um ano bissexto, mesmo caso do ano final de projeção (2020), mas também por ser um ano próximo aos trabalhos de Maçaira (2015), Bastos et al. (2017) e Leite (2017), cujas previsões anuais foram utilizados como ponto de partida. Outro ponto relevante é que as projeções usadas para validar a Estrutura foram efetuadas em discretização horária e um ano à frente, ou seja, 8760 passos de projeção.

Quatro métricas são usadas para mensurar a qualidade da projeção. As métricas clássicas, Mean Absolute Percentage Error (MAPE) (4.1) and Root Mean Square Deviation (RMSE) (4.2) são usadas para comparar o cenário médio previsto para 2017 com a curva histórica de carga verificada do mesmo ano.

$$
\begin{aligned}
M A P E & =\frac{100 \%}{h_{\max }} \sum_{h=1}^{h_{\max }}\left|\frac{V_{h}-P_{h}}{V_{h}}\right| \\
R M S E & =\sqrt{\frac{1}{h_{\max }} \sum_{h=1}^{h_{\max }}\left(V_{h}-P_{h}\right)^{2}}
\end{aligned}
$$

Onde,

$h_{\text {max }}:$ número de horas analisadas;

$V_{h}:$ Valor verificado na hora $h$;

$P_{h}$ : Valor previsto na hora $\mathrm{h}$.

Além dessas métricas também são usados o Prediction Interval Coverage Probability (PICP) (Khosravi, Nahavandi e Creighton, 2013) (4.3) e o Mean 
Prediction Interval Width (MPIW) (Khosravi et al., 2011) (4.4) de modo a verificar a qualidade do intervalo de previsão.

$$
\begin{gathered}
P I C P=\frac{1}{h_{\max }} \sum_{h=1}^{h_{\max }} C_{h} \\
M P I W=\frac{1}{h_{\max }} \sum_{h=1}^{h_{\max }}\left(P_{\text {Sup }_{h}}-P_{I n f_{h}}\right)
\end{gathered}
$$

Onde,

$C_{h}$ : são valores de 0 ou 1 referentes ao valor verificado estar dentro ou fora do intervalo previsto;

$P_{\text {Sup }_{h}}$ : Limite superior do intervalo de confiança da previsão;

$P_{I n f_{h}}$ : Limite inferior do intervalo de confiança da previsão;

Na Figura 20 é possível notar a diferença dos seis diferentes perfis de carga médios específicos. $\mathrm{O}$ eixo $\mathrm{Y}$ indica o valor mínimo e máximo dos perfis médios para o ano, enquanto o valor central do eixo representa o valor médio de cada perfil específico médio. 

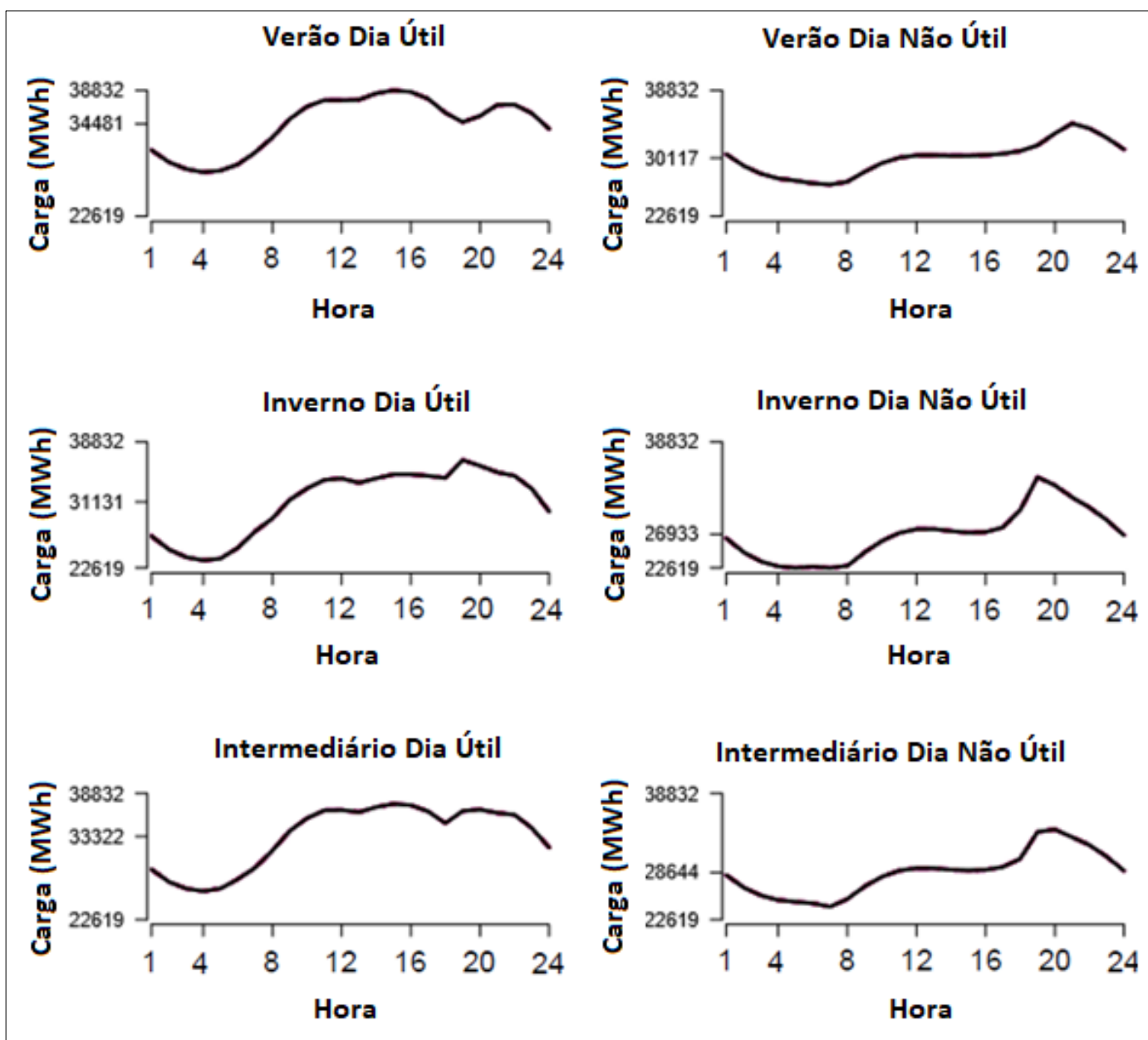

Figura 20 - Perfis específicos históricos médios para a região Sudeste no ano de 2016 (elaborado pelo autor, 2019).

Os valores históricos mostram que os dias úteis de verão tendem a ter os maiores valores médios, enquanto os dias não-úteis de inverno tendem a ter os menores.

Analisando por estação do ano, como já esperado, no verão estão os maiores valores de carga, tanto para o caso de dias úteis quanto para o caso de dias nãoúteis, devido ao uso de ar condicionado (Empresa de Pesquisa Energética - EPE, 2019b). O Brasil é um país tropical tipicamente quente, especialmente em tardes de dia de verão, fazendo o hábito do consumidor se alterar e o valor máximo de carga se deslocar para o intervalo entre 14 h e 16 h em dias úteis. Em dias de inverno é possível notar valores menores durante a tarde e o valor máximo de carga por volta das 19 h por conta das temperaturas mais baixas e não utilização intensa de ar condicionado.

É importante estudar as características históricas pelo fato de que, para os casos de valores críticos de $5 \%$ e $10 \%$, o modelo está usando a curva excedente, 
indicando que as projeções devem ter predominância do comportamento histórico e, consequentemente, deve manter essas características.

A Figura 21 mostra, em preto, os valores médios verificados de perfis específicos da carga para 2017, enquanto as curvas tracejadas em vermelho e azul representam, respectivamente, os limites superior e inferior dos cenários previstos com um intervalo de $95 \%$ de confiança, gerados pela projeção de 100 cenários futuros utilizando a Estrutura. A linha tracejada em cinza é o cenário médio de perfil específico usado para comparação com valores históricos na aplicação das métricas de erros clássicas.

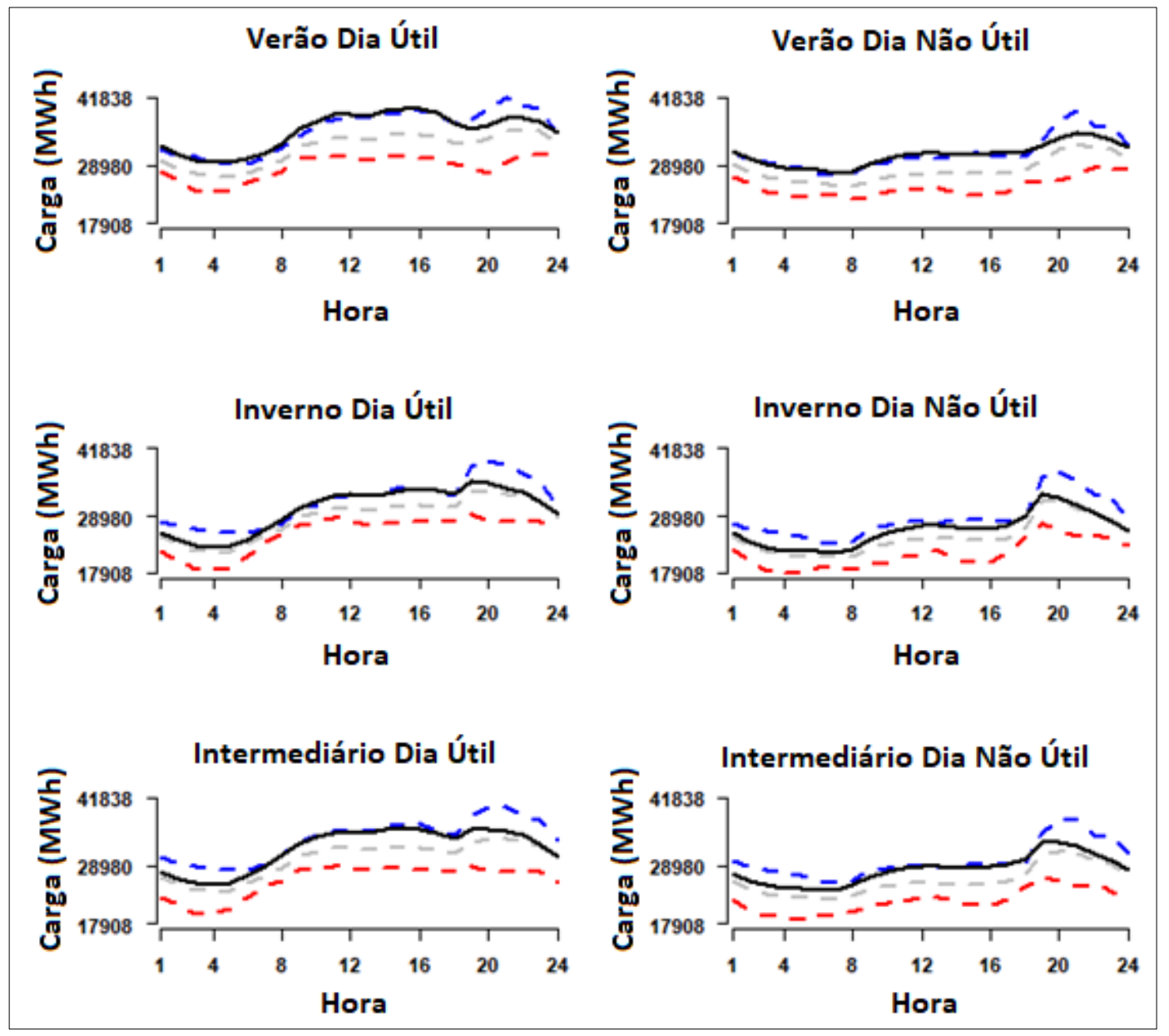

Figura 21 - Validação da Projeção para 2017 (elaborado pelo autor, 2019).

Como mostra a Tabela 5, os valores de MAPE e RMSE obtidos para o ano inteiro foram de 7,33\% e 2 902,08 MWh, respectivamente. Sobre os cenários previstos, apesar do MIPW mostrar um intervalo de confiança consistente, de 7 169,11 MWh em média para cada hora (18\% da curva média para cada hora), o PICP de 0,65 mostra que somente $65 \%$ dos valores da curva de carga verificada ficaram dentro do intervalo. 
Tabela 5 - Métricas de Erros para 2017 (elaborado pelo autor, 2019).

\begin{tabular}{|c|c|c|c|c|}
\hline \multirow{2}{*}{2017} & PICP & MIPW & RMSE & MAPE \\
\cline { 2 - 5 } & 0,65 & 7169,11 & 2902,08 & $7,33 \%$ \\
\hline
\end{tabular}

Para investigar a projeção da perspectiva de cada dia específico, essas métricas foram calculadas separadamente para cada tipo de dia e apresentadas na Tabela 6.

Tabela 6 - Resultados das Métricas para Perfis Específicos de 2017 (elaborado pelo autor, 2019).

\begin{tabular}{|c|c|c|c|c|}
\hline Tipo de Dia & PICP & MIPW & RMSE & MAPE \\
\hline Verão Dia Útil & 0,44 & 6970,67 & 3831,49 & $9,51 \%$ \\
\hline Verão Dia Não-Útil & 0,49 & 6427,63 & 3257,33 & $9,30 \%$ \\
\hline Inverno Dia Útil & 0,69 & 6011,34 & 2142,03 & $5,45 \%$ \\
\hline Inverno Dia Não-Útil & 0,87 & 6974,72 & 1717,75 & $5,15 \%$ \\
\hline Intermediário Dia Útil & 0,69 & 7825,62 & 2912,31 & $7,07 \%$ \\
\hline Intermediário Dia Não-Útil & 0,70 & 7725,73 & 2710,99 & $7,85 \%$ \\
\hline
\end{tabular}

Na Tabela 6 é notável que em dias de verão, especialmente, e em dias de estação intermediária, as métricas de erro acusaram os maiores níveis de erro. Esses dias específicos são aqueles com maior nível de carga, deixando claro, em conjunto com a Figura 21, que as previsões estão subestimando o nível de carga verificada.

A Figura 21 mostra que, mesmo com um cenário autônomo de difusão usado na abordagem bottom-up, a projeção ficou abaixo da realidade, fazendo as projeções excederem a linha de limite superior em determinadas horas do dia. É importante ressaltar que o cenário autônomo proposto considera somente a aplicação mínima de eficiência energética, mesmo assim os valores projetados foram inferiores à realidade, indicando que nem mesmo a eficiência mínima foi alcançada na região sudeste brasileira.

\section{3.}

\section{Avaliação dos Perfis Projetados}

Outra característica importante das previsões efetuadas é a qualidade dos perfis. A fim de avaliar tal característica um perfil de carga típico para 2017 foi comparado com um perfil de carga típico projetado pelo cenário médio. No Brasil, em seus procedimentos de rede, o ONS determina três patamares de carga durante o dia (Leve, Média e Pesada) (Operador Nacional do Sistema Elétrico, 2010). 
Assim, baseado nesses patamares previamente definidos, fez-se aqui a designação dos patamares de carga de maneira geral, de acordo com a Tabela 7.

Tabela 7 - Patamares de Carga Adaptados para Validação (elaborado pelo autor, 2019).

\begin{tabular}{|c|c|c|c|}
\hline Nível da Carga & Carga Leve & Carga Média & Carga Pesada \\
\hline \multirow{2}{*}{ Horário } & $0 \mathrm{~h} \mathrm{a} 7 \mathrm{~h}$ & $8 \mathrm{~h} \mathrm{a} 17 \mathrm{~h}$ & \multirow{2}{*}{$18 \mathrm{~h} \mathrm{a} 22 \mathrm{~h}$} \\
& & $23 \mathrm{~h}$ & \\
\hline
\end{tabular}

A Tabela 8 mostra a participação desses patamares para um dia médio típico da curva verificada de 2017 e para um dia médio típico do cenário médio projetado para o mesmo ano.

Tabela 8 - Percentual de Carga por Patamar (elaborado pelo autor, 2019).

\begin{tabular}{|l|c|c|c|}
\hline \multicolumn{1}{|c|}{ Perfil de Carga } & \multicolumn{3}{c|}{$\mathbf{2 0 1 7}$} \\
\cline { 2 - 4 } & Leve & Média & Pesada \\
\hline Verificado & $25,2 \%$ & $61,0 \%$ & $13,8 \%$ \\
\hline Previsto & $25,7 \%$ & $60,5 \%$ & $13,8 \%$ \\
\hline
\end{tabular}

Os resultados mostram uma superestimação de $0,5 \%$ na carga leve e subestimação de $0,5 \%$ da carga média, enquanto a carga pesada, em média, foi bem estimada. Essa superestimação da carga leve pode ser explicada pela expressiva elevação da carga anual prevista para o ar condicionado do setor residencial, que segundo os perfis da região sudeste (Programa Nacional de Conservação de Energia Elétrica - PROCEL, 2005), possui utilização mais intensa na parte da noite e madrugada.

\subsection{1.}

\section{Análise dos Perfis Projetados para os Processos}

Quando é feito um apanhado do total da carga em cada patamar de um perfil médio geral do ano base de 2016 e se compara com a participação esperada dos setores, calculada com base nos perfis de processos estimados, tem-se que estes representam grande parte da carga total no cenário de perfil médio, sintetizado utilizando-se a Metodologia de Geração de Perfis Específicos dos Processos. A Tabela 9 apresenta o percentual médio de participação de cada setor em cada patamar em um perfil médio geral. 
Tabela 9 - Participação média dos Setores por Patamar do Ano Base de 2016.

\begin{tabular}{|c|c|c|c|c|}
\hline Patamar & Residencial & Terciário & Industrial & Total \\
\hline Leve & $24 \%$ & $24 \%$ & $41 \%$ & $90 \%$ \\
\hline Média & $19 \%$ & $25 \%$ & $43 \%$ & $87 \%$ \\
\hline Pesada & $35 \%$ & $28 \%$ & $33 \%$ & $96 \%$ \\
\hline
\end{tabular}

Nota-se que ao final o total agregado indica que os perfis estimados explicam, em média, $90 \%$ da carga leve, $87 \%$ da carga média e $96 \%$ da carga pesada. O percentual faltante não explicado pelos perfis é ajustado por meio da curva residual, que completa o valor horário da carga, caso os valores agregados horários dos perfis de processos não somem o total indicado no horário da curva histórica.

Analisando por setor, percebe-se que, apesar do agregado para o residencial estar coerente com a realidade, apresentando maiores participações nos horários de carga leve e pesada, o terciário com uma participação semelhante em cada patamar e, principalmente, o industrial, com parcela alta na carga leve, desvirtuam o que se espera para a realidade da região Sudeste brasileira atual.

Tal descaracterização pode ser notada após se fazer a projeção para 2017. Na Tabela 10 é possível notar que o patamar de carga leve teve um crescimento significativo da participação dos processos, ao mesmo tempo que o patamar de carga pesada teve um decréscimo.

Tabela 10 - Participação média dos Setores por Patamar de 2017.

\begin{tabular}{|c|c|c|c|c|}
\hline Patamar & Residencial & Terciário & Industrial & Total \\
\hline Leve & $26 \%$ & $24 \%$ & $48 \%$ & $97 \%$ \\
\hline Média & $17 \%$ & $25 \%$ & $49 \%$ & $91 \%$ \\
\hline Pesada & $24 \%$ & $23 \%$ & $31 \%$ & $79 \%$ \\
\hline
\end{tabular}

Os processos passaram a explicar melhor o total dos patamares de carga leve e média devido à estimação do crescimento de processos que possuem grande participação nesses horários. No entanto, nota-se que a projeção de queda de processos que possuem grande participação no patamar de carga pesada não acompanhou a carga, perdendo expressiva participação para a curva residual.

A elevação da participação dos processos na carga leve foi alavancada em sua maior parte pelo setor industrial. Este, que teve uma estimativa de crescimento de $2 \%$ por meio da abordagem bottom-up para 2017, deveria concentrar a elevação na carga média, mas inconsistências dentre os perfis adaptados acabaram elevando sua participação estimada para $48 \%$ no cenário médio previsto para 2017. 
Quando há escassez de dados e a necessidade de adaptação dos mesmos, inconsistências como esta ocorrem e, considerando este fato, apesar do perfil médio projetado estar sendo utilizado como base de validação dos resultados, a proposição de simular diferentes cenários visa justamente minimizar tais ocorrências.

Voltando na Figura 21 é possível observar a relevante amplitude do intervalo de confiança nos horários da carga leve nos cenários específicos gerados. Nota-se que a diferença dos valores do limite mínimo para o médio é considerável, justamente porque o objetivo da Estrutura é gerar cenários para auxiliar na tomada de decisão, e não selecionar um determinado cenário.

\subsection{2.}

\section{Previsão de Longo Prazo Utilizando a Estrutura de Geração de Cenários}

Baseado nas avaliações efetuadas para 2017, mostrando deficiência na estimação das informações detalhadas, mas também apresentando resultados razoáveis, seja nas métricas dos erros ou no percentual total de carga por patamar, é possível estender as projeções mostrando alguns resultados para 2020.

$\mathrm{Na}$ Figura 22 as curvas tracejadas em vermelho e azul representam, respectivamente, os limites superior e inferior dos cenários previstos para a região Sudeste com um intervalo de $95 \%$ de confiança, enquanto a linha preta representa a média dos valores calculada a partir de 100 cenários gerados. A nuvem em cinza inclui todos os cenários simulados. No Apêndice C é possível ter acesso aos 100 cenários previstos para todos os processos, individualmente, justamente com os intervalos de confiança de $95 \%$ que delimita os valores máximos e mínimos. 

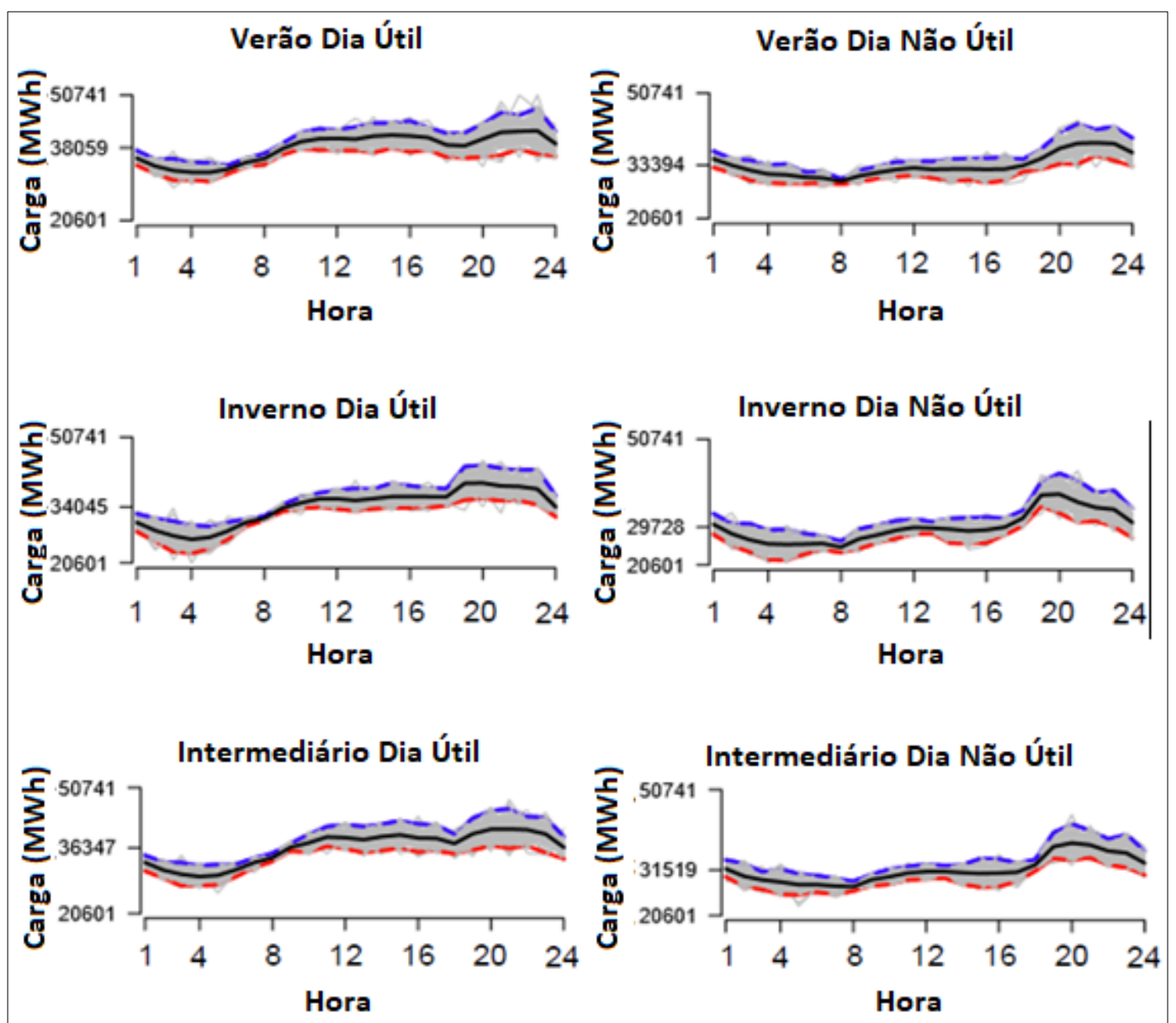

Figura 22 - Resultados de Projeção de Cenários para 2020 (elaborado pelo autor, 2019).

Como esperado em uma projeção feita por geração de cenários simulados, a amplitude máxima dos limites em 2020 é maior do que em 2017. Isso acontece porque, quanto maior o horizonte de previsão, menor a precisão, ocasionando a extensão do intervalo de confiança ao longo dos anos, como pode ser percebido por meio do boxplot apresentado na Figura 23.

No Apêndice B é possível acessar algumas estatísticas dos valores históricos, assim como das previsões de todos os processos utilizados. 


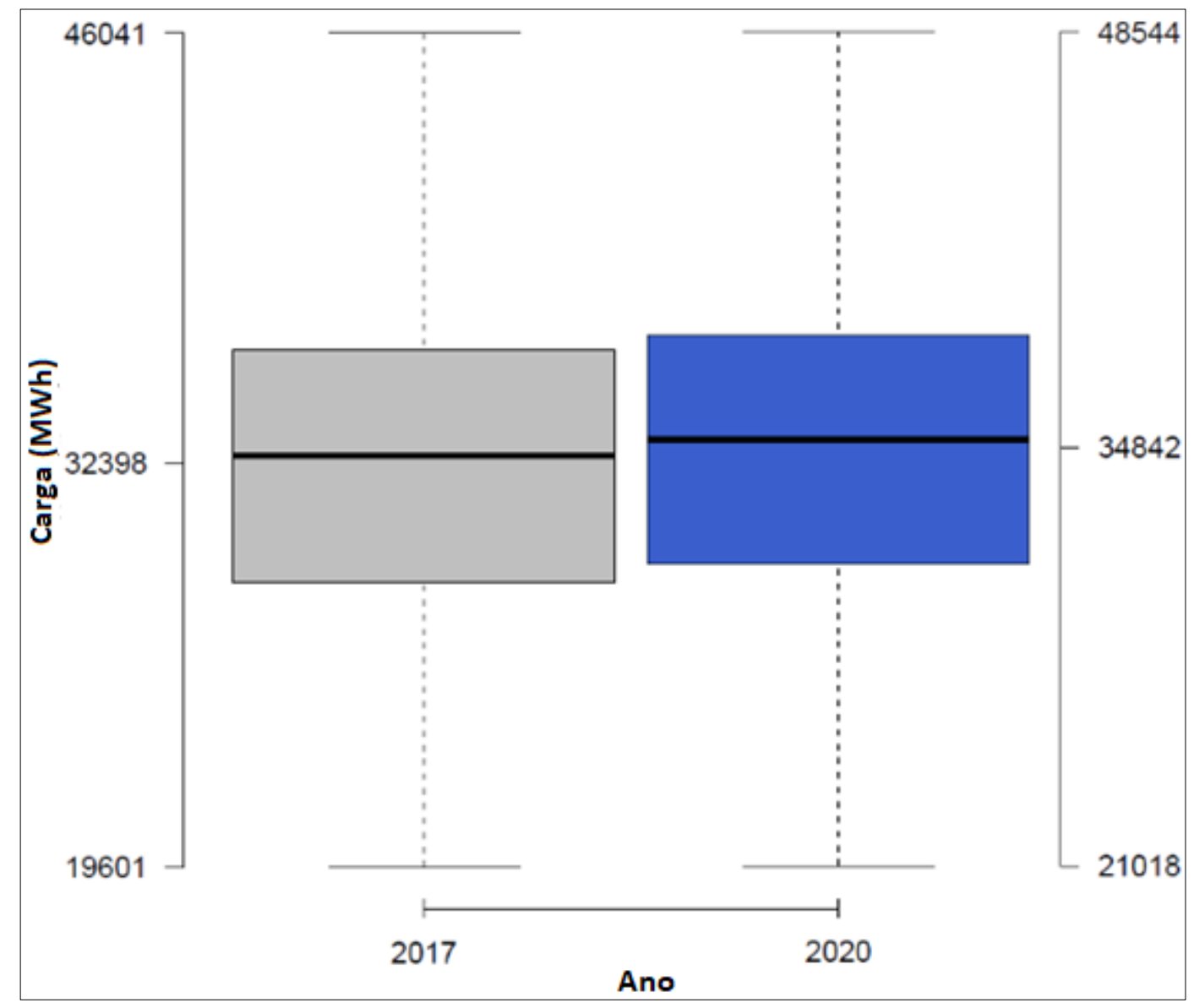

Figura 23 - Bloxplot dos valores projetados para 2017 e 2020 (elaborado pelo autor, 2019).

De 2017 para 2020 ocorreu um aumento médio horário de aproximadamente 1000 MWh nas projeções, significando que alguns valores máximos e mínimos podem ser acentuados ao longo dos anos. É importante ressaltar que, apesar da amplitude ter ocorrido principalmente em horários da noite e madrugada, devido à previsão de aumento de intensidade de uso do ar condicionado, a queda prevista pelo modelo do uso de chuveiros elétricos é claramente notada por meio da suavização dos valores altos que ocorrem entre $19 \mathrm{~h}$ e $21 \mathrm{~h}$.

A fim de reforçar a ideia, na Tabela 11 é apresentada a estimação de uso de ar condicionado e do chuveiro elétrico por patamar de carga no ano base de 2016, sendo esta comparada com a projeção por patamar efetuada para 2020 destes processos. 
Tabela 11 - Participação Média dos Processos por Patamar de Carga

\begin{tabular}{|c|c|c|c|}
\hline \multirow{2}{*}{ Processo } & \multicolumn{3}{|c|}{$\mathbf{2 0 1 6}$} \\
\cline { 2 - 4 } & Leve & Média & Pesada \\
\hline Ar condicionado & $14,3 \%$ & $1,9 \%$ & $0,3 \%$ \\
\hline Chuveiro Elétrico & $0,0 \%$ & $2,9 \%$ & $8,0 \%$ \\
\hline \multirow{2}{*}{ Processo } & \multicolumn{3}{|c|}{$\mathbf{2 0 2 0}$} \\
\cline { 2 - 4 } & Leve & Média & Pesada \\
\hline Ar condicionado & $20,3 \%$ & $2,8 \%$ & $1,0 \%$ \\
\hline Chuveiro Elétrico & $0,0 \%$ & $2,1 \%$ & $5,3 \%$ \\
\hline
\end{tabular}

Dentre todos os processos, o ar condicionado foi o que mais teve aumento de participação. É esperado que tal processo colabore com $6 \%$ do aumento somente na carga leve, $0,9 \%$ na carga média e $0,7 \%$ na carga pesada, com um total de 7,6 $\%$ de participação média ao longo de um dia típico.

Em contrapartida, o chuveiro elétrico foi o processo que perdeu mais participação na carga total. Com um total de 7,4 \% de participação estimada em um dia típico de 2020, espera-se uma redução de 3,5 \% em comparação com a participação estimada de 2016.

A Figura 24 e a Figura 25 apresentam os perfis de consumo estimados do ar condicionado e do chuveiro elétrico, respectivamente, de um dia típico médio de 2016, além dos cenários médios estimados para estes processos em dias típicos médios de 2017 e 2020. Como já foi mostrado na Tabela 9, o crescimento esperado do ar condicionado na carga leve e a redução esperada do chuveiro elétrico na carga pesada podem ser notados mais claramente.

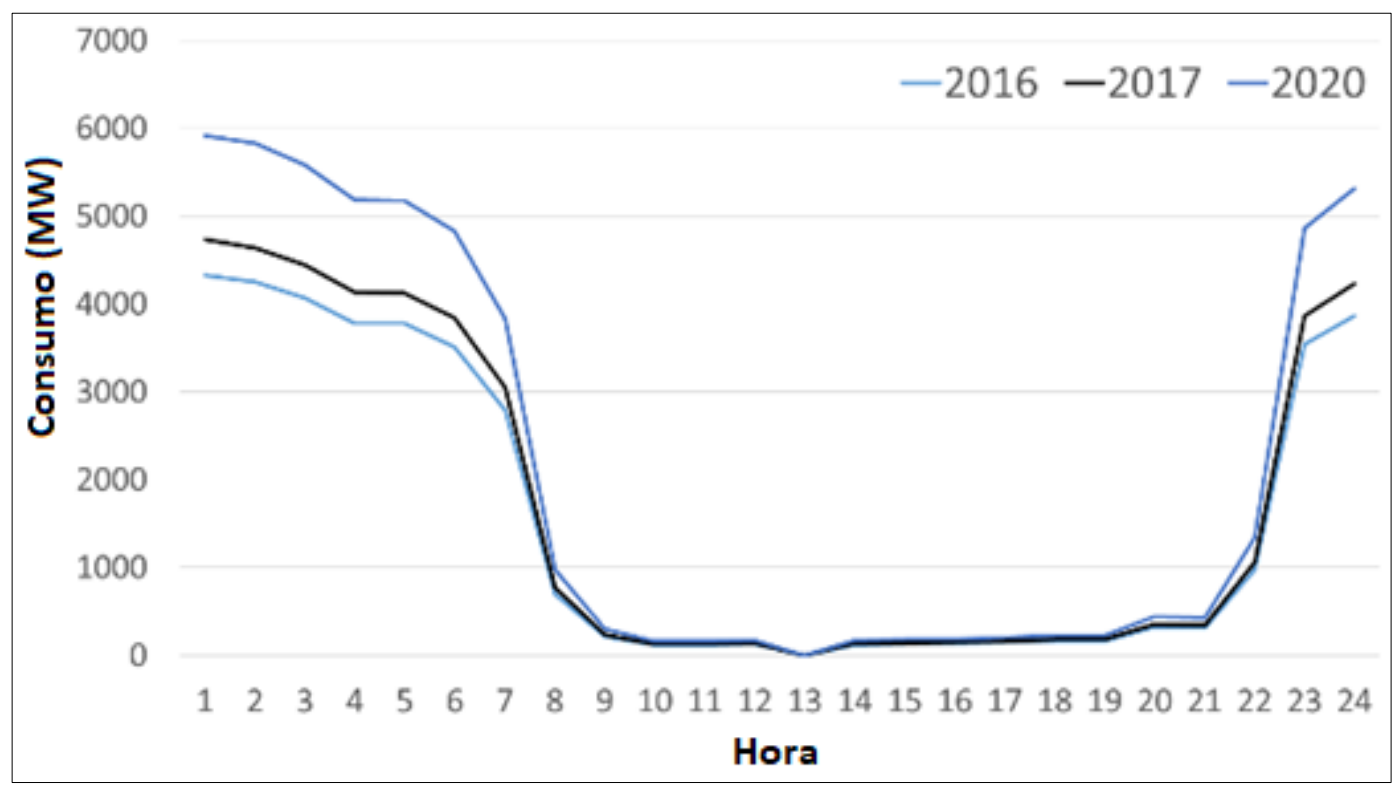

Figura 24 - Perfis Médios Gerais do Ar Condicionado (elaborado pelo autor, 2019). 


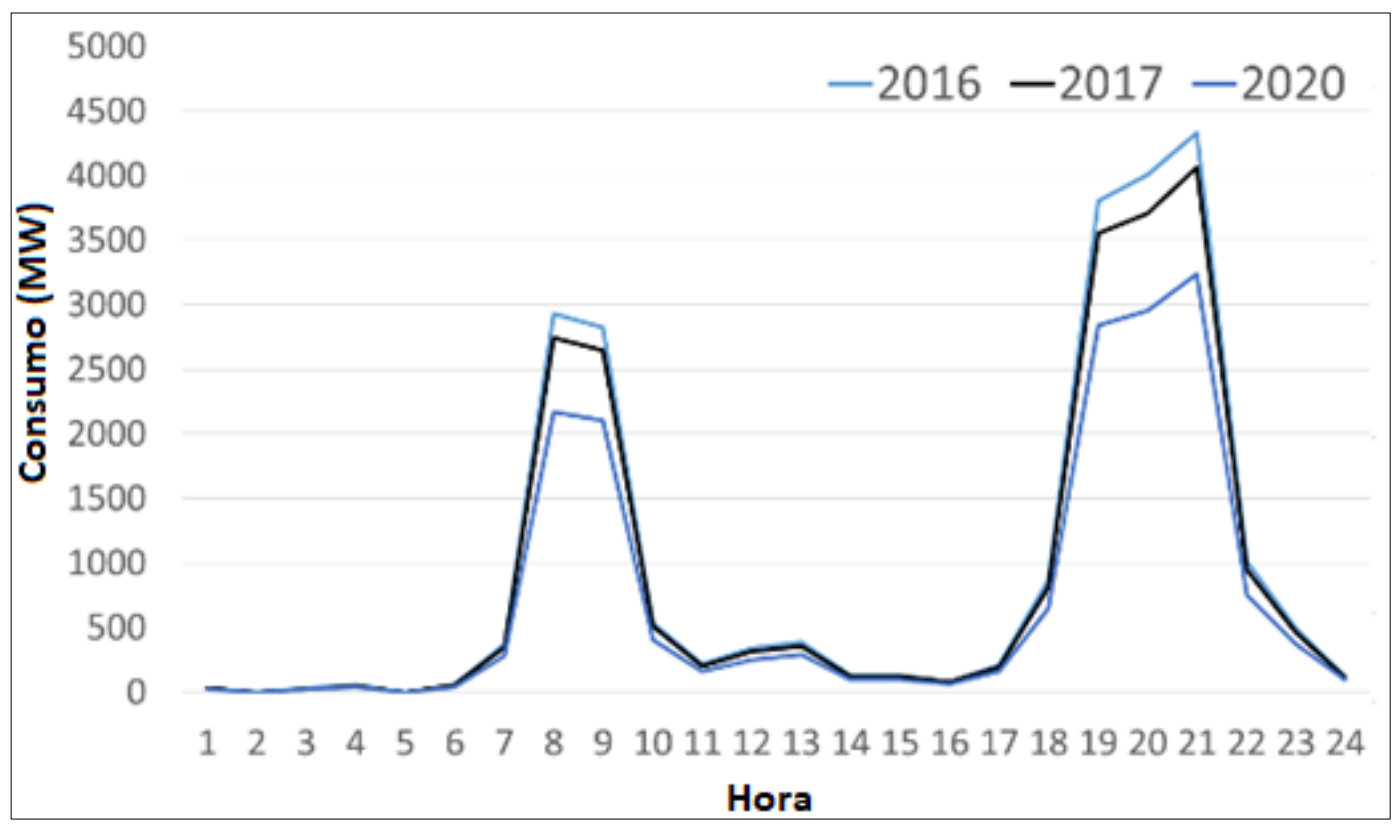

Figura 25 - Perfis Médios Gerais do Chuveiro Elétrico (elaborado pelo autor, 2019).

Para oferecer uma visão geral dos resultados, a Tabela 12 mostra uma análise das projeções horárias médias de cada setor feitas para 2020 em comparação com a participação esperada em 2016.

Tabela 12 - Participação Média de Setores por Patamar

\begin{tabular}{|c|c|c|c|}
\hline \multicolumn{3}{|c|}{$\mathbf{2 0 1 6}$} \\
\hline Setor & Residencial & Terciário & Industrial \\
\hline Leve & $23,9 \%$ & $24,4 \%$ & $40,9 \%$ \\
\hline Média & $21,9 \%$ & $25,6 \%$ & $41,9 \%$ \\
\hline Pesada & $32,0 \%$ & $29,0 \%$ & $32,3 \%$ \\
\hline \multicolumn{3}{|c|}{$\mathbf{2 0 2 0}$} \\
\hline Setor & Residencial & Terciário & Industrial \\
\hline Leve & $31,6 \%$ & $27,4 \%$ & $46,9 \%$ \\
\hline Média & $24,1 \%$ & $28,5 \%$ & $47,2 \%$ \\
\hline Pesada & $30,0 \%$ & $29,3 \%$ & $33,3 \%$ \\
\hline
\end{tabular}

A tabela 12 mostra que há uma redução da participação média somente do setor residencial nos horários de carga pesada. A maior parte desta redução é influenciada pela redução da participação do chuveiro elétrico, como já foi apresentado anteriormente, mas também é importante ressaltar a queda de consumo esperada para as lava-roupas e televisão por conta da produção de dispositivos mais eficientes. 


\section{5 \\ Conclusões}

Nesta Tese de Doutorado foi desenvolvida um modelo para Geração de Cenários de Carga Horária de Longo Prazo. O método utiliza abordagem bottomup para efetuar previsões anuais de demanda, o Método de Geração de Perfil Específico para adaptar perfis de processos e a Abordagem de Decomposição Parcial para desagregar a previsão anual para previsão horária. Inicialmente, três perfis específicos para cada processo foram adaptados e utilizados no PDA, quando três níveis de relevância diferentes (valores limiares) foram especificados. A combinação entre os perfis específicos e os níveis de relevância foram a base para gerar nove cenários diferentes de projeções de curvas de carga, utilizados para simular cem cenários com base no método Monte Carlo com distribuição gaussiana.

Tal método garante a evolução do PDA de forma a transformar um modelo de resultado discreto em um previsor de cenários, garantindo um leque de possibilidades para o especialista e tomador de decisão. Além disso, também garante a geração de insumos sintéticos para alimentação do modelo, quando estes não estão disponíveis na região alvo do estudo, sem grande impacto no resultado pelo fato dos erros imbutidos nos mesmos serem minimizados, tanto pela simulação, quanto pela consideração dos três limiares.

Primeiramente, a validação foi efetuada com base na curva total, usando a projeção da curva de carga horária média específica para 2017 e tomando PICP, MPIW, RMSE e MAPE como métricas para validar a curva de carga média projetada. Um RMSE de 2 902,08 MWh e um MAPE de 7,33 \% mostram, em geral, uma previsão de qualidade, tendo-se em vista que se trata de uma projeção de longo prazo com um ano à frente. O MPIW de 7 169,11 MWh demonstra um intervalo de confiança consistente que representa em torno de $20 \%$ da carga total, porém o valor do PICP de 0,65 demonstra um desempenho ruim no aspecto dos cenários gerados.

Dados os resultados para a curva total, passou-se à avaliação para os perfis específicos da curva de carga com as mesmas métricas utilizadas para avaliar os perfis das diferentes estações de ano e tipos de dia considerados. Os resultados 
indicaram que, apesar dos dias de inverno terem melhores resultados, com PÌCP', RMSE e MAPE de 0,87 e 2 142,03 MWh e 5,45 \%, respectivamente, em dias com níveis de carga mais altos a carga foi superestimada. Sobre o MPIW, uma amplitude de previsão satisfatória, de cerca de $20 \%$ dos valores máximos foi obtida.

Tendo em vista os resultados obtidos para as métricas de erros, fez-se uma avaliação secundária baseada em patamares de carga. Para isso, patamares de carga definidos com base nos valores indicados pelo ONS foram utilizados para analisar a qualidade dos perfis projetados. A análise mostrou que, apesar da carga leve ter sido superestimada nos perfis médios típicos, com uma diferença de $0,5 \%$, sendo que esta diferença causou uma subestimação da média, esta mostrou um desempenho perfeito na carga pesada.

Para encerrar o processo de validação, a mesma avaliação por patamares foi aplicada para os setores. Neste caso, como o histórico também é estimado, fez-se uma avaliação baseada no que se espera para o cenário brasileiro. Nos resultados apresentados nota-se que nas projeções somente o setor residencial se assemelha à realidade brasileira, com seu consumo mais alto no patamar de carga pesada, seguido da leve e com pouco consumo na média. Os setores industrial e terciário, apesar de apresentarem maior consumo na média, como se espera, apresentam alta participação nas cargas leve e pesada. Quando o foco é voltado para os patamares estimados na curva sintética de 2016, nota-se que o problema não está nas projeções, mas sim na qualidade dos perfis. A alta participação destes setores nas cargas leve e pesada permanecem, indicando a necessidade de melhoria destes perfis.

Efetuada a validação, o método foi aplicado para prever a curva de carga para 2020, esperando-se que se evidencie as mudanças esperadas nas curvas para os próximos anos. Os resultados mostraram que o ar condicionado, com um total de 7,6 \% de participação esperada ao longo de um dia típico, e o chuveiro elétrico, com uma perda de participação de $3,5 \%$ sobre o mesmo tipo de dia, causaram a maior parte dos impactos. Esta ocorrência se deu sem negligenciar a participação histórica pois, além de as projeções mostrarem um comportamento que se assemelha ao histórico, também é possível notar pequenas alterações causadas pelos impactos das mudanças dos processos. 


\section{1. Vantagens e Desvantagens do Método Proposto}

Apesar dos bons resultados apresentados na curva e perfil total, quando comparada a previsão ao valor verificado, notam-se inconsistências nas informações individuais. Pelo fato da estrutura demonstrar grande sensibilidade a todo tipo de informação base previamente especificada, essas informações individuais inconsistentes ocasionaram incoerências no resultado final.

Primeiramente, no cálculo dos erros por estação do ano, nota-se que houve subestimação da carga, principalmente em dias mais quentes, quando os níveis de carga são mais relevantes. Essa subestimação pode ter sido ocasionada pelo cenário de difusão autônoma usado como base para as previsões anuais. Apesar de serem previstas reduções do crescimento da demanda ao longo dos anos de recessão, talvez não tenha havido boa percepção da capacidade de investimento para eficiência energética. $O$ valor total de carga estimada para a região Sudeste brasileira a partir da carga verificada do subsistema SE/CO foi de 275,03 TWh, enquanto a previsão anual efetuada para este mesmo ano foi de 255,92 TWh.

Em um segundo momento, a avaliação da qualidade de perfis dos setores utilizando os patamares de carga pré-determinados indicaram superestimação dos perfis dos setores terciário e industrial nas cargas leve e pesada. Apesar desse problema ser aliviado na carga pesada pelo fato de haver neste patamar grande participação da curva excedente, a carga leve não seguiu a mesma direção, apresentando um problema de superestimação no perfil médio típico. Nota-se que, mesmo com a previsão anual subestimando a carga, uma melhor estimação no patamar de carga leve, que seria abaixo da efetuada, poderia causar uma maior estimação no patamar de carga média, evitando o rompimento dos valores verificados no limite superior dos cenários previstos.

No Brasil não existem dados horários de participação de processos e/ou setores na carga final. Este fato faz com que a metodologia estime de maneira totalmente sintética a curva de atuação dos processos e, consequentemente, setores. Além disso, todas as previsões anuais de processos, setores e regiões são efetuadas por modelos de estimação, fazendo com que os erros se acumulem com o tempo. A adaptação do PDA, de um método determinístico para um gerador de cenários simulados, possibilita a consideração desses erros nos resultados. Apesar do PDA 
continuar uma ferramenta altamente sensível às informações de entrada e transmitir esta desvantagem para o gerador de cenários, a disponibilidade de diferentes prospectivas dá uma liberdade ao operador de considerar aquele que lhe parece mais plausível.

\section{2.}

\section{Trabalhos Futuros}

No geral cada região estudada deve ter suas próprias características consideradas no desenvolvimento dos dados de entrada, tendo estes que ser estudados para serem respeitados aqueles com maior relevância.

É importante ressaltar que não somente processos de relevância atual devem ser considerados, mas também aqueles que podem causar impacto no horizonte de estudo. Novas tecnologias que possam elevar o nível da carga e/ou alterar seu formato, como carros elétricos, e outras que possam reduzir o nível da carga em determinados horários, como a geração distribuída, apesar de não serem importantes para o Brasil no horizonte abordado nesta tese, podem ter seu uso difundido para horizontes mais distantes. No caso da geração distribuída, como esta é utilizada para dar suporte à geração de energia elétrica e ajuda a abater a demanda, o perfil da mesma seria construído com valores negativos a fim de reduzir os valores futuros.

Além destas tecnologias serem consideradas em trabalhos futuros, dependendo do horizonte de previsão a ser abordado, existe uma nova pesquisa de posses e hábitos sendo efetuada para todos os equipamentos de uso residencial, possibilitando a atualização dos processos mais relevantes e dos perfis utilizados como insumo da metodologia. Quanto aos subsetores do setor terciário e industrial, uma base de dados mais recente deverá ser estudada, além de ser considerada a utilização do ar condicionado em cada um desses subsetores separadamente. 


\section{Referências Bibliográficas}

AGÊNCIA NACIONAL DE ENERGIA ELÉTRICA - ANEEL. Resolução No 290. Brasília: 2000.

AGRAWAL, R. K.; MUCHAHARY, F. Long Term Load Forecasting with Hourly Predictions based on Long-Short-Term-Memory Networks, 2018. IEEE Texas Power and Energy Conference (TPEC). Anais. IEEE, 2018

AKDEMIR, B.; ÇETINKAYA, N. Long-term load forecasting based on adaptive neural fuzzy inference system using real energy data. Energy Procedia. Anais. 2012

ANDERSEN, F. M.; LARSEN, H. V.; BOOMSMA, T. K. Long-term forecasting of hourly electricity load: Identification of consumption profiles and segmentation of customers. Energy Conversion and Management, v. 68, p. 244252, 2013.

ANDERSEN, F. M.; LARSEN, H. V.; GAARDESTRUP, R. B. Long term forecasting of hourly electricity consumption in local areas in Denmark. Applied Energy, v. 110, p. 147-162, 2013.

BASTOS, B. Q. et al. Modeling the impact of energy efficiency in the electricity consumption of the Brazilian tertiary sector. International Conference on the European Energy Market, EEM. Anais. 2017

BOSSMANN, T. The contribution of electricity consumers to peak shaving and the integration of renewable energy sources by means of demand response: A model-based long-term scenario analysis in consideration of structural changes in eletricity demand. Karlsruhe, KIT, 2015.

BOSSMANN, T.; PFLUGER, B.; WIETSCHEL, M. The shape matters! How structural changes in the electricity load curve affect optimal investments in generation capacity. International Conference on the European Energy Market, EEM. Anais. 2013

BUNN, D. W. Experimental study of a Bayesian method for daily electricity load forecasting. Applied Mathematical Modelling, v. 4, n. 2, p. 113-116, 1980. 
CÂMARA DE COMERCIALIZAÇÃO DE ENERGIA ELÉTRICA - CCEE. $2^{\text {a }}$ Revisão Quadrimestral das Projeções da demanda de energia elétrica do Sistema Interligado NacionalOperador Nacional. Rio de Janeiro: 2019.

CARMO, D. L. DO et al. Simulação Dos Perfis De Consumo Específicos De Energia Elétrica Para Equipamentos E Subsetores. Simpósio Brasileiro de Pesquisa Operacional. Anais. Rio de Janeiro: 2018.

Brazilian Southeast Profiles Dataset. [s.1.] Mendeley, 4 set. 2018. Disponível em: <https://data.mendeley.com/datasets/dnnds8j9hk/1>. Acesso em: 5 set. 2018 .

CARPINTEIRO, O. A. S. et al. A Hybrid Neural Model in Long-Term Electrical Load Forecasting. International Conference on Artificial Neural Networks. Anais. 2006.

CERVANTES, M. The Monte Carlo Method. Mathematics in Science and Engineering, 1972.

CHEN, T. A collaborative fuzzy-neural approach for long-term load forecasting in Taiwan. Computers and Industrial Engineering, v. 63, n. 3, p. 663-670, 2012.

CHENTHUR PANDIAN, S. et al. Fuzzy approach for short term load forecasting. Electric Power Systems Research, v. 76, n. 6-7, p. 541-548, 2006.

CHRISTIAANSE, W. R. Short-Term Load Forecasting Using General Exponential Smoothing. IEEE Transactions on Power Apparatus and Systems, v. PAS-90, n. 2, p. 900-911, 1971.

CHUAN, L.; UKIL, A. Modeling and Validation of Electrical Load Profiling in Residential Buildings in Singapore. IEEE Transactions on Power Systems, v. 30, n. 5, p. 2800-2809, 2015.

DICKERT, J.; SCHEGNER, P. A time series probabilistic synthetic load curve model for residential customers, 2011. IEEE PES Trondheim PowerTech: The Power of Technology for a Sustainable Society, POWERTECH 2011. Anais. 2011.

ELSLAND, R. et al. Analysis of structural changes of the load profiles of the German residential sector due to decentralized electricity generation and emobility. Smart Innovation, Systems and Technologies, v. 22, p. 71-84, 2013.

ELSLAND, R.; EICHHAMMER, W.; SCHLOMANN, B. Is enough electricity being saved? Impact of energy efficiency policies addressing electrical 
household appliances in Germany until 2030. Eceee, p. 1651-1662, 2013.

EMPRESA DE PESQUISA ENERGÉTICA - EPE. Anuário Estatístico de Energia Elétrica 2018. Brasília: 2018.

_. Balanço Energético Nacional - ano base 2018. Brasília: 2019.

_. Resenha Mensal do Mercado de Energia Elétrica - Fevereiro de 2019. Rio de Janeiro: 2019.

Plano Decenal de Expansão de Energia 2029. Rio de Janeiro: 2020.

FILIK, Ü. B.; GEREK, Ö. N.; KURBAN, M. A novel modeling approach for hourly forecasting of long-term electric energy demand. Energy Conversion and Management. Anais. 2011

FISCHER, H. A History of the Central Limit Theorem. [s.l: s.n.].

FLEITER, T. et al. Where are the promising energy-efficient technologies? A comprehensive analysis of the German energy-intensive industries. Energy efficiency first. The foundation of a low-carbon society. Anais. 2011.

FRAUNHOFER ISI, IREES, T. E. FORECAST/eLOAD Website. Disponível em: <https://forecast-model.eu>. Acesso em: 24 mar. 2020.

FRIEDRICH, L.; AFSHARI, A. Short-term Forecasting of the Abu Dhabi Electricity Load Using Multiple Weather Variables. Energy Procedia, v. 75, p. 3014-3026, 2015.

GRANDJEAN, A.; ADNOT, J.; BINET, G. A review and an analysis of the residential electric load curve models. Renewable and Sustainable Energy Reviews, v. 16, n. 9, p. 6539-6565, 2012.

GREEN, R.; STAFFELL, I.; VASILAKOS, N. Divide and Conquer? kmeans clustering of demand data allows rapid and accurate simulations of the British electricity system. IEEE Transactions on Engineering Management, v. 61, n. 2, p. 251-260, 2014.

GUAN, W. et al. Advanced Load Forecast with hierarchical forecasting capability. IEEE Power and Energy Society General Meeting. Anais. 2013.

HAIDA, T.; MUTO, S. Regression based peak load forecasting using a transformation technique. IEEE Power Systems Transactions on, v. 9, n. 4, p. 1788-1794, 1994.

HAINOUN, A. Construction of the hourly load curves and detecting the annual peak load of future Syrian electric power demand using bottom-up approach. 
International Journal of Electrical Power \& Energy Systems, v. 31, n. 1, p. 112, 2009.

HAYKIN, S. Neural networks-A comprehensive foundation. New York: IEEE Press. Herrmann, M., Bauer, H.-U., \& Der, R, 1994.

HENDRY, D. F.; HUBRICH, K. Combining disaggregate forecasts or combining disaggregate information to forecast an aggregate. Journal of Business and Economic Statistics, 2011.

HERNÁNDEZ, L. et al. Improved short-term load forecasting based on twostage predictions with artificial neural networks in a microgrid environment. Energies, v. 6, n. 9, p. 4489-4507, 2013.

JAKOB, M. et al. The impact of policy measures on the electricity demand of the tertiary sector of the European countries: An analysis with the bottom-up model FORECAST. Ieecb'12, n. April, 2012.

KANDIL, N. et al. An efficient approach for short term load forecasting using artificial neural networks. International Journal of Electrical Power \& Energy Systems, v. 28, n. 8, p. 525-530, 2006.

KHOSRAVI, A. et al. Comprehensive review of neural network-based prediction intervals and new advances. IEEE Transactions on Neural Networks, v. 22, n. 9, p. 1341-1356, 2011.

KHOSRAVI, A.; NAHAVANDI, S.; CREIGHTON, D. Quantifying uncertainties of neural network-based electricity price forecasts. Applied Energy, v. 112, p. 120-129, 2013.

KIM, H.; ROBERT, C. P.; CASELLA, G. Monte Carlo Statistical Methods. [s.l: s.n.].

KORENEFF, G. et al. Future development trends in electricity demandVTT Tiedotteita - Valtion Teknillinen Tutkimuskeskus, 2009.

LÓPEZ, M. et al. Empirical Comparison of Neural Network and AutoRegressive Models in Short-Term Load Forecasting. Energies, v. 11, n. 8, p. 2080, 2018.

LOU, C. W.; DONG, M. C. A novel random fuzzy neural networks for tackling uncertainties of electric load forecasting. International Journal of Electrical Power and Energy Systems, v. 73, p. 34-44, 2015.

MAÇAIRA, P. M. Modelagem e previsão das séries de consumo de energia elétrica no Brasil com métodos de suavização exponencial de Pegels e 
abordagem bottom up por uso final. Pontifícia Universidade Católica do Rio de Janeiro, 2017.

MINISTÉRIO DE MINAS E ENERGIA. Portaria No 301. Brasília: 2019.

MURATORI, M. et al. A highly resolved modeling technique to simulate residential power demand. Applied Energy, v. 107, p. 465-473, 2013.

NIÑO, C. H. V. Modelo híbrido ESN-GA-SRG : uma abordagem de otimização e seleção de topologias em Echo State Networks para previsão de séries temporais. Pontificia Universidade Catolica do Rio de Janeiro, 2016.

OPERADOR NACIONAL DO SISTEMA ELÉTRICO. Submódulo 5.6 Consolidação da previsão de carga para a elaboração do Programa Mensal da Operação Energética. Procedimentos de Rede. Rio de Janeiro - RJ.

_. Histórico da Operação. Rio de Janeiro: 2017. Disponível em: $<$ http://www.ons.org.br/Paginas/resultados-da-operacao/historico-daoperacao/curva_carga_horaria.aspx>. Acesso em: 28 nov. 2019.

Plano da Operação Energética 2019 - 2023. Rio de Janeiro: 2019.

_.. Balanço de Demanda - Metodologia. Rio de Janeiro: 2019.

PAATERO, J. V.; LUND, P. D. A model for generating household electricity load profiles. International Journal of Energy Research, v. 30, n. 5, p. 273-290, abr. 2006.

PANG, Y. et al. Hierarchical electricity time series forecasting for integrating consumption patterns analysis and aggregation consistency IJCAI International Joint Conference on Artificial Intelligence. Anais. 2018

PINA, A.; SILVA, C.; FERRÃO, P. Modeling hourly electricity dynamics for policy making in long-term scenarios. Energy Policy, v. 39, n. 9, p. 4692-4702, 2011.

POULIN, A. et al. Load duration curve: A tool for technico-economic analysis of energy solutions. Energy and Buildings, v. 40, n. 1, p. 29-35, 2008.

PROCEL. Sinpha. Disponível em: <http://www.procelinfo.com.br/Sinpha/Home.asp>. Acesso em: 1 set. 2018.

PROGRAMA NACIONAL DE CONSERVAÇÃO DE ENERGIA ELÉTRICA - PROCEL. Pesquisa de Posse de Equipamentos e Hábitos de Uso Ano Base 2005. Brasília - DF.

RICHARDSON, I. et al. Domestic electricity use: A high-resolution energy demand model. Energy and Buildings, v. 42, n. 10, p. 1878-1887, 2010. 
SCHILL, W. P. Residual load, renewable surplus generation and storage requirements in Germany. Energy Policy, v. 73, p. 65-79, 2014.

SILVA, F. L. C. et al. A bottom-up methodology for long term electricity consumption forecasting of an industrial sector - Application to pulp and paper sector in Brazil. Energy, v. 144, p. 1107-1118, 2018.

SILVA, F. L. C. DA. Extensão Estocástica Bayesiana da Abordagem Bottom-up Determinística para a Previsão de Longo Prazo do Consumo de Energia. Pontifícia Universidade Católica do Rio de Janeiro, 2017.

SUBGRUPO DE TRABALHO DE OPERAÇÃO E PREÇO. Implantação do DESSEM nas atividades de programação da operação e formação de preço horário - METODOLOGIA. Disponível em: <http://www.mme.gov.br/c/document_library/get_file?uuid=28c1bd8f-636c-a89e0839-e61d40a4051d\&groupId=36070>. Acesso em: 24 mar. 2020.

TORRINI, F. C. et al. Long term electricity consumption forecast in Brazil: A fuzzy logic approach. Socio-Economic Planning Sciences, v. 54, p. 18-27, 2016.

URI, N. D.; MAYBEE, J. S. Forecasting the load duration curve using boxjenkins time series analysis. Engineering Optimization, v. 3, n. 4, p. 193-199, 1978.

VÄHÄKYLA, P.; HAKONEN, E.; LÉMAN, P. Short-term forecasting of grid load using Box-Jenkins techniques. International Journal of Electrical Power and Energy Systems, v. 2, n. 1, p. 29-34, 1980.

WANG, H. et al. How real time pricing modifies Chinese households' electricity consumption. Journal of Cleaner Production, v. 178, p. 776-790, mar. 2018.

WANG, Y. et al. Short-term load forecasting with multi-source data using gated recurrent unit neural networks. Energies, v. 11, n. 5, 2018.

WHITLEY, D. A genetic algorithm tutorial. Statistics and Computing, v. 4, n. 2, p. 65-85, 1994.

WIDIARTA, H.; VISWANATHAN, S.; PIPLANI, R. Forecasting aggregate demand: An analytical evaluation of top-down versus bottom-up forecasting in a production planning framework. International Journal of Production Economics, 2009.

WORRELL, E.; PRICE, L. Policy scenarios for energy efficiency 
improvement in industry. Energy Policy, v. 29, n. 14, p. 1223-1241, 2001.

WORRELL, E.; RAMESOHL, S.; BOYD, G. Advances in Energy Forecasting Models Based on Engineering Economics *. Annu. Rev. Environ. Resour., v. 29, p. 345-81, 2004.

YUE, L. et al. The Fuzzy Logic Clustering Neural Network Approach for Middle and Long Term Load ForecastingInternational Conference on Grey Systems and Intelligent Services. Anais...2007

ZADEH, L. A. Fuzzy setsInformation and Control, 1965. 


\section{Apêndice A}

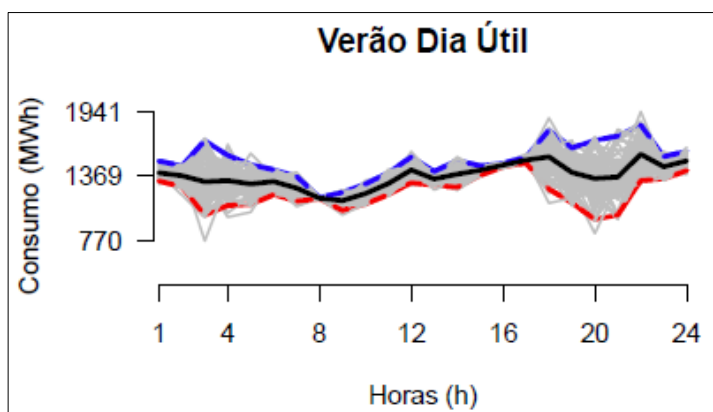

Inverno Dia Útil

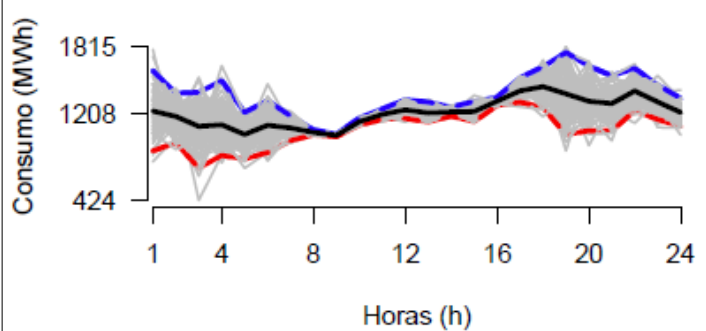

Intermediário Dia Útil

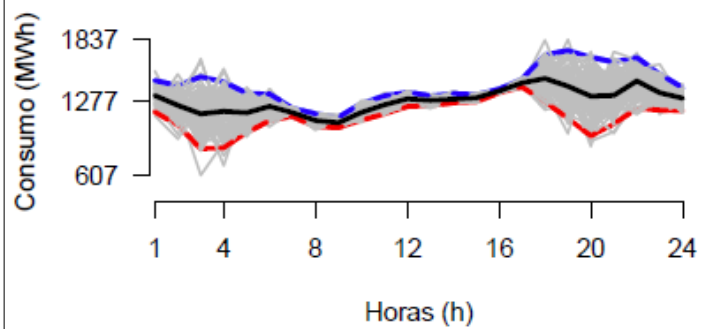

Verão Dia Não Útil

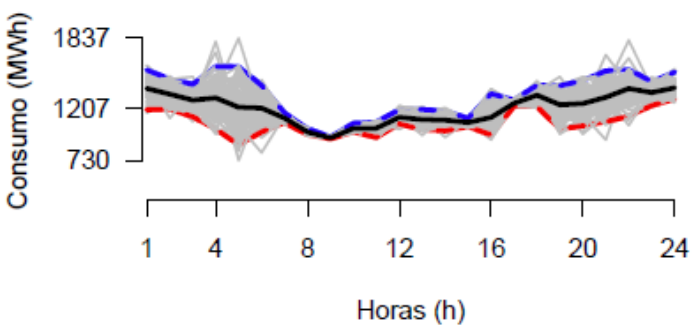

Inverno Dia Não Útil

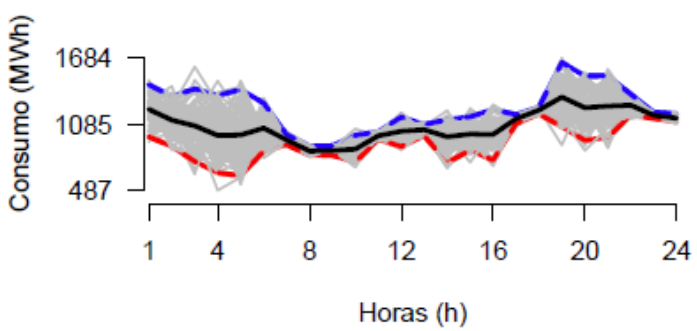

Intermediário Dia Não Útil

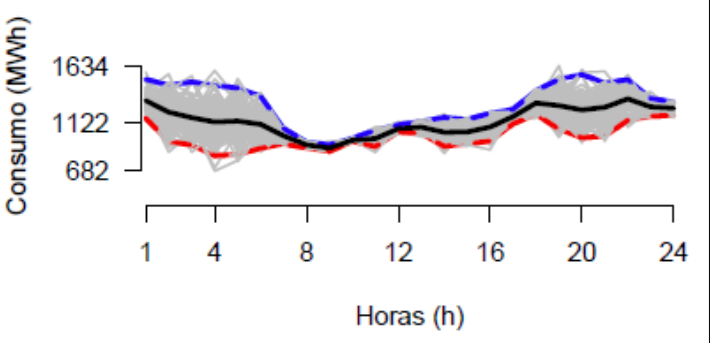

Figura 26 - Perfis Médios Sintéticos Históricos: Alimentos, bebidas e Tabaco (elaborado pelo autor, 2019). 

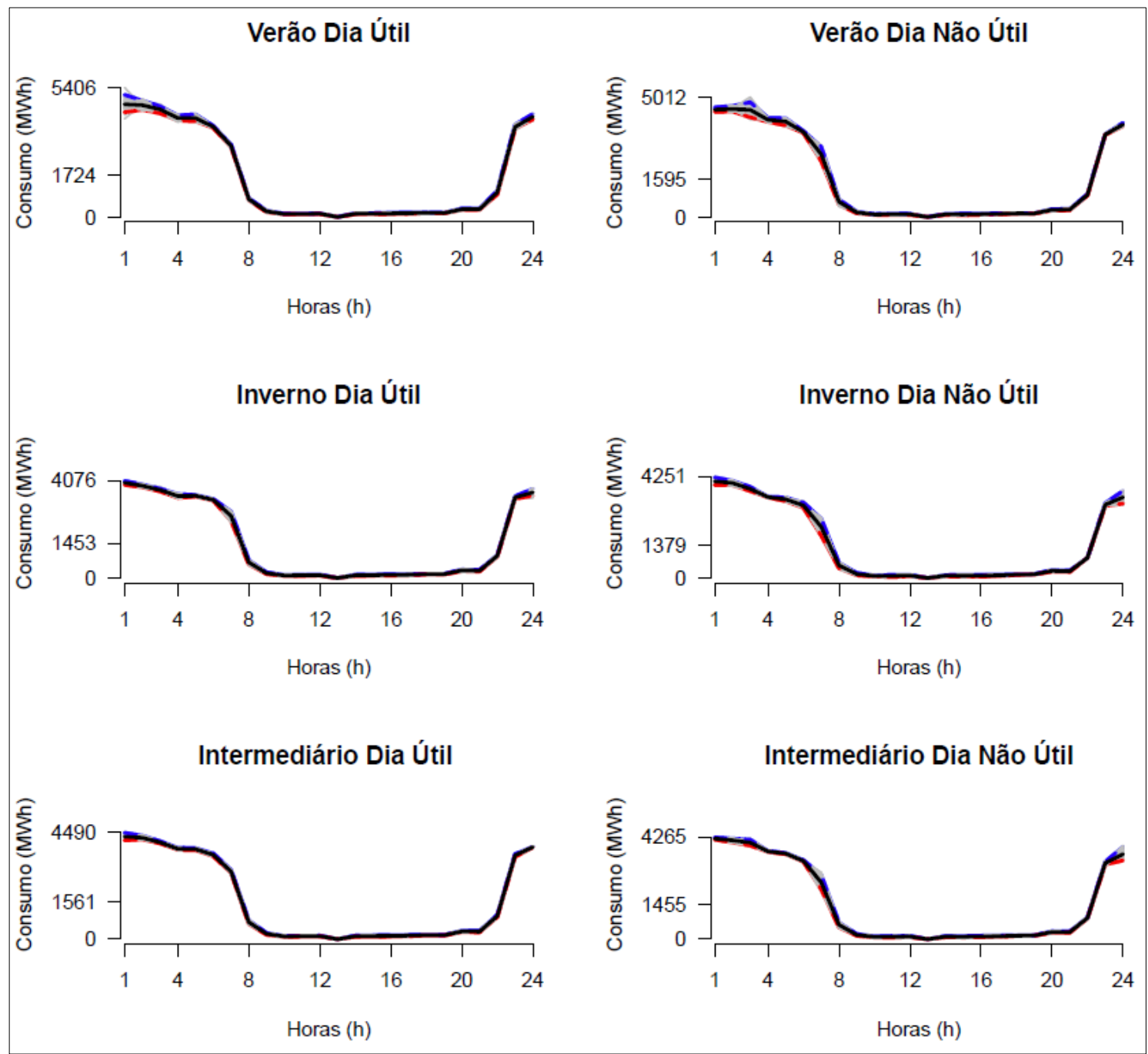

Figura 27 - Perfis Médios Sintéticos Históricos: Ar Condicionado (elaborado pelo autor, 2019). 


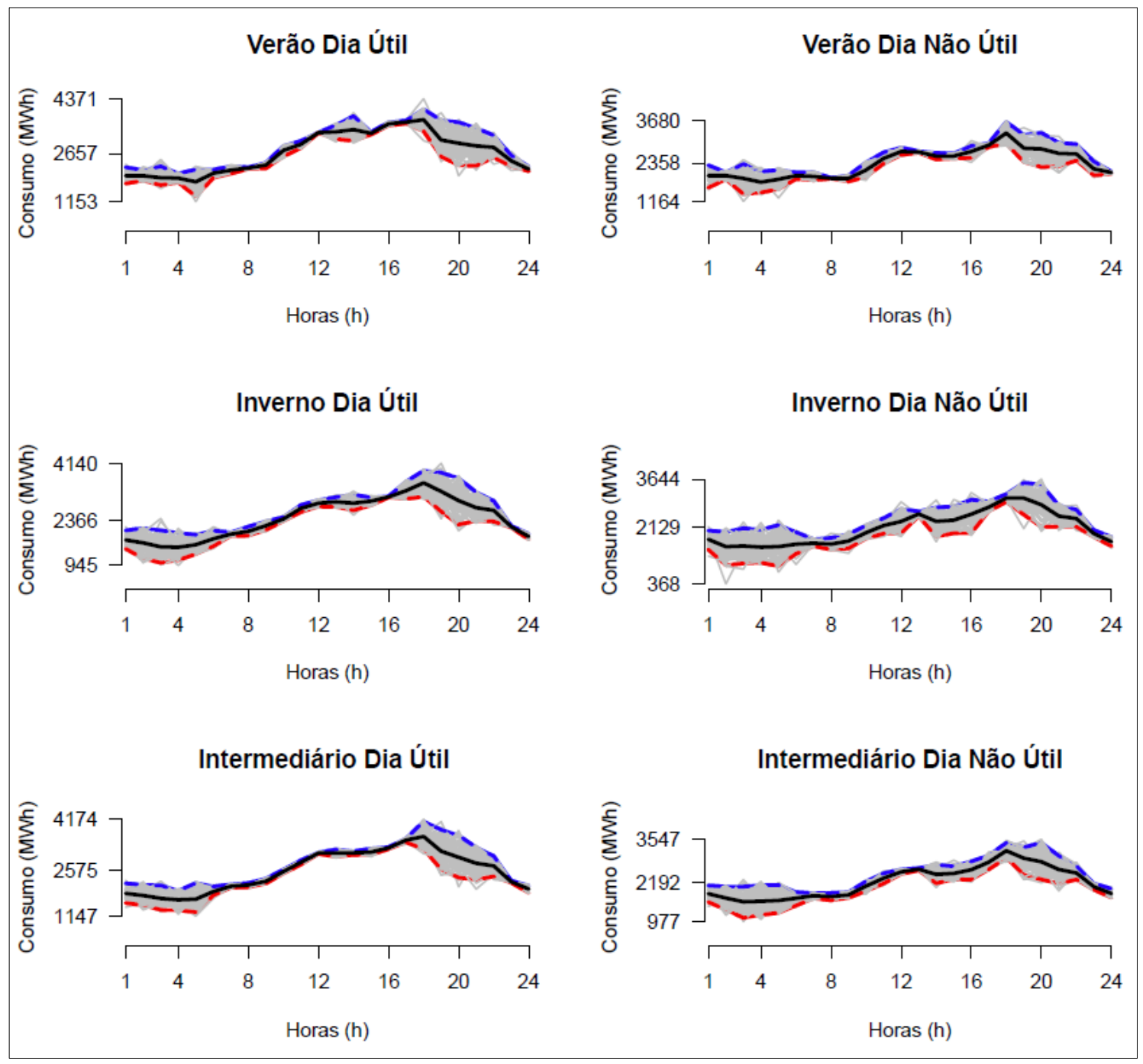

Figura 28 - Perfis Médios Sintéticos Históricos: Atacado e Varejo (elaborado pelo autor, 2019). 

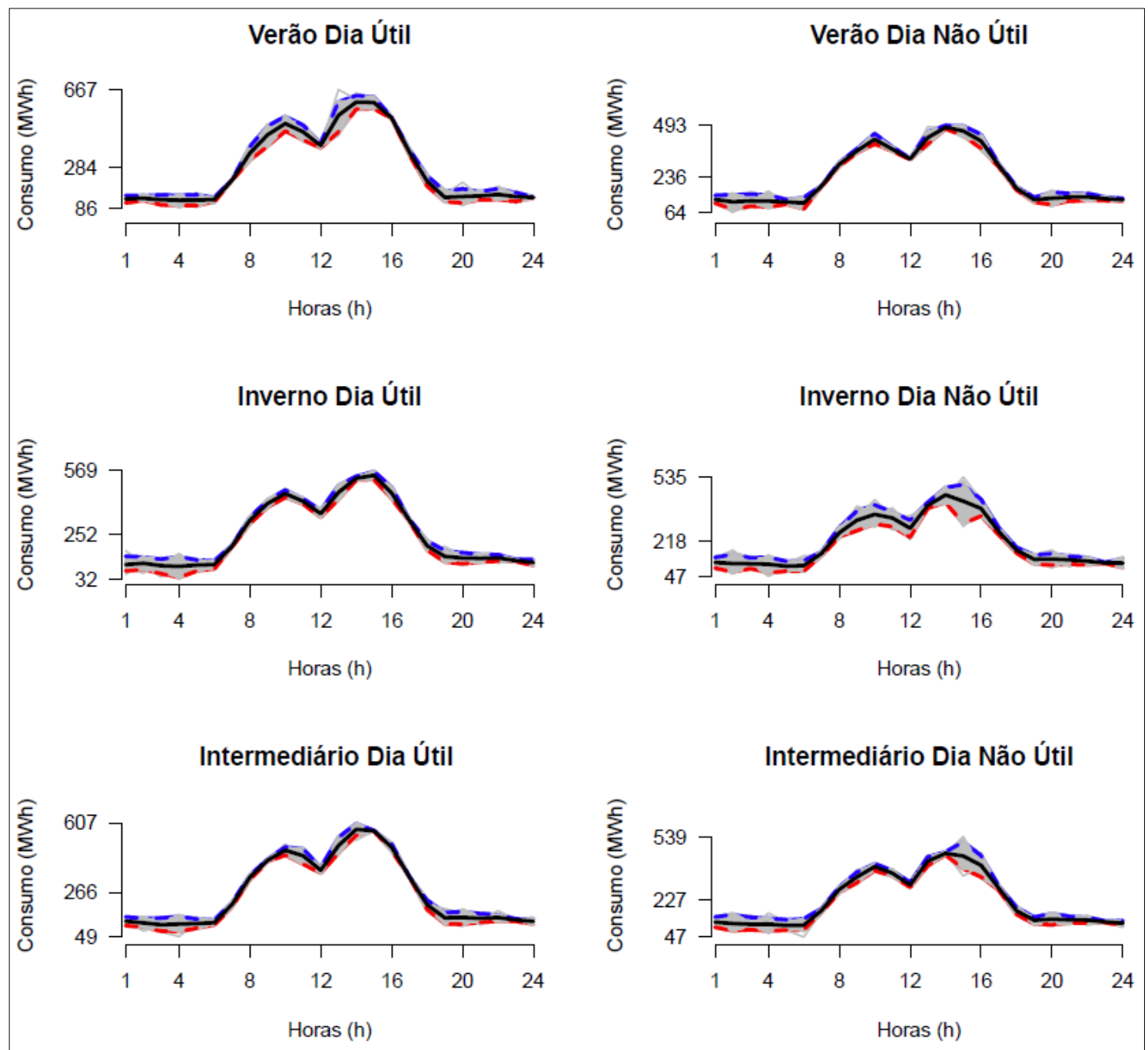

Figura 29 - Perfis Médios Sintéticos Históricos: Cerâmica (elaborado pelo autor, 2019). 


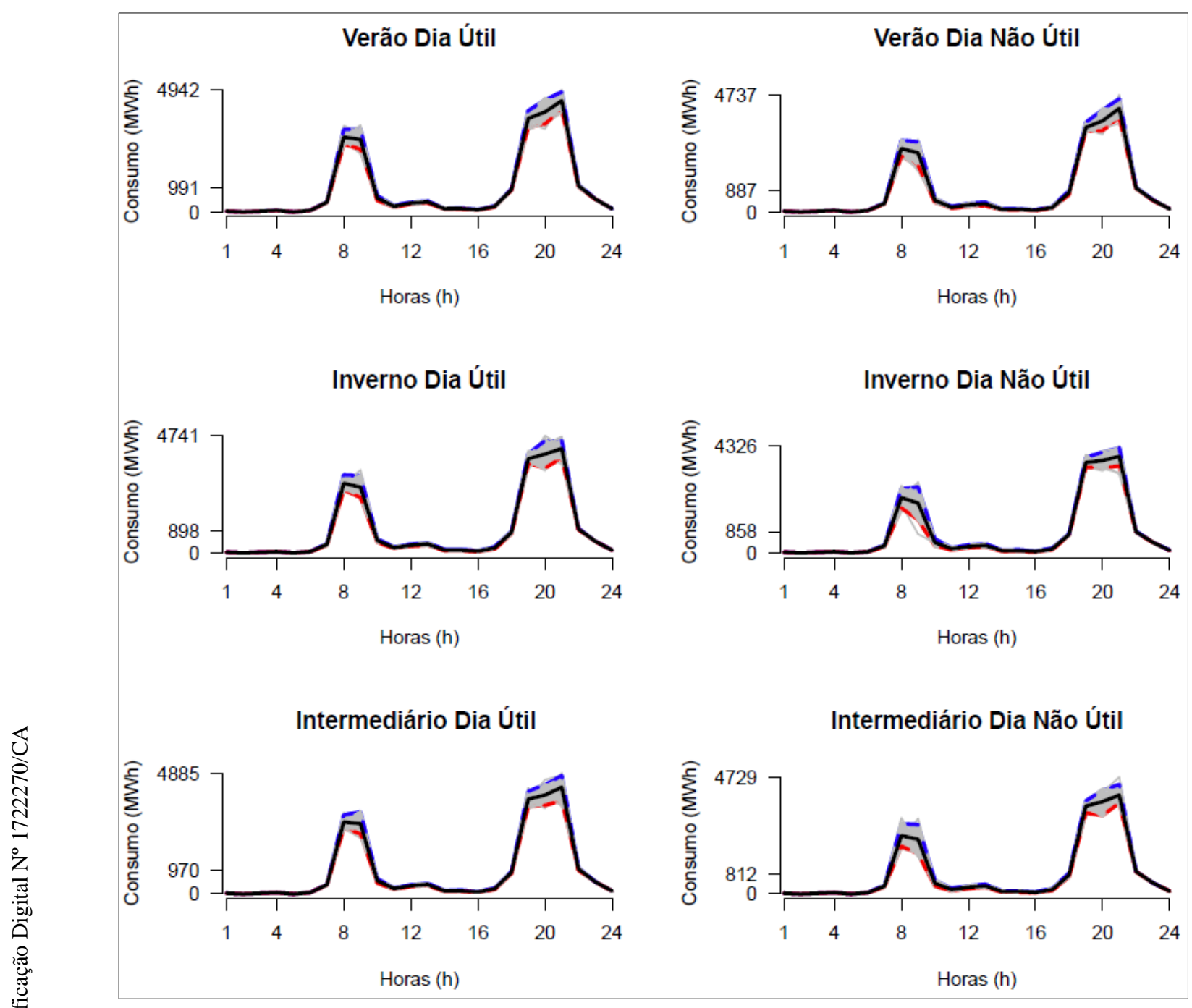

Figura 30 - Perfis Médios Sintéticos Históricos: Chuveiro Elétrico (elaborado pelo autor, 2019). 


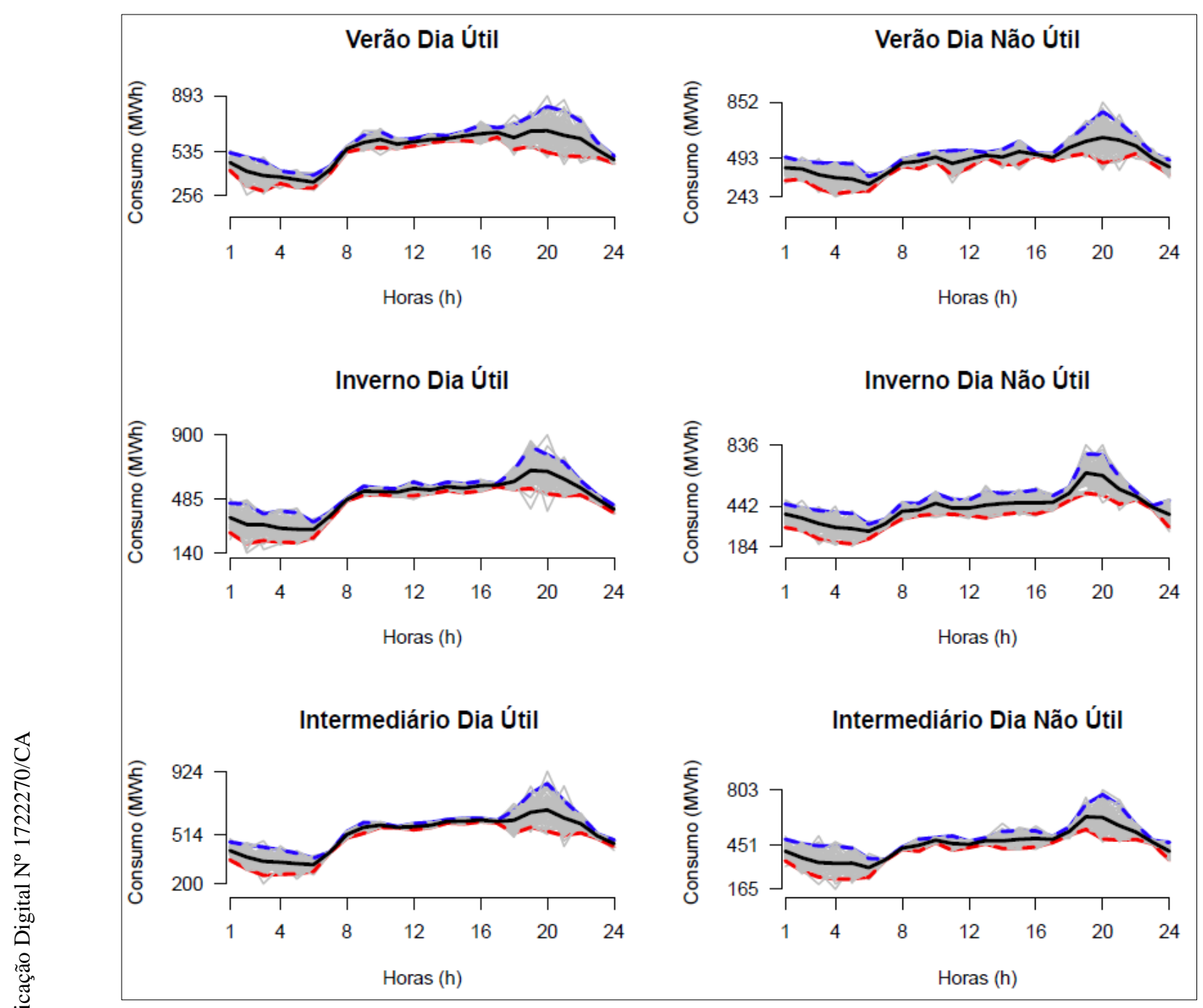

Figura 31 - Perfis Médios Sintéticos Históricos: Cimento (elaborado pelo autor, 2019). 


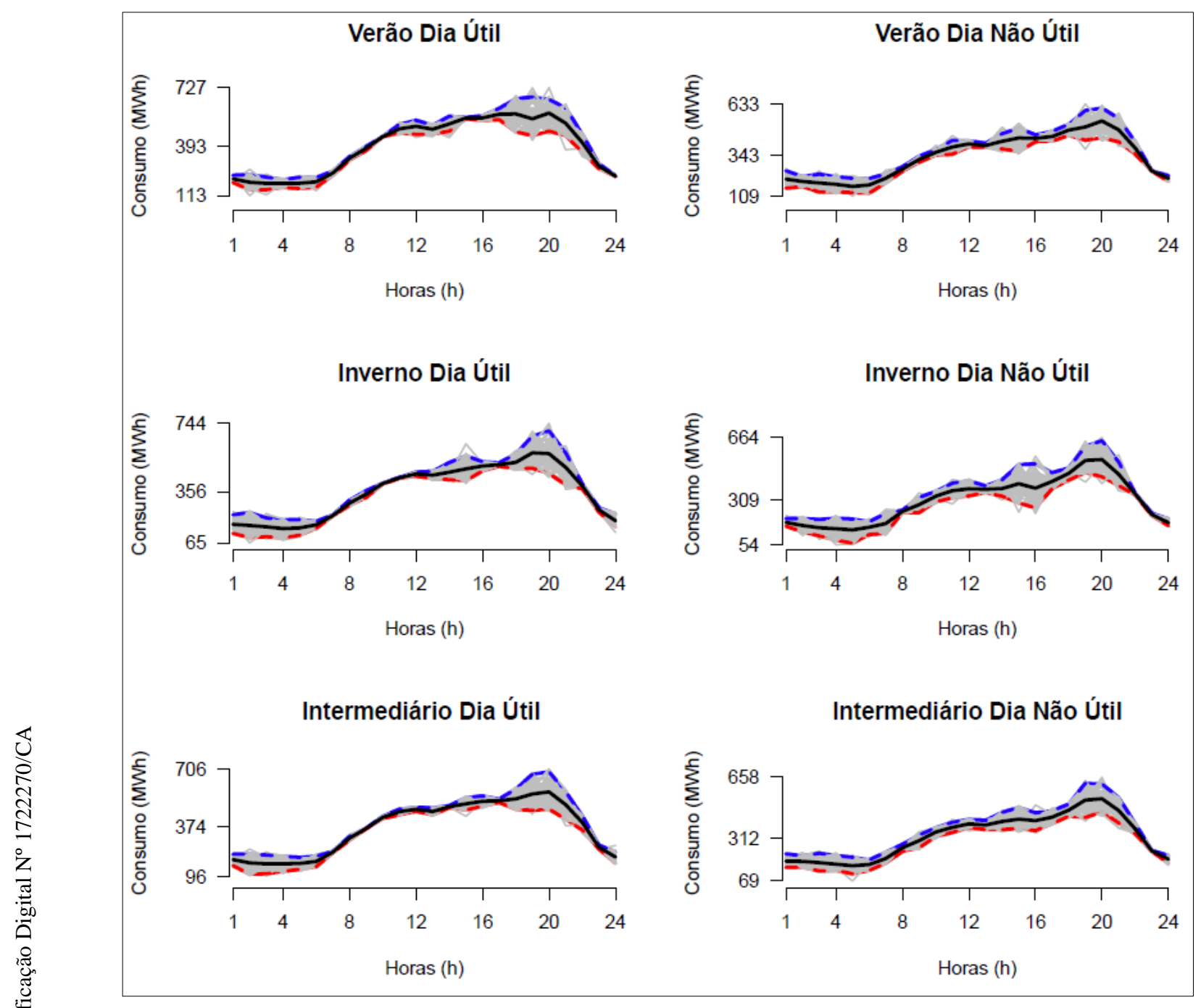

Figura 32 - Perfis Médios Sintéticos Históricos: Educação (elaborado pelo autor, 2019). 


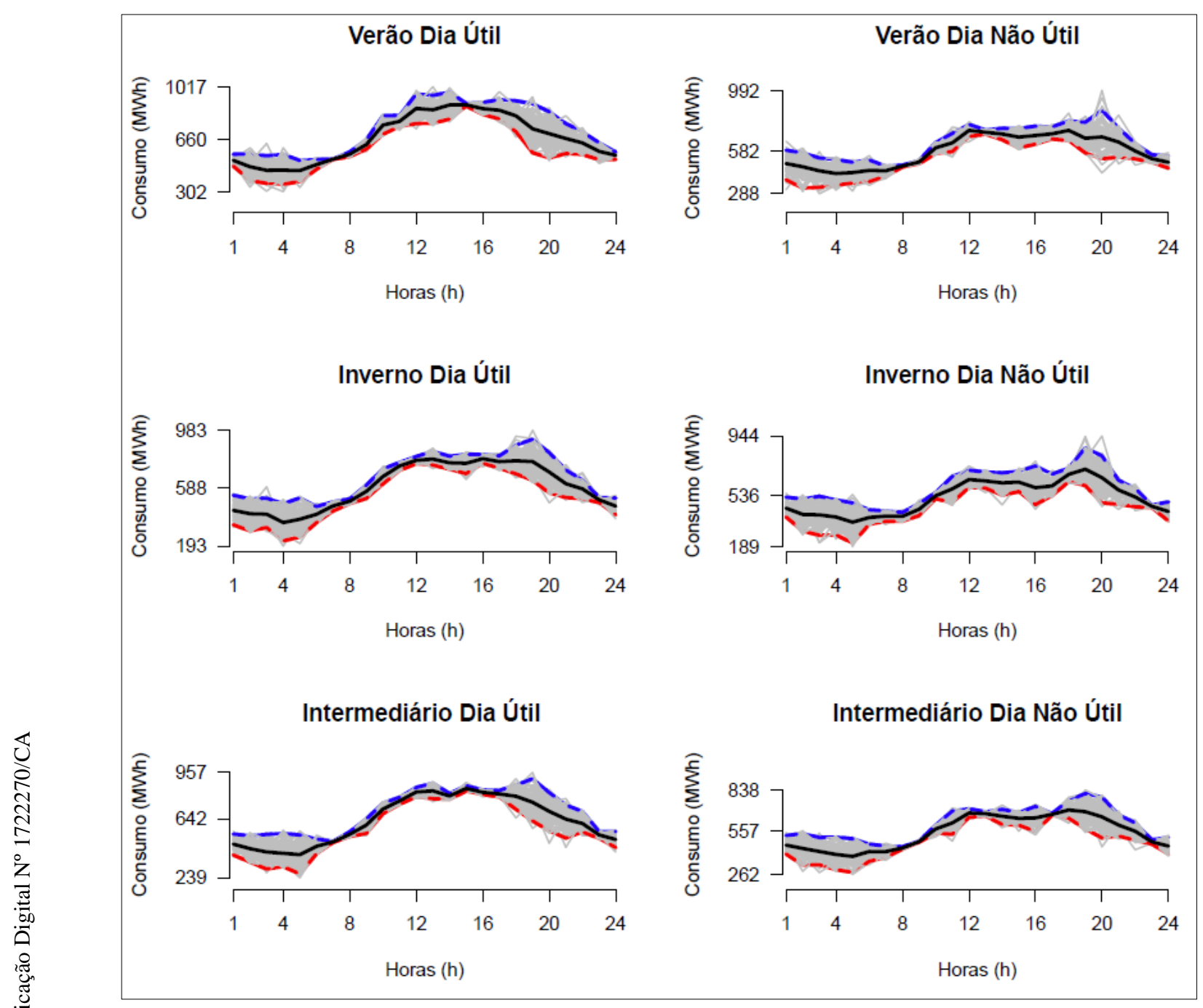

Figura 33 - Perfis Médios Sintéticos Históricos: Escritório Público (elaborado pelo autor, 2019). 


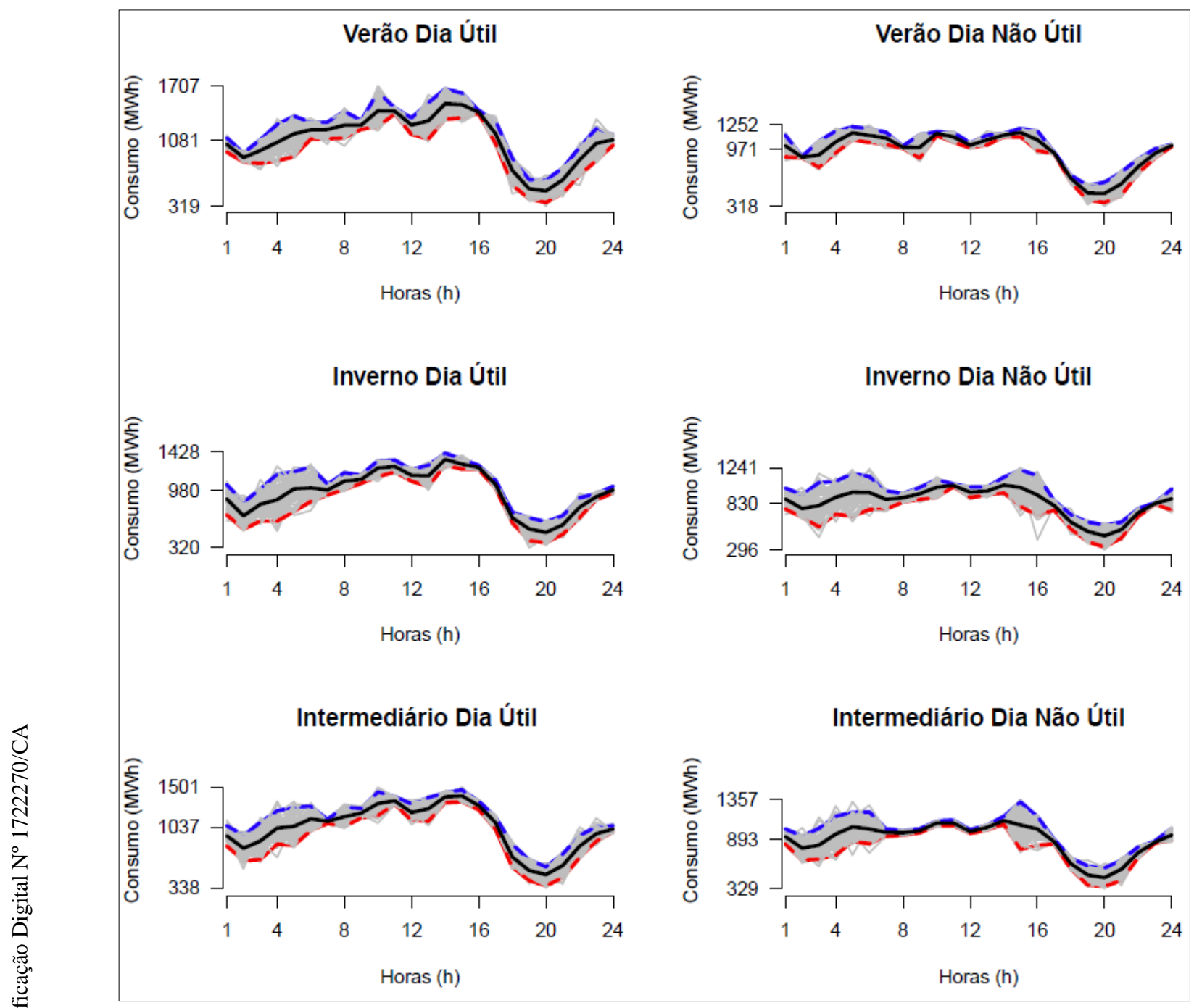

Figura 34 - Perfis Médios Sintéticos Históricos: Ferro e Aço (elaborado pelo autor, 2019). 


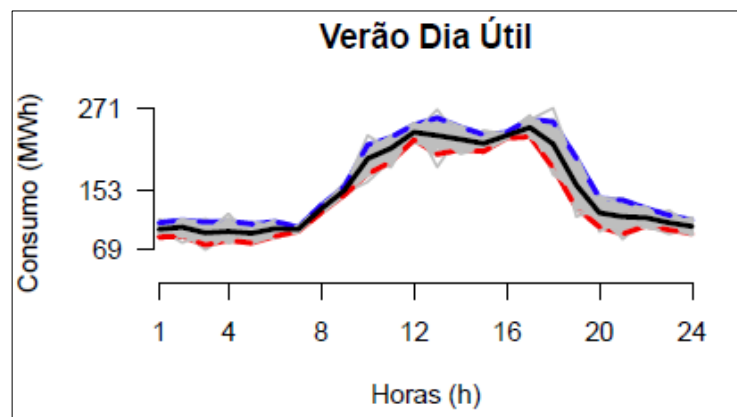

Inverno Dia Útil
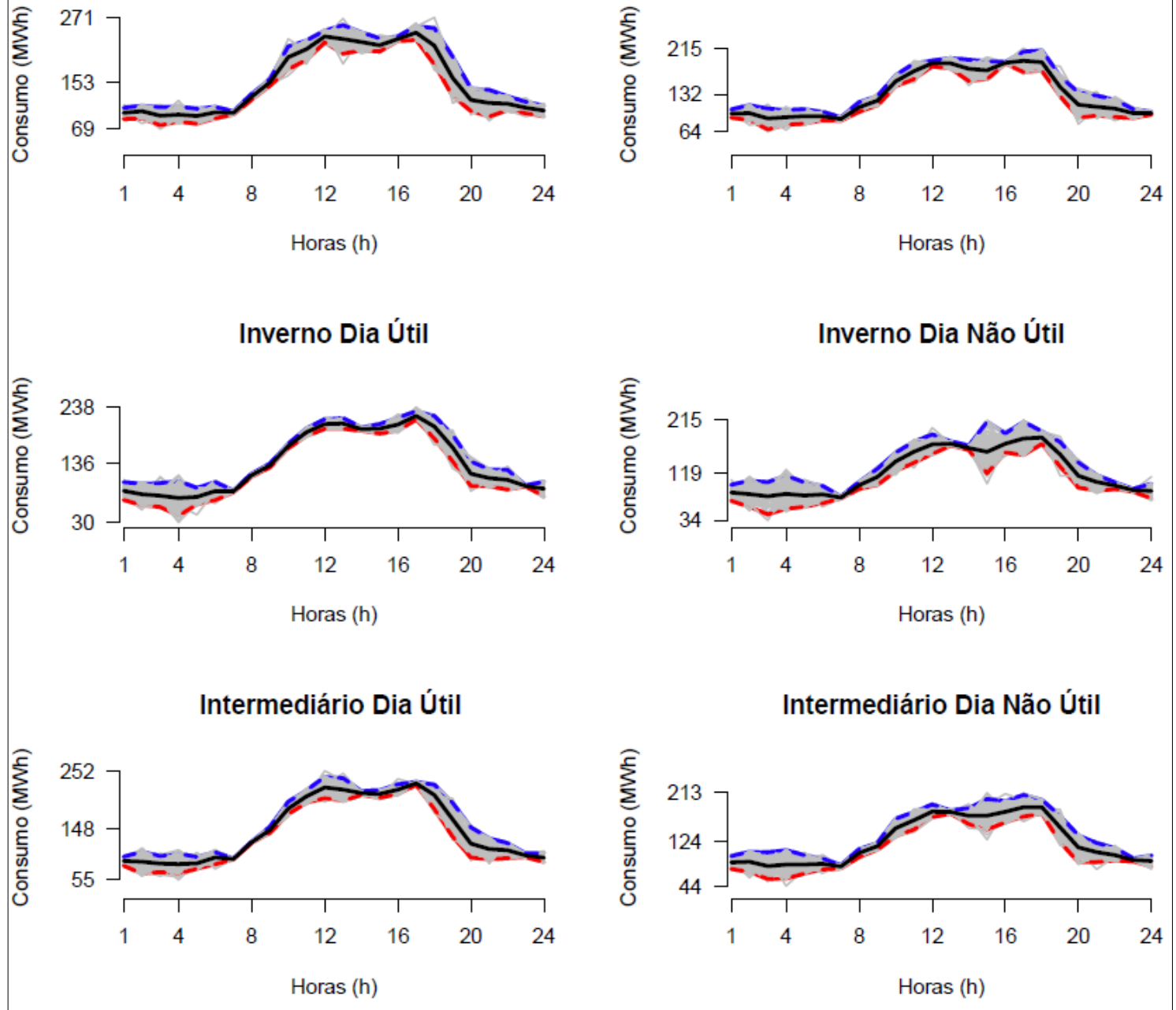

Figura 35 - Perfis Médios Sintéticos Históricos: Finanças (elaborado pelo autor, 2019). 


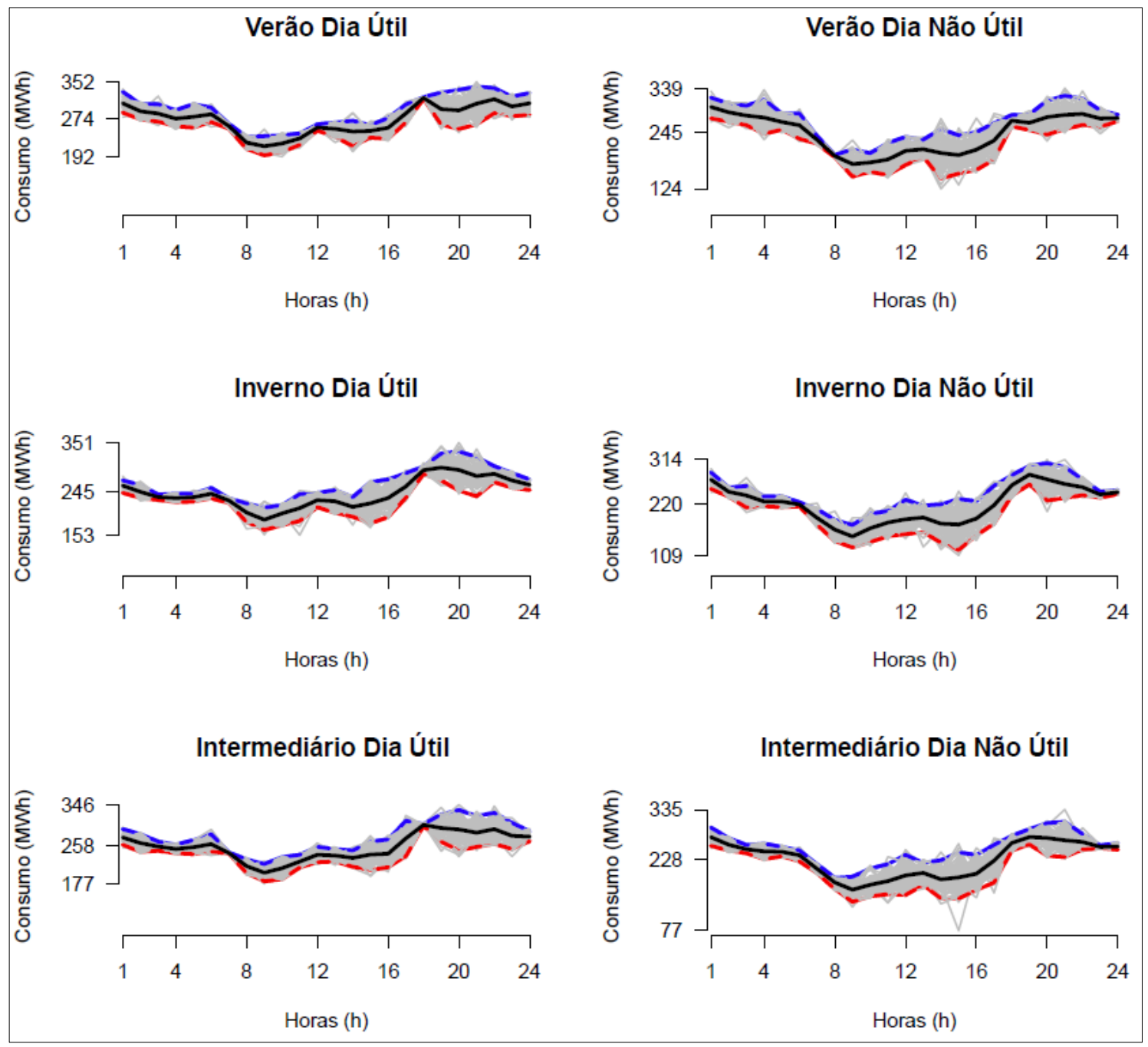

Figura 36 - Perfis Médios Sintéticos Históricos: Freezer (elaborado pelo autor, 2019). 


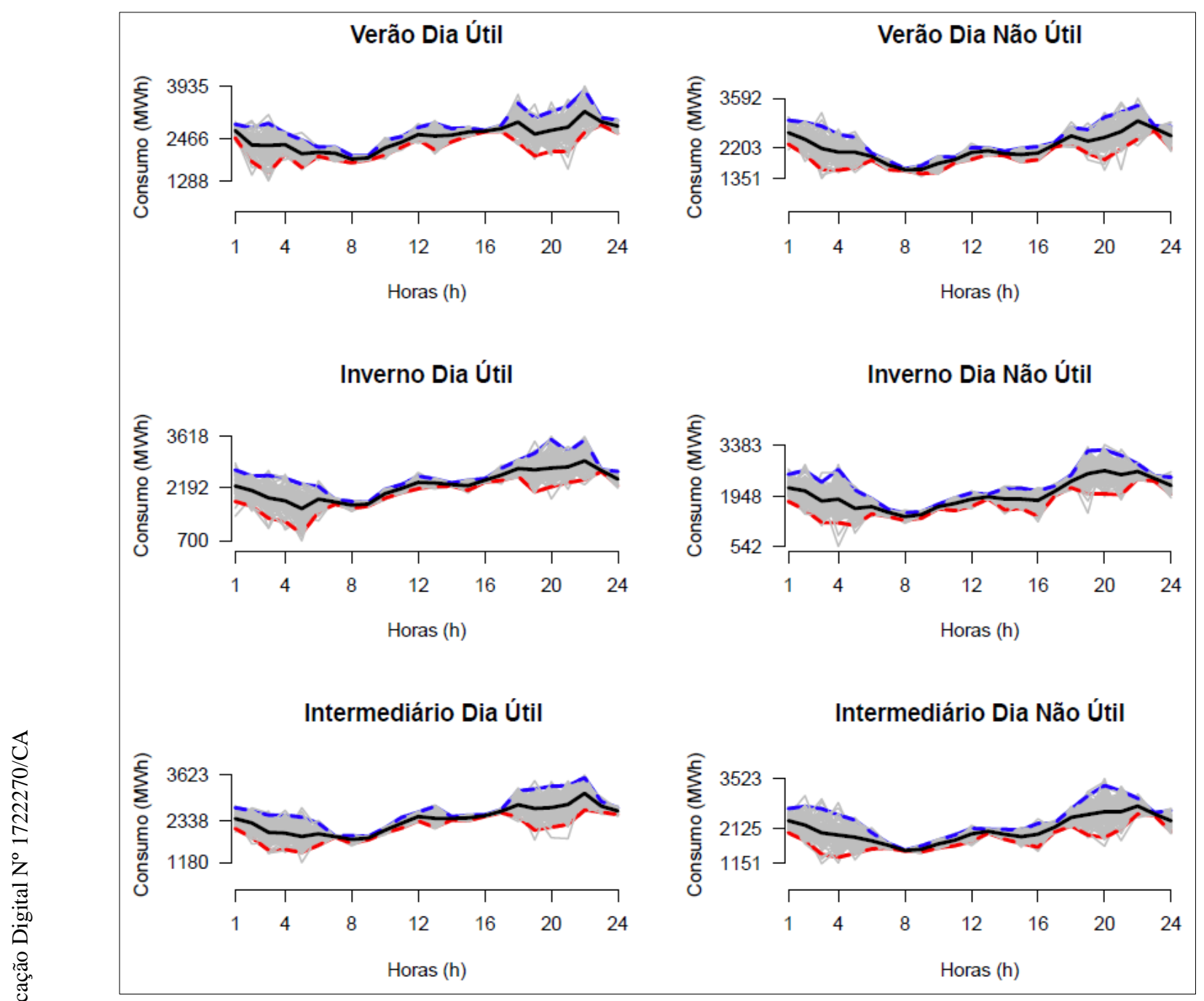

Figura 37 - Perfis Médios Sintéticos Históricos: Hotel, Café e Restaurante (elaborado pelo autor, 2019). 


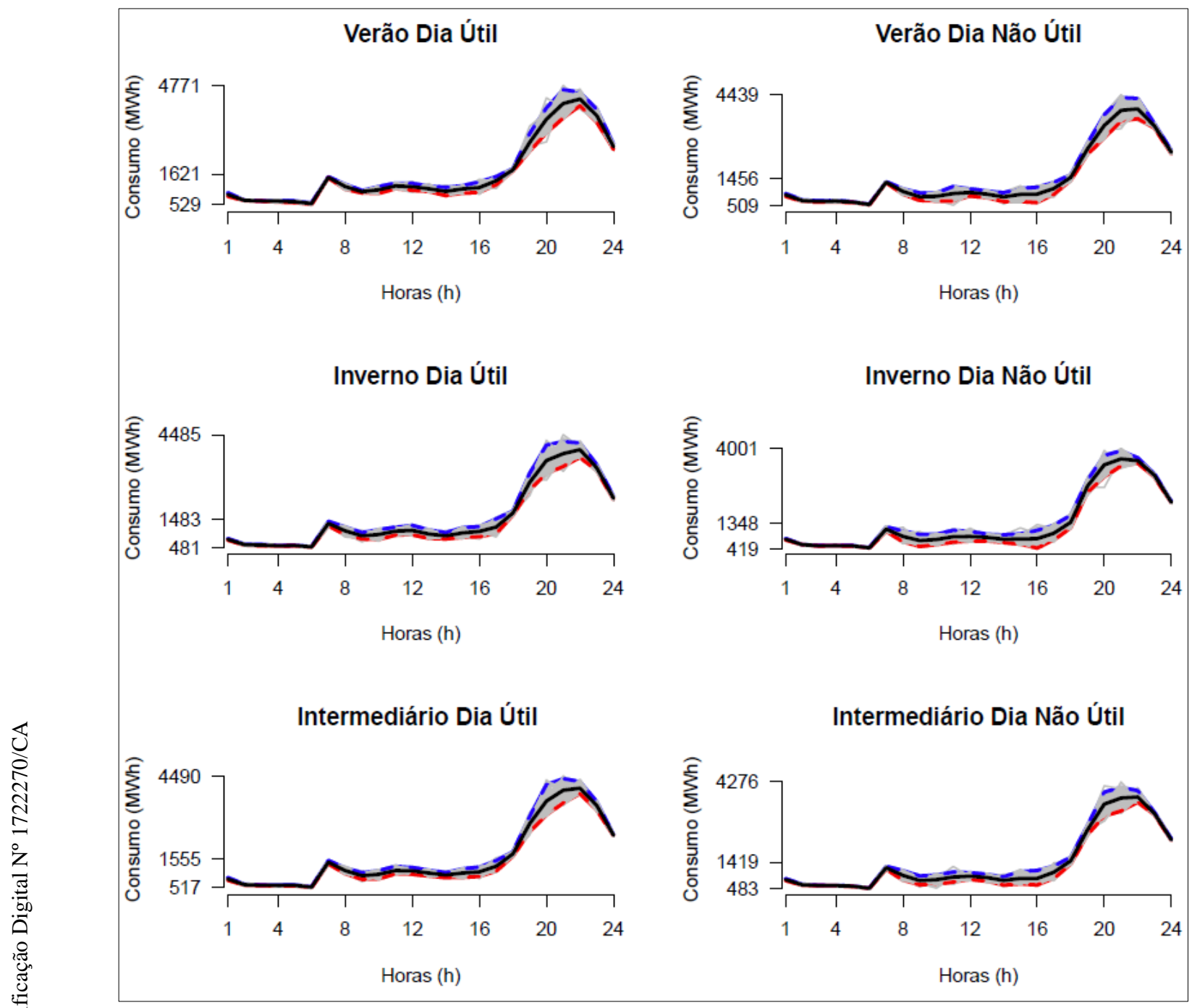

Figura 38 - Perfis Médios Sintéticos Históricos: lluminação (elaborado pelo autor, 2019). 


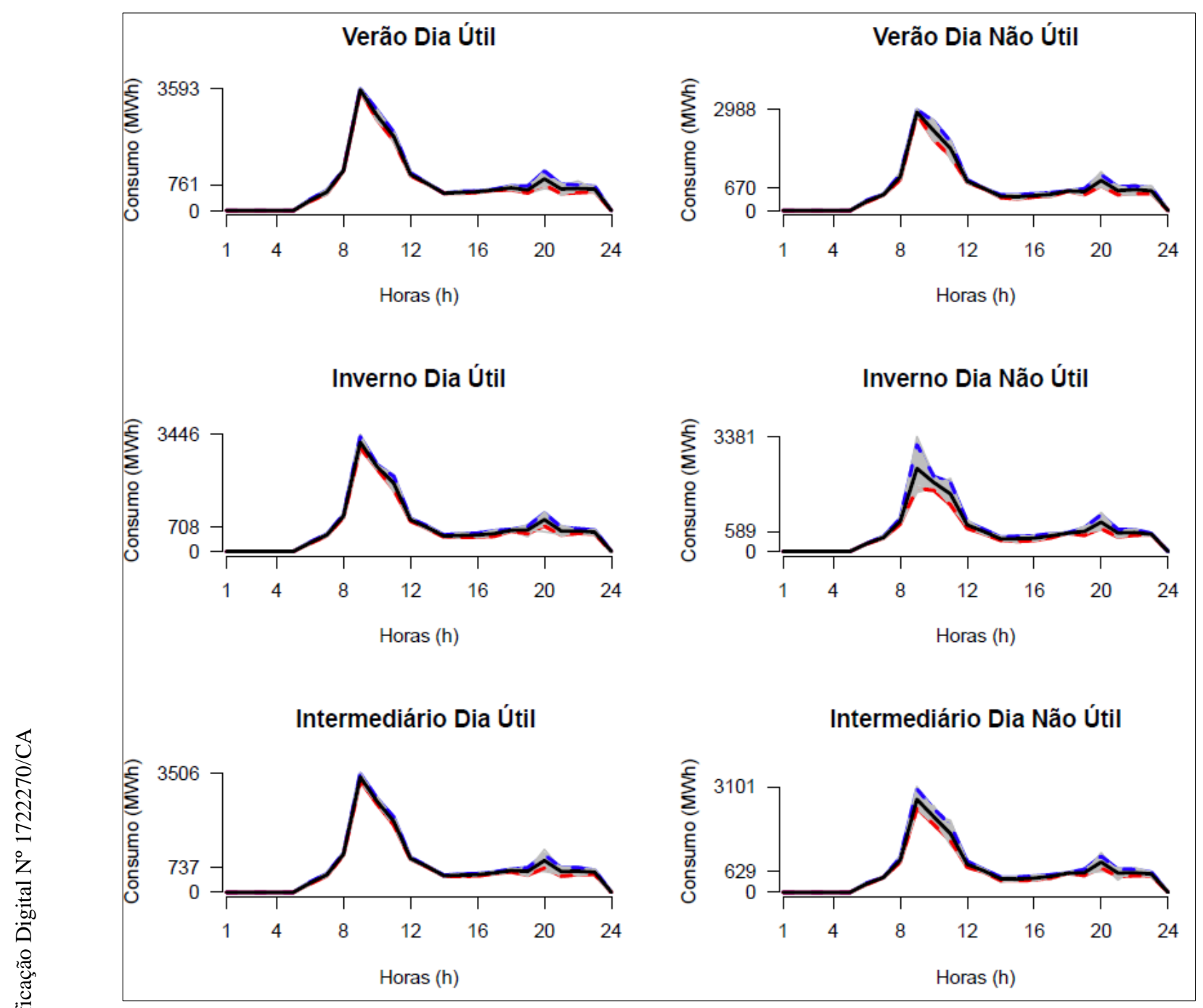

Figura 39 - Perfis Médios Sintéticos Históricos: Lava Roupas (elaborado pelo autor, 2019). 


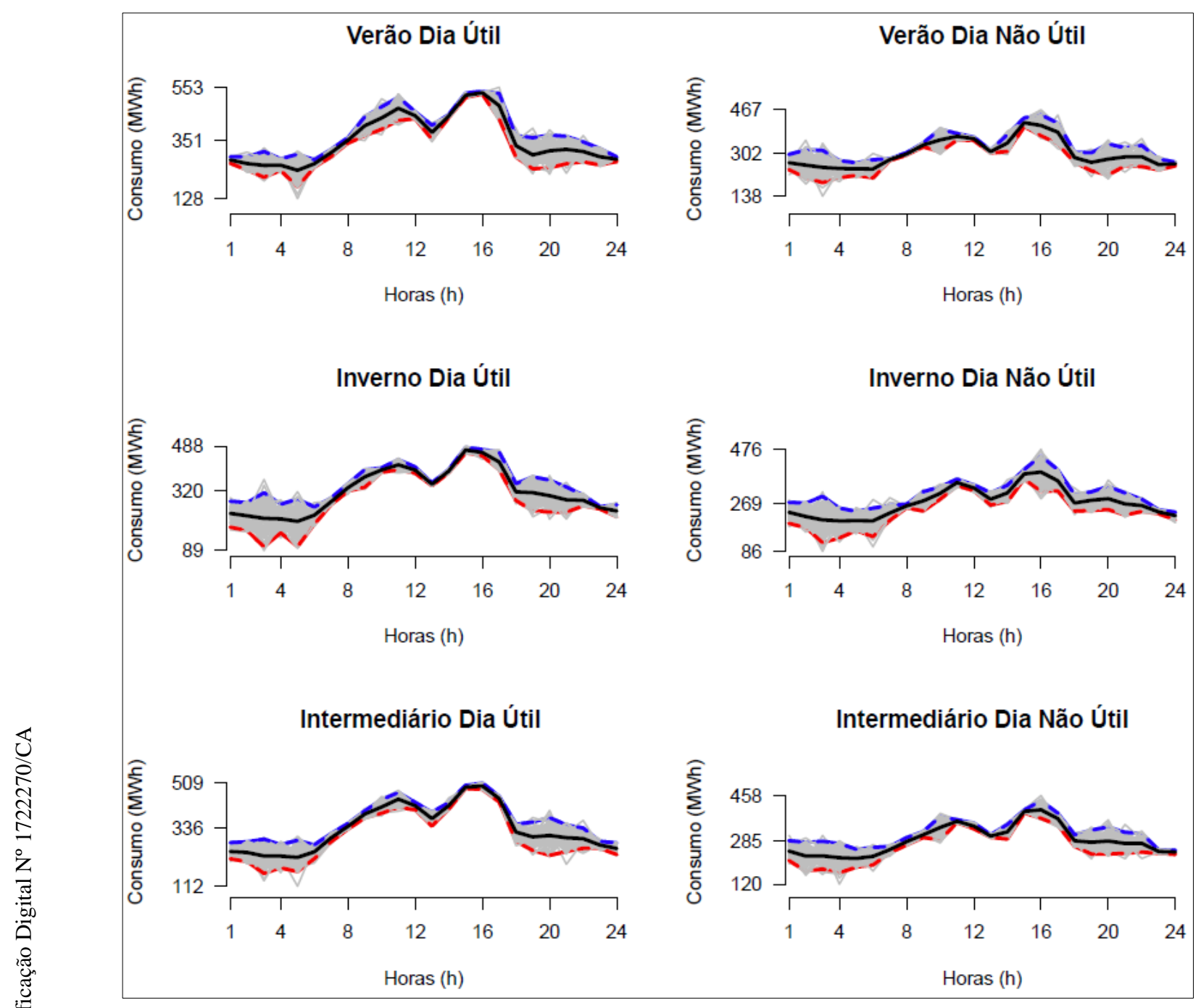

Figura 40 - Perfis Médios Sintéticos Históricos: Liga de Ferro (elaborado pelo autor, 2019). 

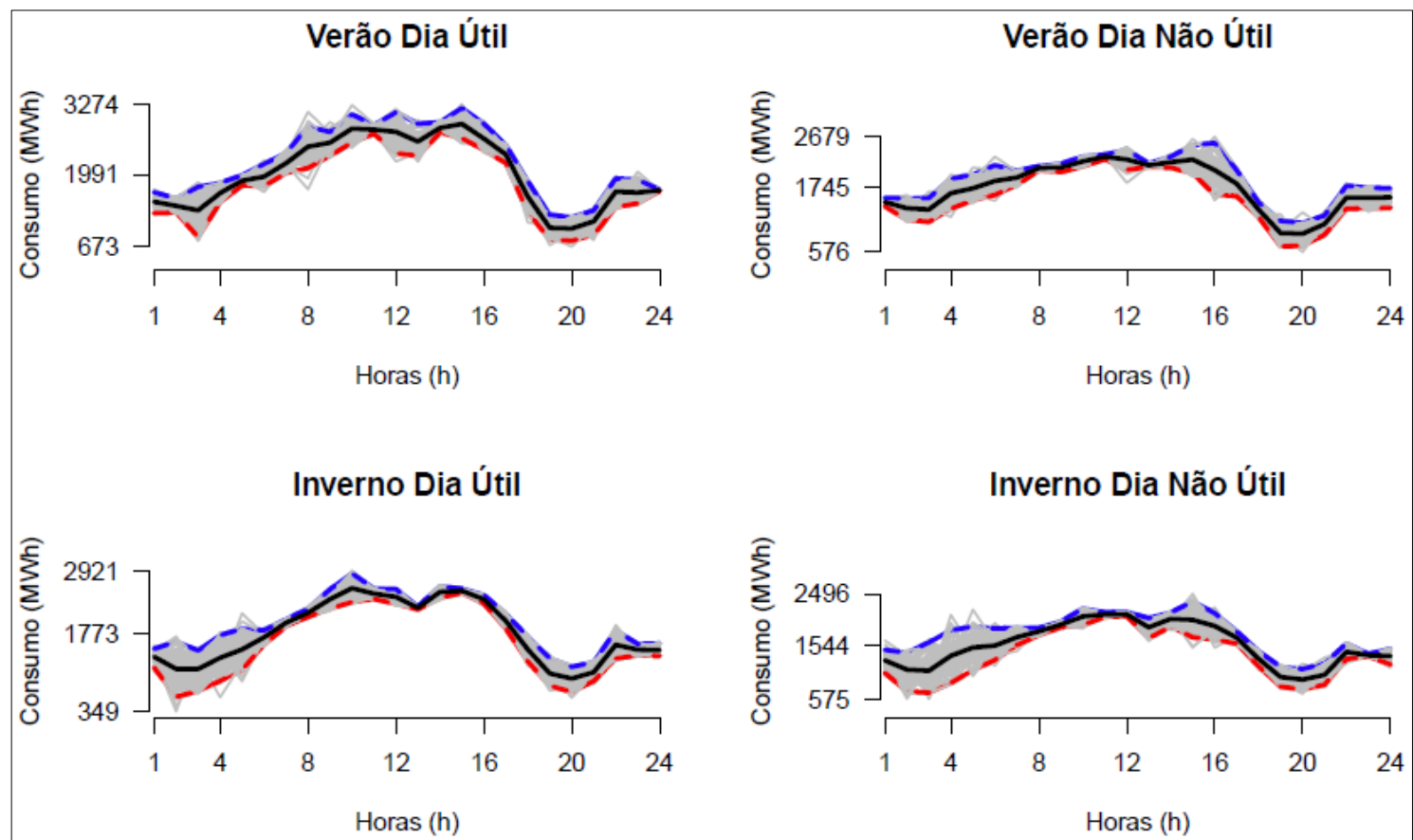

Intermediário Dia Útil

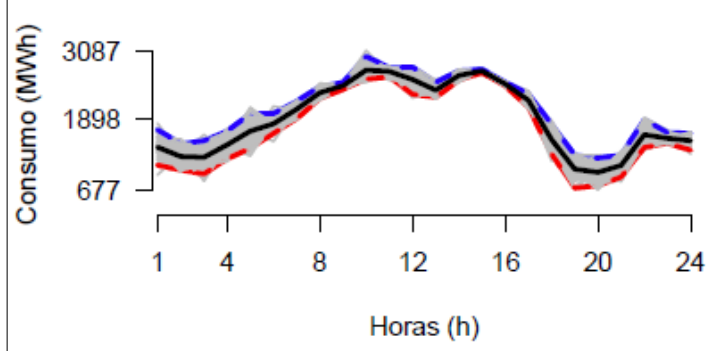

Intermediário Dia Não Útil

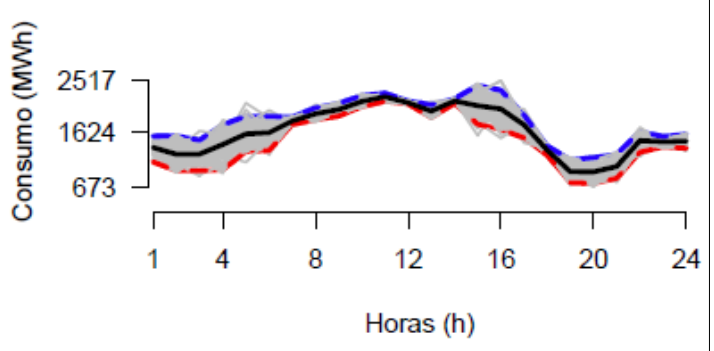

Figura 41 - Perfis Médios Sintéticos Históricos: Metais Não-Ferrosos (elaborado pelo autor, 2019). 


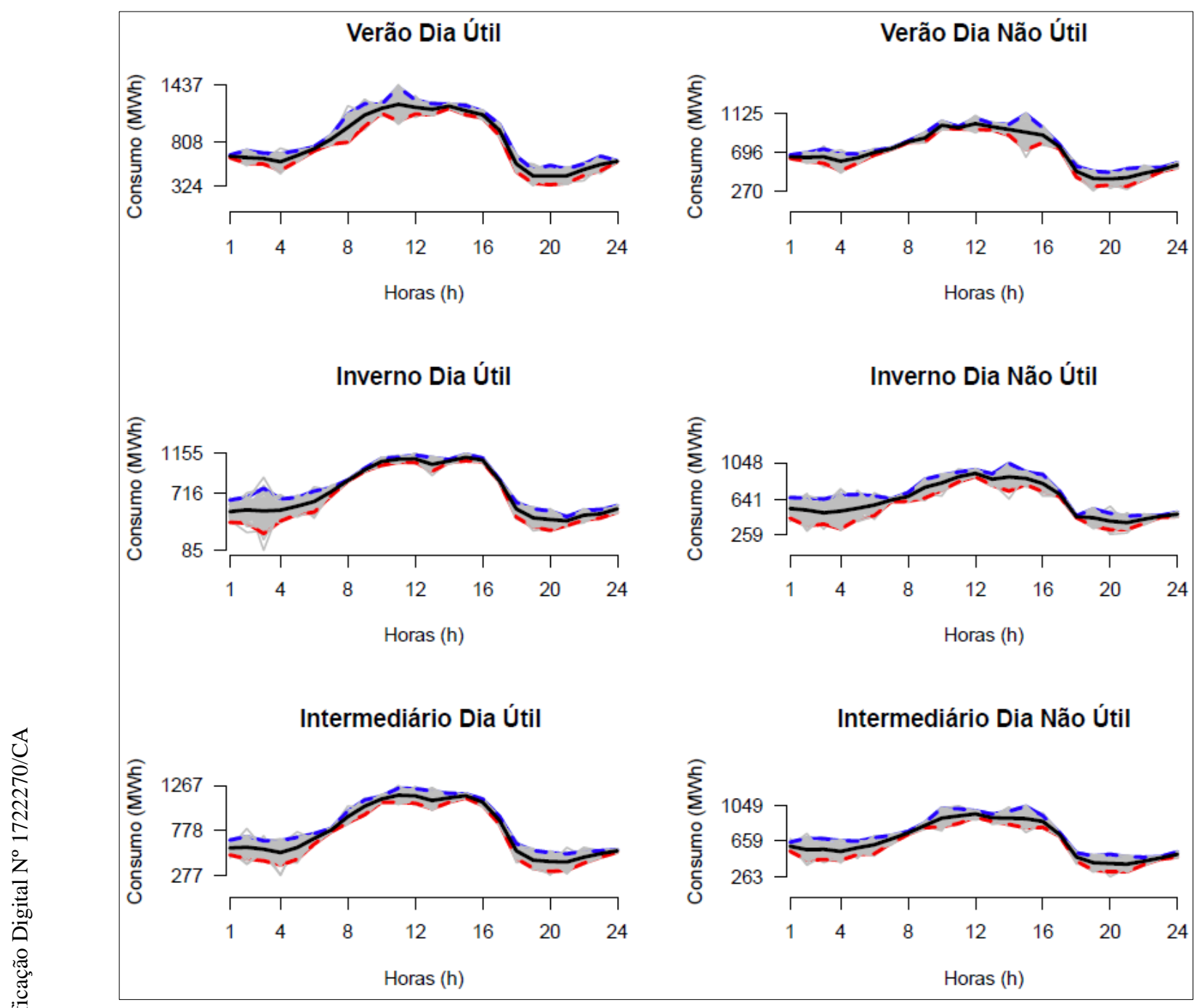

Figura 42 - Perfis Médios Sintéticos Históricos: Mineração e Peletização (elaborado pelo autor, 2019). 


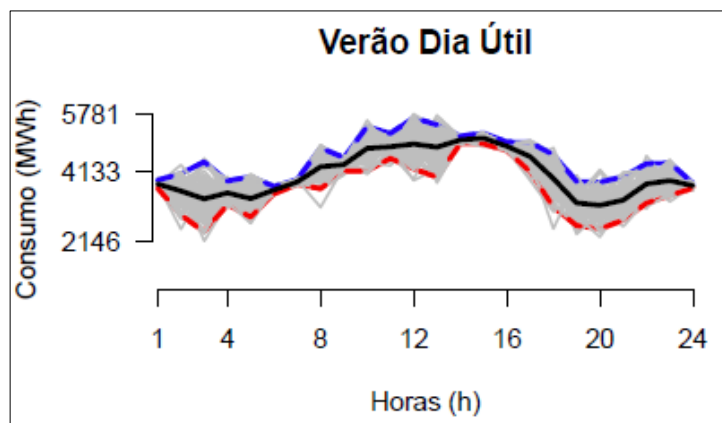

Verão Dia Não Útil

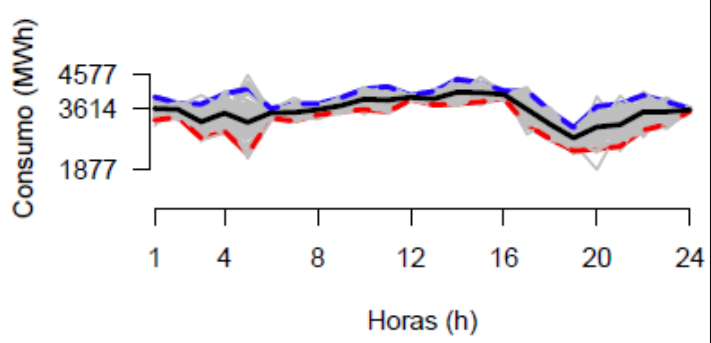

Inverno Dia Útil

Inverno Dia Não Útil
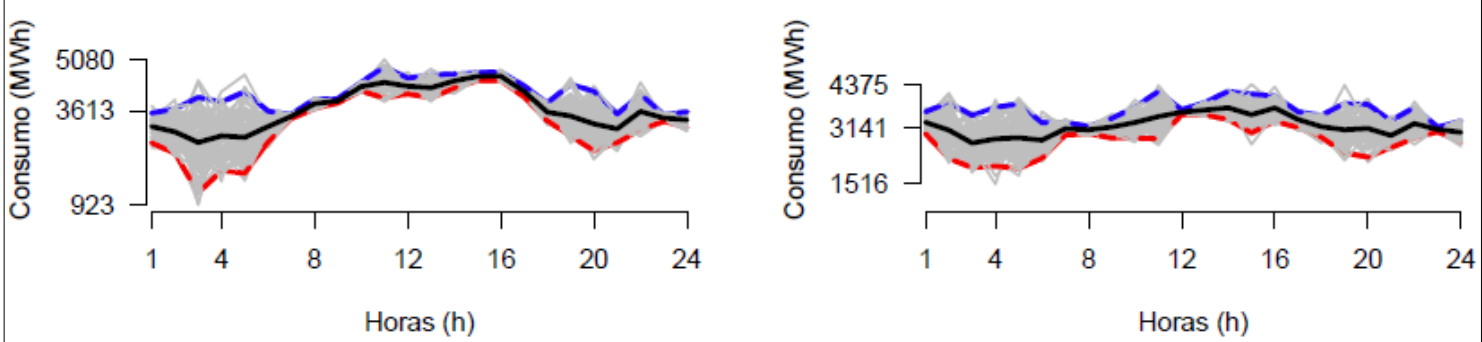

Intermediário Dia Útil

Intermediário Dia Não Útil
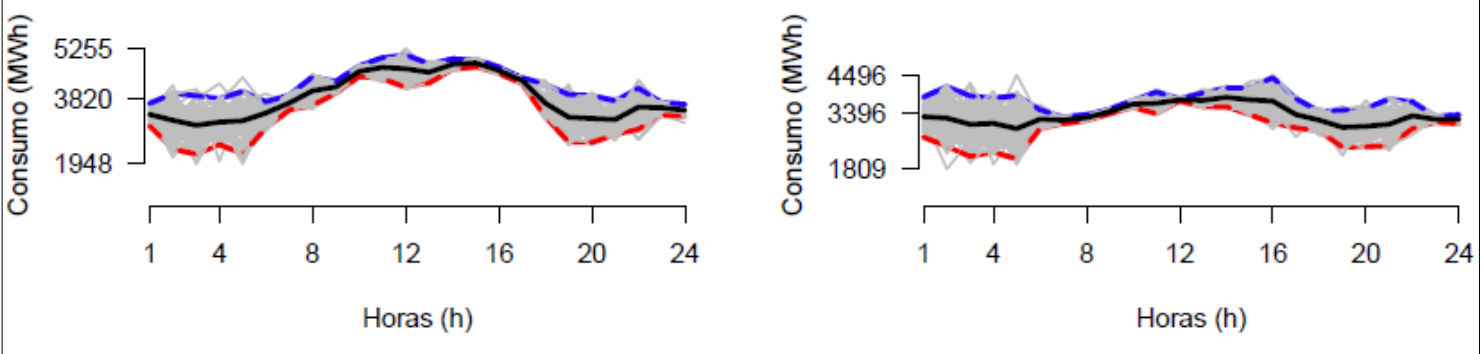

Figura 43 - Perfis Médios Sintéticos Históricos: Outros Industrial (elaborado pelo autor, 2019). 


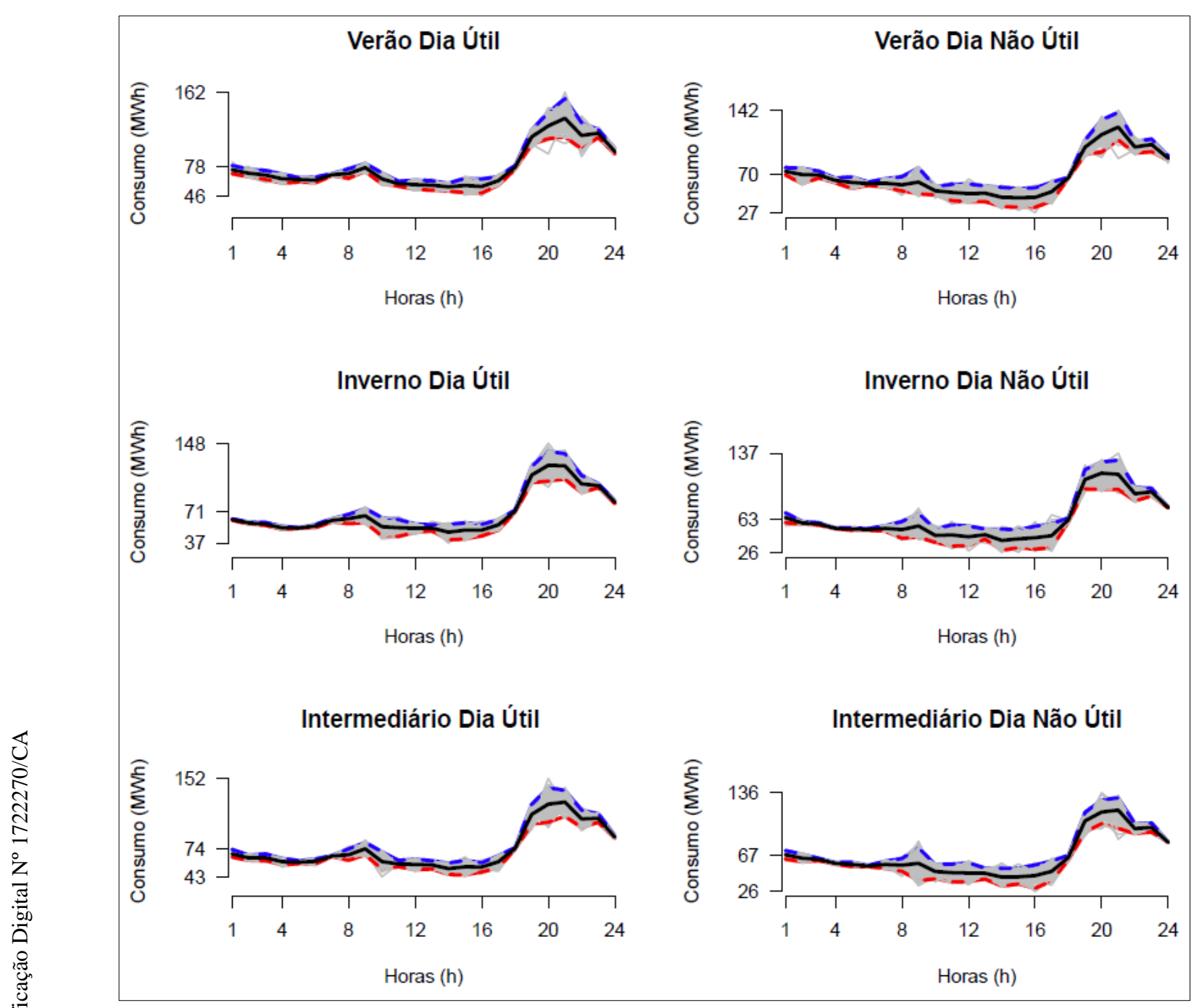

Figura 44 - Perfis Médios Sintéticos Históricos: Outros Residencial (elaborado pelo autor, 2019). 


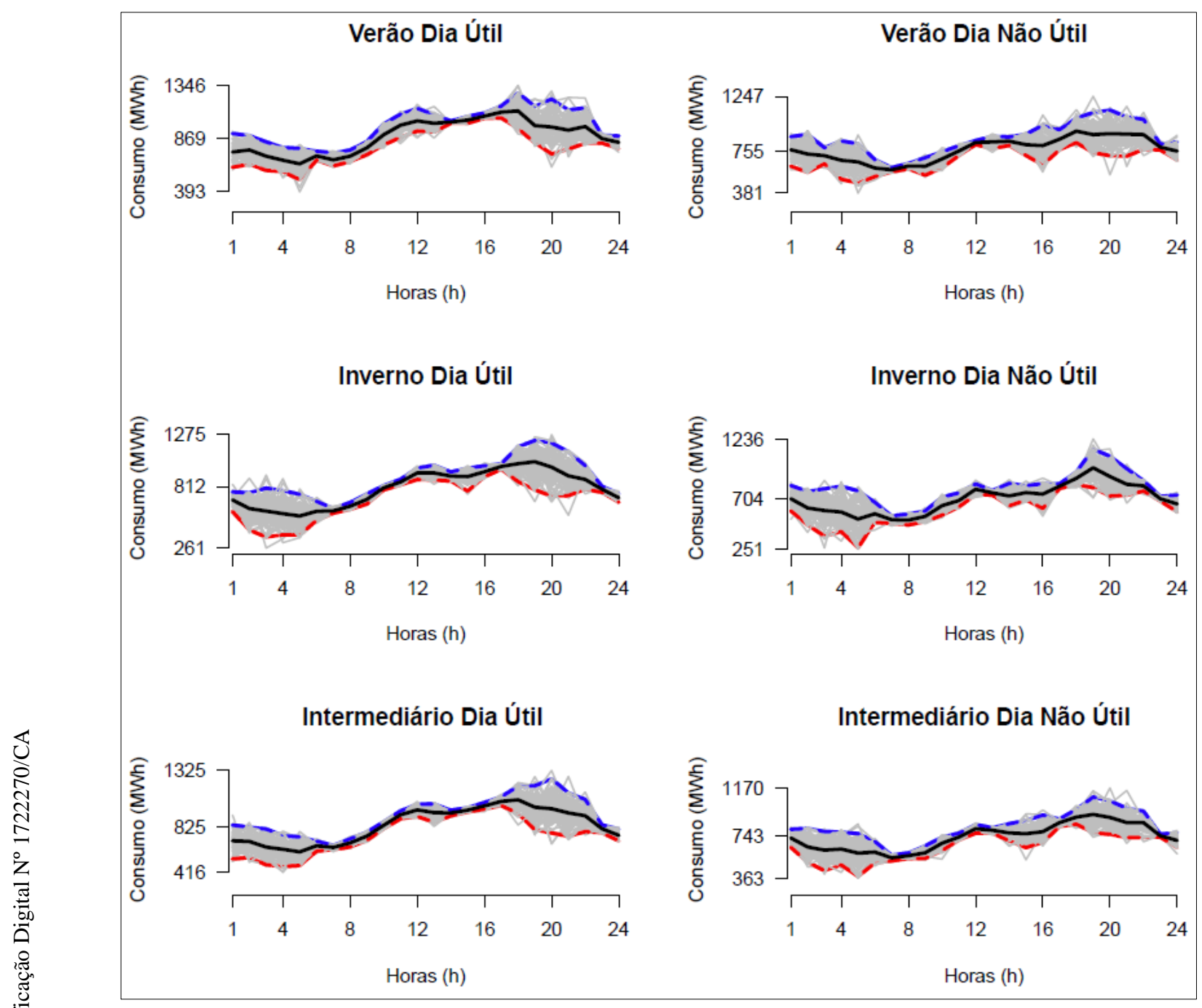

Figura 45 - Perfis Médios Sintéticos Históricos: Outros Terciário (elaborado pelo autor, 2019). 


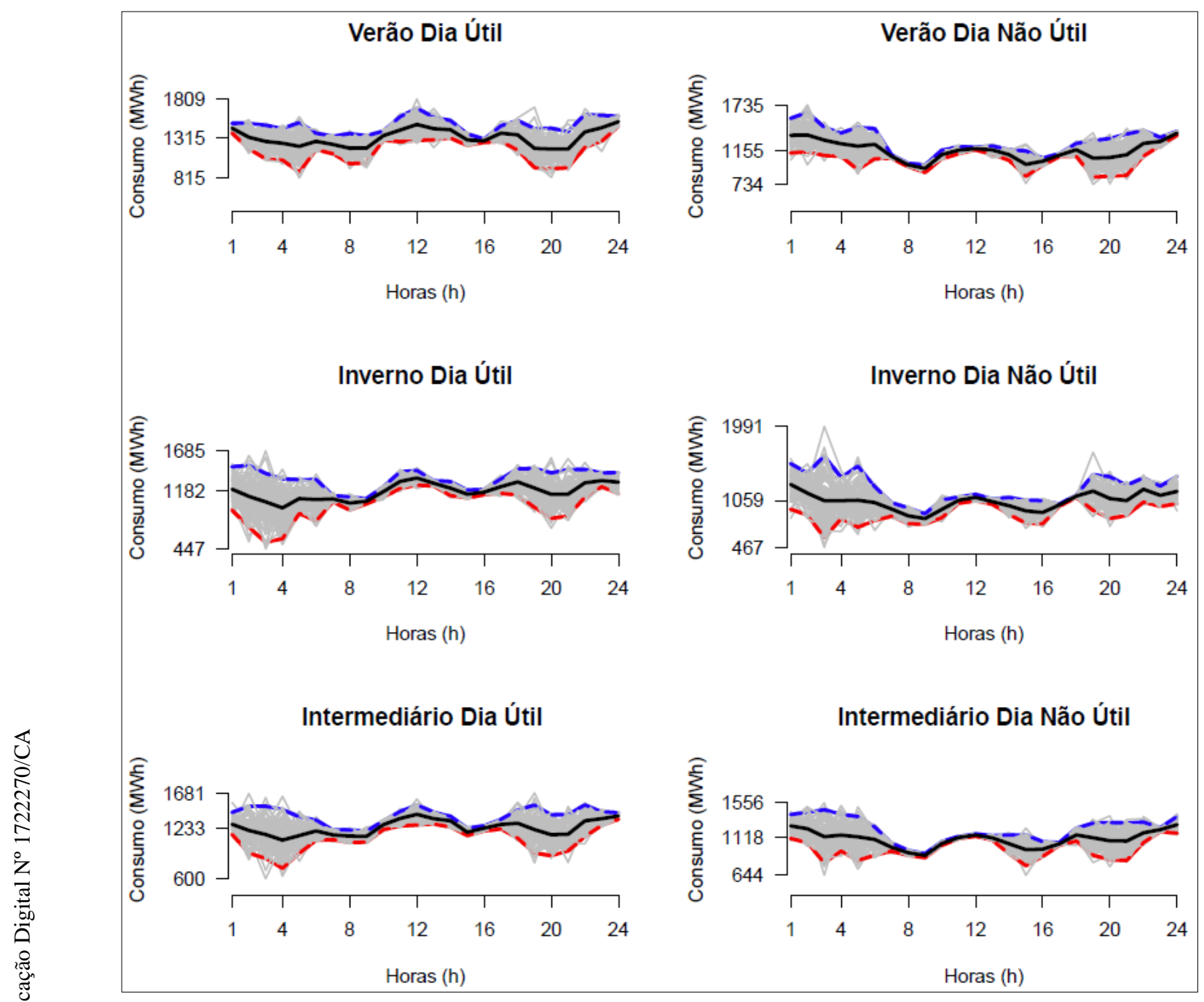

Figura 46 - Perfis Médios Sintéticos Históricos: Papel e Celulose (elaborado pelo autor, 2019). 


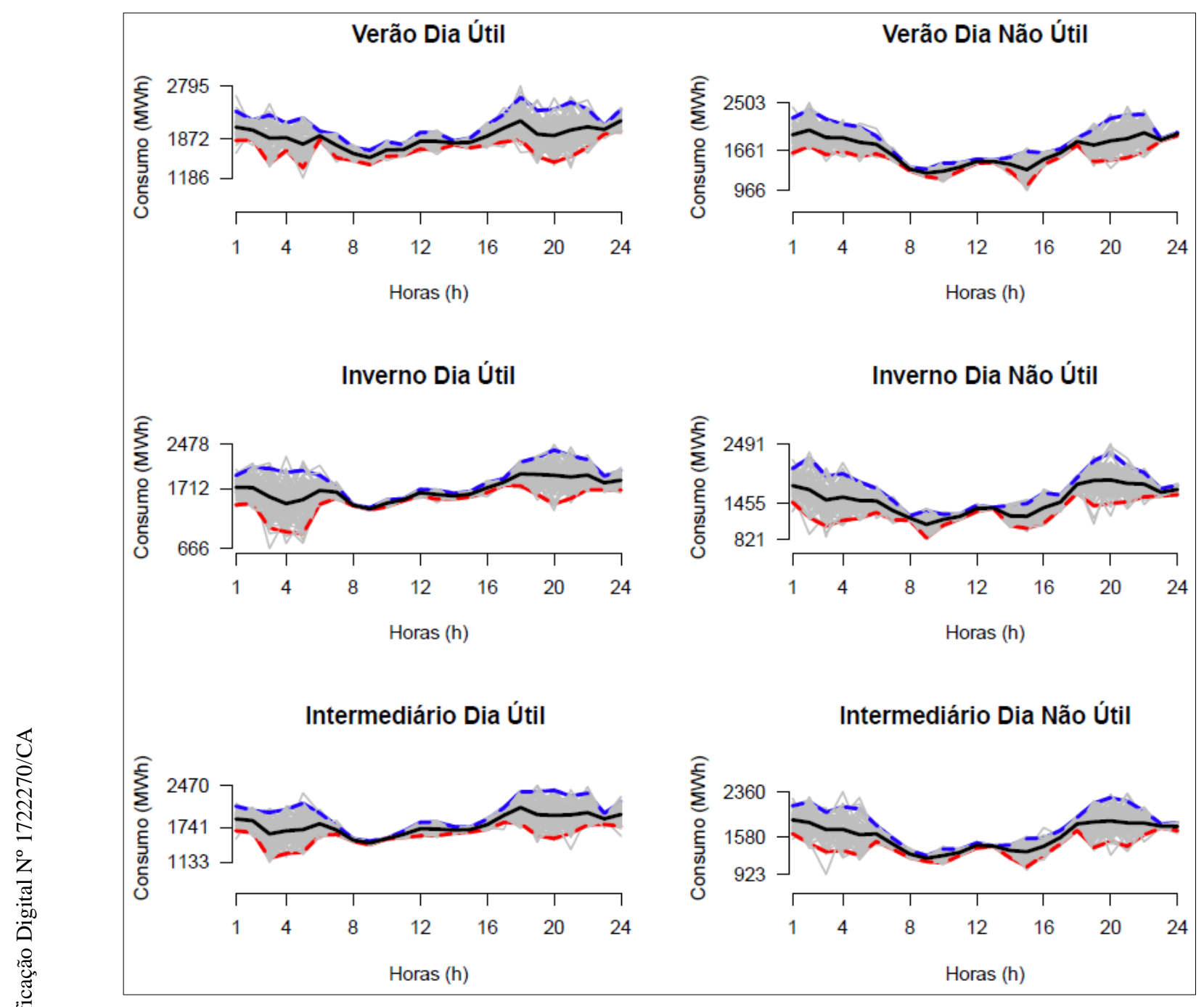

Figura 47 - Perfis Médios Sintéticos Históricos: Química (elaborado pelo autor, 2019). 


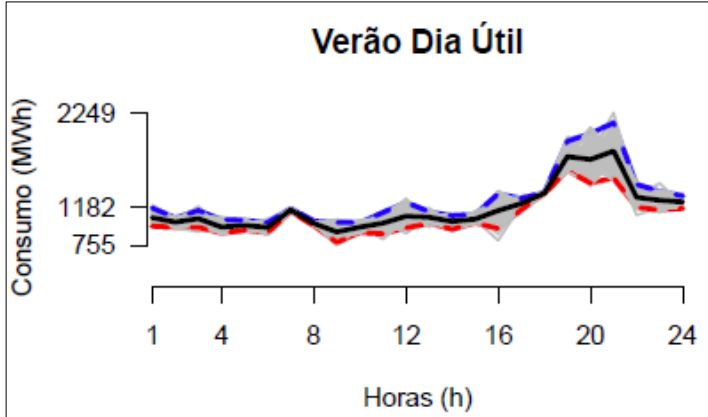

Verão Dia Não Útil

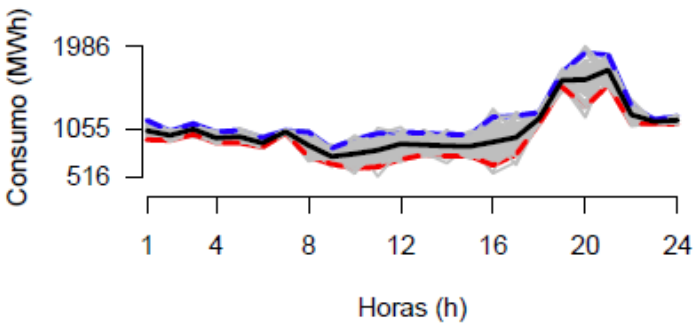

Inverno Dia Útil

Inverno Dia Não Útil
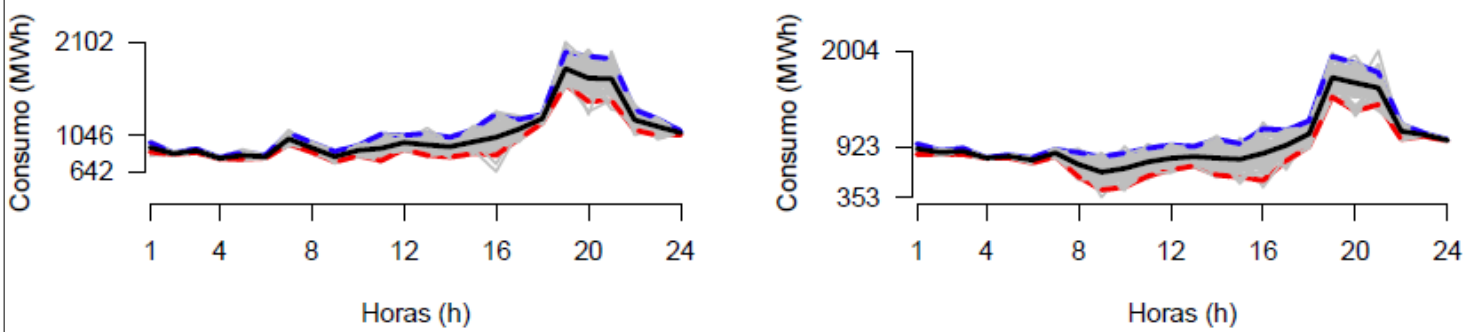

Intermediário Dia Útil

Intermediário Dia Não Útil
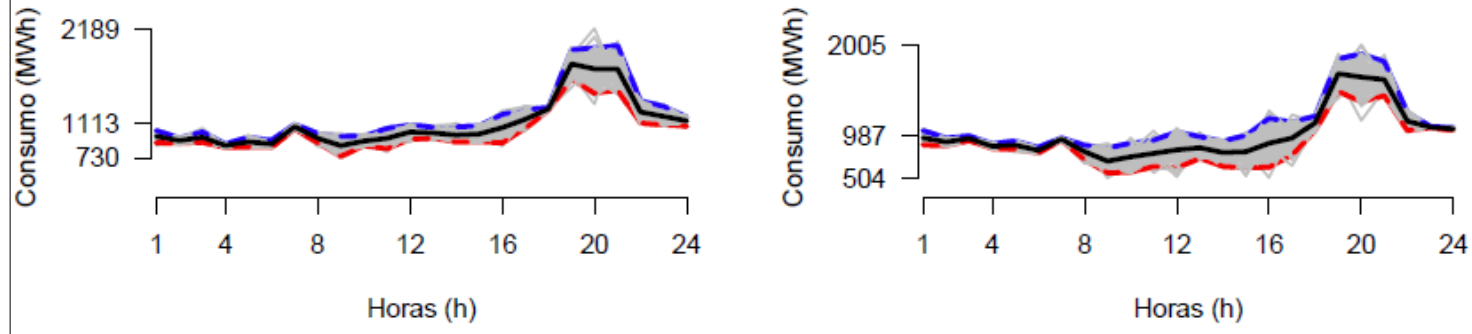

Figura 48 - Perfis Médios Sintéticos Históricos: Refrigerador (elaborado pelo autor, 2019). 


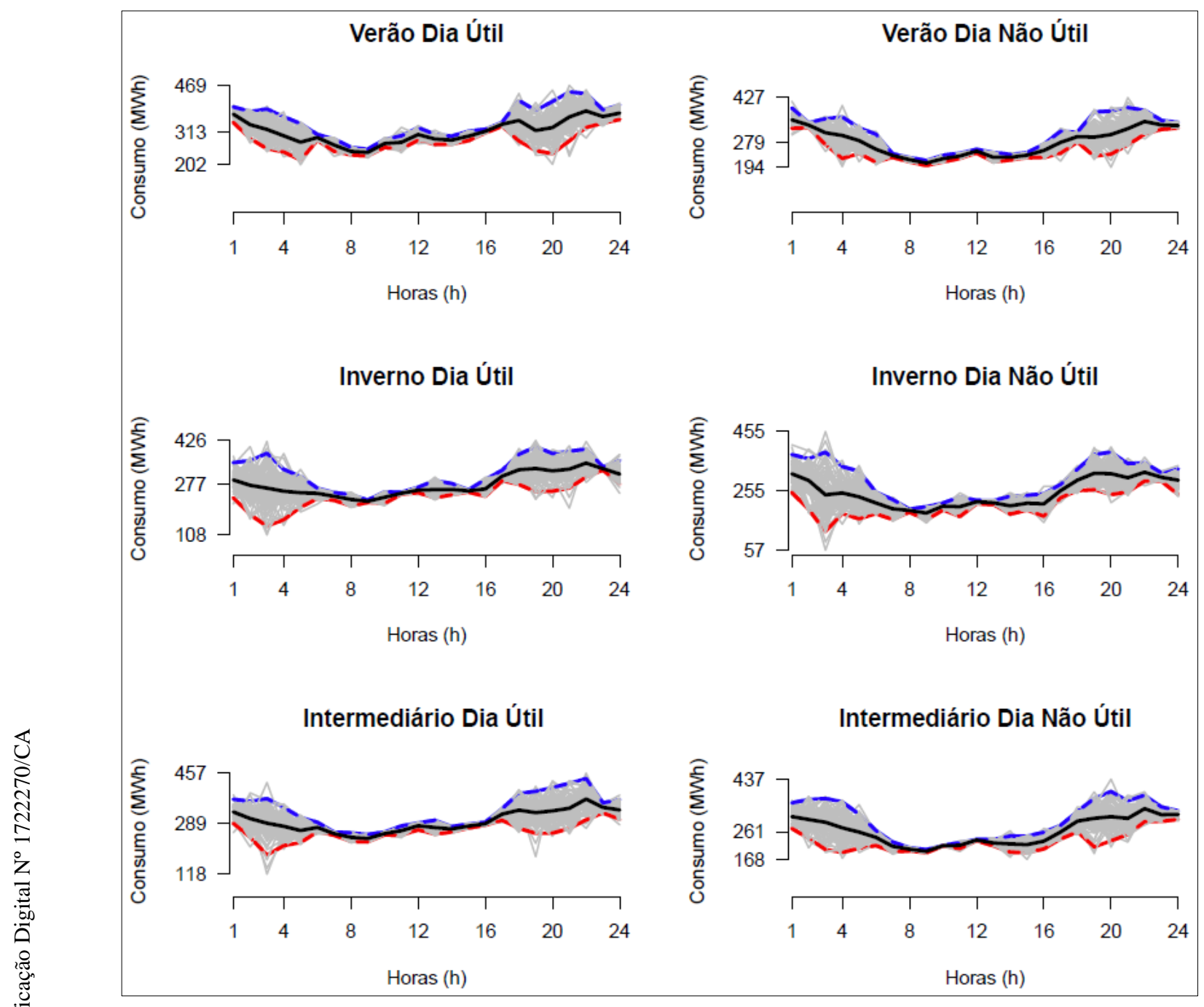

Figura 49 - Perfis Médios Sintéticos Históricos: Saúde (elaborado pelo autor, 2019). 


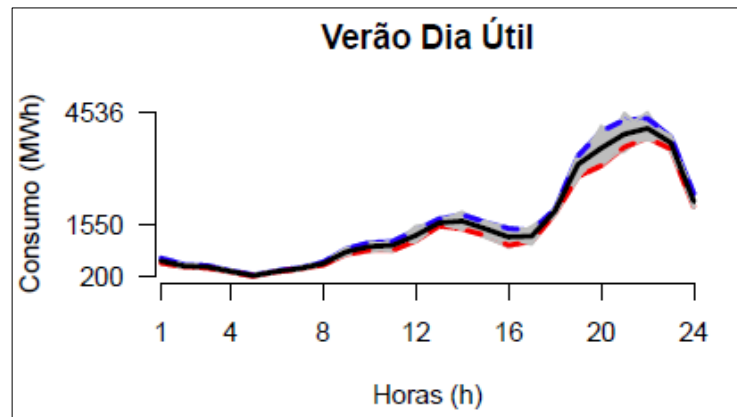

Verão Dia Não Útil

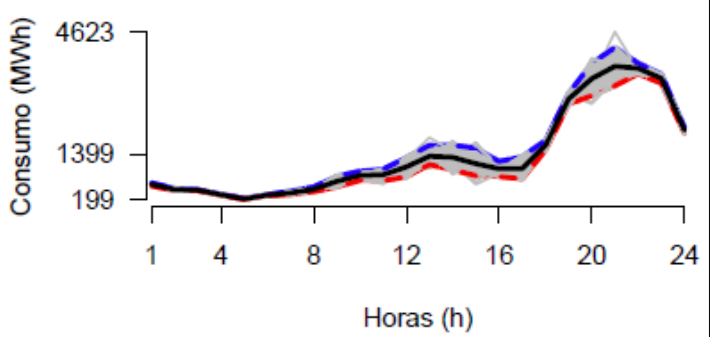

Inverno Dia Útil

Inverno Dia Não Útil
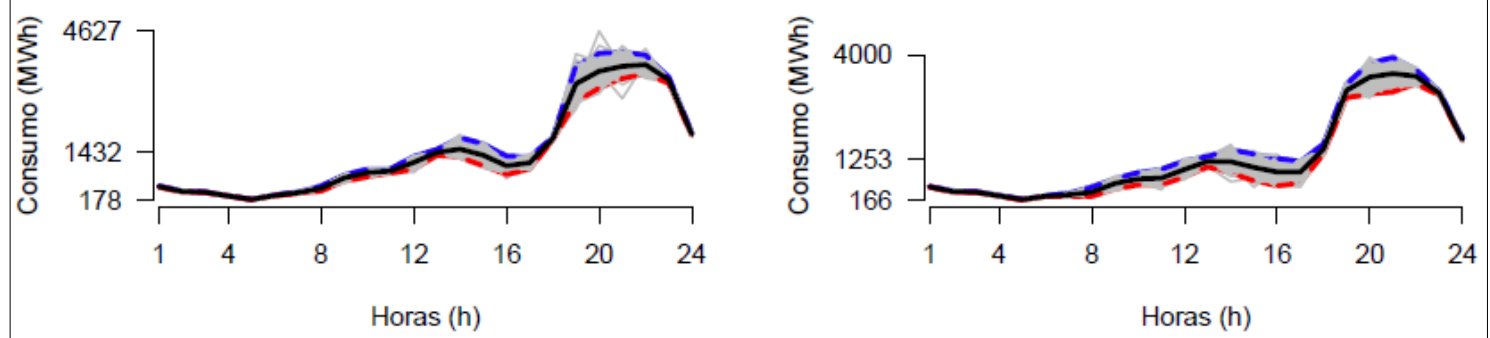

Intermediário Dia Útil

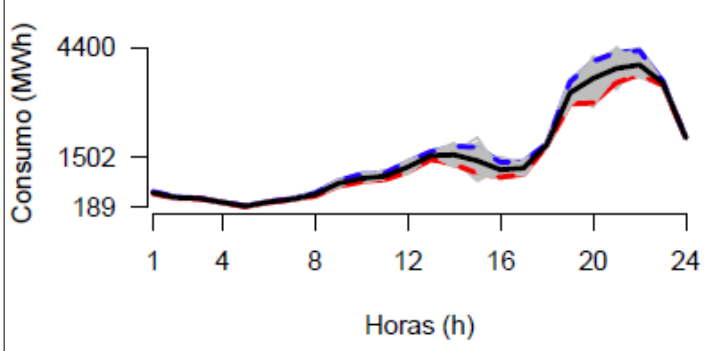

Intermediário Dia Não Útil

Figura 50 - Perfis Médios Sintéticos Históricos: Televisores (elaborado pelo autor, 2019). 


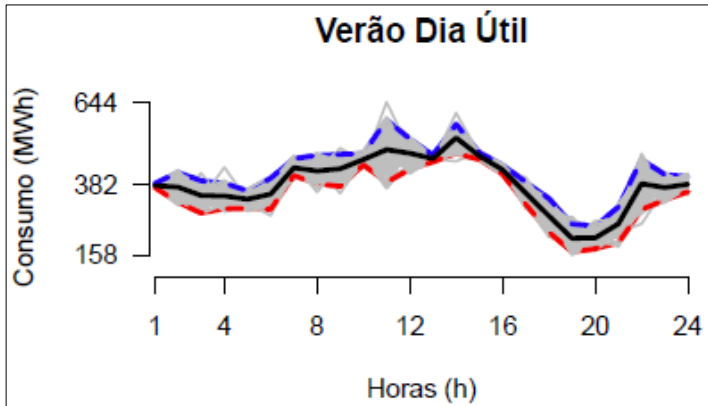

Inverno Dia Útil
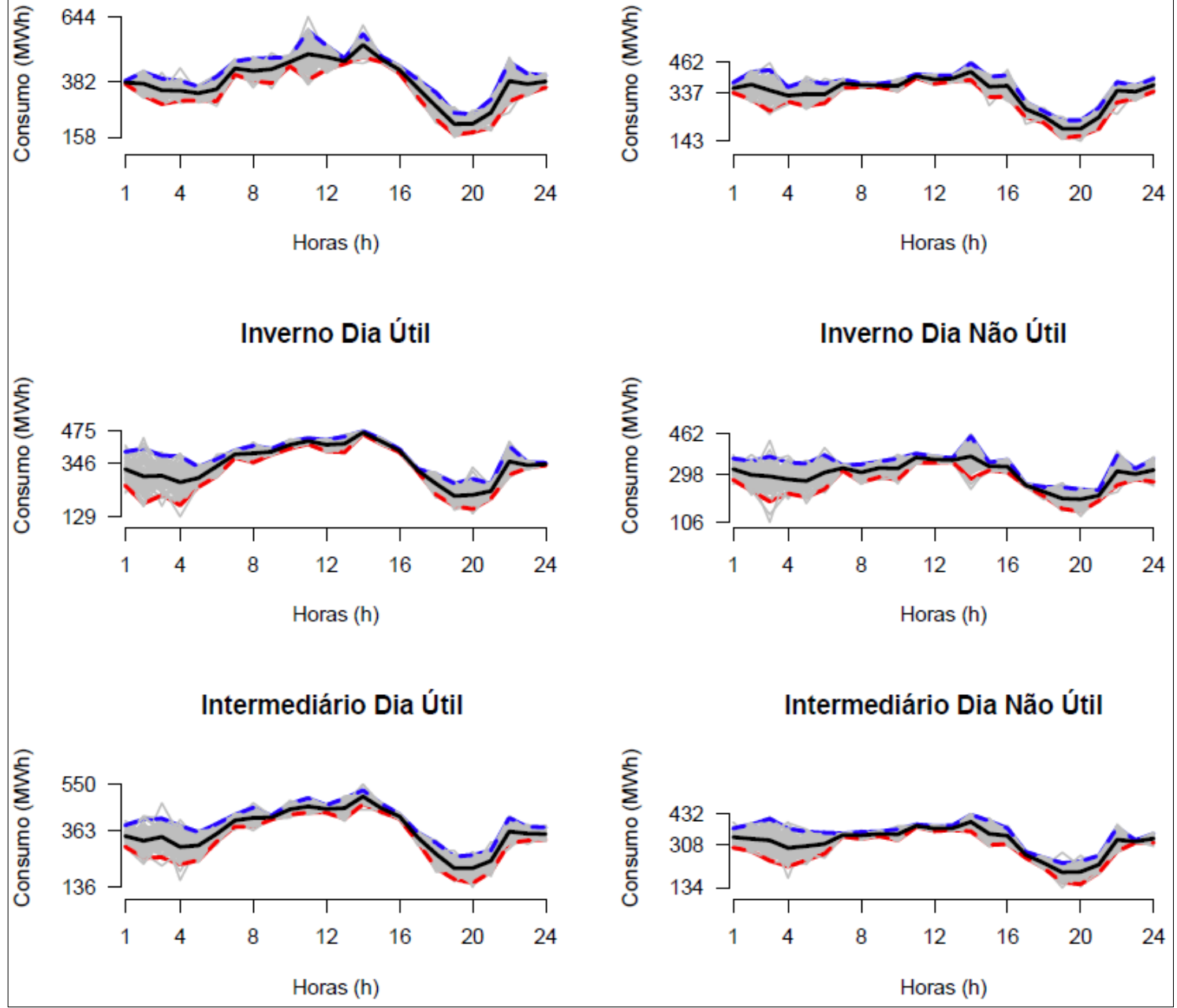

Figura 51 - Perfis Médios Sintéticos Históricos: Têxtil (elaborado pelo autor, 2019). 


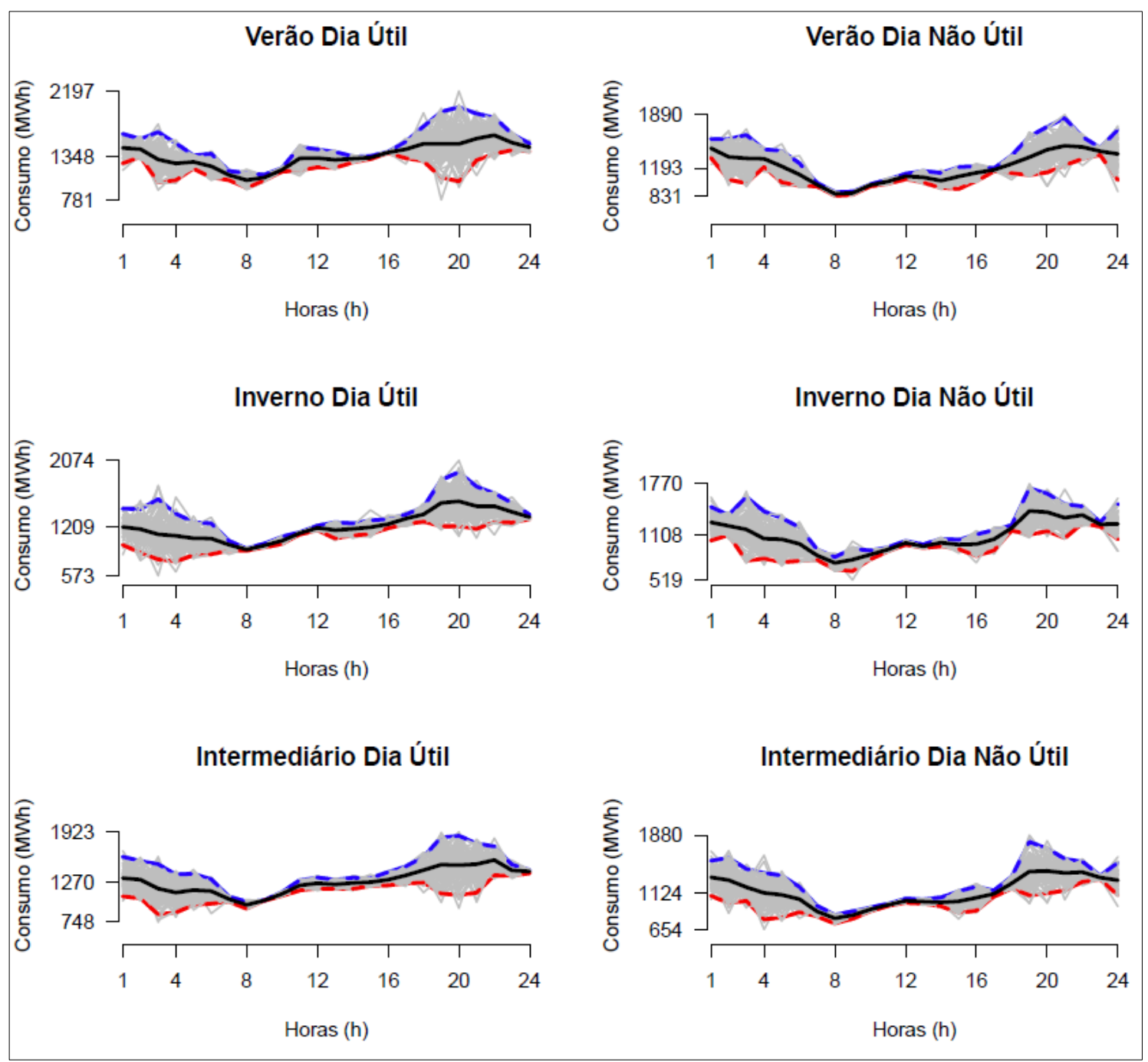

Figura 52 - Perfis Médios Sintéticos Históricos: Tráfego e Transmissão de Dados (elaborado pelo autor, 2019). 


\section{8 \\ Apêndice B}

Tabela 13 - Estatística dos Processos: Alimentos, bebidas e Tabaco (elaborado pelo autor, 2019).

\begin{tabular}{|l|r|r|r|r|}
\hline & $\mathbf{2 0 1 7}$ & $\mathbf{2 0 1 8}$ & $\mathbf{2 0 2 0}$ & Histórico \\
\hline Mínimo & 773,689 & 799,796 & 833,129 & 760,426 \\
\hline $\mathbf{1}^{\circ}$ Quartil & 1144,95 & 1183,8 & 1234,49 & 1126,77 \\
\hline Mediana & 1269,91 & 1315,13 & 1370,07 & 1250,51 \\
\hline Média & 1262,721 & 1305,918 & 1360,949 & 1242,078 \\
\hline $\mathbf{3}^{\circ}$ Quartil & 1383,21 & 1429,89 & 1489,85 & 1359,82 \\
\hline Máximo & 1749,8 & 1808,85 & 1884,23 & 1719,81 \\
\hline
\end{tabular}

Tabela 14 - Estatística dos Processos: Ar Condicionado (elaborado pelo autor, 2019).

\begin{tabular}{|l|r|r|r|r|}
\hline & $\mathbf{2 0 1 7}$ & $\mathbf{2 0 1 8}$ & $\mathbf{2 0 2 0}$ & Histórico \\
\hline Mínimo & 0 & 0 & 0 & 0 \\
\hline $\mathbf{1}^{\circ}$ Quartil & 143,835 & 157,989 & 183,043 & 133,25 \\
\hline Mediana & 341,276 & 370,229 & 428,93 & 312,259 \\
\hline Média & 1684,847 & 1828,091 & 2118,737 & 1542,351 \\
\hline $\mathbf{3}^{\circ}$ Quartil & 3783,92 & 4104,67 & 4768,89 & 3471,85 \\
\hline Máximo & 5390,13 & 5847,02 & 6773,12 & 4930,96 \\
\hline
\end{tabular}

Tabela 15 - Estatística dos Processos: Atacado e Varejo (elaborado pelo autor, 2019).

\begin{tabular}{|l|r|r|r|r|}
\hline & $\mathbf{2 0 1 7}$ & $\mathbf{2 0 1 8}$ & $\mathbf{2 0 2 0}$ & Histórico \\
\hline Mínimo & 1098,63 & 1113,33 & 1161,44 & 1084,65 \\
\hline $\mathbf{1}^{\circ}$ Quartil & 1950,86 & 1977,18 & 2062,58 & 1926,37 \\
\hline Mediana & 2437,9 & 2470,78 & 2577,5 & 2407,29 \\
\hline Média & 2490,743 & 2525,278 & 2635,408 & 2461,164 \\
\hline $\mathbf{3}^{\circ}$ Quartil & 2973,71 & 3014,02 & 3147,91 & 2936,74 \\
\hline Máximo & 4023,7 & 4077,53 & 4253,73 & 3972,49 \\
\hline
\end{tabular}


Tabela 16 - Estatística dos Processos: Cerâmica (elaborado pelo autor, 2019).

\begin{tabular}{|l|r|r|r|r|}
\hline & $\mathbf{2 0 1 7}$ & $\mathbf{2 0 1 8}$ & $\mathbf{2 0 2 0}$ & Histórico \\
\hline Mínimo & 68,2015 & 69,7104 & 71,1738 & 67,5896 \\
\hline $\mathbf{1}^{\circ}$ Quartil & 126,12 & 129,079 & 131,79 & 125,153 \\
\hline Mediana & 163,736 & 167,384 & 170,926 & 162,311 \\
\hline Média & 258,92 & 264,7891 & 270,5158 & 256,8442 \\
\hline $\mathbf{3}^{\circ}$ Quartil & 400,739 & 410,324 & 418,983 & 397,866 \\
\hline Máximo & 639,668 & 653,82 & 667,545 & 633,929 \\
\hline
\end{tabular}

Tabela 17 - Estatística dos Processos: Chuveiro Elétrico (elaborado pelo autor, 2019).

\begin{tabular}{|l|r|r|r|r|}
\hline & $\mathbf{2 0 1 7}$ & $\mathbf{2 0 1 8}$ & $\mathbf{2 0 2 0}$ & Histórico \\
\hline Mínimo & 0 & 0 & 0 & 0 \\
\hline $\mathbf{1}^{\circ}$ Quartil & 57,6663 & 53,7136 & 46,0733 & 61,5208 \\
\hline Mediana & 231,24 & 215,412 & 184,775 & 246,733 \\
\hline Média & 865,2752 & 806,2994 & 691,8035 & 923,735 \\
\hline $\mathbf{3}^{\circ}$ Quartil & 851,108 & 792,828 & 680,057 & 908,095 \\
\hline Máximo & 4449,95 & 4144,93 & 3555,34 & 4747,38 \\
\hline
\end{tabular}

Tabela 18 - Estatística dos Processos: Cimento (elaborado pelo autor, 2019).

\begin{tabular}{|l|r|r|r|r|}
\hline & $\mathbf{2 0 1 7}$ & $\mathbf{2 0 1 8}$ & $\mathbf{2 0 2 0}$ & Histórico \\
\hline Mínimo & 233,488 & 245,826 & 266,332 & 224,811 \\
\hline $\mathbf{1}^{\circ}$ Quartil & 421,648 & 443,98 & 481,015 & 406,025 \\
\hline Mediana & 531,01 & 561,113 & 608,068 & 513,254 \\
\hline Média & 518,439 & 546,1006 & 591,9791 & 499,6389 \\
\hline $\mathbf{3}^{\circ}$ Quartil & 609,368 & 641,644 & 695,706 & 586,867 \\
\hline Máximo & 792,698 & 834,587 & 904,206 & 763,24 \\
\hline
\end{tabular}


Tabela 19 - Estatística dos Processos: Educação (elaborado pelo autor, 2019).

\begin{tabular}{|l|r|r|r|r|}
\hline & $\mathbf{2 0 1 7}$ & $\mathbf{2 0 1 8}$ & $\mathbf{2 0 2 0}$ & Histórico \\
\hline Mínimo & 101,938 & 103,102 & 107,419 & 100,77 \\
\hline $\mathbf{1}^{\circ}$ Quartil & 202,134 & 204,442 & 213,002 & 199,818 \\
\hline Mediana & 386,017 & 390,45 & 406,123 & 381,642 \\
\hline Média & 360,5356 & 364,8151 & 380,3096 & 356,692 \\
\hline $\mathbf{3}^{\circ}$ Quartil & 494,497 & 500,997 & 522,055 & 489,695 \\
\hline Máximo & 646,488 & 653,869 & 681,246 & 639,08 \\
\hline
\end{tabular}

Tabela 20 - Estatística dos Processos: Escritório Público (elaborado pelo autor, 2019).

\begin{tabular}{|l|r|r|r|r|}
\hline & $\mathbf{2 0 1 7}$ & $\mathbf{2 0 1 8}$ & $\mathbf{2 0 2 0}$ & Histórico \\
\hline Mínimo & 258,854 & 265,005 & 282,047 & 254,31 \\
\hline $\mathbf{1}^{\circ}$ Quartil & 482,518 & 493,984 & 525,75 & 474,048 \\
\hline Mediana & 611,055 & 625,633 & 666,052 & 600,441 \\
\hline Média & 618,6137 & 633,5865 & 674,7019 & 608,2315 \\
\hline $\mathbf{3}^{\circ}$ Quartil & 754,763 & 775,07 & 825,144 & 743,861 \\
\hline Máximo & 978,348 & 1001,59 & 1066 & 961,174 \\
\hline
\end{tabular}

Tabela 21 - Estatística dos Processos: Ferro e Aço (elaborado pelo autor, 2019).

\begin{tabular}{|l|r|r|r|r|}
\hline & $\mathbf{2 0 1 7}$ & $\mathbf{2 0 1 8}$ & $\mathbf{2 0 2 0}$ & Histórico \\
\hline Mínimo & 409,892 & 422,983 & 441,078 & 401,055 \\
\hline $\mathbf{1}^{\circ}$ Quartil & 846,101 & 872,964 & 910,116 & 827,574 \\
\hline Mediana & 1033,87 & 1067,3 & 1112,53 & 1012,3 \\
\hline Média & 1010,176 & 1042,76 & 1087,806 & 989,0042 \\
\hline $\mathbf{3}^{\circ}$ Quartil & 1195,93 & 1234,13 & 1289,61 & 1172,59 \\
\hline Máximo & 1648,24 & 1700,57 & 1772,94 & 1612,15 \\
\hline
\end{tabular}


Tabela 22 - Estatística dos Processos: Finanças (elaborado pelo autor, 2019).

\begin{tabular}{|l|r|r|r|r|}
\hline & $\mathbf{2 0 1 7}$ & $\mathbf{2 0 1 8}$ & $\mathbf{2 0 2 0}$ & Histórico \\
\hline Mínimo & 55,2328 & 56,2465 & 59,2366 & 54,3422 \\
\hline $\mathbf{1}^{\circ}$ Quartil & 96,1376 & 97,925 & 103,144 & 94,6251 \\
\hline Mediana & 121,569 & 123,817 & 130,425 & 119,642 \\
\hline Média & 142,4127 & 145,1036 & 152,9129 & 140,2549 \\
\hline $\mathbf{3}^{\circ}$ Quartil & 193,212 & 197,3 & 207,815 & 190,652 \\
\hline Máximo & 259,273 & 264,032 & 278,068 & 255,093 \\
\hline
\end{tabular}

Tabela 23 - Estatística dos Processos: Freezer (elaborado pelo autor, 2019).

\begin{tabular}{|l|r|r|r|r|}
\hline & $\mathbf{2 0 1 7}$ & $\mathbf{2 0 1 8}$ & $\mathbf{2 0 2 0}$ & Histórico \\
\hline Mínimo & 134,673 & 131,355 & 124,367 & 137,441 \\
\hline $\mathbf{1}^{\circ}$ Quartil & 220,722 & 215,284 & 203,986 & 225,26 \\
\hline Mediana & 244,465 & 238,458 & 226,414 & 250,22 \\
\hline Média & 243,4057 & 237,4995 & 224,9691 & 248,5955 \\
\hline $\mathbf{3}^{\circ}$ Quartil & 271,136 & 264,472 & 250,42 & 276,743 \\
\hline Máximo & 323,024 & 315,066 & 298,304 & 329,665 \\
\hline
\end{tabular}

Tabela 24 - Estatística dos Processos: Hotel, Café e Restaurante (elaborado pelo autor, 2019).

\begin{tabular}{|l|r|r|r|r|}
\hline & $\mathbf{2 0 1 7}$ & $\mathbf{2 0 1 8}$ & $\mathbf{2 0 2 0}$ & Histórico \\
\hline Mínimo & 1184,28 & 1196,73 & 1245,28 & 1173,68 \\
\hline $\mathbf{1}^{\circ}$ Quartil & 1976,35 & 1997,38 & 2078,69 & 1960,965 \\
\hline Mediana & 2322,19 & 2351,83 & 2449,9 & 2306,78 \\
\hline Média & 2309,597 & 2334,943 & 2430,963 & 2290,902 \\
\hline $\mathbf{3}^{\circ}$ Quartil & 2631,66 & 2659,84 & 2768,9 & 2609,07 \\
\hline Máximo & 3610,66 & 3648,63 & 3796,66 & 3578,35 \\
\hline
\end{tabular}


Tabela 25 - Estatística dos Processos: lluminação (elaborado pelo autor, 2019).

\begin{tabular}{|l|r|r|r|r|}
\hline & $\mathbf{2 0 1 7}$ & $\mathbf{2 0 1 8}$ & $\mathbf{2 0 2 0}$ & Histórico \\
\hline Mínimo & 480,523 & 508,241 & 561,847 & 456,286 \\
\hline $\mathbf{1}^{\circ}$ Quartil & 813,538 & 863,756 & 951,221 & 775,458 \\
\hline Mediana & 1106,59 & 1170,37 & 1296,33 & 1052,73 \\
\hline Média & 1612,794 & 1706,341 & 1886,975 & 1532,303 \\
\hline $\mathbf{3}^{\circ}$ Quartil & 1959,588 & 2072,645 & 2291,355 & 1860,798 \\
\hline Máximo & 4712,22 & 4983,83 & 5509,42 & 4474,27 \\
\hline
\end{tabular}

Tabela 26 - Estatística dos Processos: Lava Roupas (elaborado pelo autor, 2019).

\begin{tabular}{|l|r|r|r|r|}
\hline & $\mathbf{2 0 1 7}$ & $\mathbf{2 0 1 8}$ & $\mathbf{2 0 2 0}$ & Histórico \\
\hline Mínimo & 0 & 0 & 0 & 0 \\
\hline $\mathbf{1}^{\circ}$ Quartil & 173,5898 & 175,671 & 178,0448 & 170,5973 \\
\hline Mediana & 565,071 & 571,899 & 579,578 & 555,393 \\
\hline Média & 723,872 & 732,9494 & 743,1061 & 712,0138 \\
\hline $\mathbf{3}^{\circ}$ Quartil & 808,692 & 823,641 & 834,7 & 799,869 \\
\hline Máximo & 3660,99 & 3705,23 & 3754,98 & 3598,3 \\
\hline
\end{tabular}

Tabela 27 - Estatística dos Processos: Liga de Ferro (elaborado pelo autor, 2019).

\begin{tabular}{|l|r|r|r|r|}
\hline & $\mathbf{2 0 1 7}$ & $\mathbf{2 0 1 8}$ & $\mathbf{2 0 2 0}$ & Histórico \\
\hline Mínimo & 148,005 & 154,123 & 161,864 & 144,474 \\
\hline $\mathbf{1}^{\circ}$ Quartil & 262,054 & 272,898 & 286,651 & 256,542 \\
\hline Mediana & 305,006 & 317,649 & 333,68 & 297,786 \\
\hline Média & 327,3614 & 341,0378 & 358,379 & 319,7965 \\
\hline $\mathbf{3}^{\circ}$ Quartil & 396,477 & 412,882 & 433,69 & 387,043 \\
\hline Máximo & 553,88 & 576,84 & 605,951 & 540,768 \\
\hline
\end{tabular}


Tabela 28 - Estatística dos Processos: Metais Não-Ferrosos (elaborado pelo autor, 2019).

\begin{tabular}{|l|r|r|r|r|}
\hline & $\mathbf{2 0 1 7}$ & $\mathbf{2 0 1 8}$ & $\mathbf{2 0 2 0}$ & Histórico \\
\hline Mínimo & 827,334 & 856,568 & 897,641 & 808,256 \\
\hline $\mathbf{1}^{\circ}$ Quartil & 1408,44 & 1458,1 & 1528,07 & 1375,83 \\
\hline Mediana & 1795,15 & 1858,14 & 1946,88 & 1752,98 \\
\hline Média & 1873,914 & 1940,753 & 2034,698 & 1831,87 \\
\hline $\mathbf{3}^{\circ}$ Quartil & 2385,21 & 2468,91 & 2586,82 & 2329,19 \\
\hline Máximo & 3188,75 & 3300,65 & 3458,28 & 3113,86 \\
\hline
\end{tabular}

Tabela 29 - Estatística dos Processos: Mineração e Peletização (elaborado pelo autor, 2019).

\begin{tabular}{|l|r|r|r|r|}
\hline & $\mathbf{2 0 1 7}$ & $\mathbf{2 0 1 8}$ & $\mathbf{2 0 2 0}$ & Histórico \\
\hline Mínimo & 346,082 & 355,982 & 368,385 & 340,632 \\
\hline $\mathbf{1}^{\circ}$ Quartil & 520,559 & 535,577 & 554,411 & 512,618 \\
\hline Mediana & 665,288 & 684,32 & 708,162 & 654,812 \\
\hline Média & 750,3278 & 772,2015 & 799,5611 & 739,2515 \\
\hline $\mathbf{3}^{\circ}$ Quartil & 985,928 & 1014,37 & 1050,04 & 972,63 \\
\hline Máximo & 1366,53 & 1405,62 & 1454,59 & 1345,01 \\
\hline
\end{tabular}

Tabela 30 - Estatística dos Processos: Outros Industrial (elaborado pelo autor, 2019).

\begin{tabular}{|l|r|r|r|r|}
\hline & $\mathbf{2 0 1 7}$ & $\mathbf{2 0 1 8}$ & $\mathbf{2 0 2 0}$ & Histórico \\
\hline Mínimo & 1748,56 & 1799,62 & 1863,87 & 1720,2 \\
\hline $\mathbf{1}^{\circ}$ Quartil & 3321,5 & 3419,16 & 3542,21 & 3268,97 \\
\hline Mediana & 3683,48 & 3791,78 & 3928,24 & 3625,22 \\
\hline Média & 3772,637 & 3884,691 & 4025,504 & 3714,871 \\
\hline $\mathbf{3}^{\circ}$ Quartil & 4246,67 & 4371,54 & 4528,86 & 4179,51 \\
\hline Máximo & 5553,85 & 5716,04 & 5920,11 & 5463,76 \\
\hline
\end{tabular}


Tabela 31 - Estatística dos Processos: Outros Residencial (elaborado pelo autor, 2019).

\begin{tabular}{|l|r|r|r|r|}
\hline & $\mathbf{2 0 1 7}$ & $\mathbf{2 0 1 8}$ & $\mathbf{2 0 2 0}$ & Histórico \\
\hline Mínimo & 35,3532 & 35,8837 & 36,7373 & 34,6488 \\
\hline $\mathbf{1}^{\circ}$ Quartil & 56,2688 & 57,2183 & 58,6917 & 55,3532 \\
\hline Mediana & 63,9911 & 64,9565 & 66,5702 & 62,7828 \\
\hline Média & 72,90861 & 74,03155 & 75,83362 & 71,51251 \\
\hline $\mathbf{3}^{\circ}$ Quartil & 81,2478 & 82,4763 & 84,4533 & 79,6485 \\
\hline Máximo & 146,977 & 149,183 & 152,732 & 144,049 \\
\hline
\end{tabular}

Tabela 32 - Estatística dos Processos: Outros Terciário (elaborado pelo autor, 2019).

\begin{tabular}{|l|r|r|r|r|}
\hline & $\mathbf{2 0 1 7}$ & $\mathbf{2 0 1 8}$ & $\mathbf{2 0 2 0}$ & Histórico \\
\hline Mínimo & 365,621 & 376,527 & 406,367 & 357,536 \\
\hline $\mathbf{1}^{\circ}$ Quartil & 698,751 & 719,691 & 776,867 & 683,483 \\
\hline Mediana & 825,191 & 849,889 & 917,412 & 807,171 \\
\hline Média & 826,4119 & 851,488 & 919,5269 & 808,9176 \\
\hline $\mathbf{3}^{\circ}$ Quartil & 966,767 & 995,812 & 1076,25 & 945,78 \\
\hline Máximo & 1244,66 & 1281,78 & 1383,37 & 1217,13 \\
\hline
\end{tabular}

Tabela 33 - Estatística dos Processos: Papel e Celulose (elaborado pelo autor, 2019).

\begin{tabular}{|c|c|c|c|c|}
\hline & 2017 & 2018 & 2020 & Histórico \\
\hline Mínimo & 743,781 & 756,515 & 775,286 & 737,216 \\
\hline $1^{\circ}$ Quartil & 1105,19 & 1124,25 & 1152,49 & 1095,74 \\
\hline Mediana & 1216,105 & 1237,15 & 1270,82 & 1208,34 \\
\hline Média & 1213,938 & 1235,264 & 1266,675 & 1204,284 \\
\hline $3^{\circ}$ Quartil & 1327,49 & 1350,43 & 1384,5 & 1316,14 \\
\hline Máximo & 1619,12 & 1646,84 & 1687,7 & 1604,83 \\
\hline
\end{tabular}


Tabela 34 - Estatística dos Processos: Química (elaborado pelo autor, 2019).

\begin{tabular}{|l|r|r|r|r|}
\hline & $\mathbf{2 0 1 7}$ & $\mathbf{2 0 1 8}$ & $\mathbf{2 0 2 0}$ & Histórico \\
\hline Mínimo & 961,781 & 980,895 & 1003,35 & 933,272 \\
\hline $\mathbf{1}^{\circ}$ Quartil & 1613,16 & 1645,43 & 1683,57 & 1565,74 \\
\hline Mediana & 1795,27 & 1831,13 & 1873,83 & 1742,72 \\
\hline Média & 1777,118 & 1813,162 & 1855,811 & 1725,821 \\
\hline $\mathbf{3}^{\circ}$ Quartil & 1953,46 & 1992,41 & 2039,59 & 1896,84 \\
\hline Máximo & 2509,77 & 2559,65 & 2618,25 & 2435,38 \\
\hline
\end{tabular}

Tabela 35 - Estatística dos Processos: Refrigerador (elaborado pelo autor, 2019).

\begin{tabular}{|l|r|r|r|r|}
\hline & $\mathbf{2 0 1 7}$ & $\mathbf{2 0 1 8}$ & $\mathbf{2 0 2 0}$ & Histórico \\
\hline Mínimo & 599,653 & 627,633 & 681,872 & 569,454 \\
\hline $\mathbf{1}^{\circ}$ Quartil & 937,148 & 982,005 & 1067,03 & 891,064 \\
\hline Mediana & 1058,36 & 1107,82 & 1203,68 & 1005,2 \\
\hline Média & 1134,042 & 1187,415 & 1290,624 & 1077,716 \\
\hline $\mathbf{3}^{\circ}$ Quartil & 1220,37 & 1277,4 & 1389,7 & 1159,07 \\
\hline Máximo & 2109,45 & 2207,88 & 2398,68 & 2003,22 \\
\hline
\end{tabular}

Tabela 36 - Estatística dos Processos: Saúde (elaborado pelo autor, 2019).

\begin{tabular}{|l|r|r|r|r|}
\hline & $\mathbf{2 0 1 7}$ & $\mathbf{2 0 1 8}$ & $\mathbf{2 0 2 0}$ & Histórico \\
\hline Mínimo & 171,129 & 175,273 & 187,039 & 167,836 \\
\hline $\mathbf{1}^{\circ}$ Quartil & 253,151 & 259,306 & 276,736 & 248,324 \\
\hline Mediana & 290,755 & 297,796 & 317,787 & 285,16 \\
\hline Média & 291,1786 & 298,3504 & 318,5531 & 285,8065 \\
\hline $\mathbf{3}^{\circ}$ Quartil & 329,527 & 337,54 & 360,297 & 323,298 \\
\hline Máximo & 424,324 & 434,599 & 463,774 & 416,159 \\
\hline
\end{tabular}


Tabela 37 - Estatística dos Processos: Televisores (elaborado pelo autor, 2019).

\begin{tabular}{|l|r|r|r|r|r|}
\hline & $\mathbf{2 0 1 7}$ & $\mathbf{2 0 1 8}$ & $\mathbf{2 0 2 0}$ & Histórico \\
\hline Mínimo & 178,32 & 179,304 & 180,322 & 176,53 \\
\hline $\mathbf{1}^{\circ}$ Quartil & 467,078 & 469,654 & 472,322 & 462,389 \\
\hline Mediana & 1084,83 & 1095,245 & 1105,92 & 1082,74 \\
\hline Média & 1460,256 & 1468,751 & 1477,53 & 1446,395 \\
\hline $\mathbf{3}^{\circ}$ Quartil & 1901,06 & 1911,54 & 1922,41 & 1881,98 \\
\hline Máximo & 4326,12 & 4349,75 & 4374,21 & 4282,5 \\
\hline
\end{tabular}

Tabela 38 - Estatística dos Processos: Têxtil (elaborado pelo autor, 2019).

\begin{tabular}{|l|r|r|r|r|}
\hline & $\mathbf{2 0 1 7}$ & $\mathbf{2 0 1 8}$ & $\mathbf{2 0 2 0}$ & Histórico \\
\hline Mínimo & 176,115 & 181,754 & 189,172 & 172,922 \\
\hline $\mathbf{1}^{\circ}$ Quartil & 309,036 & 318,931 & 331,948 & 303,434 \\
\hline Mediana & 356,97 & 368,401 & 383,436 & 350,5 \\
\hline Média & 356,1049 & 367,6261 & 382,7279 & 349,8549 \\
\hline $\mathbf{3}^{\circ}$ Quartil & 410,446 & 423,589 & 440,977 & 403,0298 \\
\hline Máximo & 574,762 & 593,059 & 617,059 & 564,116 \\
\hline
\end{tabular}

Tabela 39 - Estatística dos Processos: Tráfego e Transmissão de Dados (elaborado pelo autor, 2019).

\begin{tabular}{|l|r|r|r|r|}
\hline & $\mathbf{2 0 1 7}$ & $\mathbf{2 0 1 8}$ & $\mathbf{2 0 2 0}$ & Histórico \\
\hline Mínimo & 695,421 & 705,085 & 728,93 & 686,052 \\
\hline $\mathbf{1}^{\circ}$ Quartil & 1103,15 & 1118,59 & 1156,57 & 1088,5 \\
\hline Mediana & 1261,73 & 1279,39 & 1324,525 & 1245,75 \\
\hline Média & 1256,758 & 1274,758 & 1318,606 & 1240,859 \\
\hline $\mathbf{3}^{\circ}$ Quartil & 1404,56 & 1424,32 & 1476,1 & 1389,27 \\
\hline Máximo & 1823,31 & 1848,65 & 1911,17 & 1798,75 \\
\hline
\end{tabular}




\section{9}

\section{Apêndice $C$}
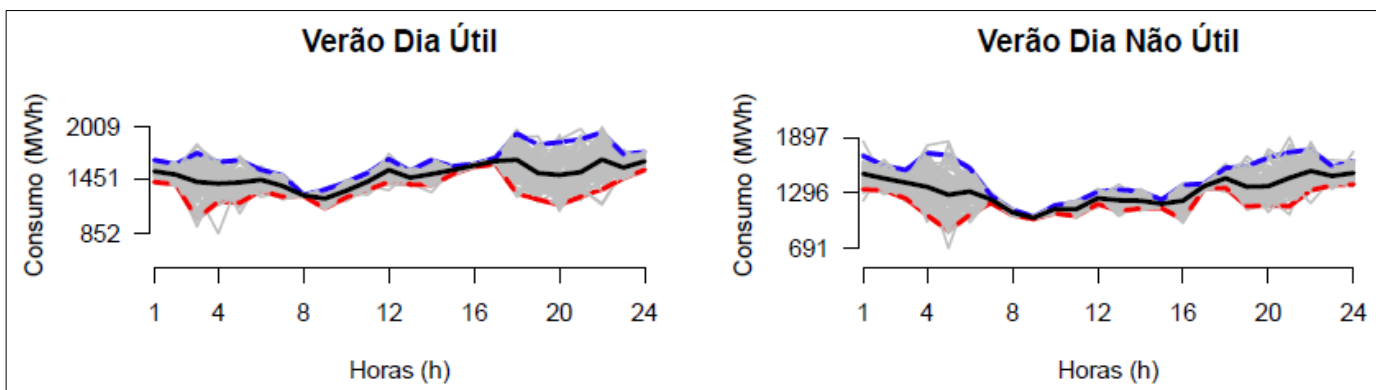

Inverno Dia Útil

Inverno Dia Não Útil

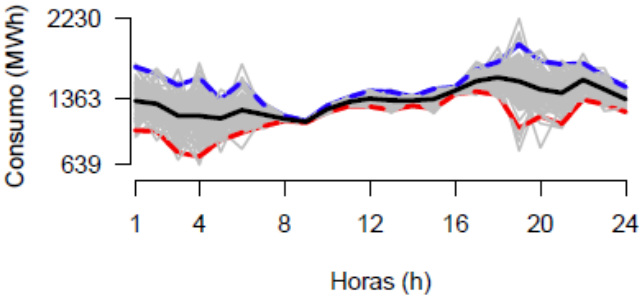

Intermediário Dia Útil

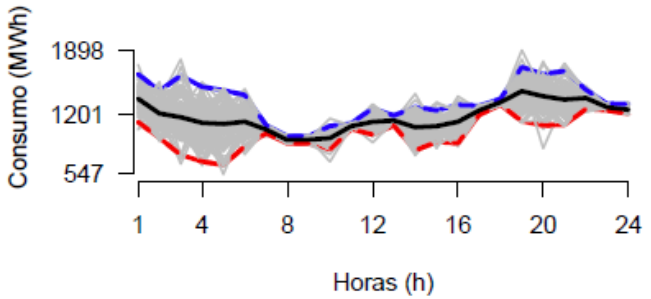

Intermediário Dia Não Útil
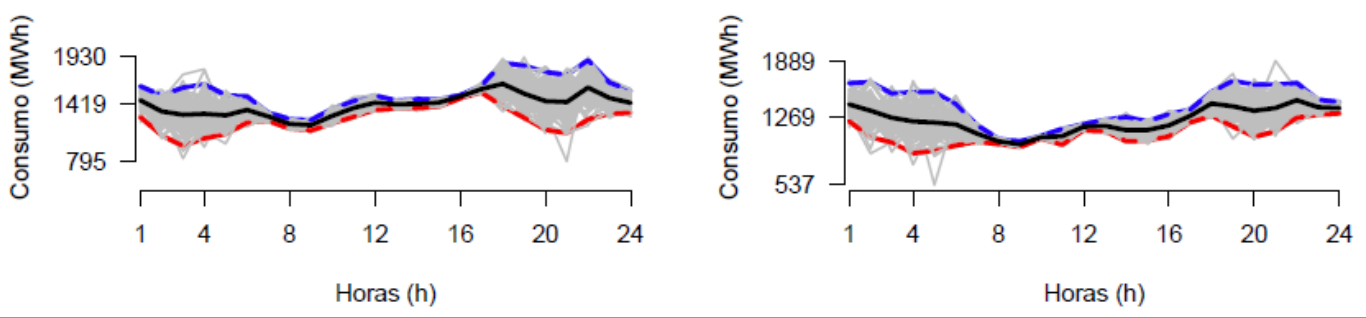

Figura 53 - Perfis Médios Previstos 2020: Alimentos, Bebidas e Tabaco (elaborado pelo autor, 2019). 

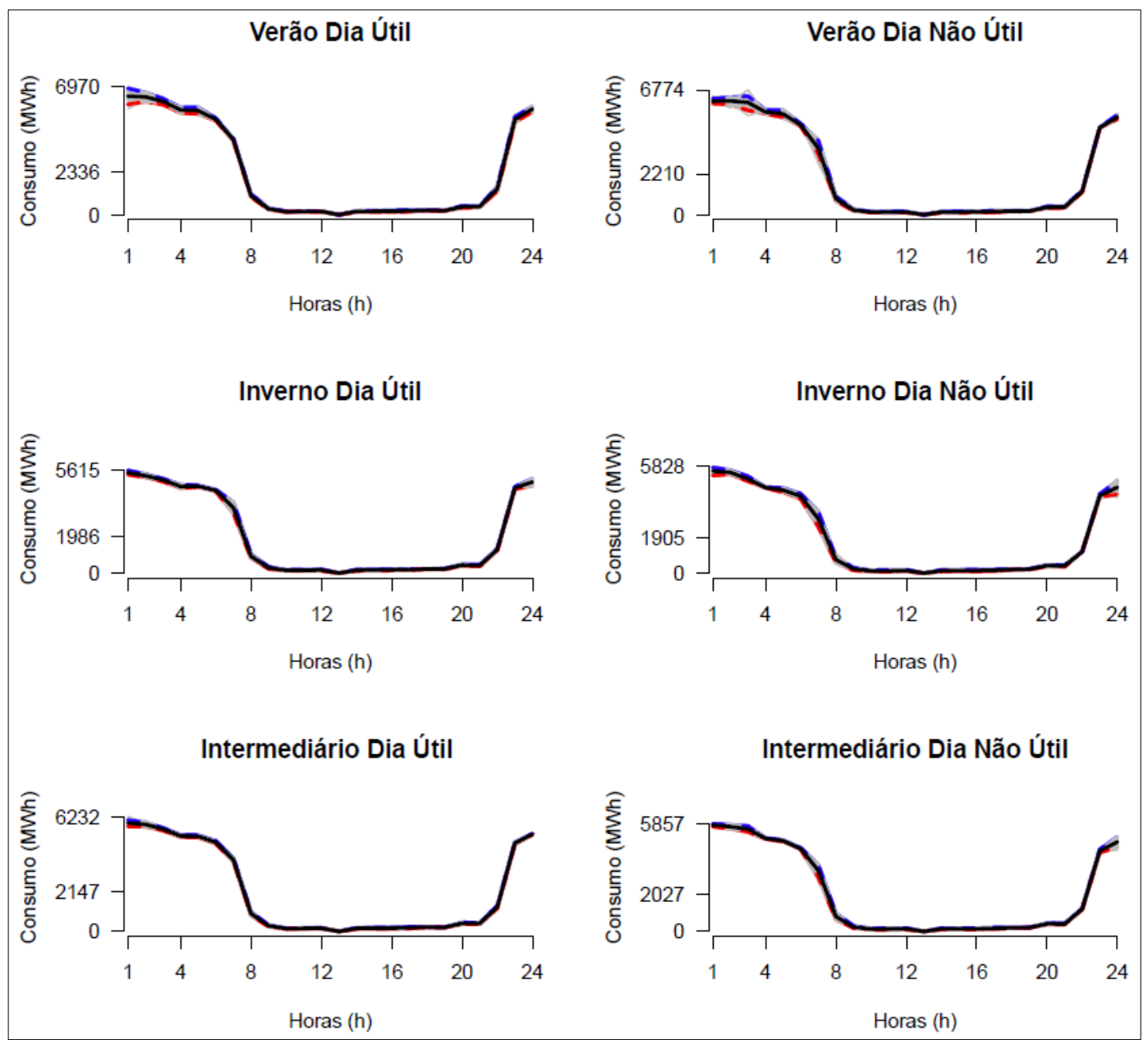

Figura 54 - Perfis Médios Previstos 2020: Ar condicionado (elaborado pelo autor, 2019). 

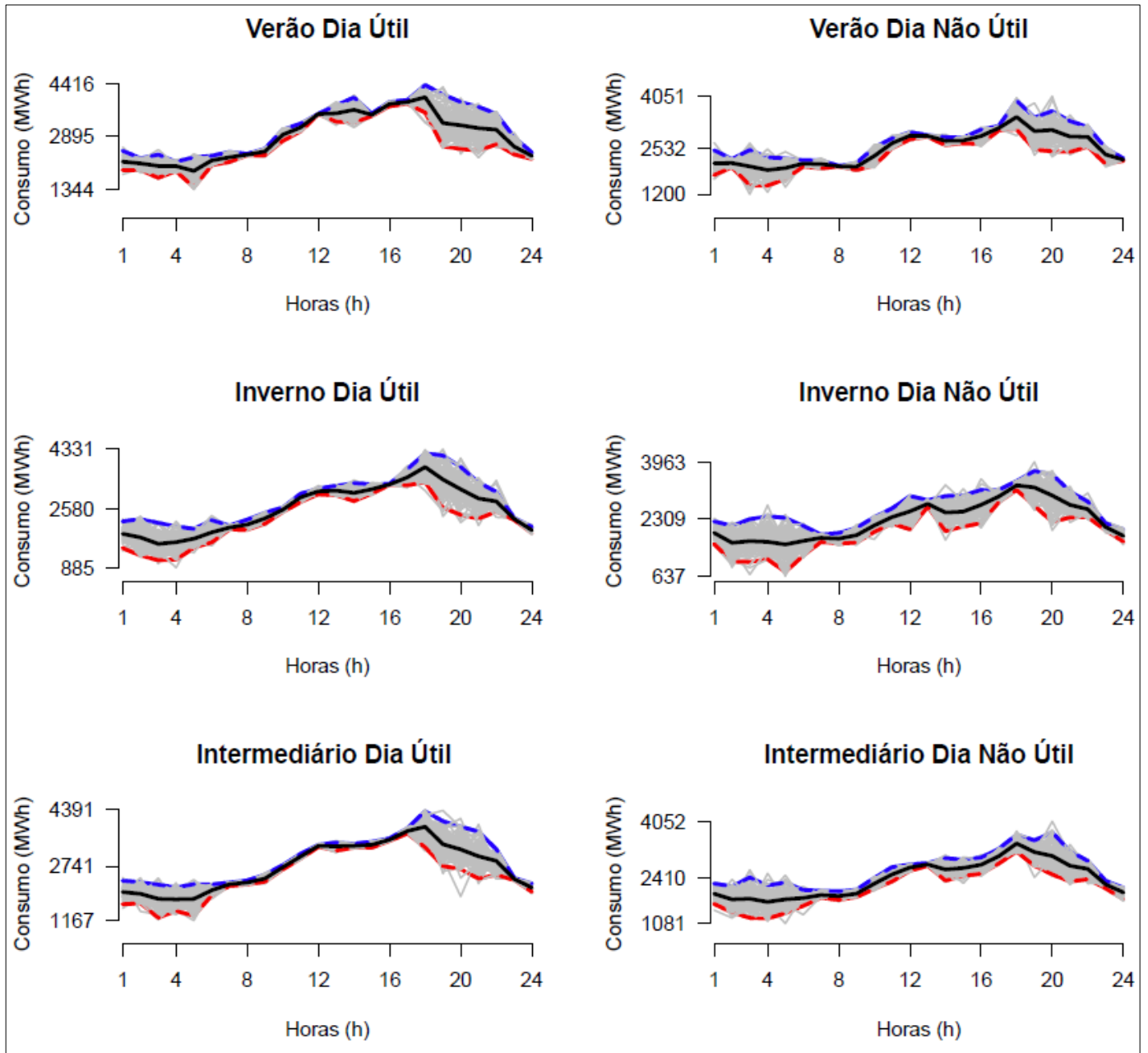

Figura 55 - Perfis Médios Previstos 2020: Atacado e Varejo (elaborado pelo autor, 2019). 


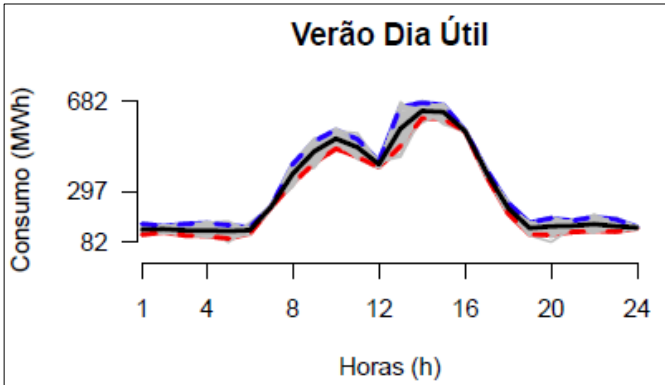

Verão Dia Não Útil

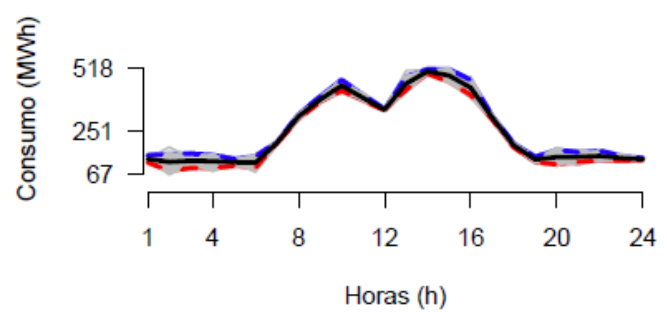

Inverno Dia Útil

Inverno Dia Não Útil
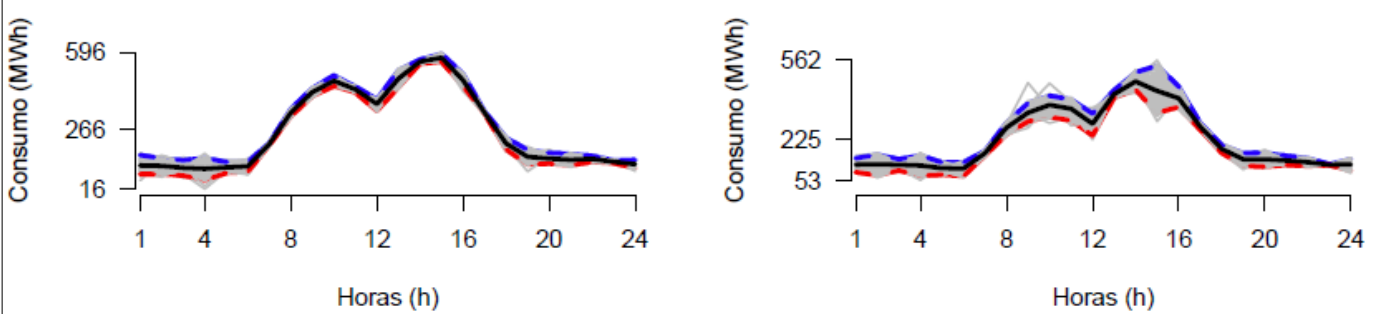

Intermediário Dia Útil

Intermediário Dia Não Útil
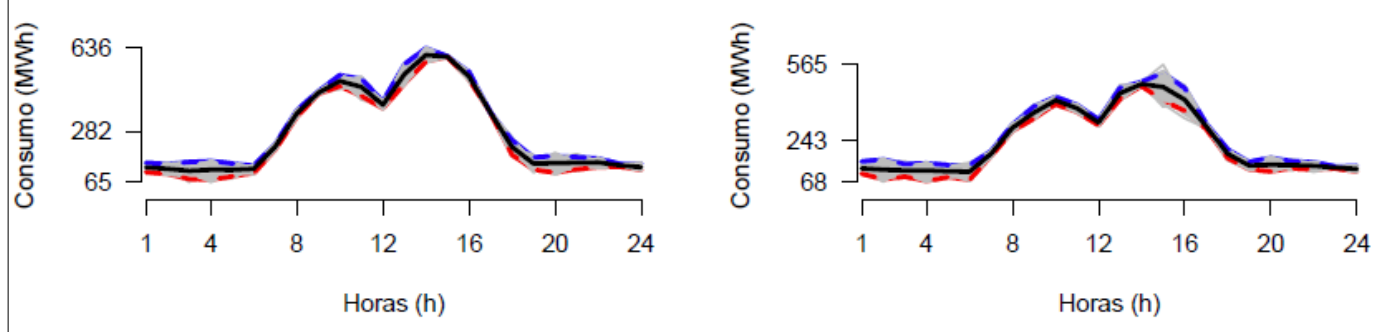

Figura 56 - Perfis Médios Previstos 2020: Cerâmica (elaborado pelo autor, 2019). 


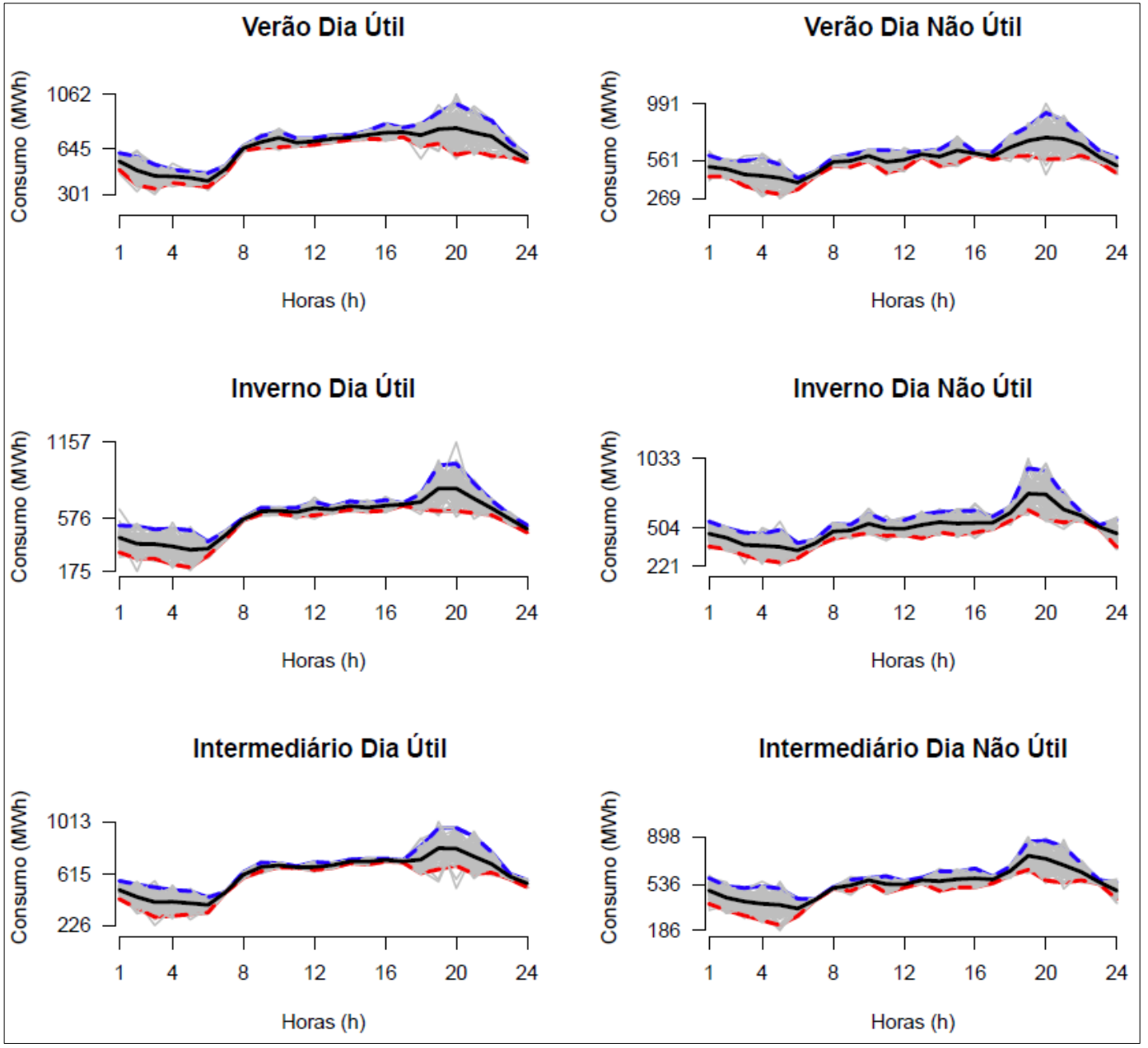

Figura 57 - Perfis Médios Previstos 2020: Cimento (elaborado pelo autor, 2019). 


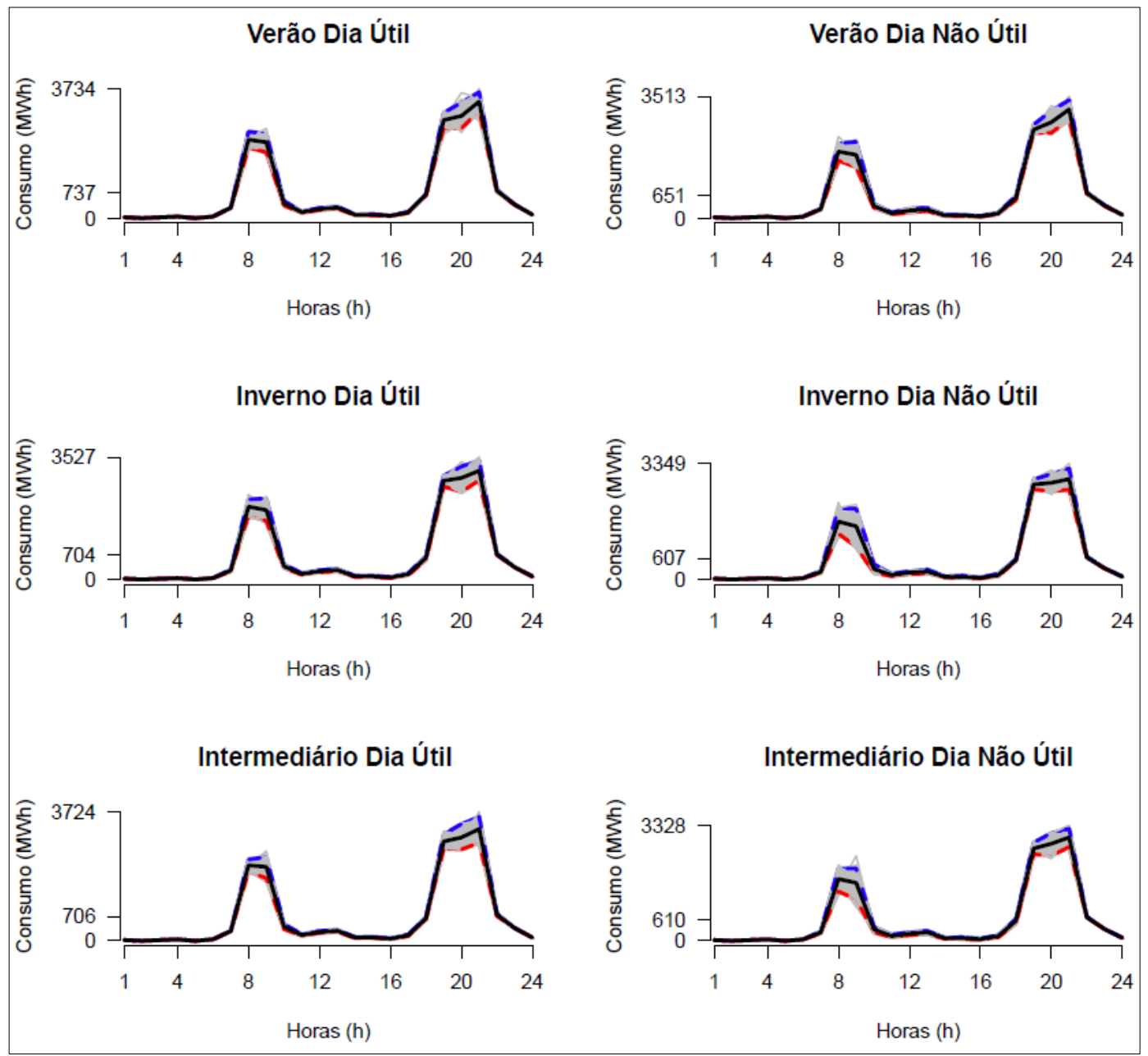

Figura 58 - Perfis Médios Previstos 2020: Chuveiro Elétrico (elaborado pelo autor, 2019). 


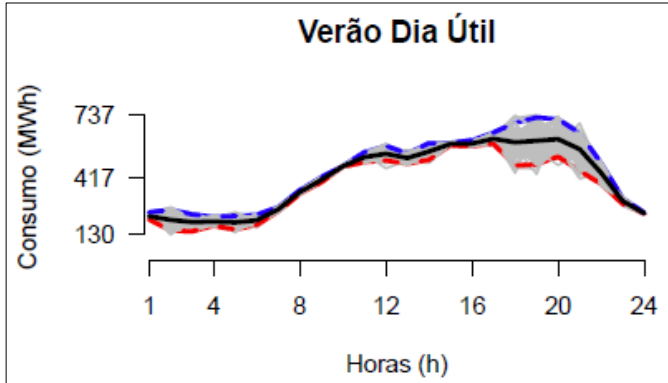

Verão Dia Não Útil

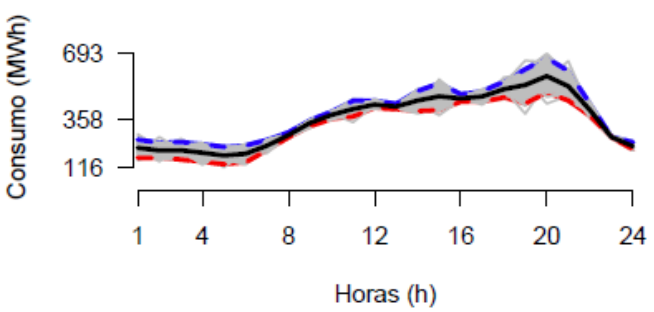

Inverno Dia Útil

Inverno Dia Não Útil
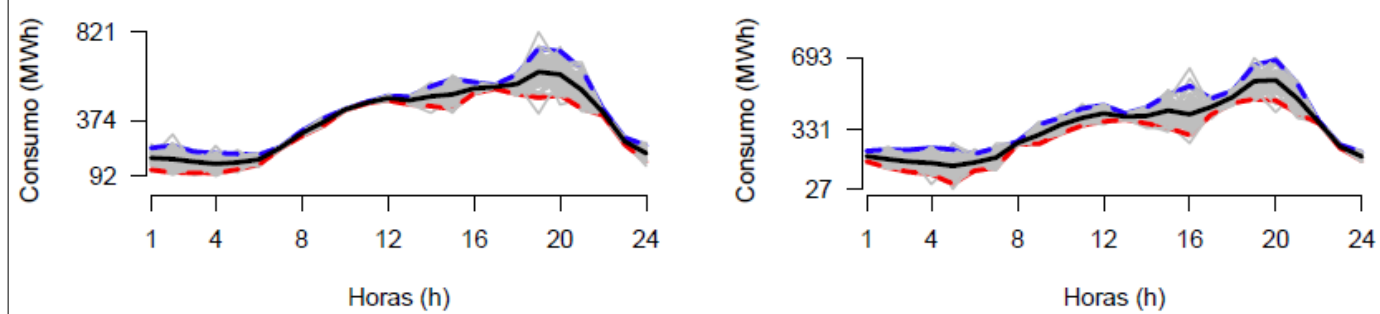

Intermediário Dia Útil

Intermediário Dia Não Útil
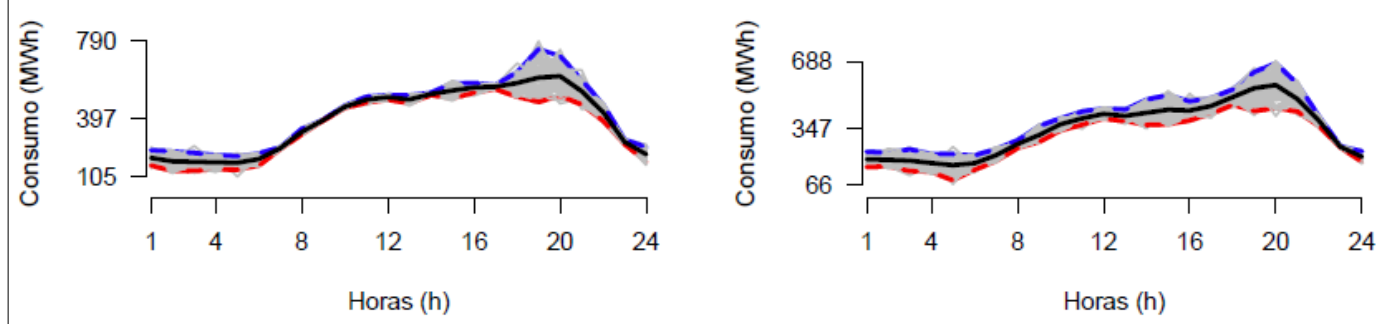

Figura 59 - Perfis Médios Previstos 2020: Educação (elaborado pelo autor, 2019). 


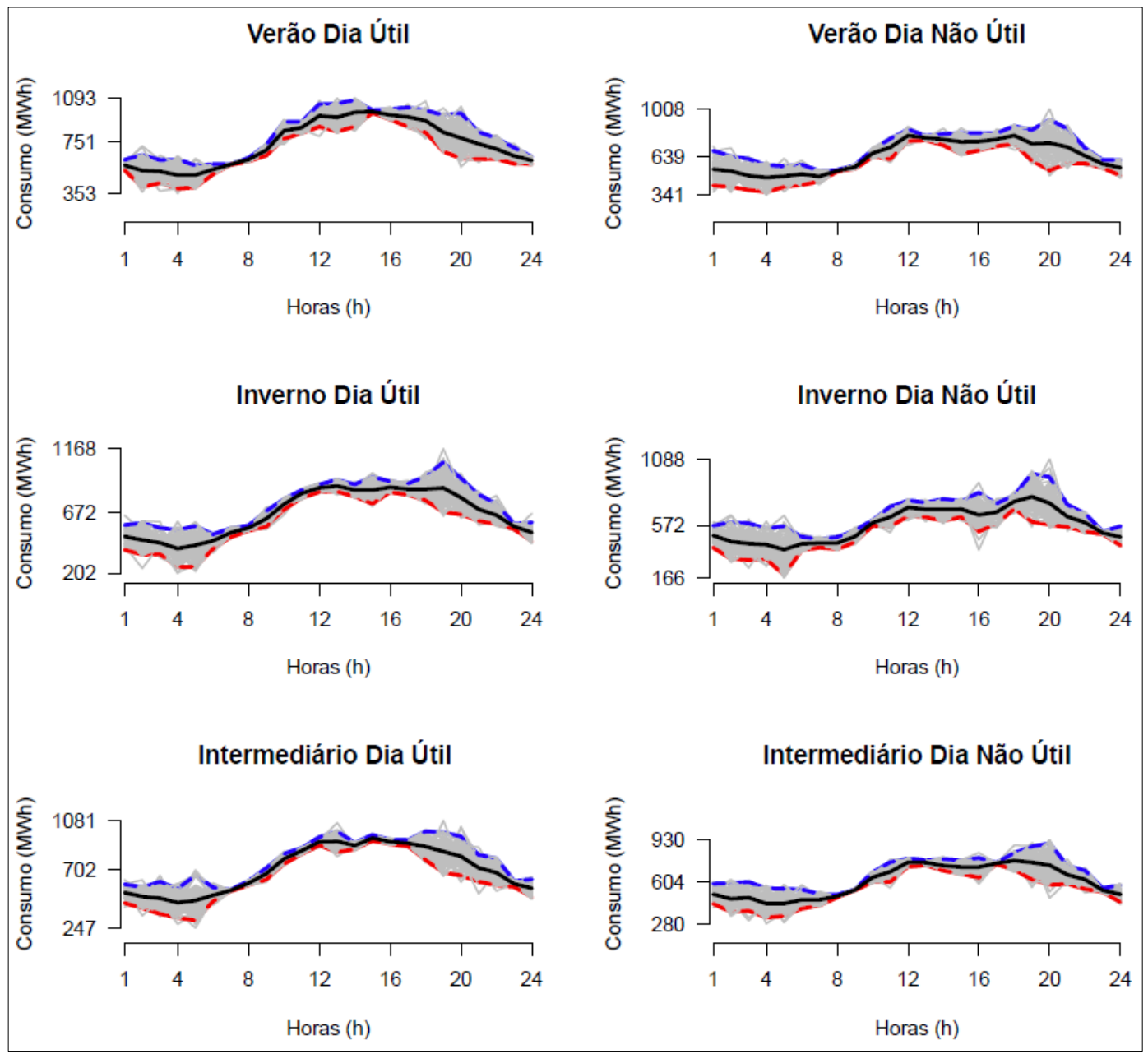

Figura 60 - Perfis Médios Previstos 2020: Escritório Público (elaborado pelo autor, 2019). 


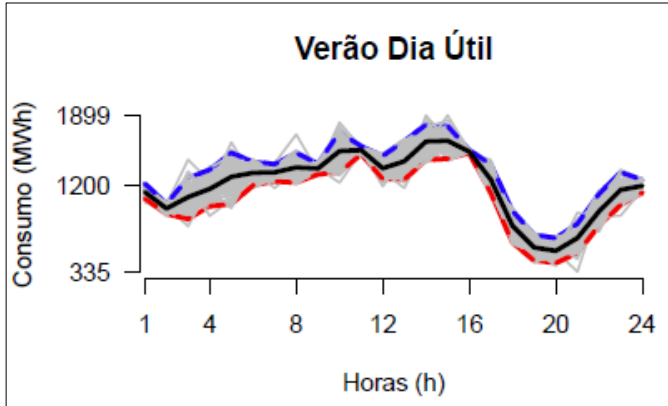

Inverno Dia Útil

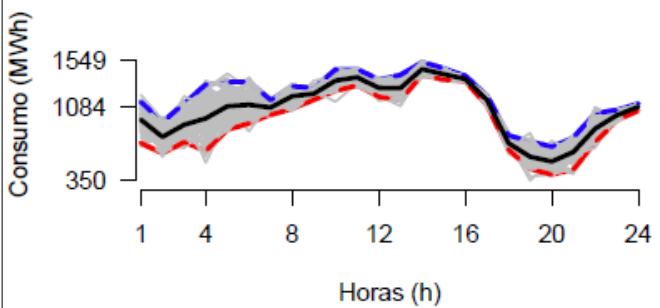

Intermediário Dia Útil

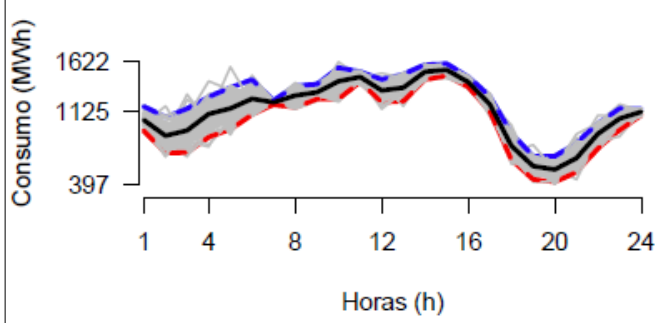

Verão Dia Não Útil

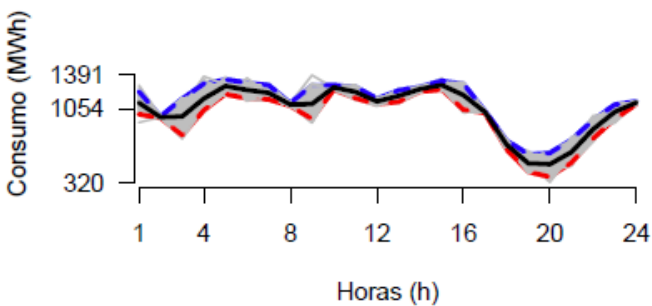

Inverno Dia Não Útil

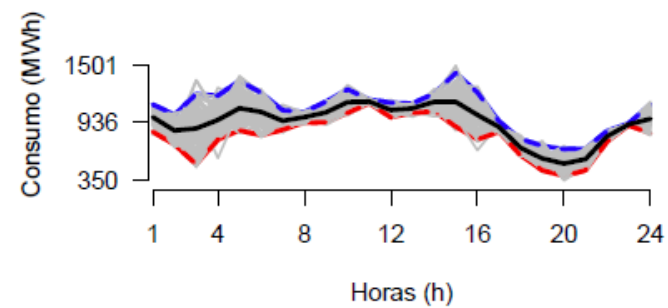

Intermediário Dia Não Útil

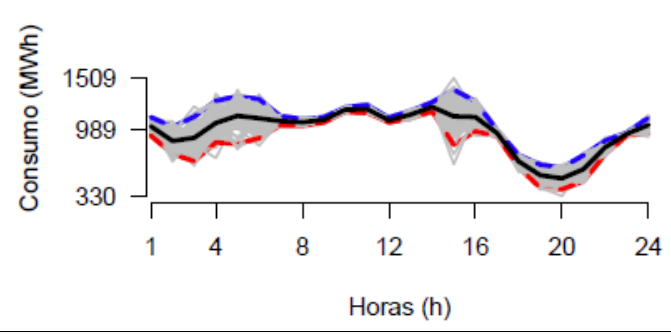

Figura 61 - Perfis Médios Previstos 2020: Ferro e Aço Gusa (elaborado pelo autor, 2019). 


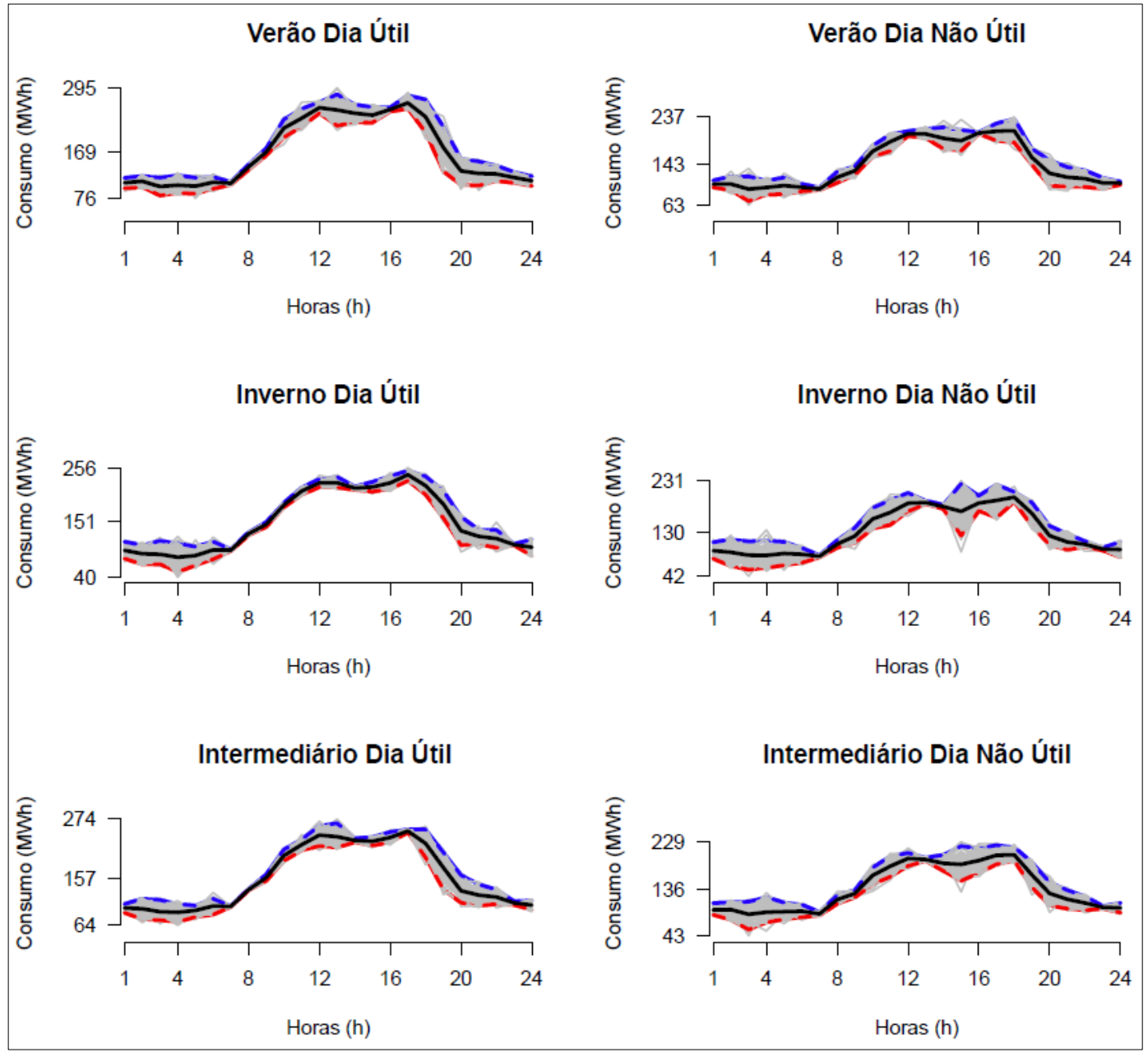

Figura 62 - Perfis Médios Previstos 2020: Finanças (elaborado pelo autor, 2019). 

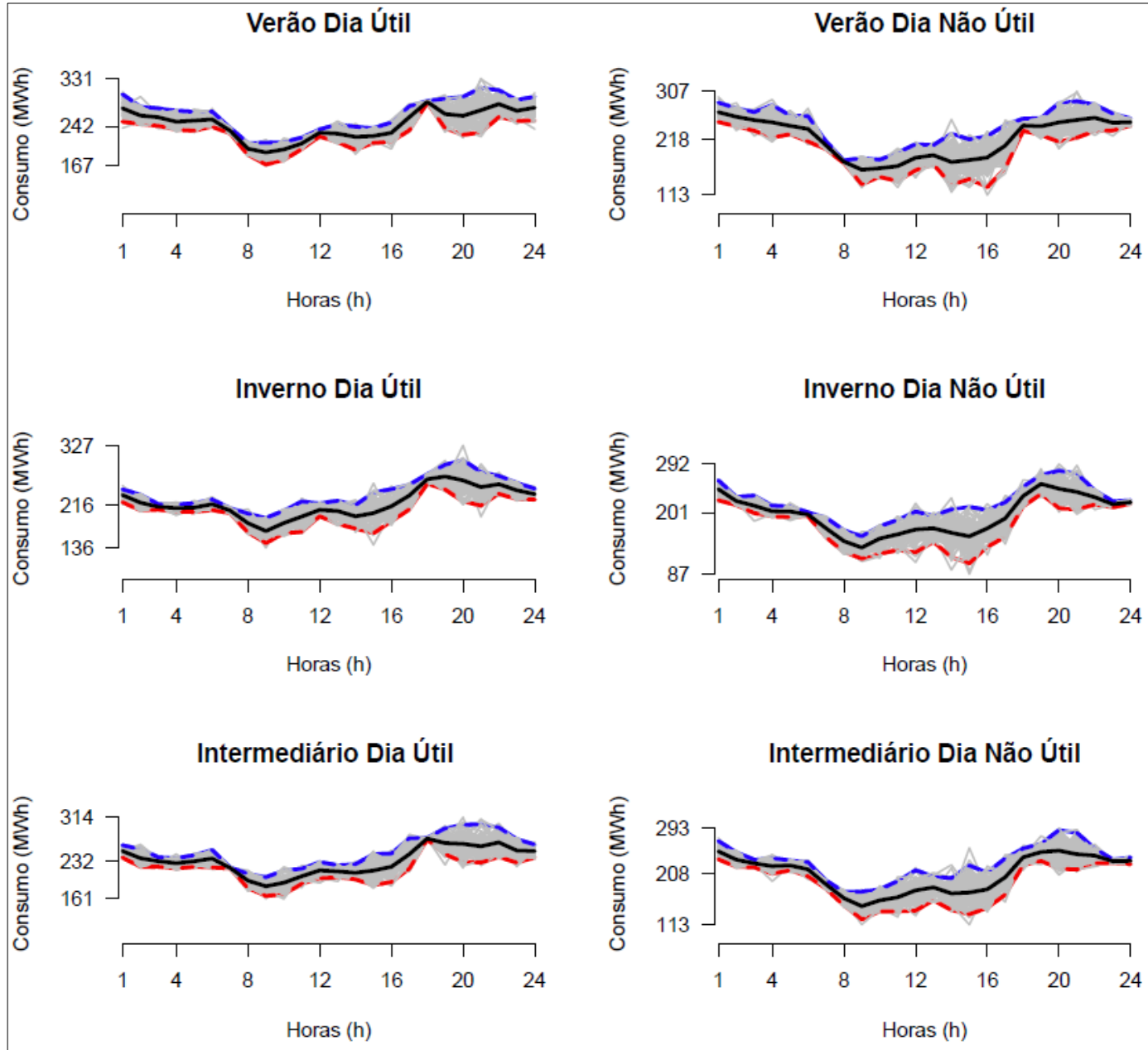

Figura 63 - Perfis Médios Previstos 2020: Freezer (elaborado pelo autor, 2019). 


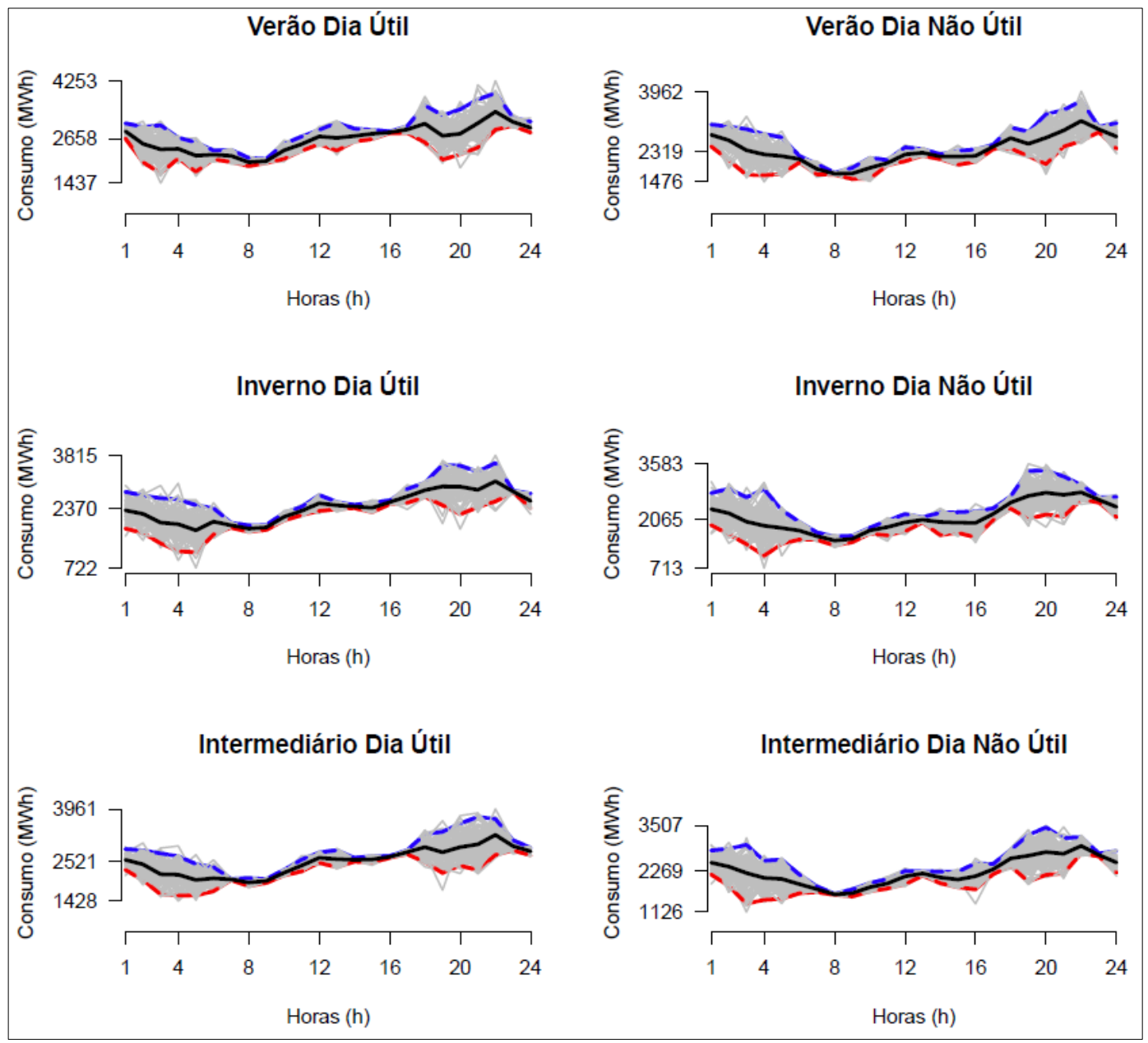

Figura 64 - Perfis Médios Previstos 2020: Hotel, Café e Restaurante (elaborado pelo autor, 2019). 


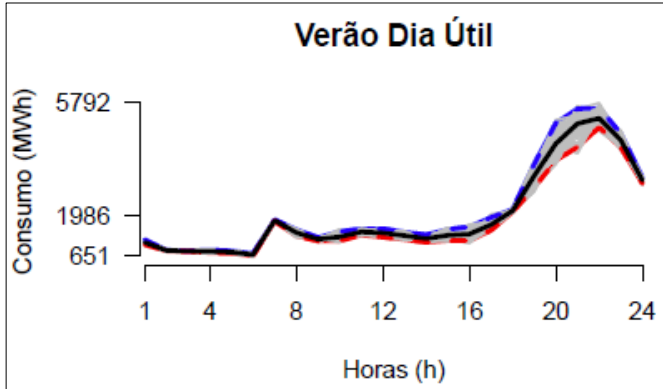

Verão Dia Não Útil

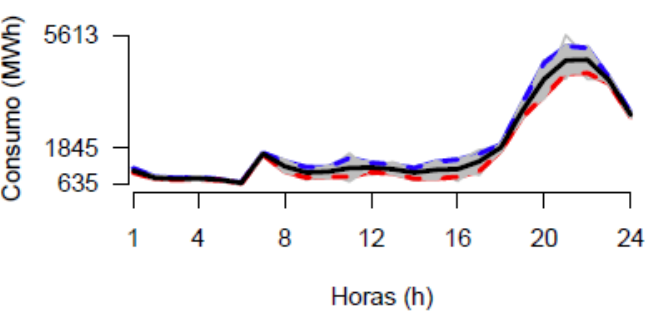

Inverno Dia Útil

Inverno Dia Não Útil
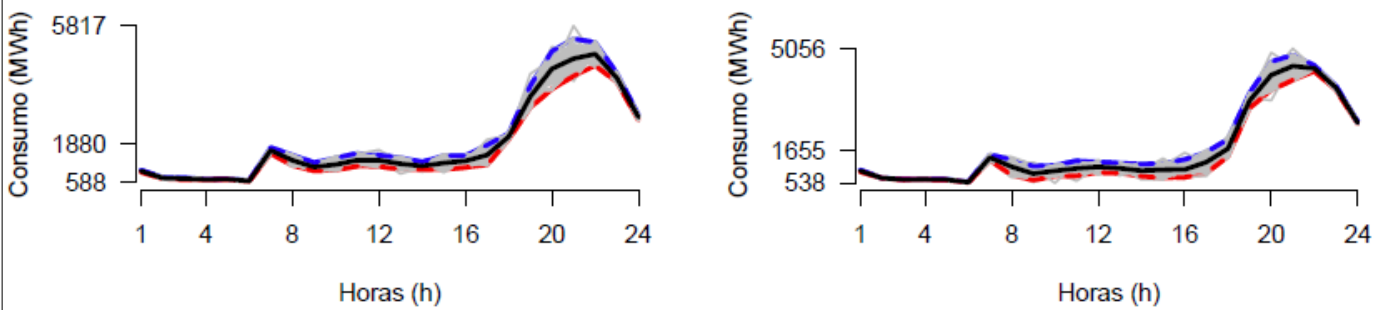

Intermediário Dia Útil

Intermediário Dia Não Útil

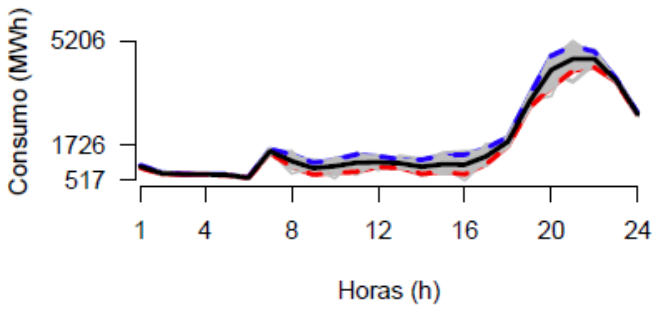

Figura 65 - Perfis Médios Previstos 2020: lluminação (elaborado pelo autor, 2019). 


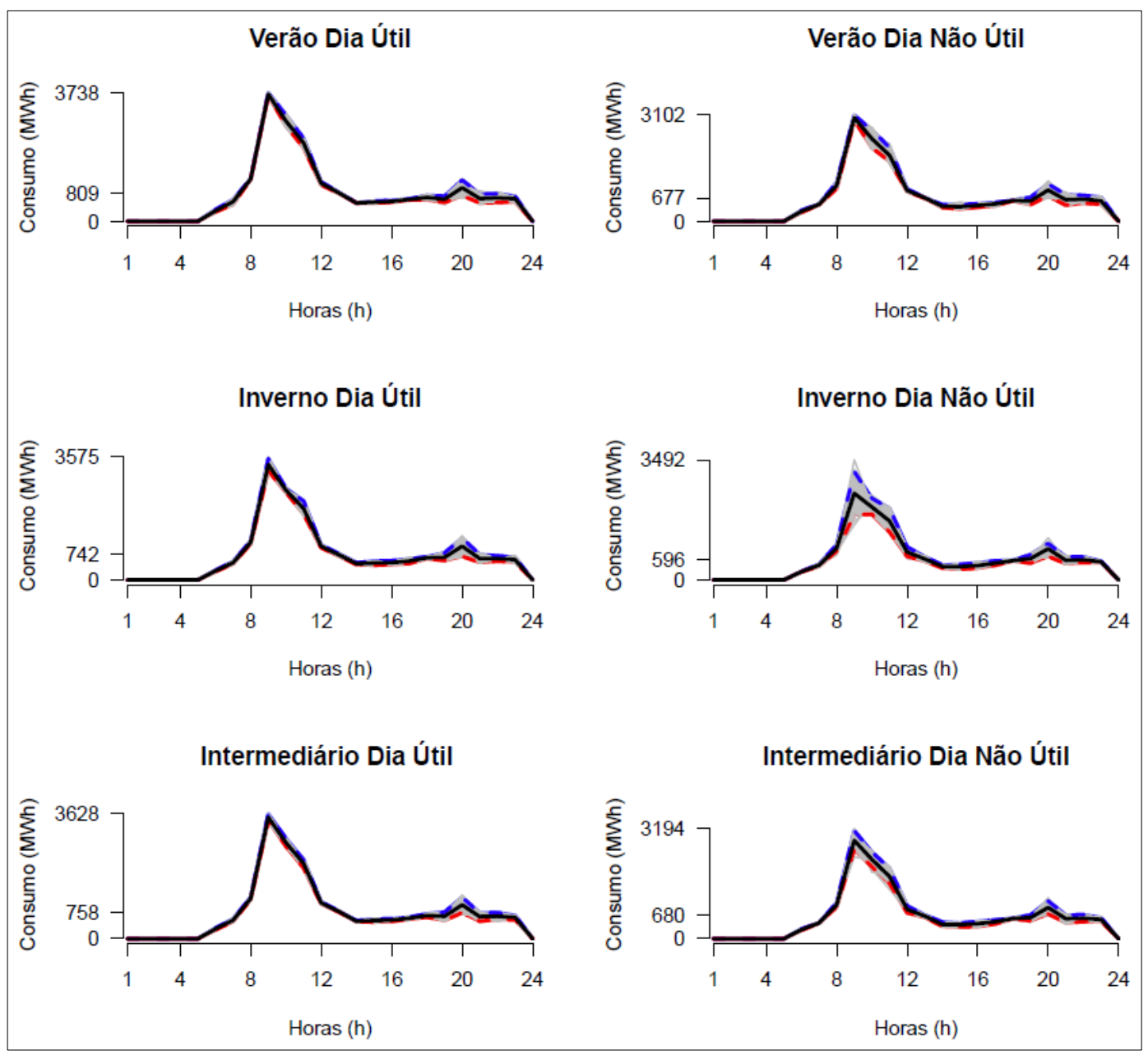

Figura 66 - Perfis Médios Previstos 2020: Lava Roupas (elaborado pelo autor, 2019). 


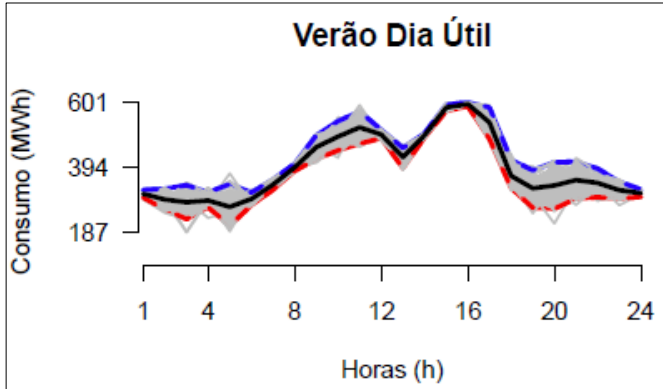

Verão Dia Não Útil

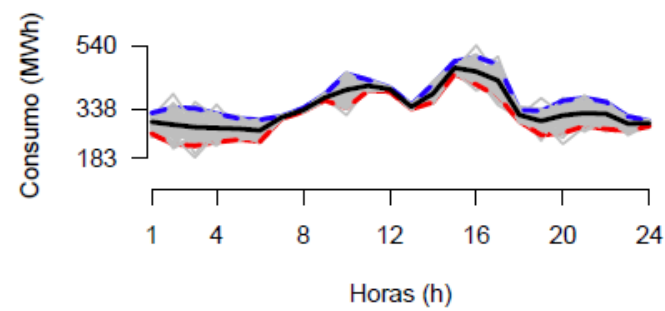

Inverno Dia Útil

Inverno Dia Não Útil
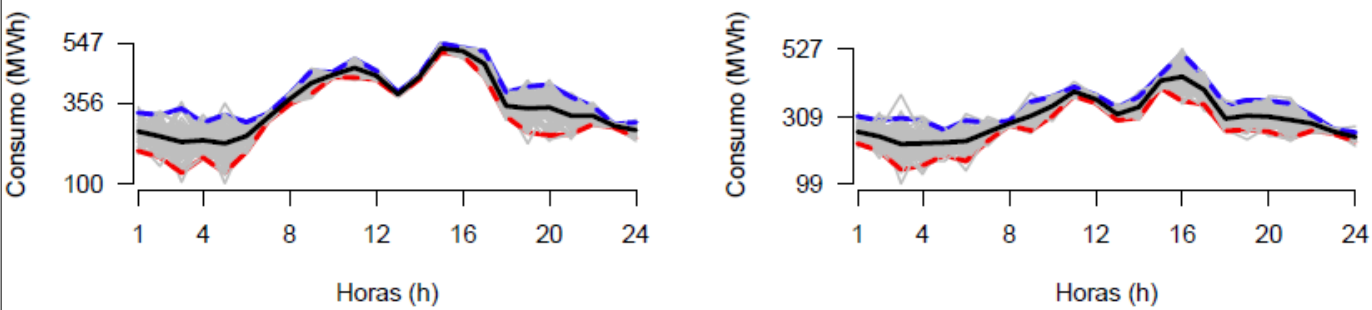

Intermediário Dia Útil

Intermediário Dia Não Útil

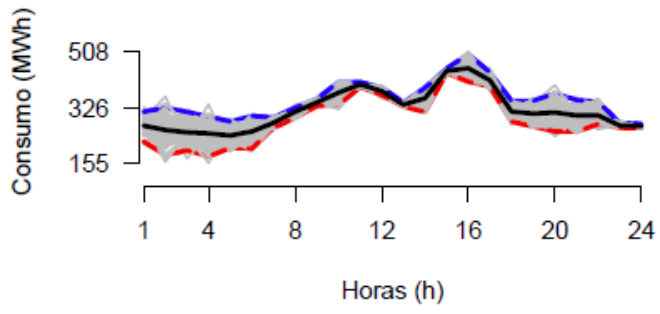

Figura 67 - Perfis Médios Previstos 2020: Liga de Ferro (elaborado pelo autor, 2019). 


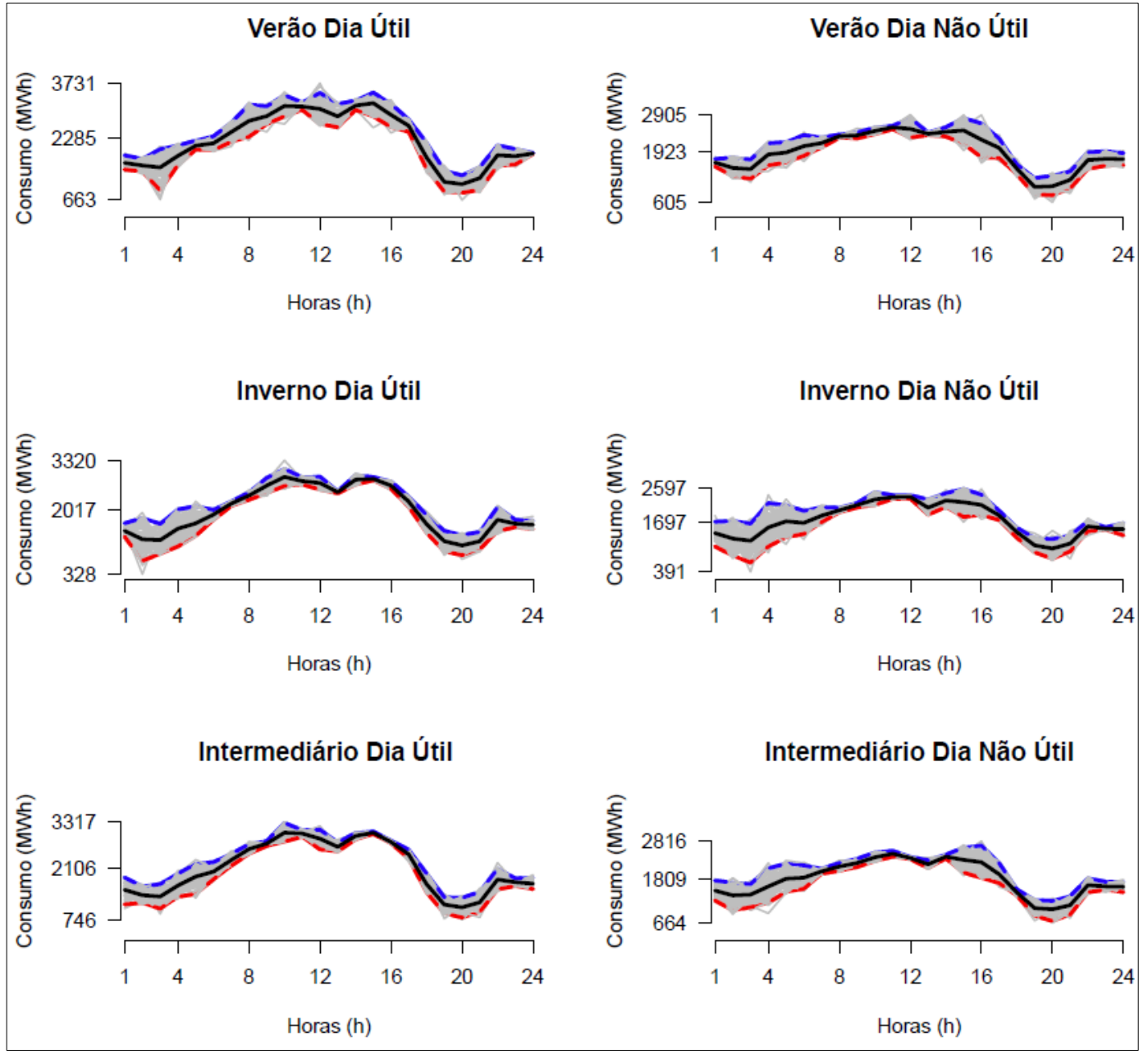

Figura 68 - Perfis Médios Previstos 2020: Metais Não-Ferrosos (elaborado pelo autor, 2019). 


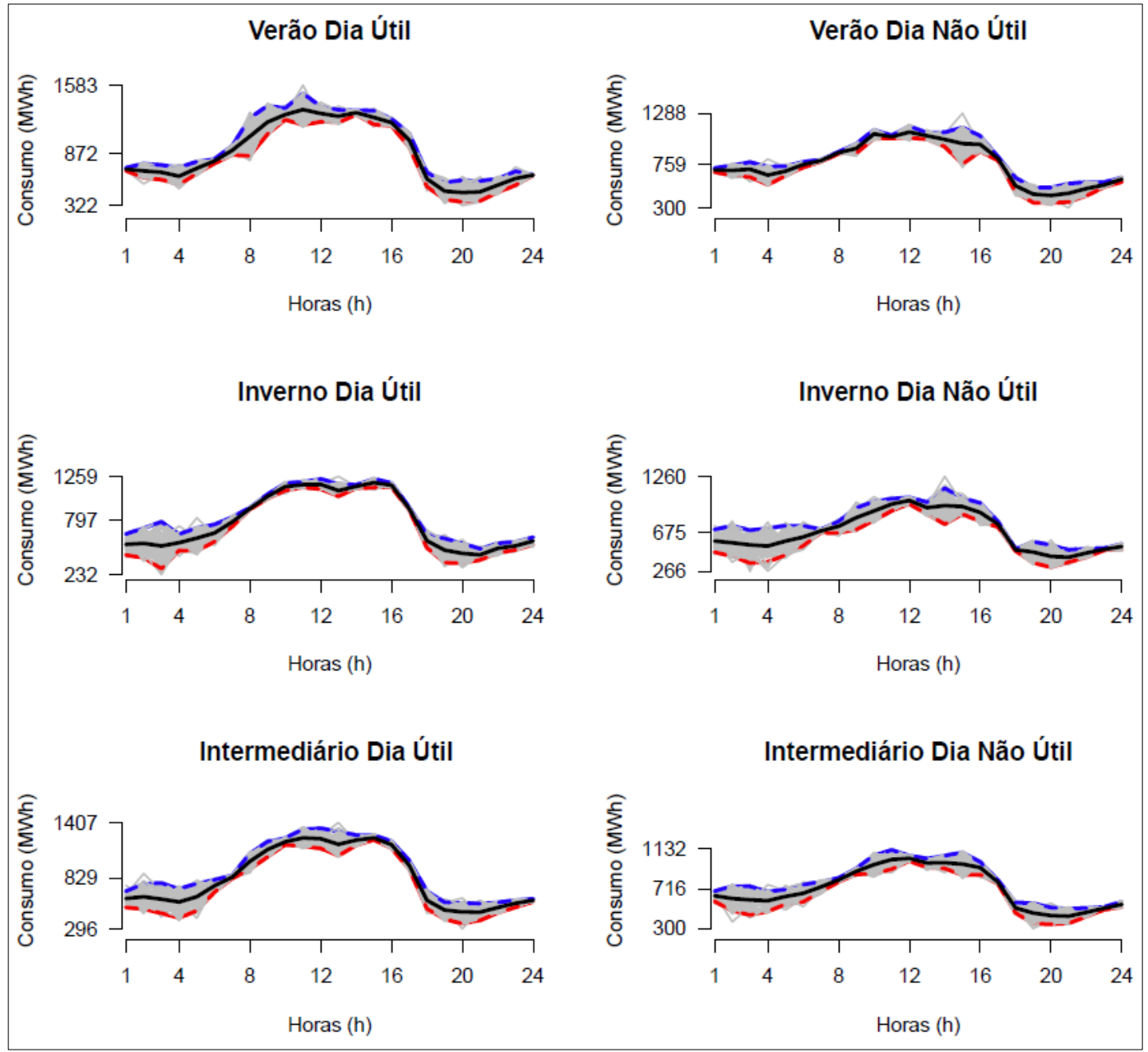

Figura 69 - Perfis Médios Previstos 2020: Mineração e Peletização (elaborado pelo autor, 2019). 


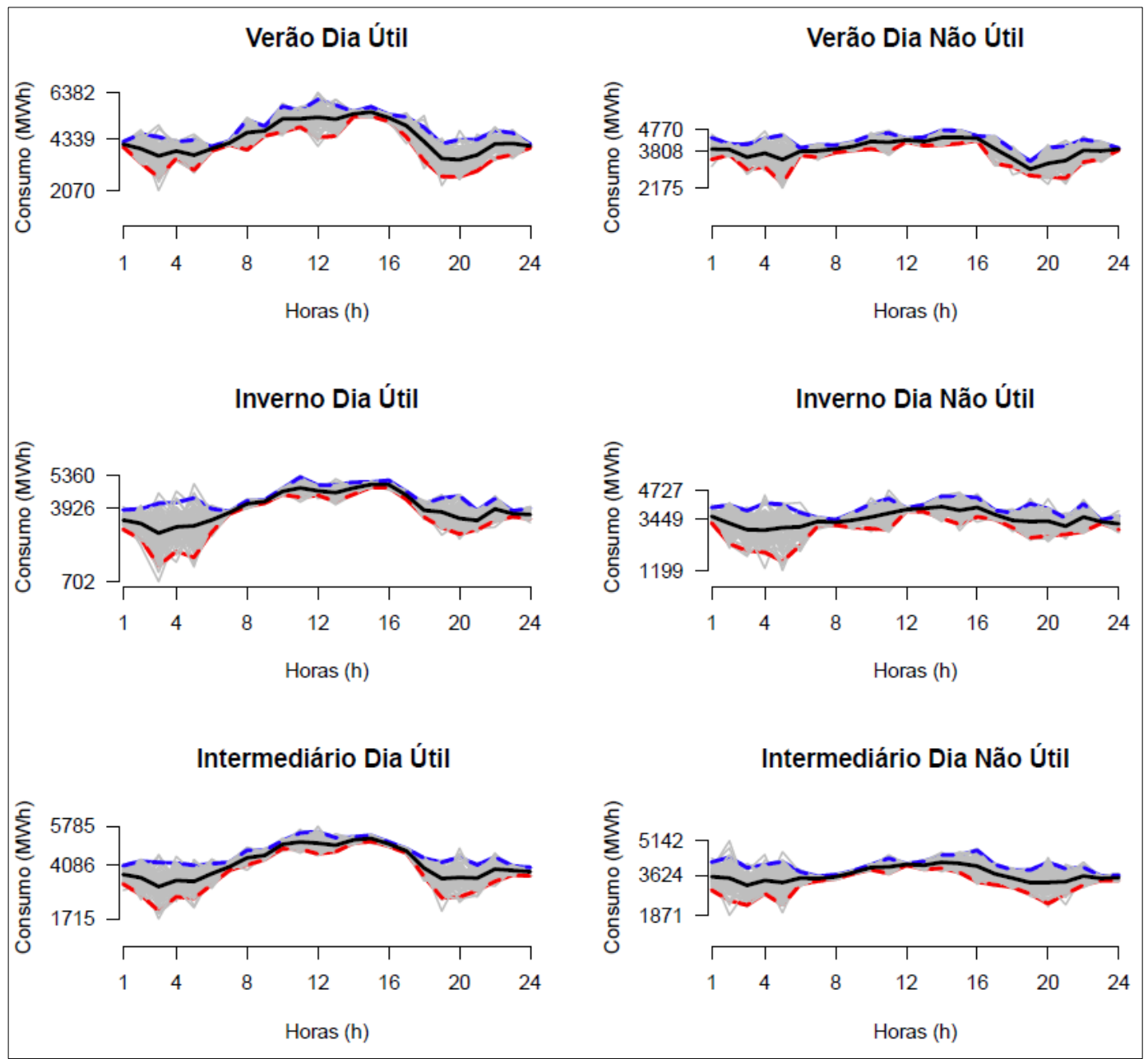

Figura 70 - Perfis Médios Previstos 2020: Outros Industrial (elaborado pelo autor, 2019). 


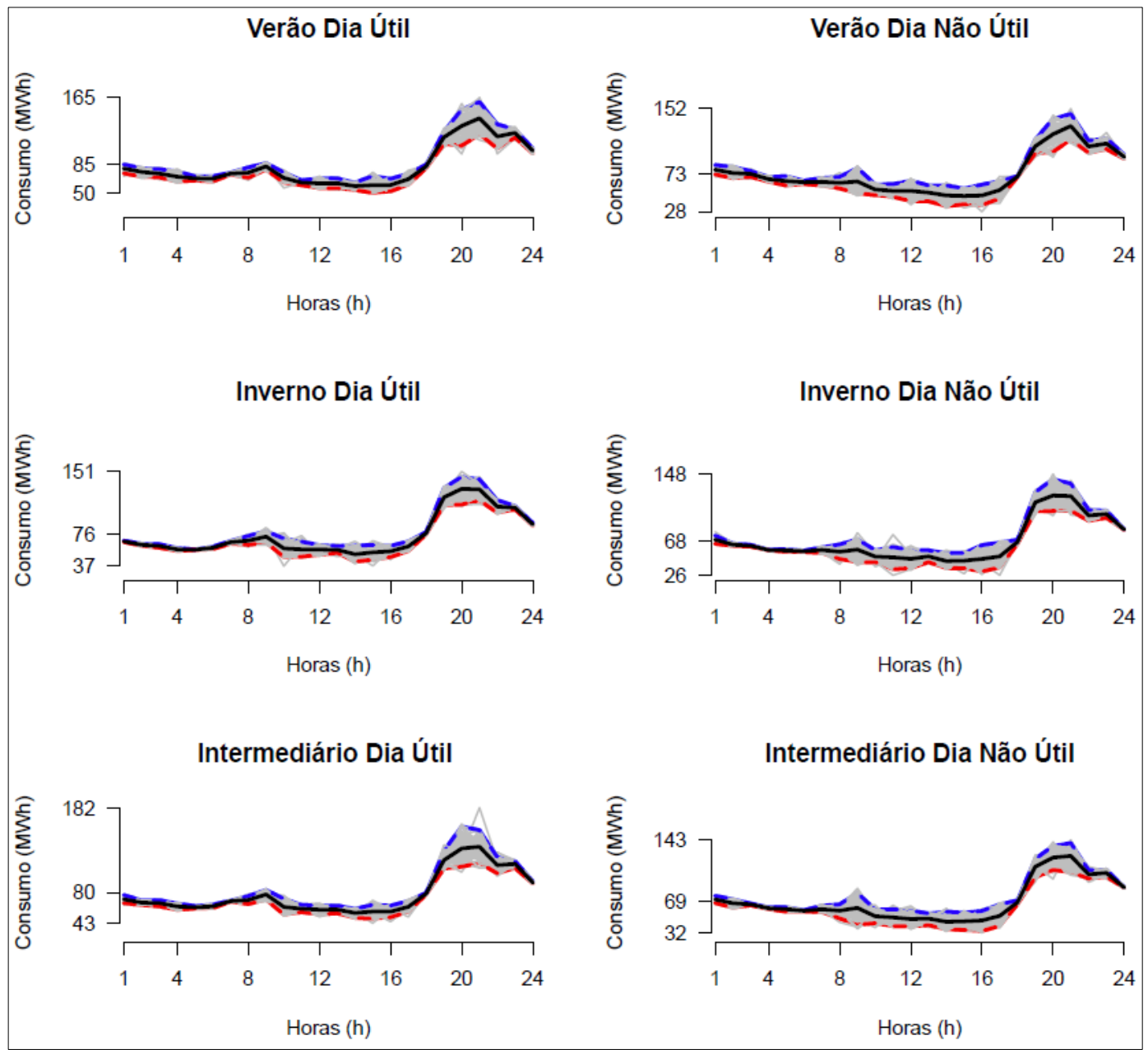

Figura 71 - Perfis Médios Previstos 2020: Outros Residencial (elaborado pelo autor, 2019). 


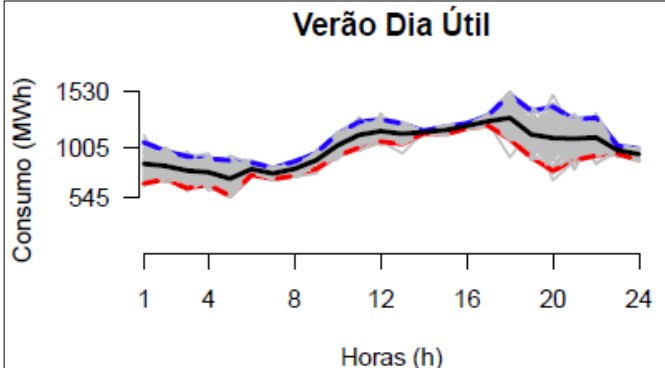

Inverno Dia Útil

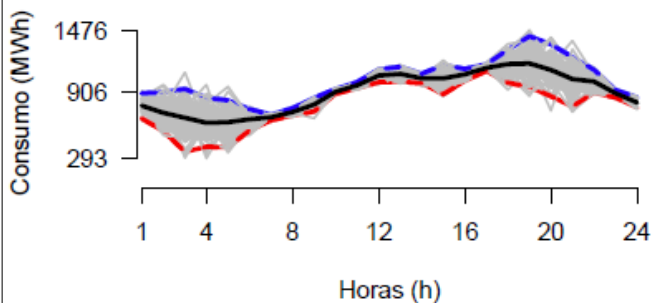

Intermediário Dia Útil

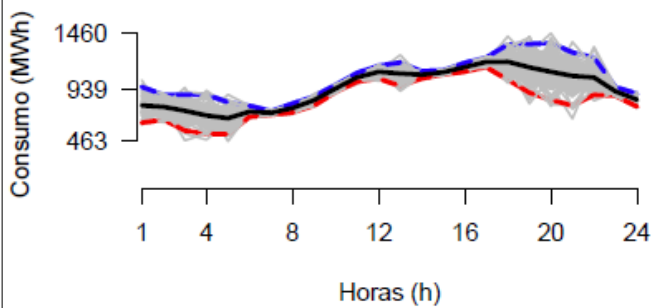

Verão Dia Não Útil

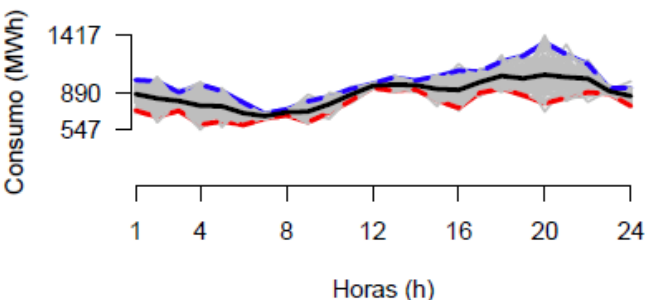

Inverno Dia Não Útil

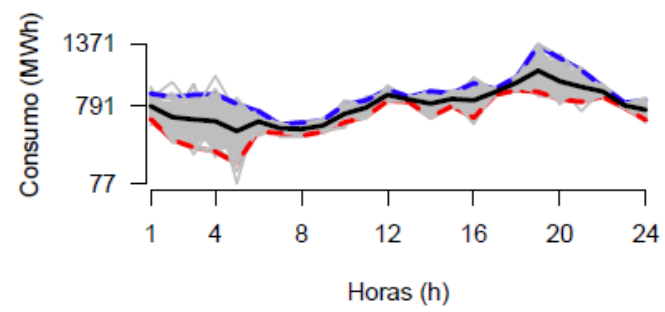

Intermediário Dia Não Útil

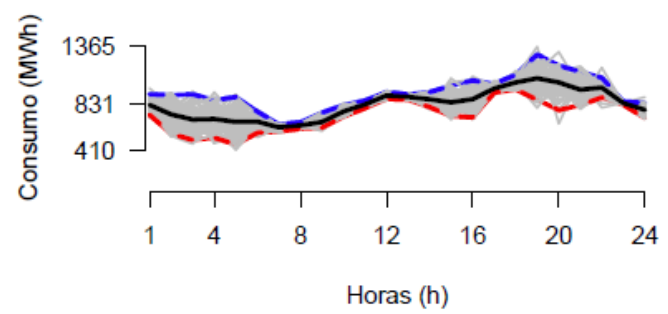

Figura 72 - Perfis Médios Previstos 2020: Outros Terciário (elaborado pelo autor, 2019). 


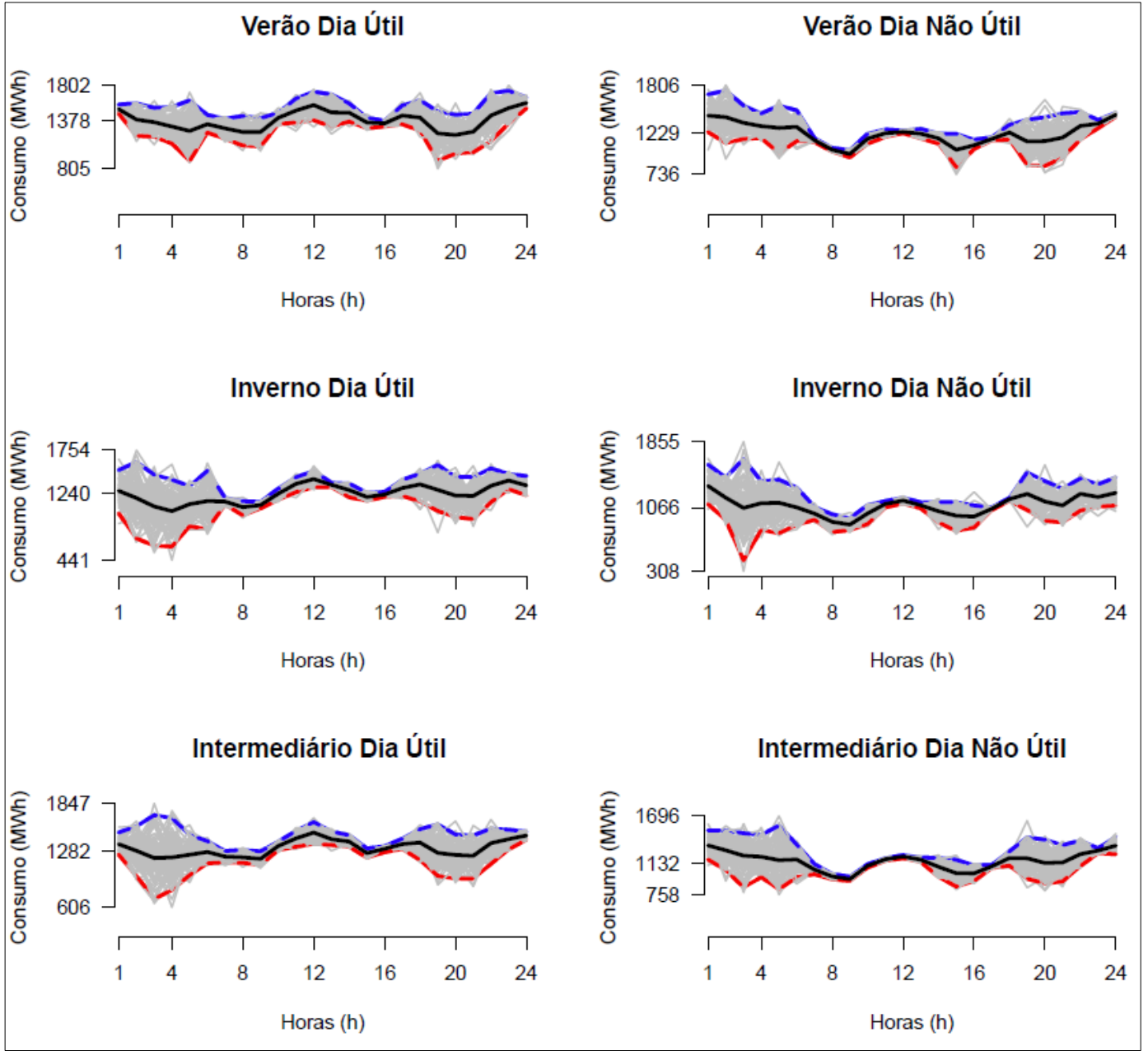

Figura 73 - Perfis Médios Previstos 2020: Papel e Celulose (elaborado pelo autor, 2019). 


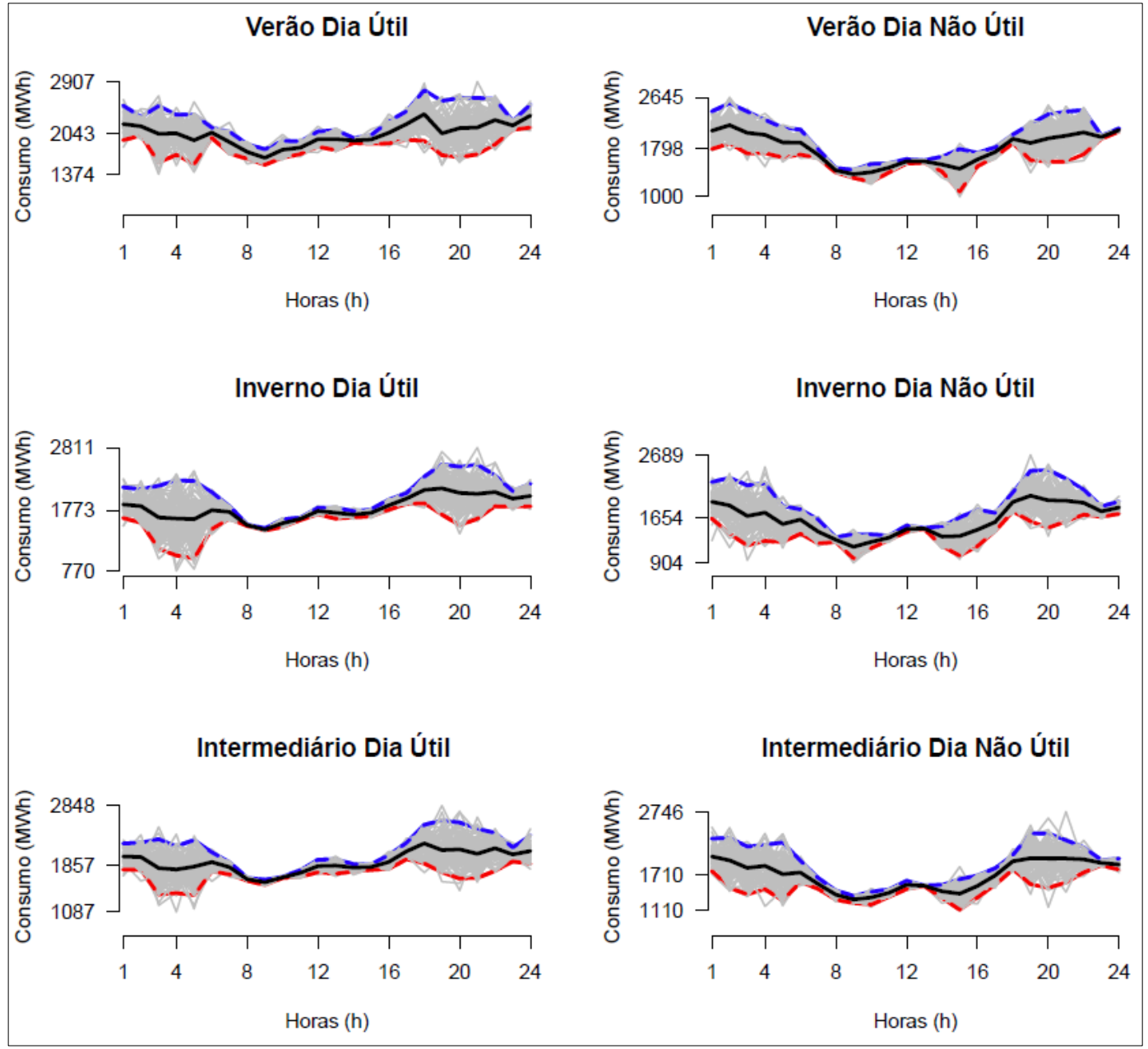

Figura 74 - Perfis Médios Previstos 2020: Química (elaborado pelo autor, 2019). 


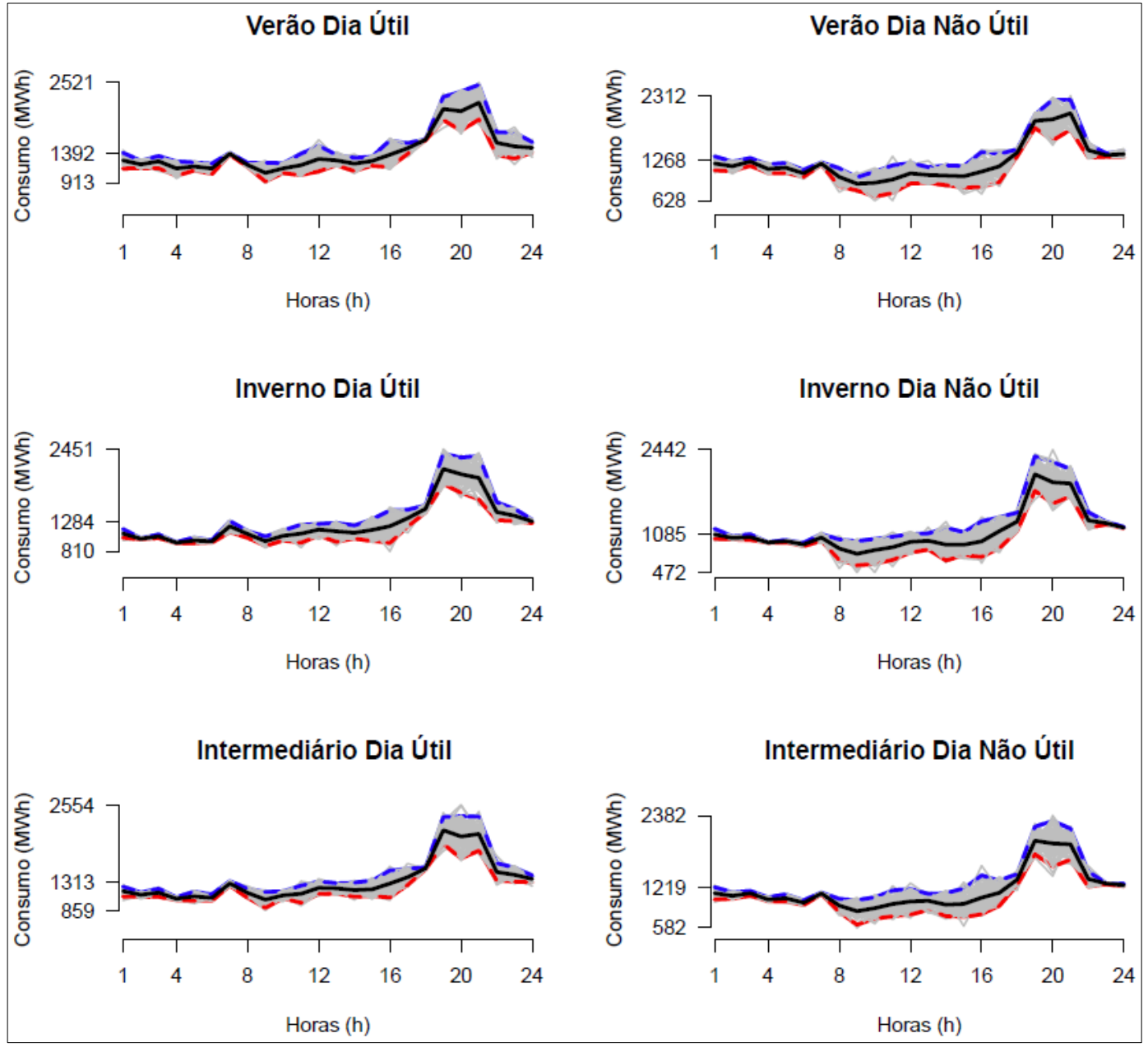

Figura 75 - Perfis Médios Previstos 2020: Refrigerador (elaborado pelo autor, 2019). 


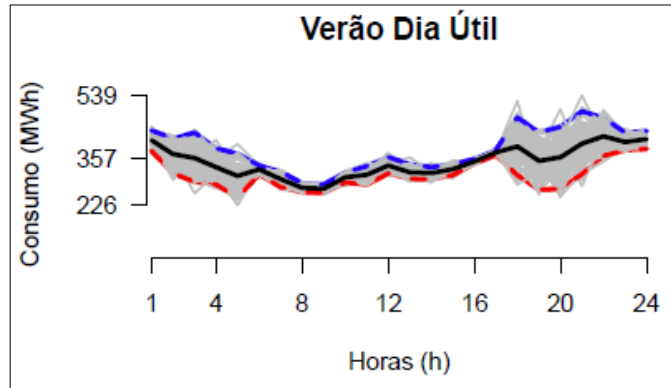

Inverno Dia Útil

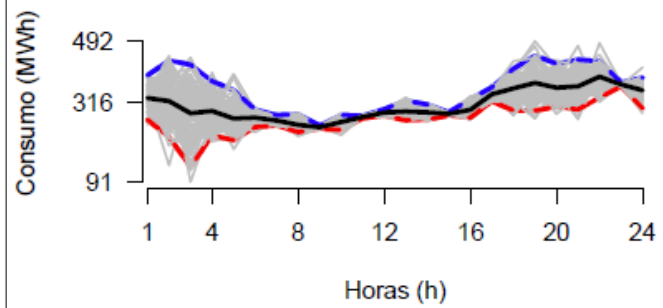

Intermediário Dia Útil

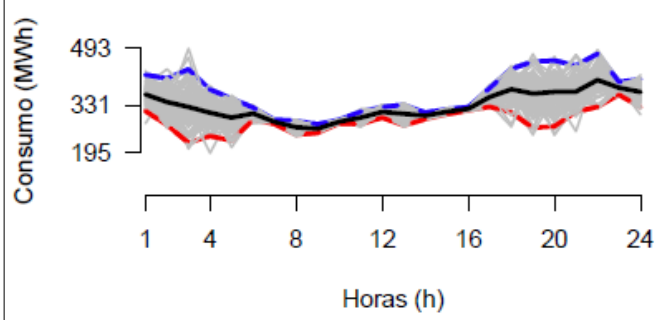

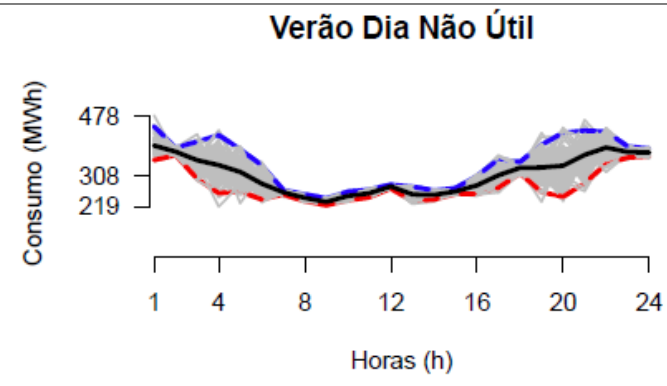

Inverno Dia Não Útil

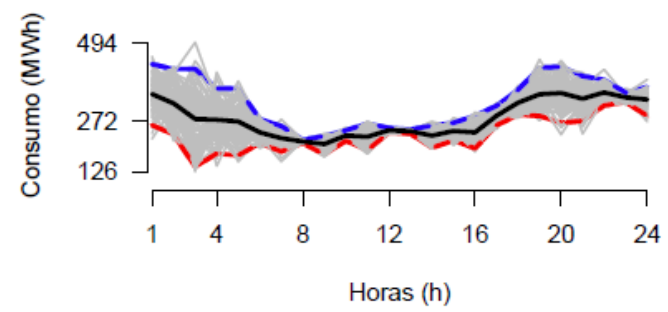

Intermediário Dia Não Útil

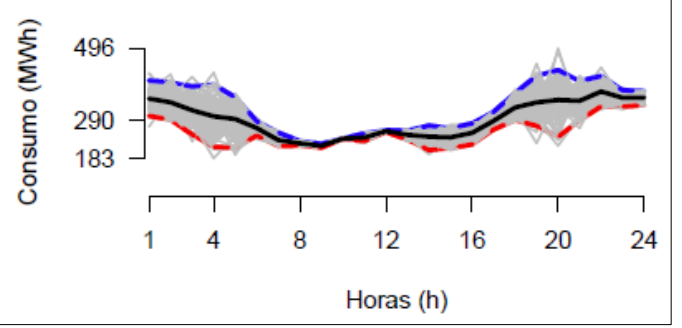

Figura 76 - Perfis Médios Previstos 2020: Saúde (elaborado pelo autor, 2019). 


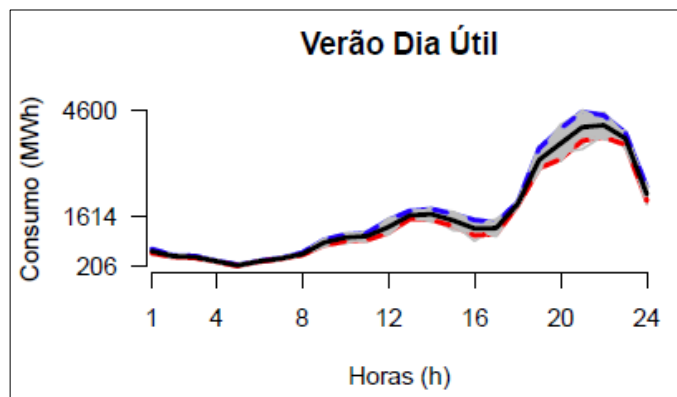

Verão Dia Não Útil

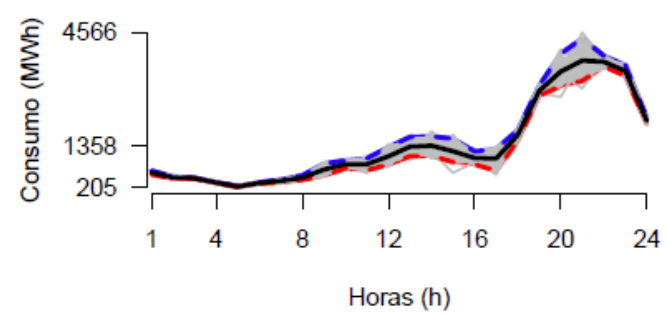

Inverno Dia Útil

Inverno Dia Não Útil
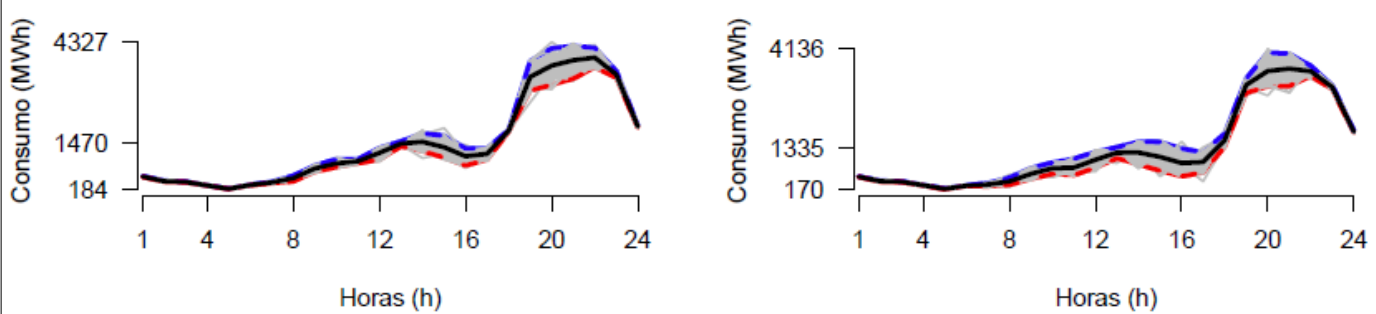

Intermediário Dia Útil

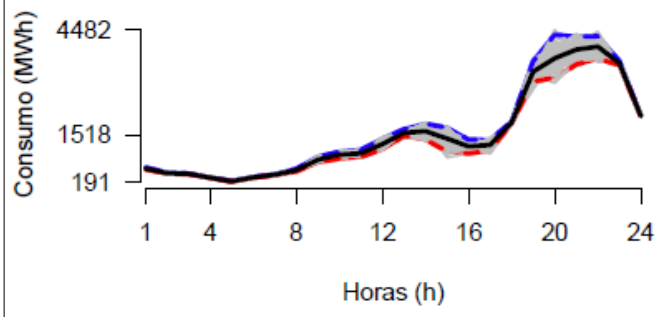

Intermediário Dia Não Útil

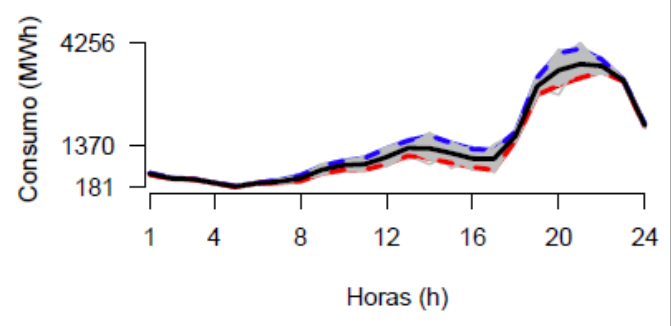

Figura 77 - Perfis Médios Previstos 2020: Televisor (elaborado pelo autor, 2019). 


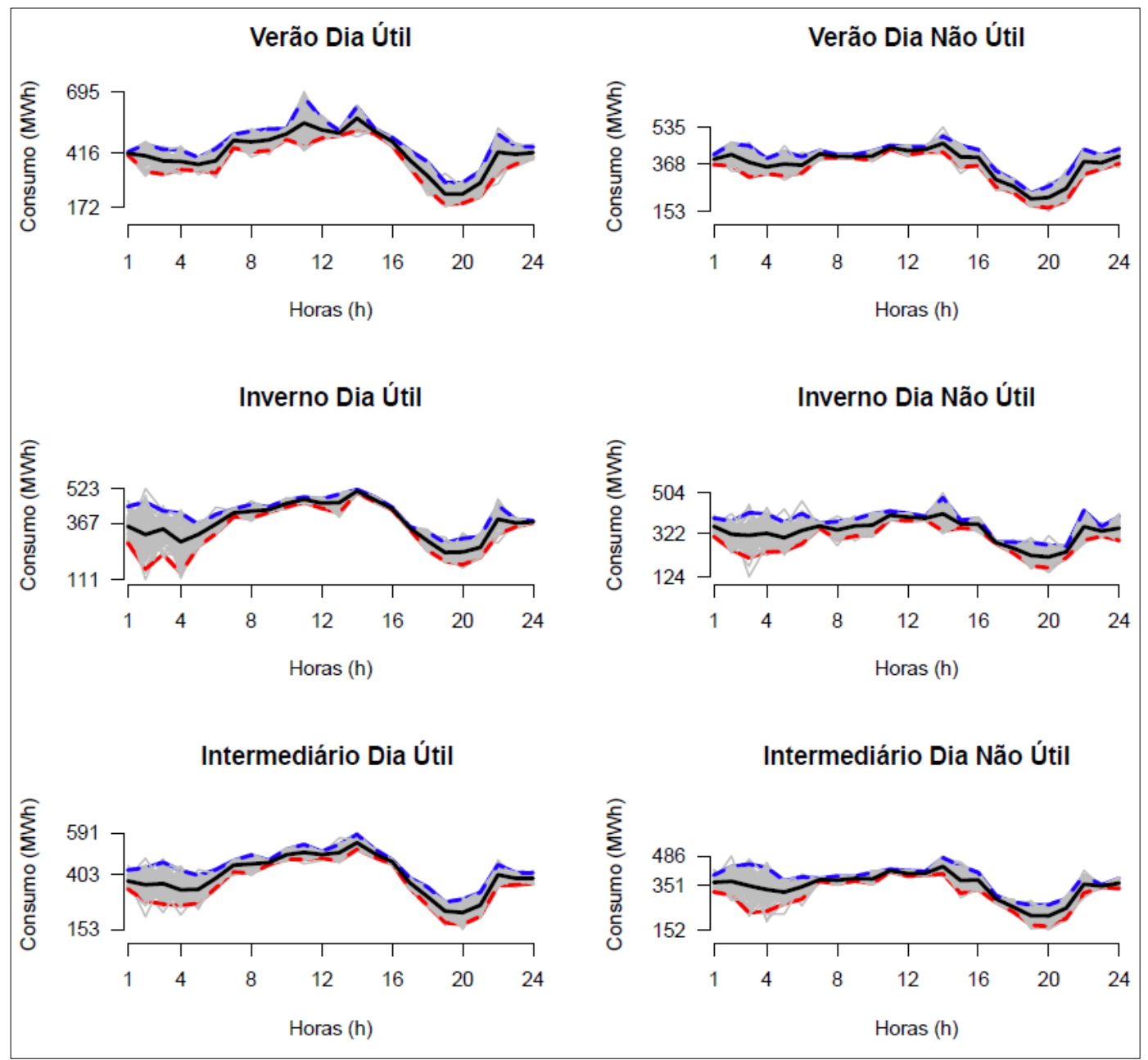

Figura 78 - Perfis Médios Previstos 2020: Têxtil (elaborado pelo autor, 2019). 


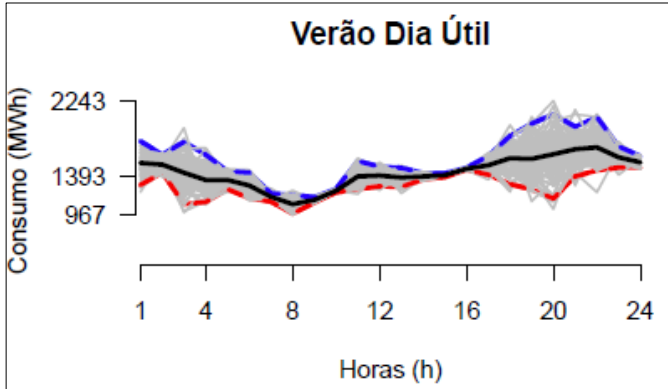

Verão Dia Não Útil

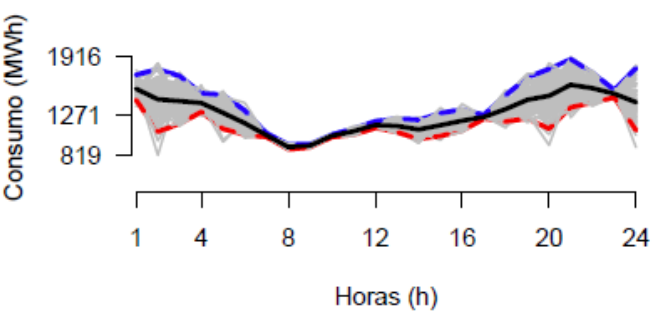

Inverno Dia Útil

Inverno Dia Não Útil
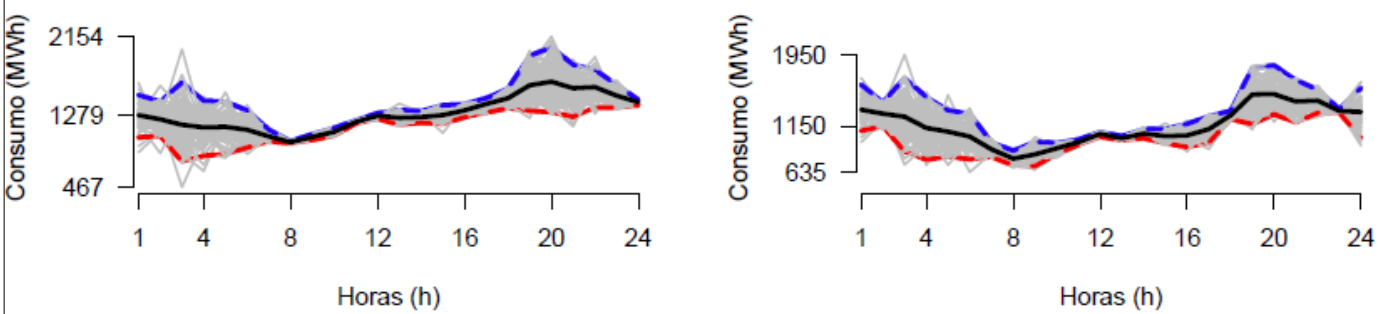

Intermediário Dia Útil

Intermediário Dia Não Útil
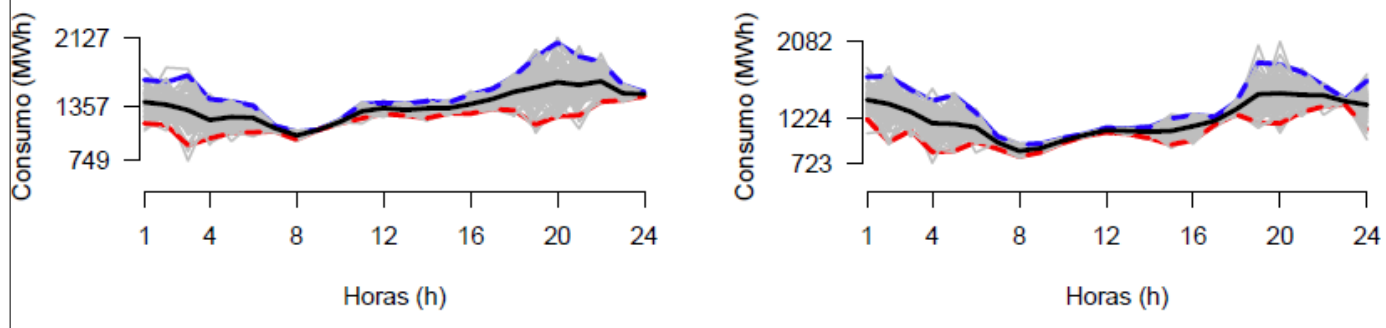

Figura 79 - Perfis Médios Previstos 2020: Tráfego e Transmissão de Dados (elaborado pelo autor, 2019). 